HNF-13820

Revision 0

\title{
TEST AND EVALUATION REPORT FOR THE HEDGEHOG-II PACKAGING SYSTEMS, DOT-7A TYPE A CONTAINER
}

DL Kelly, Duratek Technical Services

December 2003

Prepared for the U.S. Department of Energy

Assistant Secretary for Environmental Management

\section{Fluor Hanford}

P.O. Box 1000

Richland, Washington

Contractor for the U.S. Department of Energy

Richland Operations Office under Contract BE-AC06-96RL13200

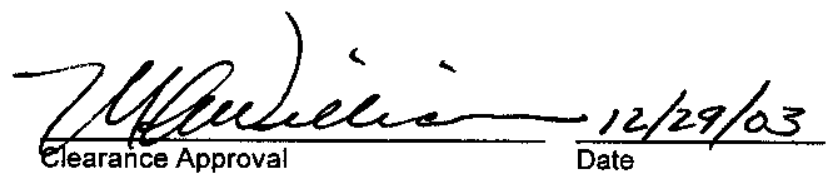

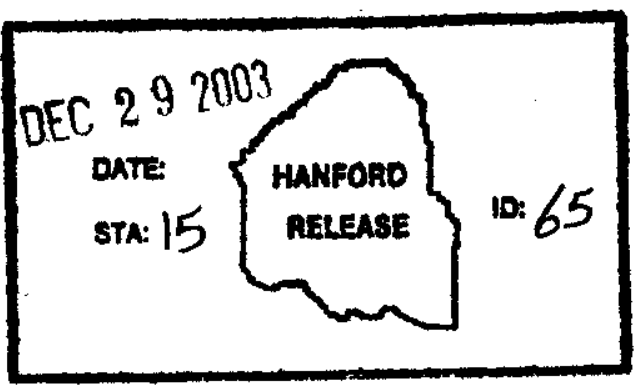

Release Approval (stamp) 


\begin{tabular}{|l|l|}
\hline \multicolumn{2}{|c|}{ For use with Technical Documents (when appropriate) } \\
\hline EDC- HNF-EDC-03-19088 & FMP- \\
\hline EDT- & ECN- \\
\hline Project No:: & Division: \\
\hline Document Type: RPT & Page Count: iTl \\
\hline
\end{tabular}

\begin{tabular}{|l|l|l|l|l|}
\hline \multicolumn{5}{|c|}{ For use with Speeches, Articles, or Presentations (when appropriate) } \\
\hline \multicolumn{1}{|c|}{ Abstract } & & \multicolumn{5}{|c|}{ Summary } & Full Paper & Visual Aid & \\
\hline Conference Name: & & & \\
\hline Conference Date: & & \\
\hline Conference Location: & & \\
\hline Conference Sponsor: & & \\
\hline Published in: & & \\
\hline Publication Date: & & \\
\hline
\end{tabular}

\section{LEGAL DISCLAIMER}

This report was prepared as an account of work sponsored by an agency of the United States Government. Neither the United States Government nor any agency thereof, nor any of their employees, nor any of their contractors, subcontractors or their employees, makes any warranty, express or implied, or assumes any legal liability or responsibility for the accuracy, completeness, or any third party's use or the results of such use of any information, apparatus, product, or process disclosed, or represents that its use would not infringe privately owned rights. Reference herein to any specific commercial product, process, or service by trade name, trademark, manufacturer, or otherwise, does not necessarily constitute or imply its endorsement, recommendation, or favoring by the United States Government or any agency thereof or its contractors or subcontractors. The views and opinions of authors expressed herein do not necessarily state or reflect those of the United States Government or any agency thereof.

Scientific or technical Information is available to U.S. Government and U.S. Government contractor personnel through the Office of Scientific and Technical Information (OSTI). It is available to others through the National Technical information Service (NTIS).

This report has been reproduced from the best available copy. 
HNF-13820

Rev. 0

Key Words: NFT can assembly, certification, liquid radioactive materials, solid radioactive materials, sample bottles

\begin{abstract}
This report documents the U.S. Department of Transportation Specification 7A (DOT-7A) Type A compliance test and evaluation results for the Hedgehog-II packaging systems. The approved Hedgehog-II packaging configurations provide primary and secondary containment. The approved packaging configurations described within this report are designed to ship Type A quantities of radioactive materials, normal form. Contents may be in solid or liquid form. Liquids transported in the approved $1 \mathrm{~L}$ glass bottle assembly shall have a specific gravity of less than or equal to 1.6. Liquids transported in all other approved configurations shall have a specific gravity of less than or equal to 2.0 . The solid contents, including packaging, are limited in weight to the gross weight of the as-tested liquids and bottles.
\end{abstract}

The approved Hedgehog-II packaging configurations described in this report may be transported by air, and have been evaluated as meeting the applicable International Air Transport Association/International Civil Aviation Organization (IATA/ICAO) Dangerous Goods Regulations in addition to the DOT requirements. 
HNF-13820, Rev. 0

\section{CONTENTS}

1.0 INTRODUCTION

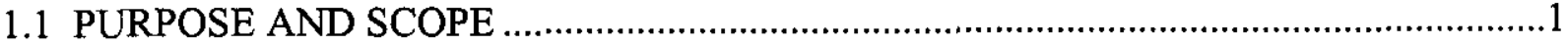

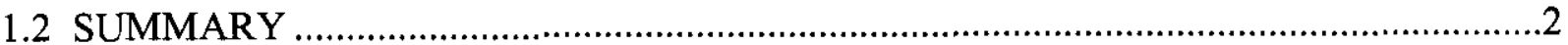

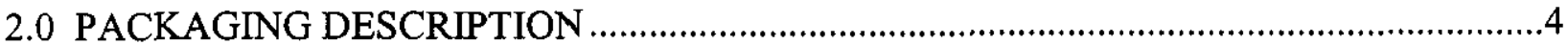

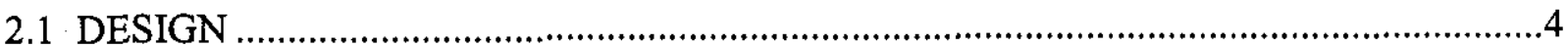

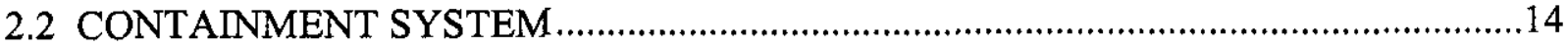

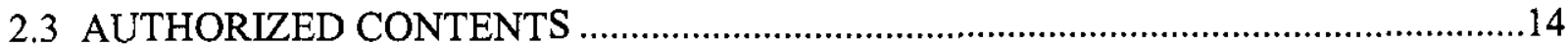

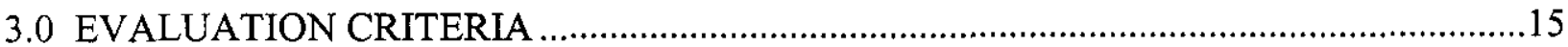

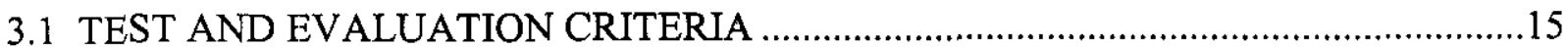

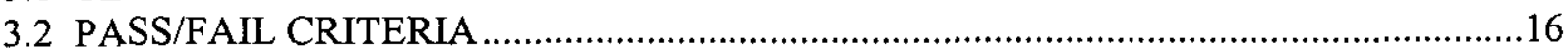

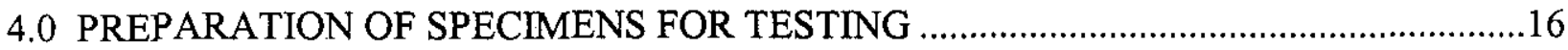

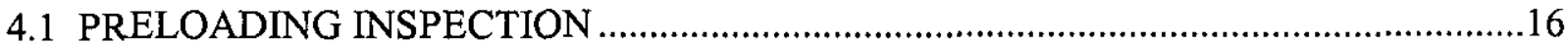

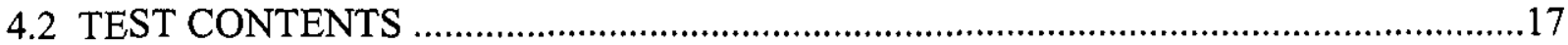

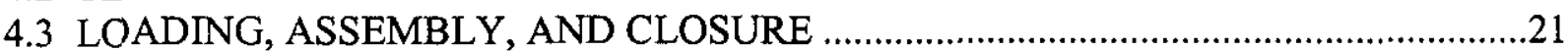

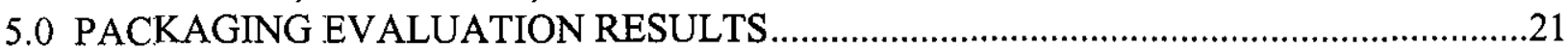

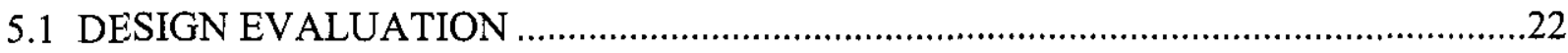

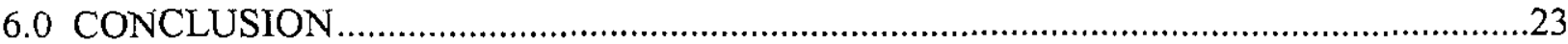

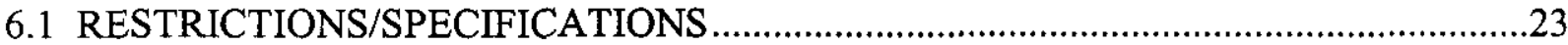

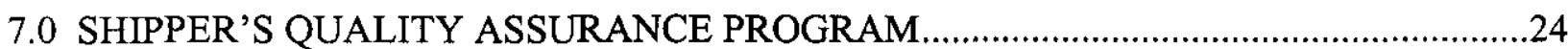

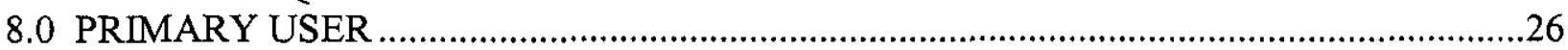

9.0 DESIGNER

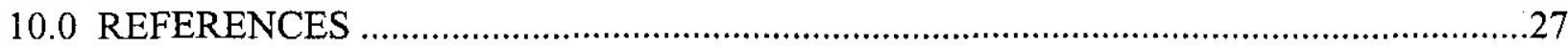

APPENDICES

A DOT-7A TYPE A PACKAGING QUALIFICATION CHECKLIST ................................... A-i

B OPENING, LOADING, AND CLOSURE INSTRUCTIONS USED FOR TESTING ......... B-i

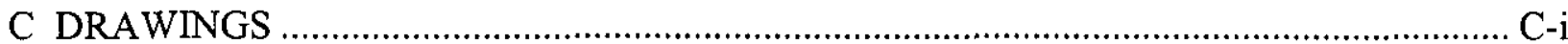

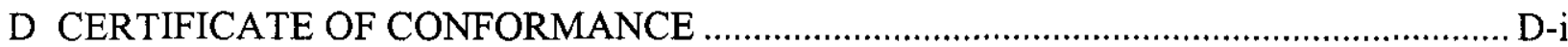

\section{TABLES}

Table 2-1. Maximum Gross Weights for Hedgehog-II Configurations (Nominal)....................... 5

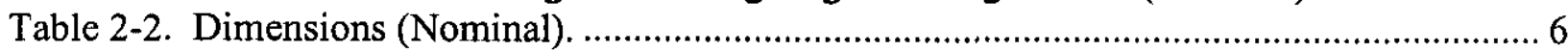

Table 2-3. Intermediate Container (NFT Can Assembly) Foam Dimensions (Nominal)............... 7

Table 2-4. Thickness of Shielding by Configuration.................................................................. 7

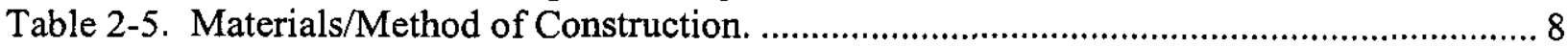


HNF-13820, Rev. 0

\section{TERMS}

\begin{tabular}{|c|c|}
\hline ASTM & $\begin{array}{l}\text { American Standard for Testing and Materials } \\
\text { centimeter }\end{array}$ \\
\hline & 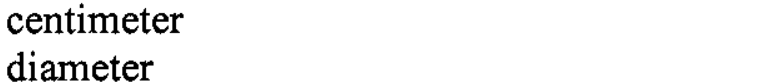 \\
\hline DTS & Duratek Technical Services \\
\hline $\mathrm{ft} \cdot \mathrm{lb}$ & foot-pound \\
\hline $\mathrm{H}$ & high \\
\hline $\begin{array}{l}\text { IATA } \\
\text { ID }\end{array}$ & International Air Transport Association \\
\hline $\begin{array}{l}\text { ID } \\
\text { in. }\end{array}$ & $\begin{array}{l}\text { inside diameter } \\
\text { inch }\end{array}$ \\
\hline $\begin{array}{l}\text { in. } \\
\text { in-lb }\end{array}$ & $\begin{array}{l}\text { inch } \\
\text { inch-pound }\end{array}$ \\
\hline $\mathrm{L}$ & $\begin{array}{l}\text { Inch-pouna } \\
\text { liter }\end{array}$ \\
\hline $\mathrm{L}$ & long \\
\hline $\mathrm{mL}$ & milliliter \\
\hline $\mathrm{N} \cdot \mathrm{m}$ & newton meter \\
\hline NFT & Nuclear Filter Technology, Inc. \\
\hline OD & outside diameter \\
\hline poly & polypropylene \\
\hline PQCL & Packaging Qualification Checklist \\
\hline & wide \\
\hline
\end{tabular}


HNF-13820, Rev. 0

\section{TEST AND EVALUATION REPORT FOR THE HEDGEHOG-II PACKAGING SYSTEMS, DOT-7A TYPE A CONTAINER}

\subsection{INTRODUCTION}

This report documents the U.S. Department of Transportation Specification 7A (DOT-7A) Type A compliance test and evaluation results of the Hedgehog-II packaging systems. Testing and evaluation activities documented herein are on behalf of Fluor Hanford, Inc., Waste Management Project, Richland, Washington.

The Hedgehog-II packaging systems were tested in March and April 2003. Due to funding limitations, completion of evaluation documentation by Duratek Technical Services (DTS) (formerly known as Duratek Federal Services, Inc., Northwest Operations [DFSNW]), under Contract 12604, Release 1 (TP-04-124), was delayed until October 2003.

The test plan used in conducting testing and evaluation activities for the Hedgehog-II was developed, approved, and implemented, as appropriate, by use of a graded approach to the DTS Quality Assurance (QA) program. The test plan used is identified as HNF-13819, Test Plan for Hedgehog-II Packaging Systems, Type A Container. The DTS QA program requirements are provided in DFSNW-QAM-001, Quality Assurance Manual, and implemented by DFSNW-QAP-001, Quality Assurance Procedures. The graded approach taken for this document is in accordance with WMTS-IP/7A-005, Test and Evaluation Procedure for DOT-7A Type A Packaging and Industrial Packaging.

Testing was administered, witnessed, and documented by DTS. The subcontracted technicians, facilities, and equipment utilized for drop testing and containment boundary verifications (i.e., leak testing) were provided by HiLine Engineering and Fabrication, Richland, Washington. For the vibration testing, the subcontracted technicians, facility, and equipment were provided by Battelle Pacific Northwest National Laboratory.

\subsection{PURPOSE AND SCOPE}

This report documents the tests and evaluations conducted by DTS in 2003 for the Hedgehog-II. The testing and evaluation documentation demonstrates that the materials of construction and design of the approved, as-tested Hedgehog-II meet all DOT-7A Type A packaging requirements of Title 49, Code of Federal Regulations (CFR), Part 178, "Specifications for Packagings," $\$ 178.350$, "Specification 7A; general packaging, Type A." A design verification procedure, HNF-SD-TP-TI-006, Documentation and Verification Required for Type A Packaging Use, was used to ensure that the packaging meets the design requirements of 49 CFR 173, "Shippers-General Requirements for Shipments and Packagings." 
The sections identified below are included in this final report, and provide detailed information regarding the designs tested and evaluated herein. The Hedgehog-II packaging designs qualify as radioactive material transport packagings when loaded as described in this test report, as they have been evaluated as meeting the requirements of 49 CFR 173.24, "General requirements for packagings and packages;" 173.24a, "Additional general requirements for non-bulk packagings and packages;" 173.410, "General design requirements;" 173.412, "Additional design requirements for Type A packages;" and 173.462, "Preparations of specimens for testing."

- Section 2.0, "Packaging Description." This section provides design and authorized configuration information.

- Appendix A, "Packaging Qualification Checklist" (PQCL). The PQCL was used to capture the design, testing, and evaluation for this packaging. The PQCL also identifies when the shipper is responsible for ensuring the noted requirement is met at the time of shipment.

- Appendix B, "Assembly, Loading, and Closure Instructions Used During Testing."

- Appendix C, "Drawings." Hanford drawings for the approved Hedgehog-II configurations as follows:

H-2-830874, Rev. 1, Hedgehog II Packaging System Assembly

H-2-830875, Rev. 1, Hedgehog II Case

H-2-830876, Rev. 1, Hedgehog II Intermediate Container

H-2-830877, Rev. 1, Hedgehog II Shielded Container Assemblies

- Appendix D, Certificate of Conformance.

\subsection{SUMMARY}

The approved Hedgehog-II designs that are tested and evaluated are described in Section 2.0, and Appendices A through D of this report.

The Hedgehog-II, $1 \mathrm{~L}$ bottle configurations (glass and polypropylene [poly]) were initially tested for liquids having a specific gravity of $\leq 2.0$. During testing activities, the $1 \mathrm{~L}$ poly bottle configuration performed adequately. However, the $1 \mathrm{~L}$ glass configuration that consisted of the I-Chem wide-mouth glass jar having a black phenolic lid with polyvinyl liner (Qorpak $\left.{ }^{1} 5024\right)$ did

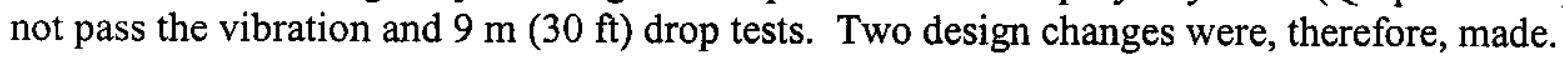
The bottle lid was changed to include a black phenolic lid with polyethylene liner (Qorpak 5082), and the loading of the contents was reduced to simulate a liquid having a specific gravity of $\leq 1.6$. This combination of changes was successful.

The approved Hedgehog-II configurations described in this report are designed to ship Type A quantities of radioactive materials, normal form. Contents may be in solid or liquid form.

\footnotetext{
'Qorpak is a registered trademark of All-Pak, Inc., Bridgeville, Pennsylvania.
} 
Liquids transported in the approved $1 \mathrm{~L}$ glass bottle assembly shall have a specific gravity of $\leq 1.6$. Liquids transported in all other approved configurations shall have a specific gravity of $\leq 2.0$. Solid contents may be normal or special form. The solid contents, including packaging, are limited in weight to the gross weight of the as-tested liquids and bottles (refer to Table 2-1).

The approved Hedgehog-II packaging configurations described in this report may be transported by air. Therefore, the configurations described meet the International Air Transport Association (IATA), Dangerous Goods Regulations (IATA 2003), for transportation of Type A liquids and solids. A comparison and evaluation of IATA 2003, as applicable for air transportation of Type A materials, was made. The applicable IATA regulations, as they compare to $49 \mathrm{CFR}$, "Transportation," are identified in Appendix A of this report.

All DOT-7A Type A requirements of 49 CFR are addressed in this report, whether or not the requirement is applicable to the tested package configuration. Testing included the vibration, $1.2 \mathrm{~m}$ (4-ft) drop, and $9 \mathrm{~m}$ (30-ft) drop tests. Containment boundary verifications (i.e., leak test) were performed before and after testing. Engineering evaluations of the water spray, stack, and penetration tests were performed and are documented in Appendix A.

This report provides documentation necessary to satisfy the requirements of 49 CFR $173.415(a)$, "Authorized Type A packages," which states:

DOT Specification 7A ( $\$ 178.350$ of this subchapter) Type A general packaging. Each offeror of a Specification 7A package must maintain on file for at least one year after the latest shipment, and shall provide to DOT on request, complete documentation of tests and an engineering evaluation or comparative data showing that the construction methods, packaging design, and materials of construction comply with that specification. Use of Specification 7A packagings designed in accordance with the requirements of $\$ 178.350$ of this subchapter in effect on June 30, 1983 (see 49 CFR Part 178 revised as of October 1, 1982), is not authorized after April 1, 1997.

This document will serve to meet the above-stated requirements when the package is used as prescribed. In addition, a description of the packaging is provided, including drawings, to allow the user/shipper to obtain the necessary components and to verify compliance with all of the specifications of the as-tested package.

By itself, this document does not ensure total compliance with all documentation necessary for making a shipment of radioactive material. In addition to documentation of tests, the shipper must maintain, on file, other appropriate documentation (i.e., evidence that the physical properties of the actual contents to be shipped are equivalent to the contents of the simulated payload). Also, implementation and documentation of a quality control program are required. 


\subsection{PACKAGING DESCRIPTION}

\subsection{DESIGN}

The major design differences between the Hedgehog and the Hedgehog-II are the intermediate container, cushioning materials, and the $1 \mathrm{~L}$ bottles and lids that are approved for use. Due to the inability to obtain the SafeSend containers, a replacement of the intermediate container and cushioning materials was required. A Nuclear Filter Technology, Inc. $\left(\mathrm{NFT}^{2}\right)$ intermediate container (i.e., NFT can assembly), additional shock-absorbing packing materials, and two different $1 \mathrm{~L}$ bottles have been incorporated into the Hedgehog-II. Table 2-5 identifies the two different $1 \mathrm{~L}$ bottle/lid assemblies that are approved for use in the Hedgehog-II.

The $1 \mathrm{~L}$ bottle/lid assemblies qualified and approved for use during testing are considered a part of the containment system. Any changes made in the type of $1 \mathrm{~L}$ bottle/lid assembly are not qualified for use and require retesting or evaluation of the applicable packaging configuration change(s). The sample bottles that are used inside the $30 \mathrm{~mL}, 125 \mathrm{~mL}$, and $250 \mathrm{~mL}$ shielded containers (outer and inner container assemblies) are considered as packaging not required and are not discussed within this report.

The outer case is manufactured by Hardigg Cases. ${ }^{3}$ The case is a rotationally molded plastic case with zinc chromate steel hinges and butterfly latches. A silicone sponge cording (gasket) is located on the case lid and is notched on one side to prevent pressurization within the case. When the case is oriented in the upright position for transport purposes, this notch is located at the base of the package to ensure that water in-leakage does not occur. Polyethylene foam $\left(2.2 \mathrm{lb} / \mathrm{ft}^{3}\right)$ and a $0.32 \mathrm{~cm}(0.125$-in.) acrylonitrile-butadiene-styrene load spreader are added internally to the case to hold the NFT can assembly into place. The dimension for the case foam cushioning that rests adjacent to the lid of the NFT can assembly is dependent upon the configuration intended for shipment; i.e., shielded containers or a $1 \mathrm{~L}$ bottle.

The NFT can assembly is made of stainless steel and includes an o-ring, threaded closure, and plunger locking mechanism. The pull-ring plunger assembly ensures the lid torque remains constant. Ethylene vinyl acetate foam cushioning having a density of $2 \mathrm{lb} / \mathrm{ft}^{3}$ is provided with this assembly. Additional packing materials are added inside the NFT can assembly for impact absorption and to act as load spreaders. These materials include a stainless steel disk and/or a stainless steel belleville washer, and are dependent upon the configuration to be shipped.

The stainless steel shielded containers (outer and inner container assemblies) used in the Hedgehog-II are identical to the Hedgehog, and are fabricated in accordance with Hanford drawing H-2-830877. These outer and inner container assemblies incorporate o-rings and socket or Torx ${ }^{4}$ flat head screws. When the shielded container configuration is intended for shipment, a nylon insert is nested on each side of the NFT can assembly lid handle and the case foam piece identified as 724-04FB (see drawing H-2-830875).

\footnotetext{
${ }^{2}$ NFT is a registered trademark of Nuclear Filter Technology, Inc., Lakewood, Colorado.

${ }^{3}$ Hardigg Cases is a registered trademark of Hardigg Industries, Inc., Deerfield, Massachusetts.

${ }^{4}$ Torx is a registered trademark of Textron Inc. DBA The Camcar Screw \& Mfg. Company, Rockford, Illinois.
} 
Appendix A contains the PQCL that was used to capture the design, testing, and evaluation for the Hedgehog-II packaging configurations. Appendix B contains the assembly, loading, and closure instructions used during testing. Appendix $\mathrm{C}$ contains the drawings applicable for the approved, as-tested Hedgehog-II design. Appendix D contains the Certificate of Conformance.

Packaging weights obtained during testing are shown in Table 2-1 (refer to HNF-13819 and WHC-SD-OTR-001). Packaging dimensions are shown in Table 2-2. The foam dimensions for the intermediate container are provided in Table 2-3. Thickness of shielding by configuration is provided in Table 2 $\because 4$. All dimensions provided in Tables 2-2; 2-3; and 2-4 were confirmed during testing (refer to drawings provided in Appendix C). Refer to Table 2-5 for the materials/method of construction information. Design measurements noted for this packaging are provided in metric units and converted to English units. All measurements are nominal (i.e., $2.54 \mathrm{~cm}=1$ in.), unless otherwise noted.

Table 2-1. Maximum Gross Weights for Hedgehog-II Configurations (Nominal).

\begin{tabular}{|l|l|c|}
\hline \multicolumn{1}{|c|}{ Configuration } & \multicolumn{1}{|c|}{$\begin{array}{c}\text { Bottle and contents } \\
\mathrm{kg}(\mathrm{lb})\end{array}$} & $\begin{array}{c}\text { Package gross weight } \\
\mathrm{kg}(\mathrm{lb})\end{array}$ \\
\hline $30 \mathrm{~mL}$ shielded & $\begin{array}{l}\text { Bottle and contents }=0.099(0.219) \\
\text { Contents only }=0.088(0.196)\end{array}$ & $31.30(69)$ \\
\hline $125 \mathrm{~mL}$ shielded & $\begin{array}{l}\text { Bottle and contents }=0.365(0.805) \\
\text { Contents only }=0.339(0.749)\end{array}$ & $29.94(66)$ \\
\hline $250 \mathrm{~mL}$ shielded & $\begin{array}{l}\text { Bottle and contents }=0.562(1.24) \\
\text { Contents only }=0.524(1.156)\end{array}$ & $25.85(57)$ \\
\hline $1 \mathrm{~L}$ glass & $\begin{array}{l}\text { Bottle and contents }=1.72(3.8) \\
\text { Contents only }=1.27(2.8)\end{array}$ & $18.14(40)$ \\
\hline $1 \mathrm{~L}$ poly & $\begin{array}{l}\text { Bottle and contents }=1.99(4.4) \\
\text { Contents only }=1.90(4.2)\end{array}$ \\
\hline
\end{tabular}

NOTE: Information for 125 and $250 \mathrm{~mL}$ shielded configurations was obtained from WHC-SD-OTR-001. 
HNF-13820, Rev. 0

Table 2-2. Dimensions (Nominal).

\begin{tabular}{|c|c|c|}
\hline Item & $\begin{array}{l}\text { External Dimensions } \\
\text { cm (in.) }\end{array}$ & $\begin{array}{l}\text { Internal dimensions } \\
\text { cm (in.) }\end{array}$ \\
\hline Hardigg Case $^{a}$ & $\begin{array}{l}64 \mathrm{~L} \times 48 \mathrm{~W} \times 48 \mathrm{H} \\
(25 \mathrm{~L} \times 19 \mathrm{~W} \times 19 \mathrm{H})\end{array}$ & $\begin{array}{l}\text { Shielded internal cavity: } \\
26.67 \mathrm{~L} \times 16.51 \mathrm{~W} \times 17.78 \mathrm{H} \\
(10.5 \mathrm{~L} \times 6.5 \mathrm{~W} \times 7.0 \mathrm{H}) \\
\\
\frac{\text { Non-shielded internal cavity: }}{24.13 \mathrm{~L} \times 16.51 \mathrm{~W} \times 17.78 \mathrm{H}} \\
(9.5 \mathrm{~L} \times 6.5 \mathrm{~W} \times 7.0 \mathrm{H})\end{array}$ \\
\hline $\begin{array}{l}\text { Intermediate container }^{\mathrm{b}} \\
\left(\mathrm{NFT}^{\mathrm{c}} \text { can assembly) }\right.\end{array}$ & $\begin{array}{l}\text { Height with handle: } \\
27.69(10.9) \\
\text { Body dia.: } 17.14(6.75) \\
\frac{\text { Lid dia. with plunger: }}{19.68(7.75)}\end{array}$ & $\begin{array}{l}\text { Body: } 21.49(8.46) \\
\text { Body dia.: } 17.04(6.71) \\
\text { Lid dia.: } 18.24(7.18)\end{array}$ \\
\hline $\begin{array}{l}\text { Outer container assembly }(30,125, \\
\text { and } 250 \mathrm{~mL})\end{array}$ & $\begin{array}{l}17.8 \mathrm{H} \times 11.3 \mathrm{dia} . \\
(7.0 \mathrm{H} \times 4.5 \mathrm{dia} .) \\
\end{array}$ & $\begin{array}{l}13.7 \mathrm{H} \times 8.9 \text { dia. } \\
\text { (5.4 H x } 3.5 \text { dia. })\end{array}$ \\
\hline Inner container assembly $(125 \mathrm{~mL})$ & $\begin{array}{l}13.7 \mathrm{H} \times 8.9 \mathrm{dia} . \\
(5.4 \mathrm{H} \times 3.5 \text { dia. })\end{array}$ & $\begin{array}{l}10.9 \mathrm{H} \times 6.1 \mathrm{dia} . \\
(4.3 \mathrm{H} \times 2.4 \text { dia. })\end{array}$ \\
\hline Inner container assembly $(30 \mathrm{~mL})$ & $\begin{array}{l}13.2 \mathrm{H} \times 8.9 \text { dia. } \\
(5.2 \mathrm{H} \times 3.5 \text { dia. }) \\
\end{array}$ & $\begin{array}{l}8.1 \mathrm{H} \times 3.8 \text { dia. } \\
(3.2 \mathrm{H} \times 1.5 \text { dia. })\end{array}$ \\
\hline Inserts (nylon) & $\begin{array}{l}17.463 \mathrm{~L} \times 8.9 \mathrm{~W} \times 3.18 \mathrm{H} \\
(6.875 \mathrm{~L} \times 3.5 \mathrm{~W} \times 1.25 \mathrm{H})\end{array}$ & N/A \\
\hline Belleville washer & $\begin{array}{l}16.0 \text { OD } \times 0.429 \text { thick } \\
(6.3 \text { OD } \times 0.169 \text { thick })\end{array}$ & $8.20(3.23 \mathrm{ID})$ \\
\hline Disk (stainless steel) & $\begin{array}{l}16.828 \text { OD } \times 0.30 \text { thick }) \\
(6.625 \text { OD x } 0.12 \text { thick })\end{array}$ & N/A \\
\hline $1 \mathrm{~L}$ glass bottle & $\begin{array}{l}\frac{\text { Overall height with lid: }}{17.302(6.812)} \\
\frac{\text { Diamcpeter-Lid: }}{9.047(3.562)} \\
\frac{\text { Diameter-Base: }}{8.094(3.187)}\end{array}$ & $\mathrm{N} / \mathrm{A}$ \\
\hline $1 \mathrm{~L}$ poly bottle & $\begin{array}{l}\text { Overall height with lid: } \\
20.002(7.875) \\
\text { Diameter-Lid: } \\
6.667(2.625) \\
\text { Diameter-Base: } \\
7.302(2.875)\end{array}$ & N/A \\
\hline
\end{tabular}

${ }^{a}$ Hardigg Cases is a registered trademark of Hardigg Industries, Inc., Deerfield, Massachusetts.

${ }^{b}$ See Table 2-3 for intermediate container (NFT can assembly) foam dimensions. 
HNF-13820, Rev. 0

Table 2-3. Intermediate Container (NFT ${ }^{\mathrm{a}}$ Can Assembly) Foam Dimensions (Nominal).

\begin{tabular}{|c|c|c|c|c|}
\hline \multicolumn{3}{|c|}{ Configuration } & \multirow{2}{*}{ Foam } & \multirow{2}{*}{$\begin{array}{l}\text { Dimensions } \\
\mathrm{cm} \text { (in.) }\end{array}$} \\
\hline $\begin{array}{l}1 \mathrm{~L} \\
\text { glass }\end{array}$ & $\begin{array}{l}1 \mathrm{~L} \\
\text { poly }\end{array}$ & Shielded & & \\
\hline $\mathrm{X}$ & $X$ & & Top & $\begin{array}{l}16.988 \text { dia. } \times 1.588 \text { thick } \\
\text { ( } 6.687 \text { dia. } \times 0.625 \text { thick })\end{array}$ \\
\hline $\mathrm{X}$ & & $X$ & Insert & $\begin{array}{l}11.43 \text { dia. } \times 3.81 \text { thick } \\
\text { (4.50 dia. } \times 1.50 \text { thick) }\end{array}$ \\
\hline $\mathrm{X}$ & $\mathrm{X}$ & $\mathrm{X}$ & Side & $\begin{array}{l}16.988 \text { OD } \times 11.590 \mathrm{ID} \times 5.230 \text { thick } \\
\text { ( } 6.687 \text { dia. } \times 4.562 \mathrm{ID} \times 2.062 \text { thick) }\end{array}$ \\
\hline$X$ & $X$ & $\mathrm{x}$ & Bottom & $\begin{array}{l}16.988 \text { dia. } \times 1.588 \text { thick } \\
(6.687 \text { dia. } \times 0.625 \text { thick })\end{array}$ \\
\hline
\end{tabular}

Table 2-4. Thickness of Shielding by Configuration.

\begin{tabular}{|l|l|}
\hline \multicolumn{1}{|c|}{ Configuration } & \multicolumn{1}{c|}{ Shielding Thickness } \\
\hline $30 \mathrm{~mL}$ & $3.81 \mathrm{~cm}(1.5 \mathrm{in})$. \\
\hline $125 \mathrm{~mL}$ & $2.54 \mathrm{~cm}(1.0 \mathrm{in})$. \\
\hline $250 \mathrm{~mL}$ & $1.27 \mathrm{~cm}(0.5 \mathrm{in})$. \\
\hline $1 \mathrm{~L}$ (glass or poly) & No shielding \\
\hline
\end{tabular}


HNF-13820, Rev. 0

Table 2-5. Materials/Method of Construction. (3 sheets total)

\begin{tabular}{|c|c|}
\hline Item/component & Description \\
\hline Hardigg Case & $\begin{array}{l}\text { Part No. AL2216-1205-HHBA-724E. Per } \\
\text { Hanford drawing H-2-830875, Hedgehog II } \\
\text { Packaging System Assembly. Polyethylene case } \\
\text { that includes zinc chromate hardware, steel } \\
\text { butterfly latches, cardholder, notched silicone } \\
\text { gasket, } 2.2 \mathrm{lb} / \mathrm{ft}^{3} \text { polyethylene foam, and } 0.32 \mathrm{~cm} \\
(0.125 \text {-in.-) thick acrylonitrile-butadiene-styrene } \\
\text { load spreader. } \\
1 \text { L bottle configuration inner foam assembly } \\
\text { Part No. HHBA-724FA (Hanford drawing } \\
\text { H-2-830875). } \\
\text { Shielded configuration inner foam assembly } \\
\text { Part No. HHBA-724FB (Hanford drawing } \\
\text { H-2-830875). }\end{array}$ \\
\hline $\begin{array}{l}\text { Intermediate container assembly } \\
\text { (NFT can assembly) }\end{array}$ & $\begin{array}{l}\text { NFT Part No. } 21030001 \text {. Refer to Hanford } \\
\text { drawing H-2-830876. } 304 \text { stainless steel, } 22 \\
\text { gauge. Includes rigid handle, Viton } 5 \text { o-ring } \\
\text { (V835-75-Parker 2-166), pull-ring plunger } \\
\text { assembly. Lid and body serial numbers to be } \\
\text { identical. } \\
\text { Inner foam: Rubatex }{ }^{6} \text { (R-5020), or equivalent. } \\
2 \text { lb/ } \mathrm{f}^{3} \text {, white, ethylene vinyl acetate per } \\
\text { American Standard for Testing and Materials } \\
\text { (ASTM) D1056, Standard Specification for } \\
\text { Flexible Cellular Materials - Sponge or } \\
\text { Expanded Rubber. Water-jet cut preferred. } \\
\text { Collective stack-up height of four side protectors } \\
\text { must equal } 20.96 \mathrm{~cm} \text { ( } 8.25 \text { in.). }\end{array}$ \\
\hline $\begin{array}{l}\text { Outer container assembly } \\
(30,125, \text { and } 250 \mathrm{~mL})\end{array}$ & Per Hanford drawing H-2-830877. \\
\hline Cover & $\begin{array}{l}304 \text { stainless steel, ASTM A240, Standard } \\
\text { Specification for Chromium and Chromium- } \\
\text { Nickel Stainless Steel Plate, Sheet, and Strip for } \\
\text { Pressure Vessels and for General Application, or } \\
\text { ASTM A276, Standard Specification for } \\
\text { Stainless Steel Bars and Shapes. Screws are } \\
\text { alloy steel, hexagon, socket or Torx flat head }\end{array}$ \\
\hline
\end{tabular}

${ }^{5}$ Viton is a registered trademark of E. I. Du Pont de Nemours \& Company, Wilmington, Delaware.

${ }^{6}$ Rubatex is a registered trademark of RBX $\otimes$ Industries, Inc., Roanoke, Virginia. 
Table 2-5. Materials/Method of Construction. (3 sheets total)

\begin{tabular}{|c|c|}
\hline Item/component & Description \\
\hline & $\begin{array}{l}\text { countersunk cap screw; 8-32UNC-3A } \times 1 \text { in. } \\
\text { long (ASTM F835, Standard Specification for } \\
\text { Alloy Steel Socket Button and Flat Countersunk } \\
\text { Head Cap Screws). }\end{array}$ \\
\hline Wall & $\begin{array}{l}304 \text { stainless steel, ASTM A511, Standard } \\
\text { Specification for Seamless Stainless Steel } \\
\text { Mechanical Tubing, or ASTM A276. }\end{array}$ \\
\hline Base & $\begin{array}{l}304 \text { stainless steel, ASTM A240 or ASTM } \\
\text { A276. Screws are alloy steel, ASTM F835, } \\
\text { hexagon, socket or Torx flat head countersunk } \\
\text { cap screw; } 8-32 \text { UNC-3A x } 3 / 4 \text { in. long. }\end{array}$ \\
\hline O-rings & $\begin{array}{l}\text { Nitrile, Parker } 2-153-\mathrm{N} 304-75 \text { or } 2-153-\mathrm{N} 103- \\
70 ; 3.487 \text {-in. inside diameter (ID), } 0.103 \text {-in. } \\
\text { cross-section. }\end{array}$ \\
\hline Lifting cable & $\begin{array}{l}\text { SAVA Industries } 2065,7.5 \mathrm{in} \text {. long } \times 0.063 \mathrm{in} \text {. in } \\
\text { dia, uncoated stainless steel, } 7 \times 19 \text { construction. }\end{array}$ \\
\hline Cable fitting & $\begin{array}{l}\text { SAVA Industries } 805 \text {-C for } 0.063 \text {-in. cable, } \\
0.208 \text {-in. dia. } x \text { 0.3-in.-long sleeve, copper. To } \\
\text { be crimped onto lifting cable using SAVA tool } \\
\text { T- } 188 \text {. }\end{array}$ \\
\hline Inner container assembly $(125 \mathrm{~mL})$ & Hanford drawing $\mathrm{H}-2-830877$. \\
\hline Cover & $\begin{array}{l}304 \text { stainless steel, ASTM A240 or ASTM } \\
\text { A276. Screws are alloy steel, ASTM F835, } \\
\text { hexagon, socket or Torx flat head countersunk } \\
\text { cap screw; 8-32UNC-3A x } 3 / 4 \text { in. long. }\end{array}$ \\
\hline Wall & $\begin{array}{l}304 \text { stainless steel, ASTM A511 or ASTM } \\
\text { A276. }\end{array}$ \\
\hline Base & $\begin{array}{l}304 \text { stainless steel, ASTM A240 or ASTM } \\
\text { A276. Screws are alloy steel, ASTM F } 835 \text {, } \\
\text { hexagon, socket or Torx flat head countersunk } \\
\text { cap screw; } 8-32 \text { UNC-3A x } 3 / 4 \text { in. long. }\end{array}$ \\
\hline O-rings & $\begin{array}{l}\text { Nitrile, Parker } 2-142-\mathrm{N} 304-75 \text { or } 2-142-\mathrm{N} 103- \\
70 ; 2.362 \text {-in. ID, } 0.103 \text {-in. cross-section. }\end{array}$ \\
\hline Inner container assembly $(30 \mathrm{~mL})$ & Hanford drawing H-2-830877. \\
\hline Cover & $\begin{array}{l}304 \text { stainless steel, ASTM A240 or ASTM } \\
\text { A276. Screws are alloy steel, ASTM F835, } \\
\text { hexagon, socket or Torx flat head countersunk } \\
\text { cap screw; 8-32UNC-3A x } 1 \text { in. long. }\end{array}$ \\
\hline Wall & $\begin{array}{l}304 \text { stainless steel, ASTM A511 or ASTM } \\
\text { A276. }\end{array}$ \\
\hline
\end{tabular}


Table 2-5. Materials/Method of Construction. (3 sheets total)

\begin{tabular}{|c|c|}
\hline Item/component & Description \\
\hline Base & $\begin{array}{l}304 \text { stainless steel, ASTM A240 or ASTM } \\
\text { A276. Screws are alloy steel, ASTM F835, } \\
\text { hexagon, socket or Torx flat head countersunk } \\
\text { cap screw; 8-32UNC-3A x } 1 \text { in. long. }\end{array}$ \\
\hline O-rings & $\begin{array}{l}\text { Nitrile, Parker } 2-125-\mathrm{N} 304-75 \text { or } 2-125-\mathrm{N} 103- \\
70 ; 1.299 \text {-in. ID, 0.103-in. cross-section. }\end{array}$ \\
\hline Lifting cable & $\begin{array}{l}\text { SAVA Industries } 2065,5.5 \mathrm{in} \text {. long } \times 0.063 \mathrm{in} \text {. in } \\
\text { dia, uncoated stainless steel, } 7 \times 19 \text { construction. }\end{array}$ \\
\hline Cable fitting & $\begin{array}{l}\text { SAVA Industries } 805-\mathrm{C} \text { for } 0.063 \text {-in. cable, } \\
0.208 \text {-in. dia. } \mathrm{x} 0.3 \text {-in.-long sleeve, copper. To } \\
\text { be crimped onto lifting cable using SAVA tool } \\
\text { T-188. }\end{array}$ \\
\hline Cushioning Materials & Per Hanford drawing H-2-830874. \\
\hline Inserts & $\begin{array}{l}\text { Nylon, } 6.875 \text { in. long } \times 3.5 \text { in. wide } \times 1.25 \text { in. } \\
\text { thick }\end{array}$ \\
\hline Belleville washer & $\begin{array}{l}\text { Rolex Part No. SAM-1608243, stainless steel } \\
\text { (17/7-PH), 6.3-in. outside diameter (OD) x } \\
\text { 3.23-in. ID x 0.169-in. thickness. }\end{array}$ \\
\hline Disc & $\begin{array}{l}\text { Type } 304 \text { stainless steel, bar stock or } 11 \text { ga., } \\
6.625 \text {-in. dia. } x 0.120 \text {-in. thickness. }\end{array}$ \\
\hline $1 \mathrm{~L}$ glass bottle/lid & $\begin{array}{l}\text { Per Hanford drawing H-2-830874. } \\
\text { Wide-mouth, I-Chem } 321-1000 \text { or Fisher } \\
\text { Scientific } 05-719-89 \text {. The existing lid is } \\
\text { replaced with a black phenolic lid with } \\
\text { polyethylene liner (Qorpak 5082). }\end{array}$ \\
\hline $1 \mathrm{~L}$ polyethylene bottle/lid & $\begin{array}{l}\text { Per Hanford drawing H-2-830874. } \\
\text { Wide-mouth, poly bottle and lid, Nalgene 2105- } \\
0032 \text { or Fisher Scientific 02-893D. }\end{array}$ \\
\hline Tape (1 L bottle/lid interface) & $\begin{array}{l}\text { Per Hanford drawing H-2-830874. } \\
\text { Shurtape }{ }^{7} \text {, Stock \#VP410, 2-in.-wide, PVC film, } \\
\text { or equivalent. }\end{array}$ \\
\hline
\end{tabular}

${ }^{\mathrm{a}}$ Hardigg Cases is a registered trademark of Hardigg Industries, Inc., Deerfield, Massachusetts.

\footnotetext{
${ }^{7}$ Shurtape is a registered trademark of Shuford Mills, Inc., Hickory, North Carolina.
} 
HNF-13820, Rev. 0

\subsection{AUTHORIZED CONFIGURATIONS}

The authorized Hedgehog-II configurations approved for use as documented within this final report (see Section 4.2 and Appendix B) are as follows.

CONFIGURATION

$30 \mathrm{~mL}$ Hedgehog-II Assembly
$125 \mathrm{~mL}$ Hedgehog-II Assembly

\section{DESCRIPTION}

Hardigg Case (Part No. AL2216-1205-HHBA-724E) including shielded configuration inner foam assembly Part No: HHBA-724FB.

Hanford drawing H-2-830875

Nylon inserts

Stainless steel belleville washer

Stainless steel disc

Hanford drawing H-2-830874

Intermediate container and foam

Hanford drawing H-2-830876

Outer container assembly $(250 \mathrm{~mL})$

Inner container assembly $(30 \mathrm{~mL})$

Hanford drawing H-2-830877

$30 \mathrm{~mL}$ sample bottle

Gross package weight $=31.30 \mathrm{~kg}(69 \mathrm{lb})$. Content and bottle weight $=0.099 \mathrm{~kg}(0.219 \mathrm{lb})$.

For use with liquids having a specific gravity of $\leq 2.0$ and solids limited in weight (to include packaging) to the maximum weights identified above.

The $125 \mathrm{~mL}$ assembly was not tested in 2003 due to the similarity in design with the $30 \mathrm{~mL}$ assembly. The $125 \mathrm{~mL}$ assembly utilizes the inner and outer stainless steel containers, o-rings, and screws that are similar in construction to those of the $30 \mathrm{~mL}$ assembly. The o-ring seals on the $125 \mathrm{~mL}$ assembly prevent liquids from exiting the shield. Primary containment is provided by the common outer shield assembly, which is the same as that used in the 30 and $250 \mathrm{~mL}$ configurations. Secondary containment is provided by the intermediate container (NFT can assembly). When compared to the 30 and $250 \mathrm{~mL}$ versions, there is a difference in the size of the internal shield assembly and the sample bottle. This results in the $125 \mathrm{~mL}$ shielded assembly being lighter in weight than the $30 \mathrm{~mL}$ assembly; and heavier than the $250 \mathrm{~mL}$ assembly. 
HNF-13820, Rev. 0

CONFIGURATION

\section{DESCRIPTION}

Hardigg Case (Part No. AL2216-1205-HHBA-724E) including shielded configuration inner foam assembly Part No: HHBA-724FB.

Hanford drawing $\mathrm{H}-2-830875$

Nylon inserts

Stainless steel belleville washer

Stainless steel disc

Hanford drawing $\mathrm{H}-2-830874$

Intermediate container and foam

Hanford drawing $\mathrm{H}-2-830876$

Outer container assembly $(250 \mathrm{~mL})$

Inner container assembly $(125 \mathrm{~mL})$

Hanford drawing H-2-830877

$125 \mathrm{~mL}$ sample bottle

Gross package weight $=29.94 \mathrm{~kg}(66 \mathrm{lb})$. Content and bottle weight $=0.365 \mathrm{~kg}(0.805 \mathrm{lb})$.

For use with liquids having a specific gravity of $\leq 2.0$ and solids limited in weight (to include packaging) to the maximum weights identified above.

The $250 \mathrm{~mL}$ assembly was not tested in 2003 due to the similarity in design with the 30 and $125 \mathrm{~mL}$ assemblies. The $250 \mathrm{~mL}$ assembly utilizes the outer stainless steel container, o-rings, and screws that are similar in construction to those of the 30 and $125 \mathrm{~mL}$ assemblies. The o-ring seals on the $250 \mathrm{~mL}$ assembly prevent liquids from exiting the shield. Primary containment is provided by the outer shield assembly, which is the same as that used in the 30 and $125 \mathrm{~mL}$ configurations. Secondary containment is provided by the intermediate container (NFT can assembly). When compared to the 30 and $125 \mathrm{~mL}$ versions, the $250 \mathrm{~mL}$ version offers less shielding; however, a larger sample bottle is used. The $250 \mathrm{~mL}$ shielded assembly is the lightest in weight of the three shielded Hedgehog-II configurations.

Hardigg Case (Part No. AL2216-1205-HHBA-724E) including shielded configuration inner foam assembly Part No. HHBA-724FB.

Nylon inserts

Hanford drawing H-2-830875

Stainless steel belleville washer

Stainless steel disc 
HNF-13820, Rev. 0

CONFIGURATION

1 L Glass Bottle

Hedgehog-II Assembly
1 L Poly Bottle Hedgehog-II Assembly

\section{DESCRIPTION}

Hanford drawing $\mathrm{H}-2-830874$

Intermediate container and foam

Hanford drawing $\mathrm{H}-2-830876$

Outer container assembly $(250 \mathrm{~mL})$

Hanford drawing H-2-830877

$250 \mathrm{~mL}$ sample bottle

Gross package weight $=25.85 \mathrm{~kg}(57 \mathrm{lb})$. Content and bottle weight $=0.562 \mathrm{~kg}(1.24 \mathrm{lb})$.

For use with liquids having a specific gravity of $\leq 2.0$ and solids limited in weight (to include packaging) to the maximum weights identified above.

Hardigg Case (Part No. AL2216-1205-HHBA-724E) including $1 \mathrm{~L}$ bottle configuration inner foam assembly Part No. HHBA-724FA.

Hanford drawing $\mathrm{H}-2-830875$

Stainless steel disc.

Hanford drawing $\mathrm{H}-2-830874$

Intermediate container and foam

Hanford drawing H-2-830876

$1 \mathrm{~L}$ wide-mouth glass jar (I-Chem 321-1000 or Fisher Scientific 05-719-89). The existing lid shall be replaced with a black phenolic lid with polyethylene liner (Qorpak 5082). Bottle lid/body interface shall be taped circumferentially with Shurtape VP410, 2-in.-wide, PVC film tape (or equivalent).

The $1 \mathrm{~L}$ glass bottle shall be double-bagged prior to insertion into the intermediate container. Refer to Section 4.2 and Appendix B for additional information.

Gross package weight $=18.14 \mathrm{~kg}(40 \mathrm{lb})$. Content and bottle weight $=1.72 \mathrm{~kg}(3.8 \mathrm{lb})$.

For use with liquids having a specific gravity of $\leq 1.6$ and solids limited in weight (to include packaging) to the maximum weights identified above.

Hardigg Case (Part No. AL2216-1205-HHBA-724E) including $1 \mathrm{~L}$ bottle configuration inner foam assembly 
HNF-13820, Rev. 0

CONFIGURATION

\section{DESCRIPTION}

Part No. HHBA-724FA.

Hanford drawing $\mathrm{H}-2-830875$

Intermediate container and foam. Hanford drawing H-2-830876

$1 \mathrm{~L}$ wide-mouth poly bottle and lid (Nalgene $2105-0032$ or

Fisher Scientific 02-893D). Bottle lid/body interface shall be taped circumferentially with Shurtape VP410, 2-in.-wide, PVC film tape (or equivalent).

The $1 \mathrm{~L}$ poly bottle shall be double-bagged prior to insertion into the intermediate container. Refer to Section 4.2 and Appendix $B$ for additional information.

Gross package weight $=17.92 \mathrm{~kg}(39.5 \mathrm{lb})$. Content and bottle weight $=1.99 \mathrm{~kg}(4.4 \mathrm{lb})$.

For use with liquids having a specific gravity of $\leq 2.0$ and solids limited in weight (to include packaging) to the maximum gross weight identified above.

\subsection{CONTAINMENT SYSTEM}

The Hedgehog-II packaging provides two containment boundaries. Except for the $1 \mathrm{~L}$ assemblies (glass or poly bottles), the primary containment boundary exists through the utilization of the stainless steel shielded containers that incorporate o-rings and screws. The $1 \mathrm{~L}$ assembly is dependent upon the bottle, bottle lid, and tape as the primary containment boundary system.

The secondary containment boundary for the Hedgehog-II is the intermediate container (i.e., the NFT can assembly) that utilizes a gasketed threaded closure. The NFT can assembly also incorporates a pull ring plunger assembly, plunger mount, and pin capture to ensure the lid torque remains constant.

\subsection{AUTHORIZED CONTENTS}

The approved packaging configurations described herein are designed to ship Type A quantities of radioactive materials, normal form. Contents may be in solid or liquid form. Liquids transported in the $1 \mathrm{~L}$ glass bottle shall have a specific gravity of $\leq 1.6$. Liquids transported in all other configurations shall have a specific gravity of $\leq 2.0$. Solid contents may be normal or special form. The solid contents, including packaging, are limited in weight to the gross weight of the as-tested liquids and bottles. 
The simulated payload used for testing purposes was water, steel shot (BB size), and/or sand to equal a liquid having a specific gravity of 1.6 or 2.0 as appropriate for the configuration tested.

\subsection{EVALUATION CRITERIA}

\subsection{TEST AND EVALUATION CRITERIA}

As required by 49 CFR $\S 173.412(j)$, when evaluated against the performance requirements of this section and the tests specified in $\$ 173.465$ (and $\$ 173.466$ ) or using any of the methods authorized by $\S 173.461(\mathrm{a})$, the packaging will prevent the following.

(1) Loss or dispersal of the radioactive contents.

(2) A significant increase in the radiation levels recorded or calculated at the external surfaces for the condition before the test.

For air transport, if the package were subjected to the tests specified in IATA 2003, 10.6.2.1.1.6, the packaging would prevent the following.

(1) Loss of shielding integrity which would result in more than a $20 \%$ increase in the radiation level at any external surface of the package.

(2) Loss or dispersal of the radioactive contents.

NOTE: The shipper must ensure that the amount of radiation at any surface of the packaging would not increase by more than $20 \%$ as a result of the decrease in distance to the center of the package load or because of shifting of the load [IAEA 2000, Paragraph 646(b)].

Testing was conducted using a uniform distributed load. No consideration was given to point sources being in the package. It is the responsibility of the shipper to use the damage information provided in this report to determine if a significant change in radiation level would result for a specific load.

Refer to Appendix A, Section 4.7, paragraph 173.465(c) and Section 4.8, paragraph 173.466(a) for drop test data/results. 


\subsection{PASS/FAIL CRITERIA}

For all tests, except where otherwise indicated, the packages tested were considered to fail if there was significant damage to the packaging and/or loss of the simulated contents. Rupture or leakage from any of the packages constitutes failure. Movement of the simulated contents was measured and evaluated to determine changes in dose rate at the surface of the package.

\subsection{PREPARATION OF SPECIMENS FOR TESTING}

\subsection{PRELOADING INSPECTION}

Prior to testing, each test unit was inspected according to Section 4.0 of the test plan (HNF-13819, Test Plan for Hedgehog-II Packaging Systems, Type A Container). Refer to Appendix A, Section 5.0, 49 CFR 173.462, "Preparation of Specimens for Testing." 
HNF-13820, Rev. 0

\subsection{TEST CONTENTS}

The simulated payload that was used for testing the Hedgehog-II configurations consisted of sample bottles ( $30 \mathrm{~mL}$ and $1 \mathrm{~L}$ ). The 125 and $250 \mathrm{~mL}$ configurations were not tested due to their similarity in design to the $30 \mathrm{~mL}$ configuration.

The $30 \mathrm{~mL}$ bottle was filled with water and steel shot (BB size) to equal a specific gravity equal to 2.0 . The $1 \mathrm{~L}$ poly bottles were filled with water, steel shot (BB size) and sand to equal a specific gravity of 2.0. Initially, the $1 \mathrm{~L}$ glass bottles were filled with water, steel shot (BB size) and sand to equal a specific gravity of 2.0. Due to the inability of the $1 \mathrm{~L}$ glass bottles to pass testing when loaded in this manner, a reduction/change in simulated contents was required. The approved, as-tested $1 \mathrm{~L}$ glass bottles were filled with water and sand to equal a specific gravity of 1.6. Fluorescein was added to all of the $1 \mathrm{~L}$ configurations for leak detection purposes.

Refer to Appendix B for assembly, loading, and closure instructions used during testing.

The following describes the Hedgehog-II, as-tested configurations that took place in 2003 .

30.mL assembly:

Due to the results that were encountered after the first $9 \mathrm{~m}$ (30-ft) drop test using the $250 \mathrm{~mL}$ outer shielded container (S/N 006959-02-250-C), a new $250 \mathrm{~mL}$ outer shielded container (S/N 006959-02-250-A) was used for the remainder of testing activities. (Refer to Appendix A.)

The $30 \mathrm{~mL}$ assembly is the heaviest of all the shielded configurations. When tested, the $30 \mathrm{~mL}$ assembly consisted of a $30 \mathrm{~mL}$ inner shielded container (S/N 006959-02-30-A) and a $250 \mathrm{~mL}$ outer shielded container (S/N 006959-02-250-A).

The $30 \mathrm{~mL}$ bottle was filled with water and steel shot (BB size) to equal a specific gravity of 2.0. The bottle was filled with at least $60 \mathrm{~g}(2.1 \mathrm{oz})$ of shot, and the remainder filled with water, leaving $10 \%$ ullage. No fluoresceine was added to this sample bottle.

The $30 \mathrm{~mL}$ bottle was bagged one time, the bag twisted closed, and the excess of the bag wrapped around the bottle such that it could be inserted into the $30 \mathrm{~mL}$ inner shielded container. The $30 \mathrm{~mL}$ inner shielded container was closed, and inserted into the $250 \mathrm{~mL}$ outer shielded container. This assembly was then closed and inserted into the NFT can assembly (S/N HH-005). The appropriate-sized foam impact cushioning materials, disk, and belleville washer were inserted as shown on Hanford 
$125 \mathrm{~mL}$ and $250 \mathrm{~mL}$ assemblies: drawing H-2-830874 for the shielded container configuration. The concave side of the belleville washer was placed above the stainless steel disk.

The NFT can assembly was bagged and inserted into the Hardigg Case having the HHBA-724FB foam assembly for the shielded container configuration. A nylon insert was nested on each side of the NFT can assembly lid handle and the case foam piece identified as 724-04FB prior to closure of the case. Several Hardigg Cases were used throughout testing activities and were as follows.

HH2-TU-01; HH2-TU-02; HH2-TU-03; and HH2-TU-01 (refurbished).

NOTE: The purpose of the bag around the NFT can assembly is for ease in handling operations.

These two shielded assemblies are evaluated in lieu of testing.

The $125 \mathrm{~mL}$ assembly is similar to the $30 \mathrm{~mL}$ assembly. It utilizes the inner and outer stainless steel containers and o-rings that are similar in construction to those of the $30 \mathrm{~mL}$ assembly. The only difference is in the size of the bottle and internal shielded container. This also results in the $125 \mathrm{~mL}$ shielded assembly being lighter in weight than the $30 \mathrm{~mL}$ assembly.

The $250 \mathrm{~mL}$ assembly utilizes the outer stainless steel container, providing one level of shielding in lieu of two. The o-rings are similar in construction to those of the $30 \mathrm{~mL}$ and $125 \mathrm{~mL}$ assemblies. The only difference is in the size of the bottle. The $250 \mathrm{~mL}$ shielded assembly is the lightest of the three shielded Hedgehog-II configurations.

The loaded assembly is closed and inserted into the NFT can assembly. The appropriate-sized foam impact cushioning materials, disk, and belleville washer are inserted as shown on Hanford drawing H-2-830874 for the shielded container configuration. The concave side of the belleville washer is placed above the stainless steel disk.

The NFT can assembly is bagged and inserted into the Hardigg Case having the HHBA-724FB foam assembly 
for the shielded container configuration. A nylon insert is nested on each side of the NFT can assembly lid handle and the case foam piece identified as $724-04 \mathrm{FB}$ prior to closure of the case.

NOTE: The purpose of the bag around the NFT can assembly is for ease in handling operations.

Because of the similarities in the design and construction of the 30,125 , and $250 \mathrm{~mL}$ versions, testing of the 125 and $250 \mathrm{~mL}$ configurations was not conducted.

NOTE: The original $1 \mathrm{~L}$ bottle/lid tested had a payload with a specific gravity equal to 2.0 , and consisted of a wide-mouth glass jar (I-Chem 321-1000 [Fisher Scientific 05-719-89]) having its existing lid replaced with a black phenolic lid/polyvinyl liner (Qorpak 5024 [Fisher Scientific 02-883-2Q] Because of the failures that occurred during vibration and drop testing, a change was required during testing that identified the use of a different closure lid, as well as contents having a reduced specific gravity for this particular configuration.

The $1 \mathrm{~L}$ glass bottle lid tested and approved for use consists of a black phenolic lid with polyethylene liner (Qorpak 5082). The approved loading for this configuration is a liquid having a specific gravity equal to 1.6 .

The approved $1 \mathrm{~L}$ glass bottle configuration was filled with water and sand to equal a specific gravity of 1.6. The bottle was filled with $1.04 \mathrm{~kg}(2.3 \mathrm{lb})$ of sand and $0.23 \mathrm{~kg}(0.5 \mathrm{lb})$ of water, leaving a $10 \%$ ullage. Fluoresceine was added for leak detection purposes. The lid to the $1 \mathrm{~L}$ sample bottle was secured with tape, circumferentially around the lid/body interface. Shurtape VP410, 2-in.-wide, PVC film tape was used.

The approved $1 \mathrm{~L}$ glass bottle configuration was inserted into a bag, the open end of the bag twisted closed (NOT horsetailed), and the twisted portion sealed with masking tape. The twisted and taped portion of the bag was placed along one side of the bottle and not directly over the lid area. These contents were then bagged a second time, repeating this same process. The second bag was twisted and taped along the opposite side of the bottle (from the first twisted closure). The twisted and taped area of the bag shall not be 
placed directly over the lid or the lid/bottle threaded area.

The $1 \mathrm{~L}$ bottle was inserted into an NFT can assembly (S/N HH-002) that included the appropriate-sized foam impact cushioning materials and disk as shown on Hanford drawing $\mathrm{H}-2-830874$ for the approved $1 \mathrm{~L}$ glass bottle configuration.

The NFT can assembly was bagged and inserted into the Hardigg Case having the HHBA-724FA foam assembly for the $1 \mathrm{~L}$ bottle configuration. Several Hardigg Cases were used throughout testing activities and were as follows.

HH2-TU-02; HH2-TU-01 (refurbished); and HH2-TU-04.

NOTE: The purpose of the bag around the NFT can assembly is for ease in handling operations.

$1 \mathrm{~L}$ poly bottle assembly:

The $1 \mathrm{~L}$ bottles were filled with water, steel shot (BB size), and sand to equal a specific gravity of 2.0. The bottles were filled with $0.49 \mathrm{~kg}(1.09 \mathrm{lb})$ of sand, $0.76 \mathrm{~kg}$ $(1.67 \mathrm{lb})$ of shot, and $0.35 \mathrm{~kg}(0.78 \mathrm{lb})$ of water, leaving a 10\% ullage. Fluorescein was added for leak detection purposes. The lid to the $1 \mathrm{~L}$ bottle was secured with tape, circumferentially around the lid/body interface. Shurtape VP410, 2-in.-wide, PVC film tape was used.

The $1 \mathrm{~L}$ bottle was bagged once, the open end of the bag twisted closed, and the twist sealed with masking tape. The taped end was folded onto itself and re-taped (i.e., horse-tailed). The twisting and taping of the bag may be placed directly over the lid or along the side of the lid area. These contents were then bagged a second time, repeating this same process.

The $1 \mathrm{~L}$ bottle was inserted into an NFT can assembly (S/N HH-007) that included the appropriate-sized foam impact cushioning materials as shown on Hanford drawing $\mathrm{H}-2-830874$ for the approved $1 \mathrm{~L}$ poly bottle configuration.

The NFT can assembly was bagged and inserted into the Hardigg Case having the HHBA-724FA foam assembly for the $1 \mathrm{~L}$ bottle configuration. Two Hardigg Cases were used throughout testing activities and were as follows. 
HNF-13820, Rev. 0

HH2-TU-03 and HH2-TU-02.

NOTE: The purpose of the bag around the NFT can assembly is for ease in handling operations.

\subsection{LOADING, ASSEMBLY, AND CLOSURE}

The packaging configurations were assembled, loaded, and closed in accordance with the instructions provided in Appendix B of this report. The configurations tested and evaluated are described in Sections 2.2 and 4.2 of this report. The simulated contents and associated specific gravity for liquids is identified in Section 4.2 and Appendix B of this report.

\subsection{PACKAGING EVALUATION RESULTS}

The following list shows the primary sections of 49 CFR applicable to Type A packaging. Each of these regulations where identification and documentation of compliance are presented in the PQCL (see Appendix A) is marked with an asterisk $\left({ }^{*}\right)$. It is the responsibility of the user of the package to ensure compliance with the unmarked regulations and with the parts identified within the PQCL as the "responsibility of the shipper."

NOTE: This list highlights the performance requirements and is not intended to be allencompassing.

- 173.24 General requirements for packagings and packages*

- 173.24a Additional general requirements for non-bulk packagings and packages*

- 173.24b Additional general requirements for bulk packagings*

- 173.27 General requirements for transportation by aircraft*

- 173.410 General design requirements*

- 173.412 Additional design requirements for Type A packages*

- 173.415(a) Authorized Type A packages

- 173.442 Thermal limitations

- 173.461 Demonstration of compliance with tests 
HNF-13820, Rev. 0

- 173.462 Preparations of specimens for testing*

- 173.465 Type A packaging tests*

- 173.466 Additional tests for Type A packagings designed for liquids and gases*

- 173.474 Quality control for construction of packaging

- 173.475 Quality control requirements prior to each shipment of Class 7 (radioactive) materials

- $178.3 \quad$ Marking of packagings*

- 178.350 Specification 7A; general packaging, Type A

- 178.608 Vibration standard*

As the Hedgehog-II packaging configurations are also approved for transportation by aircraft (49 CFR 173.27), IATA 2003, Section 10, "Radioactive Material" is also applicable.

\subsection{DESIGN EVALUATION}

This report, including Appendices A, B, and C, provides the evaluation and testing information for the Hedgehog-II configurations as applicable to the Type A packaging regulations identified in 49 CFR. Appendix A provides the PQCL that was used by DTS to evaluate the ability of the Hedgehog-II packaging configurations to meet performance-related regulations.

Compliance with all applicable regulations signifies that the packaging meets the design and performance testing requirements for a DOT-7A Type A packaging. In addition, the IATA requirements for air transport are identified, and the results of the evaluated compliance indicated. 


\subsection{CONCLUSION}

When loaded as described in this report (refer to Sections 4.2, 4.3, and Appendix B), the evaluation and testing indicates that the Hedgehog-II configurations (as described in Section 2.0 and Appendices A through D of this report) meet applicable DOT-7A Type A design and compliance test requirements, and where applicable, meet IATA design and compliance test requirements for transportation by aircraft. The packagings shall be loaded, assembled, and closed as described in this document (Section 4.3 and Appendix B). Deviations from the astested packaging system configurations require retesting or evaluation.

\subsection{RESTRICTIONS/SPECIFICATIONS}

1. The shielded configurations and $1 \mathrm{~L}$ poly bottle configuration are approved for shipping liquids having a specific gravity of $\leq 2.0$. The $1 \mathrm{~L}$ glass bottle configuration is approved for shipping liquids having a specific gravity of $\leq 1.6$. Solid contents are authorized for shipment of normal or special form. The solid materials, including packaging, are limited in weight to the gross weight of the as-tested liquids and bottles. The shipper must determine that the actual contents are closely simulated by the test contents. If they are not, testing/analysis must be conducted and documented to demonstrate the actual contents comply with DOT-7A Type A requirements.

2. Assurance that the proper orientation of the Hardigg Case is marked. Note that the internal, black, acrylonitrile-butadiene-styrene load spreader is located underneath the intermediate container as the package is normally positioned during transport conditions. The slit in the lid gasket is located at the base of the package as it is normally positioned during transport conditions.

3. Improper tightening of the NFT can assembly may cause leakage or breakage of contents. To ensure proper seal for transporting inner packagings, the NFT can assembly lid must be tightened to engage the lid to the o-ring. In addition, the closure pin must align with the pin capture and be engaged in the pin capture.

4. The NFT can assembly identification numbers, located on the lid and body of the can, must be identical. Do not use if they are not identical.

5. Note that two different screw sizes exist with the stainless steel shielded assemblies. The user should refer to the drawings (Appendix C) and the operating instructions (HNF-11651) when assembling the packaging configurations.

6. The top lid of each shielded assembly will be notched. Each shielded assembly is identified with a serial number. Do not use if the serial number for the corresponding parts of the shielded assembly are not identical. 
7. The shielded assembly screws shall be torqued to 1.9 to $2.0 \mathrm{~N}-\mathrm{m}(1.4$ to $1.5 \mathrm{ft}-\mathrm{lb}$, or 17 to 18 in-lb).

8. The $1 \mathrm{~L}$ versions require that the bottle remain intact and not break. The shipper must either use the approved $1 \mathrm{~L}$ bottle assemblies that were qualified for use during testing (see Appendix C), or document that, if a different bottle is used, it is equivalent to what was qualified in testing.

Note that the following bottle/lid combination is not acceptable for use: $1 \mathrm{~L}$ wide-mouth glass jar (I-Chem 321-1000 [Fisher Scientific 05-719-89]) having its existing lid replaced with a black phenolic lid/polyvinyl liner (Qorpak 5024 [Fisher Scientific 02-883-2Q]).

9. For air transport, the shipper shall ensure that the radiation level at any surface would not increase by more than $20 \%$ (IAEA 2000 and IATA 2003).

10. The maximum gross weights for the package configurations are shown in Table 2-1.

The shipper is the organization that actually uses the packaging and therefore is responsible to ensure the packaging is used in accordance with the design. The shipper shall ensure that the design is suitable in all respects for the contents to be shipped. If it is not suitable, testing/analysis must be conducted and documented to demonstrate DOT-7A Type A compliance with the actual contents. The design will dictate many of the limits placed on the contents, such as mass and physical form.

The Hedgehog-II consists of off-the-shelf components. Therefore, the shipper assumes the responsibility of the manufacturer to ensure the requirements of 49 CFR 178.3(a), (b), and (c) are met. The manufacturer (shipper) of the packaging described herein is responsible for using the packaging fabrication materials, processes, and controls that are equivalent to those used in the fabrication of the test unit packagings.

\subsection{SHIPPER'S QUALITY ASSURANCE PROGRAM}

It is critical that controls are in place to ensure that the packaging used complies with the specifications given for the packaging as tested, described, and evaluated in this document. When used by DOE contractors, each shipper must have a documented QA program, per DOE Order 414.1A, Quality Assurance, that describes how this is achieved, and the degree of certainty, in addition to documentation (audit trail) that demonstrates compliance.

The shipper's organization must implement a QA program that assures the shipment will comply with the regulations. In addition to implementing a QA program, the shipper is responsible for meeting the requirements identified in 49 CFR 173.474, "Quality control for construction of packaging" and 173.475, "Quality control requirements prior to each shipment of Class 7 
(radioactive) materials." These requirements provide quality control elements that are applicable to Type A packagings. These requirements are restated below and must be met for all shipments.

\subsection{Quality Control for Construction of Packaging}

Prior to the first use of any packaging for the shipment of Class 7 (radioactive) material, the shipper shall determine that-

(a) The packaging meets the quality of design and construction requirements as specified in this subchapter; and

(b) The effectiveness of the shielding, containment and when required, the heat transfer characteristics of the package, are within the limits specified for the package design.

\subsection{Quality Control Requirements Prior to Each Shipment of Class 7} (Radioactive) Materials

Before each shipment of any Class 7 (radioactive) materials package, the offeror must ensure, by examination or appropriate tests, that-

(a) The packaging is proper for the contents to be shipper;

(b) The packaging is in unimpaired physical condition, except for superficial marks;

(c) Each closure device of the packaging, including any required gasket, is properly installed, secured, and free of defects;

(d) For fissile material, each moderator and neutron absorber, if required, is present and in proper condition;

(e) Each special instruction for filling, closing, and preparation of the packaging for shipment has been followed;

(f) Each closure, valve, or other opening of the containment system through which the radioactive content might escape is properly closed and sealed;

(g) Each packaging containing liquid in excess of an $A_{2}$ quantity and intended for air shipment has been tested to show that it will not leak under an ambient atmospheric pressure of not more than $25 \mathrm{kPa}$, absolute ( $3.6 \mathrm{psia})$. The test must be conducted on the entire containment system, or on any receptacle or vessel within the containment system, to determine compliance with this requirement;

(h) The internal pressure of the containment system will not exceed the design pressure during transportation; and

(i) External radiation and contamination levels are within the allowable limits specified in this subchapter. 
HNF-13820, Rev. 0

\subsection{PRIMARY USER}

Mr. Jeffrey L. Westcott

Fluor Hanford, Inc.

Post Office Box 1000

Richland, Washington 99352

(509) 373-9800

Jeffrey_L_Westcott@rl.gov

\subsection{DESIGNER}

Mr. James A. Serles

Duratek Technical Services

345 Hills Street

Richland, Washington 99352

(509) 376-0298

jaserles@duratekinc.com 


\subsection{REFERENCES}

49 CFR, “Transportation," Code of Federal Regulations, as amended.

49 CFR 173, "Shippers-General Requirements for Shipments and Packagings," Code of Federal Regulations, as amended.

ASTM A240, 2002, Standard Specification for Chromium and Chromium-Nickel Stainless Steel Plate, Sheet, and Strip for Pressure Vessels and for General Application, American Society for Testing and Materials, Philadelphia, Pennsylvania.

ASTM A276, 2002, Standard Specification for Stainless Steel Bars and Shapes, American Society for Testing and Materials, Philadelphia, Pennsylvania.

ASTM A511, 1996, Standard Specification for Seamless Stainless Steel Mechanical Tubing, American Society for Testing and Materials, Philadelphia, Pennsylvania.

ASTM D1056, 2000, Standard Specification for Flexible Cellular Materials-Sponge or Expanded Rubber, American Society of Testing and Materials, Philadelphia, Pennsylvania.

ASTM F835, 2000, Standard Specification for Alloy Steel Socket Button and Flat Countersunk Head Cap Screws, American Society of Testing and Materials, Philadelphia, Pennsylvania.

DFSNW-QAM-001, Quality Assurance Manual, Duratek Federal Services, Inc., Northwest Operations, Richland, Washington.

DFSNW-QAP-001, Quality Assurance Procedures, Duratek Federal Services, Inc., Northwest Operations, Richland, Washington.

DOE Order 414.1A, Quality Assurance, U.S. Department of Energy, Washington, D.C., 1999.

HNF-11651, Operation and Maintenance Manual for the Hedgehog-II, Rev. 0, Packaging Systems, Duratek Technical Services, Richland, Washington.

HNF-13819, Test Plan for Hedgehog-II Packaging Systems, Type A Container, Rev. 1-A, Duratek Technical Services, Richland, Washington.

HNF-SD-TP-TI-006, Rev. 1, Documentation and Verification Required for Type A Packaging Use, Waste Management Technical Services, Richland, Washington. 
IAEA, 2000, Regulations for the Safe Transport of Radioactive Material: 1996 Edition (Revised), Safety Standards Series No. TS-R-1 (ST-1 Revised), International Atomic Energy Agency, Vienna, Austria.

IATA, 2003, Dangerous Goods Regulations, $44^{\text {th }}$ Edition, Effective from 1 January through 31 December 2003, International Atomic Energy Agency, Vienna, Austria.

WHC-SD-OTR-001, 1995, Test and Evaluation Report for Westinghouse Hanford Company's Hedgehog Shielded Container, Docket 94-39-7A, Type A Container, Rev. 1, Westinghouse Hanford Company, Richland, Washington.

WMTS-IP/7A-005, Rev. 0, Test and Evaluation Procedure for DOT-7A Type A Packaging and Industrial Packaging, Waste Management Technical Services, Richland, Washington. 
HNF-13820, Rev. 0

APPENDIX A

DOT-7A TYPE A PACKAGING QUALIFICATION CHECKLIST 
HNF-13820, Rev. 0

This page intentionally left blank.

A-ii 


\section{CONTENTS}

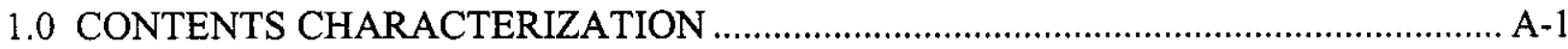

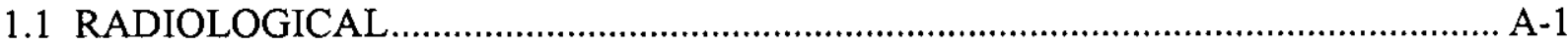

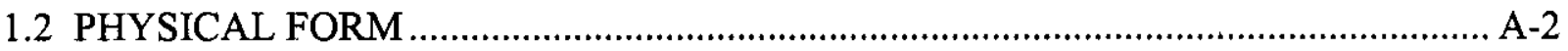

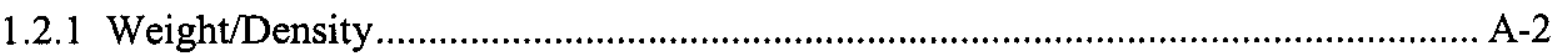

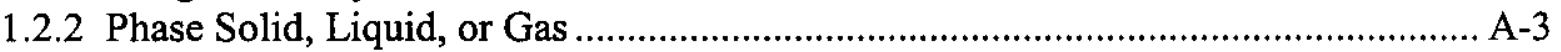

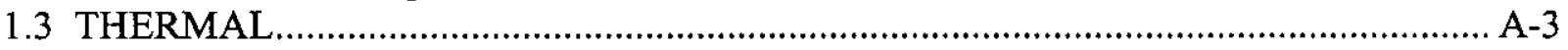

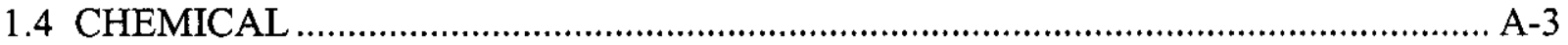

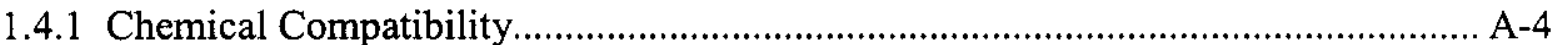

1.4.2 Hazardous Materials Proper Shipping Names..................................................... A-4

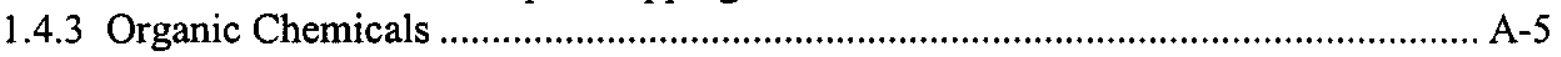

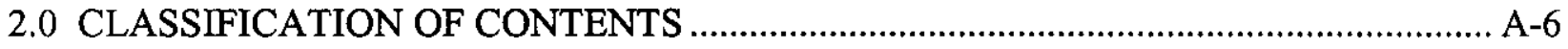

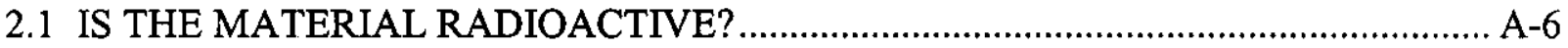

2.2 IS THE MATERIAL NONFISSILE OR FISSILE EXEMPT? ................................. A-6

2.3 CAN TYPE A QUANTITY LIMITS BE MET? ………........................................

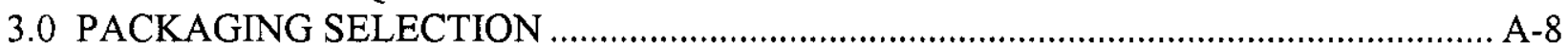

3.1 AUTHORIZED TYPE A PACKAGING CATEGORY SELECTED ........................... A -8

3.2 PHYSICAL CHARACTERISTICS OF THE LOAD …………............................. A-8

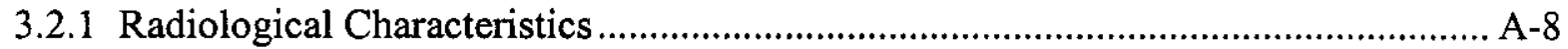

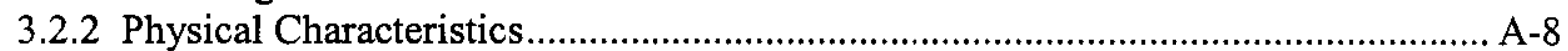

3.2.3 Physical Phase, Solid, Liquid, or Gas................................................................... A

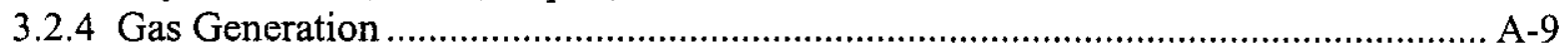

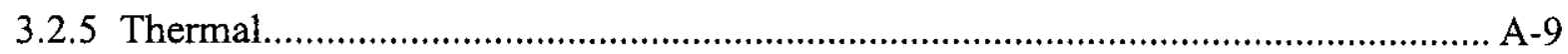

3.2.6 Chemical Characteristics ............................................................................... A

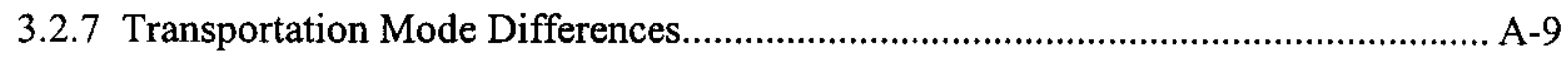

4.0 REGULATORY REQUIREMENTS..................................................................... A-

4.1 49 CFR 173.24 GENERAL REQUIREMENTS FOR PACKAGINGS AND

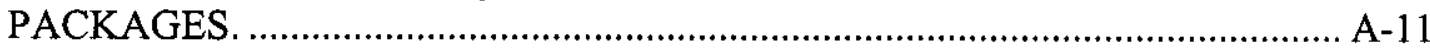

4.2 49 CFR 173.24A ADDITIONAL GENERAL REQUIREMENTS FOR NON-BULK PACKAGINGS AND PACKAGES.............................................................. A-24

4.3 49 CFR 173.24B ADDITIONAL GENERAL REQUIREMENTS FOR BULK

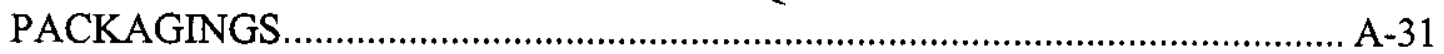

4.4 49 CFR 173.27 GENERAL REQUIREMENTS FOR TRANSPORTATION BY

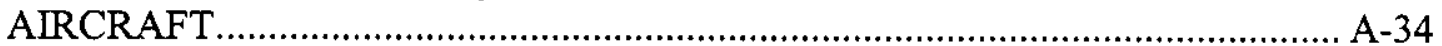

4.5 49 CFR 173.410 GENERAL DESIGN REQUIREMENTS. ................................... A-42

4.6 49 CFR 173.412 ADDITIONAL DESIGN REQUIREMENTS FOR TYPE A

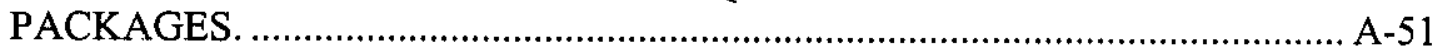

4.7 49 CFR 173.465 TYPE A PACKAGING TESTS. ................................................... A-61

4.8 49 CFR 173.466 ADDITIONAL TESTS FOR TYPE A PACKAGING DESIGNED FOR LIQUIDS AND GASES. ................................................................ A-72

5.0 49 CFR 173.462 PREPARATION OF SPECIMENS FOR TESTING ........................... A-82

6.0 MANUFACTURER'S COMMUNICATIONS ...................................................... A-86

7.0 49 CFR 178.3 MARKING OF PACKAGINGS …….......................................... A-87

8.0 49 CFR 178.608 VIBRATION STANDARD......................................................... A-90

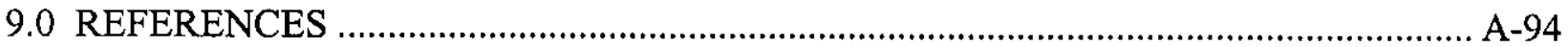


HNF-13820, Rev. 0

This page intentionally left blank. 
HNF-13820, Rev. 0

\subsection{CONTENTS CHARACTERIZATION}

\subsection{RADIOLOGICAL}

In the following table identify the radionuclides present in the material. Identify the specific isotopes; for each isotope present identify the quantity in becquerel. If the material is special form, identify the $A_{1}$ value; if normal form, identify the $\mathrm{A}_{2}$ value. Identify the weight in grams of the radionuclides present in the material when knowr. If nuclide is fissile, identify it as such. Identify the decay heat. Determine the total for each column.

\begin{tabular}{|c|c|c|c|c|c|c|}
\hline \multirow{2}{*}{ RADIONUCLIDES } & \multicolumn{5}{|c|}{ QUANTITY (per package) } & \multirow{2}{*}{$\begin{array}{c}\begin{array}{c}\text { DECAY } \\
\text { HEAT }\end{array} \\
\text { Watts/gram }\end{array}$} \\
\hline & Becquerel & $\mathbf{A}_{\mathbf{1}}$ & $\mathbf{A}_{2}$ & Grams & $\begin{array}{l}\text { Grams } \\
\text { Fissile }\end{array}$ & \\
\hline \multicolumn{7}{|c|}{$\begin{array}{l}\text { The intent of this table is for the shipper to identify the radionuclides present in material; identify the weight in } \\
\text { grams of the radionuclides present in the material, when known; identify the decay heat; and determine the total } \\
\text { for each column. }\end{array}$} \\
\hline \multicolumn{7}{|c|}{$\begin{array}{l}\text { The approved Hedgehog-II configurations described in the final evaluation report and this Packaging } \\
\text { Qualification Checklist (PQCL) are designed to ship Type A quantities of radioactive materials, normal } \\
\text { form. Contents may be in solid or liquid form. Liquids transported in the as-tested and approved } 1 \mathrm{~L} \\
\text { glass bottle configuration shall have a specific gravity of } \leq 1.6 \text {. Liquids transported in all other } \\
\text { configurations shall have a specific gravity of } \leq 2.0 \text {. The solid contents may be normal or special form. } \\
\text { The solid contents are limited in weight (to include the packaging) to the gross weight of the as-tested } \\
\text { liquids and bottles. The maximum gross shipping weights for the Hedgehog-II configurations are } \\
\text { identified below: }\end{array}$} \\
\hline $\begin{array}{l}30 \mathrm{~mL} \\
125 \mathrm{~mL} \\
250 \mathrm{~mL} \\
1 \mathrm{~L} \text { glass } \\
1 \mathrm{~L} \text { poly }\end{array}$ & $\begin{array}{l}31.30 \mathrm{~kg}( \\
29.94 \mathrm{~kg}( \\
25.85 \mathrm{~kg} \\
18.14 \mathrm{~kg} \\
17.92 \mathrm{~kg}\end{array}$ & & & & & \\
\hline \multicolumn{7}{|c|}{$\begin{array}{l}\text { Gaseous contents are not authorized for transport within any of the Hedgehog-II configurations identified } \\
\text { within the final evaluation report or this PQCL. }\end{array}$} \\
\hline \multicolumn{7}{|c|}{$\begin{array}{l}\text { It is the responsibility of the shipper to ensure that Type A quantity limits are met for normal form } \\
\text { shipments. Air transport is intended; therefore, the shipper is responsible for reviewing and complying } \\
\text { with the requirements identified in Section 10, "Radioactive Material," of the International Air Transport } \\
\text { Agency's (IATA), Dangerous Goods Regulations, } 44^{\text {th }} \text { Edition (IATA 2003). In addition, shippers are } \\
\text { responsible for reviewing and complying with the International Atomic Energy Agency's (IAEA), } \\
\text { Regulations for the Safe Transport of Radioactive Material, Requirements No. TS-R-1 (ST-1 Revised), 1996 } \\
\text { Edition (Revised) (IAEA 2000). }\end{array}$} \\
\hline \multicolumn{7}{|c|}{$\begin{array}{l}\text { The shipper is responsible to ensure that the applicable domestic and international regulations are met for } \\
\text { their specific shipment. Current revisions to regulatory publications should be reviewed prior to air or } \\
\text { international shipments. }\end{array}$} \\
\hline
\end{tabular}

(Use extra sheets if needed.) 
Using the identified radionuclidies determine the associated radiation types.

[ ] Photons ( $\mathrm{X}$ and gamma rays)

[ ] Alpha particles

[ ] Beta particles ( includes positrons)

[ ] Neutron particles

[ ] Other important radiations. Identify.

The shipper/user is responsible for identifying the associated radiation types.

\subsection{PHYSICAL FORM}

\subsubsection{Weight/Density}

Identify the total weight in grams for the material in which the radioactivity is distributed.

Total weight of the load grams.

Identify the density of the load.

Density of the load $\left(\mathrm{kg} / \mathrm{m}^{3}\right)$.

The shipper/user is responsible for identifying the above information. 


\subsubsection{Phase Solid, Liquid, or Gas}

Identify if material is special form or normal form. Determine the physical form of the material. Identify if it is a solid, liquid or gas. If the material is a solid, identify if it is considered form $1,2,3$, or a heavy, bulky solid. For heavy, bulky materials (e.g., concrete chunks, motors, and pumps), equipment/materials with sharp corners or protrusions, or material/equipment geometries that could result in highly localized forces, ensure that the contents are securely fastened/positioned within the package to prevent damage to the packaging. Identify the density of the material. For liquids identify the specific gravity and viscosity. For gas identify the volume at standard temperature and pressure (STP). Indicate if a phase change(s) can occur over the required temperature range.
Form Category:
[X] Normal
[ ] Special (see 49 CFR 173.469)
Physical Form:
$[\mathbf{X}]$ Solid
[ $\mathbf{X}]$ Form 1
[x ] Form 2
$[\mathbf{X}]$ Form 3

[ ] Heavy, bulky solid requiring dunnage.

\begin{tabular}{|c|c|c|c|}
\hline & {$[\mathbf{X}$ ] Liquid } & $\begin{array}{l}\text { Specific } \\
\text { gravity: }\end{array}$ & $\begin{array}{l}\text { Viscosity: (Shipper to determine) } \\
\leq 1.6 \text { for } 1 \mathrm{~L} \text { glass configuration } \\
\leq \mathbf{2 . 0} \text { for all other configurations }\end{array}$ \\
\hline & [ ] Gas & Volume: & $\left(\mathrm{cm}^{3}\right.$ at STP $)$ \\
\hline Phase Change: & [ ] Phase & [ ] No Ph & se change \\
\hline
\end{tabular}

The shipper is responsible for identifying if a phase change can occur over the required temperature range. Gaseous contents are not authorized for shipment within any of the Hedgehog-II configurations tested and/or evaluated as described herein.

\subsection{THERMAL}

Using the information on decay heat identified in the radioisotope table above, determine the thermal load resulting from decay heat.

Total wattage from decay heat: (watts/package)

Total wattage from other sources: (watts/package)

Total wattage of contents: (watts/package)

The shipper is responsible for identifying the thermal load resulting from decay heat.

\subsection{CHEMICAL}

Identify the chemical characteristics of the material that makes up the load. The basic chemical makeup of the contents being shipped must be understood to adequately design or select a packaging. Identify chemical properties that would make the packaging harmful to common packaging materials. Identify any materials that would be classed as hazardous materials if they were not radioactive. This would result in the identification of materials that were hazardous because they are explosive, flammable, poisonous, combustible, dangerous when wet, oxidizers, corrosives, irritants, or another hazard. It is suggested that the material be identified by the proper shipping name and identification number from the Hazardous Materials Table (49 CFR 172.101) it would have if it were not radioactive. Space is provided on the following table for the information. Identify the quantities of each material that will be in the load. 
If the package will contain organic substances, identify them and the quantity expected to be present in a single package. Also, watch for materials that are pyrophoric or materials that react with air or water.

\subsubsection{Chemical Compatibility}

List the chemical properties that may make the material being shipped incompatible with common packaging materials.

The Hedgehog-II configurations identified within this final evaluation and test report and PQCL are not intended for shipping explosive materials or chemicals forbidden by air, ground, or marine transport.

For airborne radioactive material transport, refer to Section 10.7.3, "Applicability of Hazard Labels;" Section 7, "Marking and Labeling;" and Section 3, "Classification" of IATA 2003.

The shipper is responsible for listing the chemical properties for the material to be shipped to ensure compatibility with contents and the packaging materials. Gaseous contents are not authorized for transport within the as-tested Hedgehog-II configurations.

\subsubsection{Hazardous Materials Proper Shipping Names}

\begin{tabular}{|c|c|c|c|c|}
\hline & & \multicolumn{3}{|c|}{$\begin{array}{c}\text { EXPECTED QUANTITY } \\
\text { (per package) }\end{array}$} \\
\cline { 3 - 5 } & IDENTIFICATION & $\begin{array}{c}\text { Solids } \\
\text { (grams) }\end{array}$ & $\begin{array}{c}\text { Liquids } \\
\text { (ml) }\end{array}$ & $\begin{array}{c}\text { Gases } \\
\text { (cm }{ }^{3} \text { at STP) }\end{array}$ \\
\hline
\end{tabular}

The intent of this table is for the shipper to identify the chemical characteristics of the material that makes up the load. The basic chemical makeup of the contents being shipped must be understood to adequately design or select a packaging.

Identify the chemical properties that would be harmful to common packaging materials; identify any materials that would be classed as hazardous materials if they were not radioactive (i.e., explosive, poisonous, combustible, dangerous when wet, oxidizers, corrosives, or other). Watch for materials that are pyrophoric (react with air).

Nonradioactive constituents and quantities will be identified by the shipper and entered onto the shipping papers. The Hedgehog-II packaging configurations are authorized for transport of solid and liquid radioactive contents. Gaseous contents are not authorized for use in the as-tested configurations. The shipper is responsible for documenting the compatibility of the load with the packaging.

(Use extra sheets if needed.) 
HNF-13820, Rev. 0

\subsubsection{Organic Chemicals}

\section{NAME OF ORGANIC CHEMICALS}

EXPECTED QUANTITY (per package)

The intent of this table is for the shipper to identify if the package will contain organic substances. Identify what these substances are and the quantity expected to be present in a single package. Also, watch for materials that are pyrophoric (react with air).

The shipper is responsible for documenting compatibility of the load with the packaging.

(Use extra sheets if needed.) 


\subsection{CLASSIFICATION OF CONTENTS}

\subsection{IS THE MATERIAL RADIOACTIVE?}

Determine if material is radioactive for transportation. Divide the total radioactivity in becquerel (Section 1.1) by the weight of the material in grams (Section 1.2.1)

$$
\begin{gathered}
\frac{\text { Total activity } B q}{\text { Total material } g}=X \mathrm{~Bq} / \mathrm{g} \\
\text { If } X>70 \text { material is radioactive for transportation. }
\end{gathered}
$$

For transportation, the material is classified as: $\quad[\mathbf{X}]$ Radioactive $\quad[$ NNonradioactive

The shipper is responsible to determine if the material is radioactive or nonradioactive (refer to 49 CFR 173.403, "radioactive material.") The Hedgehog-II packaging configurations as documented within the final evaluation and test report and PQCL were tested and evaluated for use as a Type A packaging per U.S. Department of Transportation (DOT) requirements. For airborne/international shipments, the shipper shall refer to the applicable requirements identified in IATA 2003 and IAEA 2000.

\subsection{IS THE MATERIAL NONFISSILE OR FISSILE EXEMPT?}

Are fissile nuclides present? If no, the material is nonfissile. If yes, can the material meet the conditions in 10 CFR 71.53 ? If yes, the material is fissile exempt. If no, the material is fissile and requires a certified packaging. Check the appropriate box.

$$
\text { [ } \mathbf{X} \text { ] Nonfissile [ } \quad \text { ] Fissile Exempt [ ] Fissile (Certified Package Required) }
$$

The shipper is responsible to determine if the material is nonfissile or fissile exempt. For airborne/international shipments, the shipper shall refer to the applicable requirements identified in IATA 2003 and IAEA 1996. 


\subsection{CAN TYPE A QUANTITY LIMITS BE MET?}

If more than one nuclide is present, determine the $A_{1}$ or $A_{2}$ value, as applicable, for the mixture. If only one nuclide is present, use the value from the table. Determine if the total activity to be placed in the package is less than or equal to a Type A quantity.

$A_{1}$ or $A_{2}$ value calculated or from table TBq.

Type A quantity present [ ] Yes [ ] No

If yes, identify the proper shipping name from 49 CFR 172.101 Hazardous Materials Table.

For the identified proper shipping name, does the entry in column 8 (Packaging) identify 49 CFR 173.415 ?
49 CFR 173.415 referenced.
[ ] Yes
[ ] No

The shipper is responsible for determining if the Type A quantity limits are met. For airborne/international shipments, the shipper shall refer to the applicable requirements identified in IATA 2003 and IAEA 2000. 


\subsection{PACKAGING SELECTION}

\subsection{AUTHORIZED TYPE A PACKAGING CATEGORY SELECTED}

The DOT authorizes four categories of packagings for use when shipping Type A quantities of radioactive material. Identify the category selected.

[X] Specification 7A, General Packaging, Type A. For packaging in this category, completion of this checklist will identify required documentation.

[ ] Other Type A Packagings. When using other Type A packagings, be sure to register as a user and follow all conditions of use identified for the packaging.

[ ] Type B Packagings. When using a Type B packaging, be sure to register as a user and follow all conditions of use identified for the packaging. If using a Type B packaging as a Type A packaging, conduct required evaluations. The documentation requirements identified in this document apply to a Type B packaging as a Type A packaging.

[ ] Foreign-made Packagings. When using a foreign-made packaging, obtain the packaging's documentation and verify the packaging was used for import. While not directly applicable, this checklist provides some idea of the type of documentation that should be found.

[ ] Packaging meets the standards in International Atomic Energy Agency (IAEA) Regulations for the Safe Transport of Radioactive Material, 1995 Edition, Safety Series No. 6 (IAEA 1990) and bears the marking "Type A."

[ ] Packaging was used for the import of Class 7 (radioactive) materials.

[ ] Possess the applicable documentation of tests and engineering evaluations and maintain the documentation on file in accordance with 49 CFR 173.415(a).

\subsection{PHYSICAL CHARACTERISTICS OF THE LOAD}

Selection of a proper packaging requires knowledge of the physical characteristics of the load. Space is provided in the following subsections to identify where the documentation for the radiological, physical, thermal, and chemical data for the load is found. The information is needed to document compatibility of the load with the packaging.

\subsubsection{Radiological Characteristics}

If not provided in Section 1 of the checklist, identify where the documentation of radionuclidies present in the load can be found.

The shipper is responsible for identifying radionuclides present in the load, prior to shipment.

\subsubsection{Physical Characteristics}

If not provided in Section 1 of the checklist, identify where the documentation of physical characteristics of the load can be found.

The shipper is responsible for identifying this information prior to shipment. 


\subsubsection{Physical Phase, Solid, Liquid, or Gas}

If not provided in Section 1 of the checklist, identify where the documentation of physical characteristics of the load can be found.

The shipper is responsible for identifying this information prior to shipment. Gaseous contents are not authorized for shipment in the Hedgehog-II configurations identified within this final evaluation and test report and PQCL.

\subsubsection{Gas Generation}

If not provided in Section 1 of the checklist, identify where the documentation of gas generation by the load can be found.

The shipper is responsible for identifying this information prior to shipment. Gaseous contents are not authorized for shipment in the Hedgehog-II configurations identified within this final evaluation and test report and PQCL.

\subsubsection{Thermal}

If not provided in Section 1 of the checklist, identify where the documentation on thermal characteristics of the load can be found.

The shipper is responsible for identifying this information prior to shipment.

\subsubsection{Chemical Characteristics}

If not provided in Section 1 of the checklist, identify where the documentation of chemical characteristics of the load can be found.

The shipper is responsible for identifying this information prior to shipment.

\subsubsection{Transportation Mode Differences}

Identify the mode of transportation.

$$
\text { [ } \mathbf{X} \text { ] Aircraft. } \quad[\mathbf{X}] \text { Highway, rail, vessel. }
$$

If shipment is by aircraft, identify if the package contents are liquid, solid, or gas.

$$
\text { [ } \mathbf{X} \text { ] Liquid. [ [X] Solid. [ ] Gas. }
$$
$\left(13.8 \mathrm{Ib} / \mathrm{in}^{2}\right)$.

If shipment is by air and is liquid, does the packaging meet the minimum pressure differential of $95 \mathrm{kPa}$

$$
\text { [ } \mathbf{X} \text { ] Yes. [ ] No, do not use packaging for shipment of liquid by }
$$
aircraft. 
If liquid, do the contents require the ability to meet a higher differential pressure? If yes, identify the pressure required and documentation that shows the packaging meets the requirement.

The identified containment boundaries for the Hedgehog-II packaging are as follows:

$1 \mathrm{~L}$ bottles (glass or polypropylene [poly])

Shielded assemblies $(30 \mathrm{~mL}, 125 \mathrm{~mL}$, and $250 \mathrm{~mL})$

Nuclear Filter Technology $\left(\mathrm{NFT}^{\mathbf{i}}\right)$ can assembly

The as-tested $1 \mathrm{~L}$ configurations require that the bottle remain intact and not break. The shipper must either use the same $1 \mathrm{~L}$ bottles and lids that were approved for use during testing, or document that if a different bottle is used it is equivalent to what was qualified during testing. The bottles approved for use during testing are either wide-mouth poly with poly lid (Nalgene 2105-0032 or Fisher Scientific 02-893D) or wide-mouth glass jar (I-Chem 321-1000 or Fisher Scientific 05-719-89). For the $1 \mathrm{~L}$ glass jar only, the IChem lid is replaced with a black phenolic lid with polyethylene liner (Qorpak ${ }^{2}$ 5082). The $1 \mathrm{~L}$ bottles (glass and poly) are secured by taping the lid/body interface circumferentially with Shurtape ${ }^{3}$ VP410, 2-in.-wide, polyvinyl chloride (PVC) film tape. The $1 \mathrm{~L}$ bottle assemblies are double-bagged prior to insertion into the NFT can assembly.

The shielded assemblies $(30 \mathrm{~mL}, 125 \mathrm{~mL}$, and $250 \mathrm{~mL}$ ) are identical to the shielded assemblies that were tested under the U.S. Department of Energy's (DOE) Type A Test Program under Docket 94-39-7A in 1995. The packaging configurations and testing information for the original Hedgehog shielded packaging may be found in DOE/RL-96-57, Test and Evaluation Document for DOT Specification 7A Type A Packaging, Vol. 1. At that time, these assemblies were pressure-tested by reducing the external pressure to $20.68 \mathrm{kPa}(3.0$ psia) and holding for 15 minutes. All assemblies achieved a reduced pressure of $20.68 \mathrm{kPa}(3.0 \mathrm{psia})$. A pressure differential of $79.22 \mathrm{kPa}(11.49 \mathrm{psi})$ was achieved. Detailed testing information regarding these shielded assemblies may be found in WHC-SD-OTR-001, Test and Evaluation Report for Westinghouse Hanford Company's Hedgehog Shielded Container, Docket 94-39-7A, Type A Container.

The NFT can assembly was manufacturer-tested to $103 \mathrm{kPa}(15 \mathrm{psig})$. During DOT-7A Type A packaging testing activities, a containment boundary verification was performed on this can assembly design to $103 \mathrm{kPa}$ (15 psig), as documented herein.

Is the packaging vented?

$$
\text { [ } \mathbf{X} \text { ] No. [] Yes, do not use packaging for shipment by aircraft. }
$$
changes?

Are closures held securely in place and prevented from loosening due to vibration and temperature

$$
\text { [ } \mathbf{X} \text { ] Yes. [ ] No, do not use packaging for shipment by aircraft. }
$$

\footnotetext{
' NFT is a registered trademark of Nuclear Filter Technology.

${ }^{2}$ Qorpak is a registered trademark of All-Pak, Inc., Bridgeville, Pennsylvania.

${ }^{3}$ Shurtape is a registered trademark of Shuford Mills, Inc., Hickory, North Carolina.
} 
HNF-13820, Rev. 0

\subsection{REGULATORY REQUIREMENTS}

\subsection{CFR 173.24 GENERAL REQUIREMENTS FOR PACKAGINGS AND PACKAGES.}

\subsection{4(a) Applicability.}

(a) Applicability. Except as otherwise provided in this subchapter, the provisions of this section apply to--

(1) Bulk and non-bulk packagings;

(2) New packagings and packagings which are reused; and

(3) Specification and non-specification packagings.

All DOT-7A Type A packagings fall into one or more of the identified categories. Indicate below the type of documentation that shows this requirement is met and where the documentation can be found.
Addressed in:
[ $\mathbf{X}]$ Drawing
[] Specification
[ ] Operating Instruction
[ $\mathbf{X}$ ] Analysis Report
[ ] Manufacturer Supplied Data
[ ] Similarity or Documented Record

Specify:

The Hedgehog-II configurations were tested in March and April 2003. Due to funding limitations, completion of evaluation documentation by Duratek Technical Services (formerly known as Duratek Federal Services, Inc., Northwest Operations [DFSNW]) was delayed until October 2003. The Hedgehog-II configurations identified within the final evaluation report and this PQCL meet DOT-7A Specification 7A (DOT-7A) packaging criteria. The Hedgehog-II may be considered a non-bulk packaging, and new or reused packagings may be utilized for transport. 


\subsection{4(b) Containment.}

(b) Each package used for the shipment of hazardous materials under this subchapter shall be designed, constructed, maintained, filled, its contents so limited, and closed, so that under conditions normally incident to transportation--

(1) Except as otherwise provided in this subchapter, there will be no identifiable (without the use of instruments) release of hazardous materials to the environment;

(2) The effectiveness of the package will not be substantially reduced; for example, impact resistance, strength, packaging compatibility, etc. must be maintained for the minimum and maximum temperatures encountered during transportation;

(3) There will be no mixture of gases or vapors in the package which could, through any credible spontaneous increase of heat or pressure, significantly reduce the effectiveness of the packaging.

These requirements apply to DOT-7A Type A packagings. Documentation of the ability of the packaging to meet the more severe requirements of 49 CFR 173, Subpart I, can be used to document compliance. Indicate below the type of documentation that shows these requirements are met and where the documentation can be found.
Addressed in:
[ $\mathbf{X}$ ] Drawing
$[\mathbf{X}]$ Operating Instruction
[] Specification
[ ] Manufacturer Supplied Data
[ $\mathbf{X}$ ] Analysis Report
[] Similarity or Documented Record

Specify:

Several configurations exist for the Hedgehog-II design. These configurations were tested and evaluated to ensure that the designs comply with applicable regulations within 49 CFR as identified for DOT-7A Type A packagings, as well as IAEA and IATA regulations for air transport of Type A packagings.

The as-tested and evaluated Hedgehog-II designs are documented in the following Hanford Site drawings:

- H-2-830874, Hedgehog II Packaging System Assembly

Sheets 1-3, Rev. 1

- H-2-830875, Hedgehog II Case

Sheet 1, Rev. 1; Sheets 2-5, Rev. 0

- H-2-830876, Hedgehog II Intermediate Container

Sheets 1-2, Rev. 1; Sheets 3-5, Rev. 0

- H-2-830877, Hedgehog II Shielded Container Assemblies

Sheets 1-2, Rev. 0; Sheets 3-5, Rev. 1

Type A quantities of solid or liquid radioactive contents may be placed into an inner container (consisting of a $1 \mathrm{~L}$ poly or glass bottle, or sample bottle that has been placed inside either a $30 \mathrm{~mL}, 125 \mathrm{~mL}$, and/or $250 \mathrm{~mL}$ stainless steel shielded assembly). The shipper must either use the same $1 \mathrm{~L}$ bottles and lids that were approved for use during testing, or document that if a different bottle is used it is equivalent to what was qualified during testing. The bottles approved for use during testing are either wide-mouth poly with poly lid (Nalgene 2105-0032 or Fisher Scientific 02-893D) or wide-mouth glass jar (I-Chem 321-1000 or Fisher Scientific 05-719-89). For the $1 \mathrm{~L}$ glass jar only, the I-Chem lid is replaced with a black phenolic lid with polyethylene liner (Qorpak 5082). The $1 \mathrm{~L}$ bottles (glass and poly) are secured by taping the lid/body interface circumferentially with Shurtape VP410, 2-in.-wide, PVC film tape. The sample bottles used inside the $30 \mathrm{~mL}, 125 \mathrm{~mL}$, and $250 \mathrm{~mL}$ versions are considered as "packaging not required." Ten percent ullage remains in all of the bottles for potential expansion of contents. With the exception of the $30 \mathrm{~mL}$ bottle, all bottles are bagged twice. The $30 \mathrm{~mL}$ bottle is bagged once. 
The shielded assemblies incorporate socket or Torx ${ }^{4}$ flat head screws and Nitrile o-rings. The loaded shielded container is placed inside a stainless steel intermediate container (NFT can assembly). The NFT can assembly includes an o-ring and threaded closure with plunger locking mechanism. The NFT can assembly incorporates internal foam cushioning made from ethylene vinyl acetate (EVA), having a density of 2 pounds per cubic foot $\left(2 \mathrm{lb} / \mathrm{ft}^{2}\right)$. Depending on the configuration to be shipped, additional packing materials are added inside the NFT can assembly for impact absorption and to act as load spreaders. These materials include a stainless steel disk (used with the $1 \mathrm{~L}$ glass jar and shielded assemblies) and/or a stainless steel belleville washer (used with the shielded assemblies). The NFT can assembly also incorporates a rigid handle and includes a Viton ${ }^{5}$ gasket within the threaded lid. A pull-ring plunger assembly/mount, and pin capture are incorporated into the intermediate container design to ensure the lid torque remains constant.

The NFT can assembly is placed inside the Hardigg Case ${ }^{6}$. The case is rotationally molded polyethylene with steel butterfly latches and zinc chromate hardware. The lid of the case incorporates a silicone sponge cording (gasket) that is split to enable ease in lid closure, and to prevent pressurization within the case. When the case is oriented in the upright position for transport purposes, the split in the gasket is located at the base of the package to ensure that water in-leakage does not occur. Polyethylene foam having a density of $2.2 \mathrm{lb} / \mathrm{ft}^{2}$ and a $0.32 \mathrm{~cm}(0.125$-in.) acrylonitrile-butadiene-styrene (ABS) load spreader are added internally to the case to hold the NFT can assembly in place. The internal foam configuration used in shipping the $1 \mathrm{~L}$ bottles includes a cutout for the NFT can assembly handle (HHBA-724FA assembly). The foam configuration used in shipping the shielded configurations does not include the cut-out area for the NFT can assembly handle (HHBA-724FB assembly), but includes nylon inserts that are nested on each side of the NFT can assembly lid handle and the foam piece identified as 724-04FB.

Table A-1 provides the (nominal) approved maximum gross weights for the Hedgehog-II configurations tested and evaluated herein.

Table A-1. Maximum Gross Weights for Hedgehog-II Configurations (Nominal).

\begin{tabular}{|c|c|c|}
\hline Configuration & $\begin{array}{l}\text { Bottle and contents } \\
\qquad \mathrm{kg}(1 \mathrm{~b})\end{array}$ & $\begin{array}{l}\text { Package gross weight } \\
\text { Kg (b) }\end{array}$ \\
\hline $30 \mathrm{~mL}$ shielded & $\begin{array}{ll}\text { Bottle and contents } & =0.099(0.219) \\
\text { Contents only } & =0.088(0.196)\end{array}$ & $31.30(69)$ \\
\hline $125 \mathrm{~mL}$ shielded & $\begin{array}{ll}\text { Bottle and contents } & =0.365(0.805) \\
\text { Contents only } & =0.339(0.749)\end{array}$ & $29.94(66)$ \\
\hline $250 \mathrm{~mL}$ shielded & $\begin{array}{ll}\text { Bottle and contents } & =0.562(1.24) \\
\text { Contents only } & =0.524(1.156)\end{array}$ & $25.85(57)$ \\
\hline $1 \mathrm{~L}$ glass & $\begin{array}{l}\text { Bottle and contents }=1.72(3.8) \\
\text { Contents only }=1.27(2.8)\end{array}$ & $18.14(40)$ \\
\hline $1 \mathrm{~L}$ poly & $\begin{array}{l}\text { Bottle and contents }=1.99(4.4) \\
\text { Contents only }=1.90(4.2)\end{array}$ & $17.92(39.5)$ \\
\hline
\end{tabular}

NOTE: Information for 125 and $250 \mathrm{~mL}$ shielded configurations was obtained from WHC-SD-OTR-001.

The operating instructions, HNF-11651, Operations and Maintenance Manual for Hedgehog-II Packaging Systems, identify that orientation arrow labels are affixed to the outside of the Hardigg Case to denote the upright position.

It is the shipper's responsibility to ensure that the payload remains stable during transport.

${ }^{4}$ Torx is a registered trademark of Camcar Textron, Chapman Manufacturing Company.

${ }^{5}$ Viton is a registered trademark of E. I. Du Pont de Nemours \& Company, Wilmington, Delaware.

${ }^{6}$ Hardigg Cases is a trademark of Hardigg Industries, Inc. 


\subsection{4(c) Authorized Packagings.}

(c) Authorized packagings. A packaging is authorized for a hazardous material only if--

(1) The packaging is prescribed or permitted for the hazardous material in a packaging section specified for that material in Column 8 of the $\$ 172.101$ table and conforms to applicable requirements in the special provisions of Column 7 of the $\$ 172.101$ table and, for specification packagings (but not including UN standard packagings manufactured outside the United States), the specification requirements in parts 178 and 179 of this subchapter; or (2) The packaging is permitted under, and conforms to, provisions contained in $\$ \$ 171.11$, $171.12,171.12 \mathrm{a}, 173.3,173.4,173.5,173.7,173.27$ or 176.11 of this subchapter.

DOT-7A Type A packagings are authorized for packaging for Type A quantities of radioactive materials. Indicate below the type of documentation that shows the load is a Type A quantity and where the documentation can be found.

Addressed in:

[ $\mathbf{X}]$ Drawing $[\mathbf{X}]$ Specification [X ] Analysis Report
[ ] Operating Instruction

[ X ] Manufacturer Supplied Data

[] Similarity or Documented Record

Specify:

The Hedgehog-II configurations identified herein were tested and evaluated to ensure that the designs comply with applicable regulations within 49 CFR as identified for DOT-7A Type A packagings, as well as IAEA and IATA regulations for air transport of Type A packagings. Liquid or solid contents are intended for shipment. It is the shipper's responsibility to identify the actual contents being shipped, and to ensure that the above requirements are met.

The materials of construction for the Hedgehog-II configurations consist of the following:

- Polyethylene case with steel butterfly latches, zinc chromate hardware, and silicone sponge cording (i.e., gasket) (Bauer Cases, Part No. AL2216-1205-HHBA-724E). Includes polyethylene foam (2.2 lb/ $\left.\mathrm{ft}^{2}\right)$, and a $0.32 \mathrm{~cm}(0.125$-in.) ABS load spreader. Polyethylene foam having a notched area for the intermediate container handle and for use with the $1 \mathrm{~L}$ configurations is assembly HHBA-724FA. Polyethylene foam that does not include the notched handle and is for use with the shielded configurations is assembly HHBA-724FB. Refer to Hanford drawing H-2830875. The polyethylene materials, silicone sponge cording (gasket), and ABS load spreader are made from materials that typically meet the packaging temperature range requirements identified in 49 CFR 173.412 (c) $\left(-40\right.$ to $70^{\circ} \mathrm{C}\left[-40\right.$ to $\left.\left.158{ }^{\circ} \mathrm{F}\right]\right)$.

- The intermediate container (i.e., the NFT can assembly) is identified as NFT Part No. 21030001 and is fabricated per Hanford drawing H-2-830876. The NFT can assembly is made of 304 stainless steel (22 gauge), incorporates a rigid handle, pull-ring plunger assembly, and threaded closure that includes a Viton (V835-75) gasket having a temperature range from -40 to $204^{\circ} \mathrm{C}\left(-40\right.$ to $\left.400^{\circ} \mathrm{F}\right)$. Lid and body serial numbers shall be identical. The $2 \mathrm{lb} / \mathrm{ft}^{2}$ foam supplied with the NFT can assembly is EVA (white), per American Society of Testing and Materials (ASTM) D1056. The temperature range of the EVA foam is -73 to $82{ }^{\circ} \mathrm{C}(-100$ to $\left.180^{\circ} \mathrm{F}\right)$.

- The shielded assemblies (inner and outer) are fabricated from 304 stainless steel. The cover and base are ASTM A240 or ASTM A276. The wall is ASTM A511 or ASTM A276. The $250 \mathrm{~mL}$ outer assembly and the $30 \mathrm{~mL}$ inner assembly each incorporates a lifting cable made of stainless steel. The shielded assemblies contain Nitrile o-rings. The N103 Parker material has a temperature range of -48 to $107^{\circ} \mathrm{C}\left(-55\right.$ to $\left.225{ }^{\circ} \mathrm{F}\right)$; and the $\mathrm{N304}$ Parker material has a temperature range of -53 to $121^{\circ} \mathrm{C}\left(-65\right.$ to $\left.250^{\circ} \mathrm{F}\right)$. The screws are socket or Torx flat head cap 
screws 8-32UNC-3A $x 1 \mathrm{in}$. long or $3 / 4 \mathrm{in}$. long, depending on the shielded assembly. Refer to Hanford drawing H-2-830877.

- The as-tested and approved $1 \mathrm{~L}$ bottles are either wide-mouth poly with poly lid (Nalgene 21050032 [Fisher Scientific 02-893D]) or wide-mouth glass jar (I-Chem 321-1000 [Fisher Scientific 05-719-89]). The blue I-Chem lid that is provided with the glass jar must be replaced with a black phenolic lid with polyethylene liner (Qorpak 5082). The shipper must either use the same $1 \mathrm{~L}$ bottle/lid combinations that were approved during testing, or document that if a different bottle is used that it is equivalent to what was used during testing. The poly, phenolic, and polyethylene materials typically meet the packaging temperature range requirements identified in $49 \mathrm{CFR} 173.412$ (c) $\left(-40\right.$ to $70^{\circ} \mathrm{C}\left[-40\right.$ to $\left.\left.158{ }^{\circ} \mathrm{F}\right]\right)$.

- The as-tested belleville washer was made from 1075 carbon steel (Rolex AM-1608243). However, the belleville washer intended for use is made from 17/7-PH stainless steel (Rolex SAM-1608243). The operational loading for either of these materials is $5274.0 \mathrm{lb} @$ 0.1779 inch deflection with a normal load tolerance from $+10.0 \%$ to $-5.0 \%$. The stainless steel disc is made from 11-gauge sheet. Refer to Hanford drawing H-2-830874.

- With the exception of the $30 \mathrm{~mL}$ bottle, all bottles $(125 \mathrm{~mL} ; 250 \mathrm{~mL} ; 1 \mathrm{~L}$ poly; and $1 \mathrm{~L}$ glass) are bagged twice in an appropriately sized bag. The $30 \mathrm{~mL}$ bottle is bagged once. The $1 \mathrm{~L}$ bottle lids are secured by taping circumferentially around the lid/bottle interface with 2-in.-wide PVC film tape. Refer to Appendix B of this final evaluation report or HNF-13819, Test Plan for Hedgehog-II Packaging Systems, Type A Container, Appendix A, for the specific loading instructions that were used during testing for the $1 \mathrm{~L}$ bottle configurations.

\subsection{4(d) Specification Packagings and UN Standard Packagings Manufactured Outside the U.S.--}

(d) Specification packagings and UN standard packagings manufactured outside the U.S. (1) Specification packagings. A specification packaging, including a UN standard packaging manufactured in the United States, must conform in all details to the applicable specification or standard in part 178 or part 179 of this subchapter.

A DOT-7A Type A packaging is a specification packaging. Documentation of the ability of the package to meet the packaging requirements identified in 49 CFR 173.415(a) will document compliance with this requirement. Indicate below the type of documentation that shows this requirement is met and where the documentation can be found.
Addressed in:
[] Drawing
[] Specification
[ ] Operating Instruction
$[\mathbf{X}]$ Analysis Report
[ ] Manufacturer Supplied Data
[ ] Similarity or Documented Record

Specify:

The Hedgehog-II packaging configurations, as documented herein, have been qualified to meet DOT-7A Type A packaging requirements in accordance with 49 CFR 178.350. It is the responsibility of the shipper to ensure that the packagings used comply with the design discussed in this final evaluation report and PQCL. 
HNF-13820, Rev. 0

\subsection{4(d) Specification Packagings and UN Standard Packagings Manufactured Outside the U.S.--}

(2) UN standard packagings manufactured outside the United States. A UN standard packaging, manufactured outside the United States, in accordance with national or international regulations based on the UN Recommendations of the Transport of Dangerous Goods, may be imported and used and is considered to be an authorized packaging under the provisions of paragraph (c)(1) of this section, subject to the following conditions and limitations:

(i) The packaging fully conforms to applicable provisions in the UN Recommendations on the Transport of Dangerous Goods and the requirements of this subpart, including reuse provisions;

(ii) The packaging is capable of passing the prescribed tests in part 178 of this subchapter applicable to that standard; and

(iii) The competent authority of the country of manufacture provides reciprocal treatment for UN standard packagings manufactured in the U.S.

This requirement applies to DOT-7A Type A packagings manufactured outside the U.S. Indicate below if the requirement does or does not apply. If applicable, indicate below the form of documentation and where the documentation can be found.

[ $\mathbf{X}$ ] This requirement does not apply. The DOT-7A Type A packaging being used was manufactured in the U.S.

[ ] This requirement applies as the packaging being used was manufactured outside the U.S.

Documentation of the packaging's ability to meet the more severe requirements of 49 CFR 173, Subpart I, can be used to document compliance.
Addressed in:
[] Drawing
[] Specification
[ ] Operating Instruction
[ ] Analysis Report
[ ] Manufacturer Supplied Data
[ ] Similarity or Documented Record

Specify:

The identified Hedgehog-II configurations are manufactured in the United States; therefore, this requirement does not apply. 


\subsection{4(e) Compatibility.}

(e) Compatibility.

(1) Even though certain packagings are specified in this part, it is, nevertheless, the responsibility of the person offering a hazardous material for transportation to ensure that such packagings are compatible with their lading. This particularly applies to corrosivity, permeability, softening, premature aging and embrittlement.

This requirement applies to DOT-7A Type A packagings. Indicate below the type of documentation that shows the lading is compatible with the packaging and identify where the documentation can be found.
Addressed in:
[] Drawing
[ ] Specification
[ ] Operating Instruction
[ $\mathbf{X}$ ] Analysis Report
[] Manufacturer Supplied Data
[ ] Similarity or Documented Record

Specify:

The packaging materials, design, and arrangement of these materials are such that the intent of this requirement is met. The approved Hedgehog-II configurations tested and evaluated are identified within the final evaluation and test report and PQCL. Detailed design information is provided in Section 4.1 of this PQCL (see 173.24[a]; 173.24[b]; and 173.24[c]).

\subsection{4(e) Compatibility. (Continued)}

(2) Packaging materials and contents must be such that there will be no significant chemical or galvanic reaction between the materials and contents of the package.

This requirement applies to DOT-7A Type A packagings. Indicate below the type of documentation that shows there will be no significant chemical or galvanic reactions and where the documentation can be found.
Addressed in:
[] Drawing
[] Specification
[ $\mathbf{X}$ ] Operating Instruction
$[\mathbf{X}$ ] Analysis Report
[] Manufacturer Supplied Data
[] Similarity or Documented Record

Specify:

The packaging materials, design, and arrangement of these materials are such that the intent of this requirement is met. The approved Hedgehog-II configurations tested and evaluated are identified within the final evaluation and test report and PQCL. Detailed design information is provided in Section 4.1 of this PQCL (see 173.24[a]; 173.24[b]; and 173.24[c]). 


\subsection{4(e) Compatibility. (Continued)}

(3) Plastic packagings and receptacles:

(i) Plastic used in packagings and receptacles must be of a type compatible with the lading and may not be permeable to an extent that a hazardous condition is likely to occur during transportation, handling or refilling.

(ii) Each plastic packaging or receptacle which is used for liquid hazardous materials must be capable of withstanding without failure the procedure specified in appendix B of this part ("Procedure for Testing Chemical Compatibility and Rate Permeation in Plastic Packagings and Receptacles"). The procedure specified in appendix $B$ of this part must be performed one each plastic packaging or receptacle used for Packing Group I materials. The maximum rate of permeation of hazardous lading through or into the plastic packaging or receptacles may not exceed 0.5 percent for the materials meeting the definition of a Division 6.1 material according to $\$ 173.132$ and 2.0 percent for other hazardous materials, when subjected to a temperature no lower than-

(A) $18^{\circ} \mathrm{C}\left(64^{\circ} \mathrm{F}\right)$ for 180 days in accordance with Test Method 1 in appendix $B$ of this part;

(B) $50^{\circ} \mathrm{C}\left(122^{\circ} \mathrm{F}\right)$ for 28 days in accordance with Test Method 2 in appendix $B$ of this part; or

(C) $60^{\circ} \mathrm{C}\left(140^{\circ} \mathrm{F}\right)$ for 14 days in accordance with Test Method 3 in appendix $B$ of this part.

(iii) Alternate procedures or rates of permeation are permitted if they yield a level of safety equivalent to or greater than that provided by paragraph (e)(3)(ii) or this section and are specifically approved by the Associate Administrator for Hazardous Materials Safety.

This requirement applies to DOT-7A Type A packagings that use plastic containers to retain the load. Otherwise, the requirement does not apply. Remember to consider secondary hazards. Based on the materials of construction used for holding the load, indicate below if the requirement applies or does not apply. If the requirement applies, identify the documentation that shows compliance and identify where the documentation can be found.

This requirement: [ ] Does not apply. [ $\quad$ X ] Applies; indicate the following.

Addressed in: $\quad[\mathbf{X}]$ Drawing [] Specification [ ] Analysis Report

[ ] Operating Instruction

[] Manufacturer Supplied Data

[] Similarity or Documented Record

Specify:

The as-tested and approved $1 \mathrm{~L}$ bottles are either wide-mouth poly with poly lid (Nalgene 2105-0032 [Fisher Scientific 02-893D]) or wide-mouth glass jar (I-Chem 321-1000 [Fisher Scientific 05-719-89]). The blue IChem lid that is provided with the glass jar must be replaced with a black phenolic lid with polyethylene liner (Qorpak 5082). The shipper must either use the same $1 \mathrm{~L}$ bottle/lid combinations that were approved during testing, or document that if a different bottle is used, it is equivalent to what was used during testing. The poly, phenolic, and polyethylene materials typically meet the packaging temperature range requirements identified in $49 \mathrm{CFR} 173.412$ (c) $\left(-40\right.$ to $70^{\circ} \mathrm{C}\left[-40\right.$ to $\left.\left.158^{\circ} \mathrm{F}\right]\right)$.

The exterior of the packaging consists of a polyethylene case (Bauer Cases, Part No. AL2216-1205-HHBA724E); includes polyethylene foam (2.2 lb/ $\left./ \mathrm{ft}^{2}\right)$, and a $0.32 \mathrm{~cm}(0.125-\mathrm{in}$.) ABS load spreader. Refer to Hanford drawing H-2-830875. The polyethylene materials, silicone sponge cording (gasket), and ABS load spreader are made from materials that typically meet the packaging temperature range requirements identified in 49 CFR 173.412 (c) $\left(-40\right.$ to $70^{\circ} \mathrm{C}\left[-40\right.$ to $\left.\left.158^{\circ} \mathrm{F}\right]\right)$. 
The $2 \mathrm{lb} / \mathrm{ft}^{2}$ foam supplied with the NFT can assembly is EVA (white), per ASTM D1056. The temperature range of the EVA foam is -73 to $82^{\circ} \mathrm{C}\left(-100\right.$ to $\left.180^{\circ} \mathrm{F}\right)$. Refer to Hanford drawing $\mathrm{H}-2-830876$.

The packaging configurations described herein are authorized for transportation of liquids and solids. It is the responsibility of the shipper to ensure that the contents will not react adversely with the container.

\subsection{4(e) Compatibility. (Continued)}

(4) Mixed contents. Hazardous materials may not be packed or mixed together in the same outer packaging with other hazardous or nonhazardous materials if such materials are capable of reacting dangerously with each other and causing--

(i) Combustion or dangerous evolution of heat;

(ii) Evolution of flammable, poisonous, or asphyxiant gases; or

(iii) Formation of unstable or corrosive materials.

(5) Packagings used for solids, which may become liquid at temperatures likely to be encountered during transportation, must be capable of containing the hazardous material in the liquid state.

These requirements are applicable to DOT-7A Type A packagings. The requirements are load dependent. The primary hazards in a DOT-7A Type A packaging are not likely to result in the identified hazards. However, secondary hazards are commonly associated with the radioactivity and should be watched for the potential to produce the identified conditions. The potential for a phase change exists with radioactive materials. An evaluation of the potential for a phase change should be made and documented. Indicate below if the requirements apply or do not apply. If the requirements apply, identify the type documentation used to show compliance and where the documentation can be found.

These requirements: [ ] Do not apply.

Addressed in:
[ X ] Apply; indicate the following.

[ ] Operating Instruction

[ ] Manufacturer Supplied Data

[ ] Similarity or Documented Record

Specify:

Hazardous and/or nonhazardous materials will not be packed or mixed together such that they can cause a reaction. The subject packaging configurations, as documented herein, have been qualified to meet DOT-7A Type A packaging requirements in accordance with 49 CFR 178.350. It is the responsibility of the shipper to ensure that materials will not be combined in such a manner to cause a reaction.

The packaging configurations described in this report are authorized for liquids and solids. Primary containment for all but the $1 \mathrm{~L}$ version is provided by a stainless steel shielded assembly equipped with a cover and base that attach to the body with 8-32UNC-3A screws, and is fitted with o-rings made of Nitrile (Buna-N). Primary containment for the $1 \mathrm{~L}$ versions is provided by either a wide-mouth poly bottle with poly lid (Nalgene 2105-0032) or wide-mouth glass jar (I-Chem 321-1000) and black phenolic lid with polyethylene liner (Qorpak 5082). The $1 \mathrm{~L}$ bottles must have their lids secured by circumferentially taping the lid/bottle interface with 2-in.-wide PVC film tape.

Secondary containment is provided by the intermediate container (NFT can assembly). The NFT can assembly is made from 304 stainless steel, and includes a threaded lid closure, Viton gasket, pull-ring plunger assembly/mount, and pin capture. Internal foam cushioning made from EVA, having a density of $2 \mathrm{lb} / \mathrm{ft}^{2}$, is added for impact absorption. Depending upon the configuration to be shipped, additional packing materials inside the can assembly include a 17/7-PH stainless steel belleville washer and/or a stainless steel disc.

It is the responsibility of the shipper to ensure that the packagings used comply with the design discussed in this report. 


\subsection{4(f) Closures.}

(f) Closures.

(1) Closures on packagings shall be so designed and closed that under conditions (including the affects of temperature and vibration) normally incident to transportation--

(i) Except as provided in paragraph (g) of this section, there is no identifiable release of hazardous materials to the environment from the opening to which the closure is applied; and

(ii) The closure is secure and leakproof.

(2) Except as otherwise provided in this subchapter, a closure (including gaskets or other closure components, if any) used on a specification packaging must conform to all applicable requirements of the specification.

These requirements apply to DOT-7A Type A packagings. Indicate below the type of documentation that shows the requirements are met and where the documentation can be found.
Addressed in:
[ $\mathbf{X}$ ] Drawing
[ ] Operating Instruction
[] Specification
[ ] Manufacturer Supplied Data
[ $\mathbf{X}$ ] Analysis Report
[] Similarity or Documented Record

Specify:

Testing and evaluation of the packaging configurations described herein indicate this requirement to be satisfied. The Hardigg Case provides tamper indication, impact limitation, but no liquid containment. The NFT can assembly provides the secondary containment boundary and contains a Nitrile gasket within the threaded lid closure. When properly locked into place, the lid-locking mechanism is designed to prevent loosening due to acceleration, vibration, or vibration resonance resulting from normal conditions of transportation. The stainless steel shielded assemblies provide primary containment. The shielded assembly cover and base each incorporate an o-ring. The cover and base are secured by 8-32UNC-3A screws (4 each on cover; 4 each on base) and by applying a torque of 1.9 to $2.0 \mathrm{~N}-\mathrm{m}$ (17 to $18 \mathrm{in}-\mathrm{lb})$.

Primary containment for the $1 \mathrm{~L}$ versions is provided by either a wide-mouth poly bottle with poly lid (Nalgene 2105-0032) or wide-mouth glass jar (I-Chem 321-1000) and black phenolic lid with polyethylene liner (Qorpak 5082). The $1 \mathrm{~L}$ bottles have a hand-tightened lid. The lid is further secured by taping circumferentially around the lid/body interface with 2-in.-wide PVC film tape. Refer to Appendix B of this final evaluation report or HNF-13819, Appendix A, for the specific loading instructions that were used during testing for the $1 \mathrm{~L}$ bottle configurations.

Vibration testing was conducted at the Pacific Northwest National Laboratory (PNNL), located in the 300 Area of the Hanford Site. Refer to Section 8.0, 49 CFR 178.608, "Vibration Standard," of this PQCL for the vibration testing that was performed on the Hedgehog-II configurations. 


\subsection{4(g) Venting.}

(g) Venting of packagings, to reduce internal pressure which may develop by the evolution of gas from the contents, is permitted only when-

(1) Transportation by aircraft is not involved;

(2) Except as otherwise provided in this subchapter, the evolved gases are not poisonous, likely to create a flammable mixture with air or be an asphyxiant under normal conditions of transportation;

(3) The packaging is designed so as to preclude an unintentional release of hazardous materials from the receptacle; and

(4) For shipments in bulk packagings, venting is authorized for the specific hazardous material by a special provision in the $\$ 172.101$ table or by the applicable bulk packaging specification in part 178 of this subchapter.

These requirements apply to DOT-7A Type A packagings that are vented. The requirements are not applicable to nonvented DOT-7A Type A packagings. Based on the design, determine if the requirements apply or do not apply. If the requirements apply, indicate below the type of documentation that shows the requirements are met and where the documentation can be found.

These requirements: [ [X ] Do not apply. [] Apply; indicate the following.

Addressed in: [ ] Drawing [] Specification

[] Operating Instruction

[ ] Analysis Report

[ ] Manufacturer Supplied Data

[] Similarity or Documented Record

Specify:

The Hedgehog-II is not a bulk packaging, and the packaging configurations described and tested are authorized for transportation by aircraft. The Hardigg Case incorporates a split silicone sponge cording (gasket) and does not utilize any venting devices. The NFT can assembly has no provision for venting. The NFT can assembly (secondary containment boundary) was manufacturer-tested and also verified during DOT-7A Type A testing for contents that may produce an internal pressure of $103 \mathrm{kPa}(15 \mathrm{psi})$.

The inner and outer shielded assemblies (primary containment boundary) have no provision for venting. The shielded assemblies were pressure-tested in 1995 under Docket 94-39-7A (DOE/RL-96-57, Vol. 1) by reducing the external pressure to $20.68 \mathrm{kPa}$ (3.0 psia) and holding for 15 minutes. All assemblies achieved a reduced pressure of $20.68 \mathrm{kPa}$ (3.0 psia). Therefore, a pressure differential of $79.22 \mathrm{kPa}(11.49 \mathrm{psi})$ was achieved. Refer to WHC-SD-TP-OTR-001 or DOE/RL-96-57, Vol. 1, for detailed information regarding the containment boundary verification procedure that was performed in 1995 on the stainless steel shielded assemblies before and after testing. The design of the shielded assemblies used in the Hedgehog-II packaging configurations is basically the same as the original Hedgehog packaging. The only design modification is that an option has been allowed for use of Torx flat head cap screws in lieu of the socket head cap screws. Torx screws offer more resistance to stripping out than the regular socket screws offer.

The approved, as-tested, $1 \mathrm{~L}$ bottles (primary containment boundary) are not vented. In addition, ullage of 10 percent is required. The $1 \mathrm{~L}$ bottle lids are secured by taping circumferentially around the lid/bottle interface with 2-in.-wide PVC film tape.

It is the shipper's responsibility to ensure that no gasses will be produced that are poisonous, flammable with air, or an asphyxiant under normal conditions of transport. Gaseous contents are not authorized for shipment within the Hedgehog-II configurations. 


\subsection{4(h) Outage and Filling Limits.}

(h) Outage and filling limits-

(1) General. When filling packagings and receptacles for liquids, sufficient ullage (outage) must be left to ensure that neither leakage nor permanent distortion of the packaging or receptacle will occur as a result of an expansion of the liquid caused by temperatures likely to be encountered during transportation. Requirements for outage and filling limits for non-bulk and bulk packagings are specified in $\$ \$ 173.24 \mathrm{a}(\mathrm{d})$ and $173.24 \mathrm{~b}(\mathrm{a})$, respectively.

(2) Compressed gases and cryogenic liquids. Filling limits for compressed gases and cryogenic liquids are specified in \$\$173.301 through 173.306 for cylinders and $\$ \$ 173.314$ through 173.319 for bulk packagings.

These requirements apply to DOT-7A Type A packagings used for the shipment of liquids and gases. The requirements are not applicable to DOT-7A Type A packagings used to ship solids. Based on the load, indicate if the requirements apply or do not apply. If the requirements apply, indicate below the type of documentation that shows the requirements are met and where the documentation can be found.

These requirements: [ ] Do not apply.

Addressed in:

[ ] Drawing

[] Specification

[ X ] Analysis Report
[ X ] Apply; indicate the following.

[ $\mathbf{X}$ ] Operating Instruction

[ ] Manufacturer Supplied Data

[ ] Similarity or Documented Record

Specify:

The packaging configurations described and tested herein are authorized for transportation of liquids by aircraft. The inner bottles have an ullage of approximately 10 percent for liquid transport. The $1 \mathrm{~L}$ bottles are required to remain intact and not break becausethey are a part of the identified containment system. The shipper must either use the same $1 \mathrm{~L}$ bottles that were approved during testing (either a wide-mouth poly bottle with poly lid (Nalgene 2105-0032) or wide-mouth glass jar (I-Chem 321-1000) and black phenolic lid with polyethylene liner (Qorpak 5082), or document that if a different bottle/lid are used they are equivalent to what was used during testing. The $1 \mathrm{~L}$ lid/body interface is secured by circumferentially taping with 2-in.-wide PVC film tape.

The shielded assemblies were pressure-tested in 1995 under Docket 94-39-7A (DOE/RL-96-57, Vol. 1) by reducing the external pressure to $20.68 \mathrm{kPa}(3.0 \mathrm{psia})$ and holding for 15 minutes. All assemblies achieved a reduced pressure of $20.68 \mathrm{kPa}$ (3.0 psia). Therefore, a pressure differential of $79.22 \mathrm{kPa}(11.49 \mathrm{psi})$ was achieved. Refer to WHC-SD-TP-OTR-001 or DOE/RL-96-57, Vol. 1, for detailed information regarding the containment boundary verification procedure that was performed in 1995 on the stainless steel shielded assemblies before and after testing. The design of the shielded assemblies used in the Hedgehog-II packaging configurations is basically the same as the original Hedgehog packaging. The only design modification is that an option has been allowed for use of Torx flat head cap screws in lieu of the socket head cap screws. Torx screws offer more resistance to stripping out than the regular socket screws offer.

The NFT can assembly was manufacturer-tested and also verified during DOT-7A Type $A$ testing to withstand an internal pressure of $103 \mathrm{kPa}(15 \mathrm{psi})$ differential pressure.

The packaging will not transport compressed gases or cryogenic liquids. 
HNF-13820, Rev. 0

\subsection{4(i) Air Transportation.}

(i) Air transportation. Packages offered or intended for transportation by aircraft must conform to the general requirements for transportation by aircraft in \$173.27, except as provided in \$171.11 of this subchapter.

This requirement applies to DOT-7A Type A packagings when used for transportation by aircraft. Otherwise, the requirement does not apply. Based on the mode of transportation, indicate if the requirement applies or does not apply. If the requirement applies, indicate below the type of documentation that shows the requirement is met and where the documentation can be found.

This requirement: [ ] Does not apply. [X] Applies; indicate the following.
Addressed in:
[ $\mathbf{X}$ ] Drawing
[ X ] Operating Instruction
[] Specification
[] Manufacturer Supplied Data
[ X ] Analysis Report
[ ] Similarity or Documented Record

Specify:

Specific information regarding air transport requirements and how the Hedgehog-II configurations meet these requirements is addressed within Section 4.4 (49 CFR 173.27) of this PQCL. In addition, the IATA regulations for air transport have been identified within each section of this PQCL, as applicable.

Refer to IATA, Section 10, "Radioactive Material" (IATA 2003). 


\title{
4.2 49 CFR 173.24A ADDITIONAL GENERAL REQUIREMENTS FOR NON-BULK PACKAGINGS AND PACKAGES.
}

\author{
173.24a (a) Packaging design. Except as provided in $\$ 172.312$ of this subchapter: \\ (1) Inner packaging closures. A combination packaging containing liquid hazardous \\ materials must be packed so that closures on inner packagings are upright.
}

This requirement applies to DOT-7A Type A packagings that meet the definition of a combination packaging and are used to ship liquids. The requirement does not apply to packagings used to ship nonliquids. Based on the packaging type and load, indicate if the requirement applies or does not apply. If the requirement applies, indicate below the type of documentation that shows the requirement is met and where the documentation can be found.

This requirement: [ ] Does not apply. [ $\quad$ ] ] Applies; indicate the following.
Addressed in:
[ $\mathbf{X}$ ] Drawing
[ ] Specification
[ $\mathbf{X}$ ] Operating Instruction
[] Analysis Report
[ ] Manufacturer Supplied Data
[ ] Similarity or Documented Record

Specify:

The Hedgehog-II packaging configurations described and tested herein are authorized for transporting liquids. The internal bottles, containing the material being transported, shall be packed in the stainless steel shielded assembly $(30,125$, or $250 \mathrm{~mL}$ versions) in an upright position. The assembly will be packed in the NFT can assembly in an upright position. The identified $1 \mathrm{~L}$ bottle shall be packed in the NFT can assembly in an upright position. The NFT can assembly will be packed inside the Hardigg Case in an upright position.

The exterior of the Hardigg Case will be marked in such a manner to ensure that the inner packagings are upright and in accordance with 49 CFR 173.312. The operating instructions (HNF-11651) describe how to pack the Hedgehog-II configurations.

\subsection{4a (a) Packaging Design. (Continued)}

(2) Friction. The nature and thickness of the outer packaging must be such that friction during transportation is not likely to generate an amount of heat sufficient to alter dangerously the chemical stability of the contents.

This requirement applies to non-bulk DOT-7A Type A packagings. Indicate below the type of documentation that shows this requirement is met and where the documentation can be found.
Addressed in:
[ $\mathbf{X}$ ] Drawing
[] Specification
[ ] Operating Instruction
[ X ] Analysis Report
[] Manufacturer Supplied Data
[ ] Similarity or Documented Record

Specify:

The nature and thickness of the packaging configurations are such that friction during transport will not generate any heating that would adversely affect the contents.

The shipper is responsible to ensure that chemical stability of the contents is not affected by friction that may result in normal transport conditions. 


\subsection{4a (a) Packaging Design. (Continued)}

(3) Securing and cushioning. Inner packagings of combination packagings must be so packed, secured and cushioned to prevent their breakage or leakage and to control their movement within the outer packaging under conditions normally incident to transportation. Cushioning material must not be capable of reacting dangerously with the contents of the inner packagings.

This requirement applies to DOT-7A Type A packagings that meet the definition of a combination packaging. The requirement does not apply to non-combination packagings. Based on the packaging type, indicate if the requirement applies or does not apply. If the requirement applies, indicate below the type of documentation that shows the requirement is met and where the documentation can be found.
This requirement:
[] Does not apply.
[ $\mathbf{X}$ ] Applies; indicate the following.
Addressed in:
[ $\mathbf{X}$ ] Drawing
[] Specification
$[\mathbf{X}]$ Analysis Report
[ $\mathbf{X}$ ] Operating Instruction
[X ] Manufacturer Supplied Data
[ ] Similarity or Documented Record

Specify:

The operating instructions (HNF-11651) describe how to pack the Hedgehog-II configurations. The $1 \mathrm{~L}$ versions require that the bottle remain intact and not break because they are a part of the identified containment system. The shipper must either use the same $1 \mathrm{~L}$ bottle/lid combinations that were approved during testing, or document that if a different bottle/lid combination is used it is equivalent to what was used during testing. The shielded assemblies incorporate a gasket and screws within the cover and base to ensure containment. The NFT can assembly and outer Hardigg Case each contain foam cushioning materials that assist in the prevention of movement within the packaging. Information regarding the materials of construction is provided in Section 4.1 (49 CFR 173.24) of this PQCL.

It is the responsibility of the shipper to ensure that cushioning material is compatible with contents.

\subsection{4a (a) Packaging Design. (Continued)}

(4) Metallic devices. Nails, staples and other metallic devices shall not protrude into the interior of the outer packaging in such a manner as to be likely to damage inner packagings or receptacles.

This requirement applies to DOT-7A Type A packagings that use devices that could protrude into the interior of the outer packaging. Based on the packaging design, indicate if the requirement applies or does not apply. If the requirement applies, indicate below the type of documentation that shows the requirement is met and where the documentation can be found.

This requirement: [ ] Does not apply. [X ] Applies; indicate the following.

$\begin{array}{lll}\text { Addressed in: } & \text { [ } \mathbf{X} \text { ] Drawing } & \text { [] Operating Instruction } \\ & \text { [] Specification } & \text { [] Manufacturer Supplied Data } \\ & \text { [ [ ] Analysis Report } & \text { [] Similarity or Documented Record }\end{array}$

Specify:

The stainless steel shielded assemblies have no protrusions. The NFT can assembly incorporates a pull-ring plunger assembly/mount, and pin capture that protrudes out from one side of the lid/body interface. After repeated use, this locking mechanism will eventually cause wear into the inner foam of the Hardigg Case. The inner foam of the Hardigg Case is completely replaceable, and operating instructions (HNF-11651) shall 
identify pre-use inspections and requirements for replacement. The ABS load spreader that is located within the Hardigg Case assists in protecting the exterior of the NFT can assembly from any damage inherent to normal transportation. This component is also replaceable.

\subsection{4a (a) Packaging Design. (Continued)}

(5) Vibration. Each non-bulk package must be capable of withstanding, without rupture or leakage, the vibration test procedure specified in $\$ 178.608$ of this subchapter.

This requirement applies to non-bulk DOT-7A Type A packagings. Indicate below the type of documentation that shows this requirement is met and where the documentation can be found.
Addressed in:
[ X ] Drawing
[] Specification
[X] Analysis Report
[ ] Operating Instruction
[] Manufacturer Supplied Data
[ ] Similarity or Documented Record

Specify:

Testing and evaluation of the packaging configurations described herein indicates this requirement to be satisfied. The Hardigg Case provides tamper indication and impact limitation, but no liquid containment. The NFT can assembly provides the secondary containment boundary and contains a Nitrile gasket within the threaded lid closure. When properly locked into place, the lid-locking mechanism is designed to prevent loosening due to acceleration, vibration, or vibration resonance resulting from normal conditions of transportation. The stainless steel shielded assemblies provide primary containment. The shielded assembly cover and base each incorporates an o-ring. The cover and base are secured by 8-32UNC-3A screws (4 each on cover; 4 each on base) and by applying a torque of 1.9 to $2.0 \mathrm{~N}-\mathrm{m}$ (17 to $18 \mathrm{in}-\mathrm{lb})$.

Primary containment for the $1 \mathrm{~L}$ versions is provided by either a wide-mouth poly bottle with poly lid (Nalgene 2105-0032) or wide-mouth glass jar (I-Chem 321-1000) and black phenolic lid with polyethylene liner (Qorpak 5082). The $1 \mathrm{~L}$ bottles have a hand-tightened lid. The lid is further secured by taping circumferentially around the lid/body interface with 2-in.-wide PVC film tape. Refer to Appendix B of this final evaluation report or HNF-13819, Appendix A, for the specific loading instructions that were used during testing for the $1 \mathrm{~L}$ bottle configurations.

Vibration testing was conducted at PNNL, located in the 300 Area of the Hanford Site. Refer to Section 8.0, 49 CFR 178.608, "Vibration Standard," of this PQCL for the vibration testing that was performed on the Hedgehog-II configurations. 


\subsection{4a (b) Non-bulk Packaging Filling Limits.}

(1) A single or composite non-bulk packaging may be filled with a liquid hazardous material only when the specific gravity of the material does not exceed that marked on the packaging, or a specific gravity of 1.2 if not marked, except as follows:

(i) A Packing Group I packaging may be used for a Packing Group II material with a specific gravity not exceeding the greater of 1.8 , or 1.5 times the specific gravity marked on the packaging, provided all the performance criteria can still be met with the higher specific gravity material;

(ii) A Packing Group I packaging may be used for a Packing Group III material with a specific gravity not exceeding the greater of 2.7 , or 2.25 times the specific gravity marked on the packaging, provided all the performance criteria can still be met with the higher specific gravity material; and

(iii) A Packing Group II packaging may be used for a packing Group III material with a specific gravity not exceeding the greater of 1.8 , or 1.5 times the specific gravity marked on the packaging, provided all the performance criteria can still be met with the higher specific gravity material.

(2) Except as otherwise provided in this section, a single or composite non-bulk packaging may not be filled with a solid hazardous material to a gross mass greater than the maximum gross mass marked on the packaging.

(3) A single or composite non-bulk packaging which is tested or marked for liquid hazardous materials may be filled with a solid hazardous material to a gross mass, in kilograms, not exceeding the rated capacity of the packaging in liters, multiplied by the specific gravity marked on the packaging, or 1.2 if not marked. In addition:

(i) A single or composite non-bulk packaging which is tested and marked for Packing Group I liquid hazardous materials may be filled with a solid Packing Group II hazardous material to a gross mass, in kilograms, not exceeding the rated capacity of the packaging in liters, multiplied by 1.5 , multiplied by the specific gravity marked on the packaging, or 1.2 if not marked.

(ii) A single or composite non-bulk packaging which is tested and marked for Packing Group I liquid hazardous materials may be filled with a solid Packing Group III hazardous material to a gross mass, in kilograms, not exceeding the rated capacity of the packaging in liters, multiplied by 2.25 , multiplied by the specific gravity marked on the packaging, or 1.2 if not marked.

(iii) A single or composite non-bulk packaging which is tested and marked for Packing Group II liquid hazardous materials may be filled with a solid Packing Group III hazardous material to a gross mass, in kilograms, not exceeding the rated capacity of the packaging in liters, multiplied by 1.5 , multiplied by the specific gravity marked on the packaging, or 1.2 if not marked.

(4) Packagings tested as prescribed in \$178.605 of this subchapter and marked with the hydrostatic test pressure as prescribed in \$178.503(a)(5) of this subchapter may be used for liquids only when the vapor pressure of the liquid conforms to one of the following:

(i) The vapor pressure must be such that the total pressure in the packaging [i.e., the vapor pressure of the liquid plus the partial pressure of air or other inert gases], less $100 \mathrm{kPa}(15 \mathrm{psi})$ at $55^{\circ} \mathrm{C}\left(131^{\circ} \mathrm{F}\right)$ [determined on the basis of a maximum degree of filling in accordance with paragraph (d) of this section and a filling temperature of $15^{\circ} \mathrm{C}\left(59^{\circ} \mathrm{F}\right)$ ], will not exceed twothirds of the marked test pressure; 


\subsection{4a(b)(4) Non-bulk Packaging Filling Limits. (Continued)}

(ii) The vapor pressure at $50^{\circ} \mathrm{C}\left(122^{\circ} \mathrm{F}\right)$ must be less than four-sevenths of the sum of the marked test pressure plus $100 \mathrm{kPa}(15 \mathrm{psi})$; or

(iii) The vapor pressure at $55^{\circ} \mathrm{C}\left(131^{\circ} \mathrm{F}\right)$ must be less than two-thirds of the sum of the marked test pressure plus $100 \mathrm{kPa}(15 \mathrm{psi})$.

Specify:

These requirements are not applicable to DOT-7A Type A packagings.

- DOT-7A Type A packagings do not incorporate Packing Groups. Liquids transported in the astested and approved $1 \mathrm{~L}$ glass bottle shall have a specific gravity of $\leq 1.6$. Liquids transported in all other configurations shall have a specific gravity of $\leq 2.0$. The solid materials are limited in weight (to include packaging) to the gross weight of the as-tested liquids and bottles. The maximum weight of the bottle and liquid contents for the packages is provided in Table A-2 (includes 10 percent ullage).

Table A-2. Maximum Gross Weights for Hedgehog-II Configurations (Nominal).

\begin{tabular}{|c|c|c|}
\hline Configuration & Bottle and contents & Package gross weight \\
\hline & kg(b) & kg (b) \\
\hline $30 \mathrm{~mL}$ shielded & $\begin{array}{ll}\text { Bottle and contents } & =0.099(0.219) \\
\text { Contents only } & =0.088(0.196)\end{array}$ & $31.30(69)$ \\
\hline $125 \mathrm{~mL}$ shielded & $\begin{array}{l}\text { Bottle and contents }=0.365(0.805) \\
\text { Contents only }=0.339(0.749)\end{array}$ & $29.94(66)$ \\
\hline $250 \mathrm{~mL}$ shielded & $\begin{array}{l}\text { Bottle and contents }=0.562(1.24) \\
\text { Contents only }=0.524(1.156)\end{array}$ & $25.85(57)$ \\
\hline $1 \mathrm{~L}$ glass & $\begin{array}{l}\text { Bottle and contents }=1.72(3.8) \\
\text { Contents only } \quad=1.27(2.8)\end{array}$ & $18.14(40)$ \\
\hline $1 \mathrm{~L}$ poly & $\begin{array}{l}\text { Bottle and contents }=1.99(4.4) \\
\text { Contents only } \quad=1.90(4.2)\end{array}$ & $17.92(39.5)$ \\
\hline
\end{tabular}

NOTE: Information for 125 and $250 \mathrm{~mL}$ shielded configurations was obtained from WHC-SD-OTR-001

- The maximum gross weight is not required to be marked on DOT-7A Type A packagings by the manufacturer.

- Packing Groups are not applicable to radioactive material.

- 49 CFR 178.605 does not pertain to specification packagings. 


\subsection{4a (b) Non-bulk Packaging Filling Limits.}

(5) No hazardous material may remain on the outside of a package after filling.

Specify:

For DOT-7A Type A packagings, the requirements of 49 CFR 173.443 override this requirement. That section requires radioactive contamination on the surface of the package to be as low as reasonably achievable and establishes an upper limit for the contamination.

For air transport, see IATA, Section 10.5.3.13, "External Contamination" (IATA 2003).

\subsection{4a (c) Mixed Contents.}

(1) An outer non-bulk packaging may contain more than one hazardous material only when--

(i) The inner and outer packagings used for each hazardous material conform to the relevant packaging sections of this part applicable to that hazardous material; (ii) The package as prepared for shipment meets the performance tests prescribed in part $\mathbf{1 7 8}$ of this subchapter for the packing group indicating the highest order of hazard for the hazardous materials contained in the package;

(iii) Corrosive materials (except ORM-D) in bottles are further packed in securely closed inner receptacles before packing in outer packagings; and

(iv) For transportation by aircraft, the total net quantity does not exceed the lowest permitted maximum net quantity per package as shown in Column 9a or 9b, as appropriate, of the \$172.101 table. The permitted maximum net quantity must be calculated in kilograms if a package contains both a liquid and a solid.

Note this requirement only applies if the package is to carry both radioactive and nonradioactive hazardous materials. Based on the load, indicate if the requirement applies or does not apply. If the requirement applies, indicate below the type of documentation that shows the requirement is met and where the documentation can be found.

This requirement: [ ] Does not apply. [ $\quad$ X ] Applies; indicate the following.

Addressed in:

[ X ] Drawing

[ ] Specification

[ ] Operating Instruction

[ $\mathbf{X}$ ] Analysis Report

[ ] Manufacturer Supplied Data

[ ] Similarity or Documented Record

Specify:

The Hedgehog-II packaging configurations have been designed and tested for solid or liquid radioactive material shipments only. It is the responsibility of the shipper to ensure that reactive hazardous components are not shipped together in a packaging, and that the package complies with the above requirements.

\subsection{4a (c) Mixed Contents. (Continued)}

(2) A packaging containing inner packagings of Division 6.2 materials may not contain other hazardous materials, except dry ice.

Specify:

This requirement does not apply to DOT-7A Type A packagings. The Class 7 packaging requirements will determine the packaging that applies. 
HNF-13820, Rev. 0

\subsection{4a (d) Liquid Fill Level.}

(d) Liquids must not completely fill a receptacle at a temperature of $55^{\circ} \mathrm{C}\left(131{ }^{\circ} \mathrm{F}\right)$ or less.

This requirement applies to DOT-7A Type A packagings. Based on the load, indicate if the requirement applies or does not apply. If the requirement applies, indicate below the type of documentation that shows the requirement is met and where the documentation can be found.

This requirement: [ ] Does not apply. [ X ] Applies; indicate the following.

$\begin{array}{lll}\text { Addressed in: } & \text { [] Drawing } & \text { [ X ] Operating Instruction } \\ & \text { [] Specification } & \text { [] Manufacturer Supplied Data } \\ & \text { [] Analysis Report } & \text { [ ] Similarity or Documented Record }\end{array}$

Specify:

The operating instructions (HNF-11651) will address that the inner bottles shall have a minimum of 10 percent ullage at standard temperature and pressure. The shipper is responsible to ensure that the above requirement is met. 
HNF-13820, Rev. 0

\subsection{CFR 173.24B ADDITIONAL GENERAL REQUIREMENTS FOR BULK PACKAGINGS.}

173.24b(a) Outage and Filling Limits.

(1) Except as otherwise provided in this subchapter, liquids and liquefied gases must be so loaded that the outage is at least five percent for materials poisonous by inhalation, or at least one percent of the total capacity of a cargo tank, portable tank, tank car (including dome capacity), multi-unit tank car tank, or any compartment thereof, at the following reference temperatures-

(i) $46^{\circ} \mathrm{C}\left(115^{\circ} \mathrm{F}\right)$ for a noninsulated tank;

(ii) $43^{\circ} \mathrm{C}\left(110^{\circ} \mathrm{F}\right)$ for a tank car having a thermal protection system, incorporating a metal jacket that provides an overall thermal conductance at $15.5^{\circ} \mathrm{C}\left(60^{\circ} \mathrm{F}\right)$ of no more than 10.22 kilojoules per hour per square meter per degree Celsius (0.5 Btu per hour/per square foot/per degree F) temperature differential; or (iii) $41^{\circ} \mathrm{C}\left(105^{\circ} \mathrm{F}\right)$ for an insulated tank.

(2) Hazardous materials may not be loaded into the dome of a tank car. If the dome of a tank car does not provide sufficient outage, vacant space must be left in the shell to provide the required outage.

These requirements are not applicable to a DOT-7A Type A packaging unless it also meets the definition of a cargo tank; portable tank; tank car; or multi-unit tank car tank, or any compartment thereof, and is used to haul the identified liquids. Based on the packaging design, indicate if the requirements apply or do not apply. If the requirements apply, indicate below the type of documentation that shows the requirements are met and where the documentation can be found.

$\begin{array}{lll}\text { These requirements: } & \text { [ X ] Do not apply. } & \text { [] Apply; indicate the following. } \\ \text { Addressed in: } & \text { [ ] Drawing } & \text { [ ] Operating Instruction } \\ & \text { [] Specification } & \text { [ ] Manufacturer Supplied Data } \\ & \text { [ ] Analysis Report } & \text { [ ] Similarity or Documented Record }\end{array}$

Specify:

Although liquids may be shipped in the approved, as-tested Hedgehog-II configurations, the above items do not apply as this is not a bulk packaging (cargo tank, portable tank, tank car, or multi-unit tank car). In addition, gaseous contents are not approved for shipment in the Hedgehog-II. 
HNF-13820, Rev. 0

\subsection{4b (b) Stainless Steel Substitution.}

(b) Equivalent steel. For the purposes of this section, stainless steel is steel with a guaranteed minimum tensile strength of 51.7 deka newtons per square millimeter $(75,000 \mathrm{psi})$ and a guaranteed elongation of $\mathbf{4 0}$ percent or greater. Where the regulations permit steel other than stainless steel to be used in place of a specified stainless steel (for example, as in $\$ 172.102$ of this subchapter, special provision B30), the minimum thickness for the steel must be obtained from one of the following formulas, as appropriate:

Formula for metric units:

$$
e_{1}=\left(12.74 e_{0}\right) /\left(R m_{1} A_{1}\right)^{1 / 3}
$$

Formula for non-metric units:

$$
e_{1}=\left(144.2 e_{0}\right) /\left(R m_{1} A_{1}\right)^{1 / 3}
$$

Where:

$e_{0}=$ Required thickness of the reference stainless steel in millimeters or inches respectively;

$e_{1}=$ Equivalent thickness of the steel used in millimeters or inches respectively; $\mathbf{R m}_{1}=$ Specified minimum tensile strength of the steel used in deka newtons per square millimeter or pounds per square inch respectively; and $A_{1}=$ Specified minimum percentage elongation of the steel used multiplied by 100 (for example, 20 percent times 100 equals 20). Elongation values used must be determined from a $50 \mathrm{~mm}$ or 2-inch test specimen.

Specify:

This requirement is not applicable to DOT-7A Type A packagings as no specific materials of construction are identified by the packaging specification. 


\subsection{4b (c) Pressurized Loading:}

(c) Air pressure in excess of ambient atmospheric pressure may not be used to load or unload any lading which may create an air-enriched mixture within the flammability range of the lading in the vapor space of the tank.

This requirement applies to DOT-7A Type A packagings that meet the definition of bulk packaging. Based on the packaging design and load, indicate if the requirement applies or does not apply. If the requirement applies, indicate below the type of documentation that shows the requirement is met and where the documentation can be found.

This requirement: [ [X ] Does not apply. [] Applies; indicate the following.
Addressed in:
[ ] Drawing
[] Specification
[ ] Analysis Report
[ ] Operating Instruction
[ ] Manufacturer Supplied Data
[ ] Similarity or Documented Record

Specify:

This requirement is not applicable as this is not a bulk packaging. Also, air pressure is not used in the loading and unloading process.

\subsection{4b (d) Design Temperature Range/Weight:}

(d) A bulk packaging may not be loaded with a hazardous material that:

(1) Is at a temperature outside of the packaging's design temperature range; or

(2) Except as otherwise provided in this subchapter, exceeds the maximum weight of lading marked on the specification plate.

This requirement applies to a DOT-7A Type A packaging that also meets the definition of a bulk packaging. Based on the packaging design, indicate if the requirement applies or does not apply. If the requirement applies, indicate below the type of documentation that shows the requirement is met and where the documentation can be found.

This requirement: [ [X ] Does not apply. [ ] Applies; indicate the following.
Addressed in:
[] Drawing
[] Specification
[ ] Operating Instruction
[] Analysis Report
[ ] Manufacturer Supplied Data
[ ] Similarity or Documented Record

Specify:

This requirement is not applicable as the Hedgehog-II is not a bulk packaging. It is the responsibility of the shipper to ensure compliance with this requirement, if applicable. 


\title{
4.4 49 CFR 173.27 GENERAL REQUIREMENTS FOR TRANSPORTATION BY AIRCRAFT.
}

\author{
173.27(a) Transport by Aircraft.
}

(a) The requirements of this section are in addition to the requirements in $\$ 173.24$ and apply to packages offered or intended for transportation aboard aircraft. Notwithstanding any Packing Group III performance level specified in Column 5 of the \$172.101 table, the required performance level for packages containing Class 4,5 , or 8 materials, when offered or intended for transportation aboard aircraft, is at the Packing Group II performance level, unless otherwise excepted from performance requirements in Subpart $E$ of this part.

This requirement is applicable to DOT-7A Type A packagings when transported by aircraft. Based on the mode of transportation, indicate if the requirement applies or does not apply. If the requirement applies, indicate below the type of documentation that shows the requirement is met and where the documentation can be found.

This requirement: [ ] Does not apply. [ $\quad$ ] Applies; indicate the following.

Addressed in:

[] Drawing
[] Specification
[ X ] Analysis Report

[ ] Operating Instruction

[ ] Manufacturer Supplied Data

[ ] Similarity or Documented Record

Specify:

Liquid and solid Type A radioactive contents may be shipped in the Hedgehog-II configurations, and air transport is intended. Liquids transported in the as-tested and approved $1 \mathrm{~L}$ glass bottle shall have a specific gravity of $\leq 1.6$. Liquids transported in all other configurations shall have a specific gravity of $\leq 2.0$. The solid materials are limited in weight (to include packaging) to the gross weight of the as-tested liquids and bottles. The maximum weight of the bottle and liquid contents for the package is provided in Table A-3 (includes 10 percent ullage).

Table A-3. Maximum Gross Weights for Hedgehog-II Configurations (Nominal).

\begin{tabular}{|c|c|c|}
\hline Configuration & $\begin{array}{l}\text { Bottle and contents } \\
\text { kg (lb) }\end{array}$ & $\begin{array}{l}\text { Package gross weight } \\
\qquad \mathrm{kg} \mathrm{(b)}\end{array}$ \\
\hline $30 \mathrm{~mL}$ shielded & $\begin{array}{ll}\text { Bottle and contents } & =0.099(0.219) \\
\text { Contents only } & =0.088(0.196)\end{array}$ & $31.30(69)$ \\
\hline $125 \mathrm{~mL}$ shielded & $\begin{array}{ll}\text { Bottle and contents } & =0.365(0.805) \\
\text { Contents only } & =0.339(0.749)\end{array}$ & $29.94(66)$ \\
\hline $250 \mathrm{~mL}$ shielded & $\begin{array}{ll}\text { Bottle and contents } & =0.562(1.24) \\
\text { Contents only } & =0.524(1.156)\end{array}$ & $25.85(57)$ \\
\hline $1 \mathrm{~L}$ glass & $\begin{array}{l}\text { Bottle and contents }=1.72(3.8) \\
\text { Contents only }=1.27(2.8)\end{array}$ & $18.14(40)$ \\
\hline $1 \mathrm{~L}$ poly & $\begin{array}{l}\text { Bottle and contents }=1.99(4.4) \\
\text { Contents only }=1.90(4.2)\end{array}$ & $17.92(39.5)$ \\
\hline
\end{tabular}

NOTE: Information for 125 and $250 \mathrm{~mL}$ shielded configurations was obtained from WHC-SD-OTR-001.

Gaseous contents are not authorized for transport. The Hedgehog-II configurations are not intended for shipping explosive materials, or chemicals forbidden by air, ground, or marine transport.

For airborne radioactive material transport refer to Section 10.3, "Applicability of Hazard Labels;" Section 7, "Marking and Labeling;" and Section 3, "Classification" of IATA 2003. 
The shipper is responsible for listing the chemical properties for the material to be shipped to ensure compatibility with contents and the packaging materials. The shipper is responsible for checking carrier restrictions prior to shipment.

\subsection{7(b) Transport by Aircraft.}

(b) Packages authorized on board aircraft.

(1) When Column 9a of the $\$ 172.101$ table indicates that a material is "Forbidden", that material may not be offered for transportation or transported aboard passenger-carrying aircraft.

(2) When Column 9b of the $\$ 172.101$ table indicates that a material is "Forbidden", that material may not be offered for transportation or transported aboard aircraft.

(3) The maximum quantity of hazardous material in a package that may be offered for transportation or transported aboard a passenger-carrying aircraft or cargo aircraft may not exceed that quantity prescribed for the material in Column 9a or $9 \mathrm{~b}$, respectively, of the $\$ 172.101$ table.

(4) A package containing a hazardous material which is authorized aboard cargo aircraft but not aboard passenger aircraft must be labeled with the CARGO

AIRCRAFT ONLY label required by $\$ 172.402(b)$ of this subchapter and may not be offered for transportation or transported aboard passenger-carrying aircraft.

These requirements are applicable to DOT-7A Type A packagings when transported by aircraft. Based on the mode of transportation, indicate if the requirements apply or do not apply. If the requirements apply, indicate below the type of documentation that shows the requirements are met and where the documentation can be found.

This requirement: [ ] Does not apply. [ $\quad$ ] Applies; indicate the following.

$\begin{array}{lll}\text { Addressed in: } & \text { [] Drawing } & \text { [] Operating Instruction } \\ & \text { [] Specification } & \text { [ ] Manufacturer Supplied Data } \\ & \text { [ } \mathbf{X} \text { ] Analysis Report } & \text { [] Similarity or Documented Record }\end{array}$

Specify:

The Hedgehog-II packaging configurations are not intended for air transport of materials or chemicals listed as "forbidden."

It is the responsibility of the shipper to ensure that this requirement is met. 


\subsection{7(c) Transport by Aircraft.}

(c) Pressure requirements. (1) Packagings must be designed and constructed to prevent leakage that may be caused by changes in altitude and temperature during transportation aboard aircraft.

This requirement is applicable to DOT-7A Type A packagings when transported by aircraft. Based on the mode of transportation, indicate if the requirement applies or does not apply. If the requirement applies, indicate below the type of documentation that shows the requirement is met and where the documentation can be found.

This requirement: [] Does not apply. [ $\quad$ ] Applies; indicate the following.
Addressed in:
[] Drawing
[] Specification
[] Operating Instruction
[ X ] Analysis Report
[] Manufacturer Supplied Data
[] Similarity or Documented Record

Specify:

The approved packaging configurations described and tested herein are authorized for transportation of liquids or solids by aircraft. The inner bottles have an ullage of approximately 10 percent for liquid transport. The $1 \mathrm{~L}$ bottles are required to remain intact and not break because they are a part of the identified containment system. The shipper must either use the same $1 \mathrm{~L}$ bottles that were approved during testing (either a wide-mouth poly bottle with poly lid [Nalgene 2105-0032] or wide-mouth glass jar [I-Chem 321-1000] and black phenolic lid with polyethylene liner [Qorpak 5082]), or document that if a different bottle/lid are used they are equivalent to what was used during testing. The $1 \mathrm{~L}$ bottles are also secured by circumferentially taping the lid/body interface with 2-in.-wide PVC film tape. The $1 \mathrm{~L}$ bottles are bagged twice in an appropriately sized bag.

The shielded assemblies provide primary containment as well, and were pressure-tested in 1995 under Docket 94-39-7A (DOE/RL-96-57, Vol. 1) by reducing the external pressure to $20.68 \mathrm{kPa}$ (3.0 psia) and holding for 15 minutes. All assemblies achieved a reduced pressure of $20.68 \mathrm{kPa}(3.0 \mathrm{psia})$. Therefore, a pressure differential of $79.22 \mathrm{kPa}(11.49 \mathrm{psi})$ was achieved. Refer to WHC-SD-TP-OTR-001 or DOE/RL 96 57, Vol. 1, for detailed information regarding the containment boundary verification procedure that was performed in 1995 on the stainless steel shielded assemblies before and after testing. The design of the shielded assemblies used in the Hedgehog-II packaging configurations is basically the same as the original Hedgehog packaging. The only design modification is that an option has been allowed for use of Torx flat head cap screws in lieu of the socket head cap screws. Torx screws offer more resistance to stripping out than the regular socket screws offer.

The NFT can assembly provides secondary containment. The NFT can assembly was manufacturer-tested and also verified during DOT-7A Type A testing to withstand an internal pressure of $103 \mathrm{kPa}$ (15 psi) differential pressure.

By packaging design and testing, this requirement is met. 
HNF-13820, Rev. 0

\subsection{7(c) Transport by Aircraft. (Continued)}

(2) Packagings for which retention of liquid is a basic function must be capable of withstanding without leakage the greater of-

(i) An internal pressure which produces a gauge pressure of not less than $75 \mathrm{kPa}$ (11 psi) for liquids in Packing Group III of Class 3 or Division 6.1 or $95 \mathrm{kPa}$ (14 psi) for other liquids; or

(ii) A pressure related to the vapor pressure of the liquid to be conveyed, determined by one of the following:

(A) The total gauge pressure measured in the receptacle [i.e., the vapor pressure of the material and the partial pressure of air or other inert gases, less $100 \mathrm{kPa}(15 \mathrm{psi})$ at $55^{\circ} \mathrm{C}\left(131^{\circ} \mathrm{F}\right)$ ], multiplied by a safety factor of 1.5 ; determined on the basis of a filling temperature of $15^{\circ} \mathrm{C}\left(59^{\circ} \mathrm{F}\right)$ and a degree of filling such that the receptacle is not completely liquid full at a temperature of $55^{\circ} \mathrm{C}$ $\left(131^{\circ} \mathrm{F}\right)$ or less;

(B) 1.75 times the vapor pressure at $50^{\circ} \mathrm{C}\left(122^{\circ} \mathrm{F}\right)$ less $100 \mathrm{kPa}$

(15 psi); or

(C) 1.5 times the vapor pressure at $55^{\circ} \mathrm{C}\left(131^{\circ}\right)$ less $100 \mathrm{kPa}$ (15 psi).

This requirement is applicable to a DOT-7A Type A packaging when it is transported by aircraft and contains liquids. Based on the mode of transportation and content, indicate below if the requirement applies or does not apply. If the requirement applies, indicate the type of documentation that shows the requirement is met and where the documentation can be found.

This requirement: [ ] Does not apply. [ $\quad$ ] Applies; indicate the following.

Addressed in

[ ] Drawing

[] Specification

[ ] Operating Instruction

[ X ] Analysis Report

[] Manufacturer Supplied Data

[] Similarity or Documented Record

Specify:

The approved packaging configurations described and tested herein are authorized for transportation of liquids or solids by aircraft. The inner bottles have an ullage of approximately 10 percent for liquid transport. The $1 \mathrm{~L}$ bottles are required to remain intact and not break because they are a part of the identified containment system. The shipper must either use the same $1 \mathrm{~L}$ bottles that were approved during testing (either a wide-mouth poly bottle with poly lid [Nalgene 2105-0032] or wide-mouth glass jar [I-Chem 321-1000] and black phenolic lid with polyethylene liner [Qorpak 5082]), or document that if a different bottle/lid are used they are equivalent to what was used during testing. The $1 \mathrm{~L}$ bottles are also secured by circumferentially taping the lid/body interface with 2-in.-wide PVC film tape. The $1 \mathrm{~L}$ bottles are bagged twice in an appropriately sized bag.

The shielded assemblies provide primary containment as well, and were pressure-tested in 1995 under Docket 94-39-7A (DOE/RL-96-57, Vol. 1) by reducing the external pressure to $20.68 \mathrm{kPa}$ (3.0 psia) and holding for 15 minutes. All assemblies achieved a reduced pressure of $20.68 \mathrm{kPa}$ (3.0 psia). Therefore, a pressure differential of $79.22 \mathrm{kPa}(11.49 \mathrm{psi})$ was achieved. Refer to WHC-SD-TP-OTR-001 or

DOE/RL-96-57, Vol. 1, for detailed information regarding the containment boundary verification procedure that was performed in 1995 on the stainless steel shielded assemblies before and after testing. The design of the shielded assemblies used in the Hedgehog-II packaging configurations is basically the same as the original Hedgehog packaging. The only design modification is that an option has been allowed for use of Torx flat head cap screws in lieu of the socket head cap screws. Torx screws offer more resistance to stripping out than the regular socket screws offer. 
The NFT can assembly provides secondary containment. The NFT can assenbly was manufacturer-tested and also verified during DOT-7A Type A testing to withstand an internal pressure of $103 \mathrm{kPa}$ (15 psi) differential pressure.

By packaging design and testing, this requirement is met.

\subsection{7(c) Transport by Aircraft. (Continued)}

(3) Notwithstanding the provisions of paragraph (c)(2) of this section--

(i) Hazardous materials may be contained in an inner packaging which does not itself meet the pressure requirement provided that the inner packaging is packed within a supplementary packaging which does meet the pressure requirement and other applicable packaging requirements of this subchapter.

(ii) Packagings which are subject to the hydrostatic pressure test and marking requirements of $\$ 178.605$ and $\$ 178.503(a)(5)$, respectively, of this subchapter must have a marked test pressure of not less than $250 \mathrm{kPa}$ (36 psi) for liquids in Packing Group I, $80 \mathrm{kPa}$ (12 psi) for liquids in Packing Group III of Class 3 or Division 6.1, and $100 \mathrm{kPa}$ (15 psi) for other liquids.

Specify:

These requirements are not applicable to DOT-7A Type A packagings. Part (i) clarifies that the packaging holding the load does not have to provide the pressure boundary. Part (ii) is not applicable to DOT-7A Type A packagings as they are not subject to sections 49 CFR 178.605 or 178.503(a)(5) of the regulations.

\subsection{7(d) Transport by Aircraft.}

(d) Closures. Stoppers, corks or other such friction-type closures must be held securely, tightly and effectively in place by positive means. Each screw-type closure on any packaging must be secured to prevent closure from loosening due to vibration or substantial change in temperature.

This requirement is applicable to DOT-7A Type A packagings when transported by aircraft. Based on the mode of transportation, indicate below if the requirement applies or does not apply. If the requirement applies, indicate the type of documentation that shows the requirement is met and where the documentation can be found.

This requirement: [ ] Does not apply. [X] Applies; indicate the following.

Addressed in: $\quad[\mathbf{X}]$ Drawing [] Specification

[ $\mathbf{X}$ ] Analysis Report [] Similarity or Documented Record

Specify:

Testing and evaluation of the approved Hedgehog-II packaging configurations described herein indicates this requirement to be satisfied. The Hardigg Case provides tamper indication and impact limitation, but no liquid containment. The NFT can assembly provides the secondary containment boundary and contains a Nitrile gasket within the threaded lid. When properly locked into place, the NFT can assembly lid-locking mechanism is designed to prevent loosening due to acceleration, vibration, or vibration resonance resulting from normal conditions of transportation. The NFT can assembly was manufacturer-tested and also verified during DOT-7A Type A testing to withstand an internal pressure of $103 \mathrm{kPa}$ (15 psi) differential pressure. 
The stainless steel shielded assemblies provide primary containment. The shielded assembly cover and base each incorporate an o-ring. The cover and base are secured by 8-32UNC-3A screws (4 each on cover; 4 each on base) and by applying a torque of 1.9 to $2.0 \mathrm{~N}-\mathrm{m}(17$ to $18 \mathrm{in}-\mathrm{lb})$. The assemblies were pressure-tested in 1995 under Docket 94-39-7A (DOE/RL-96-57, Vol. 1) by reducing the external pressure to $20.68 \mathrm{kPa}$ (3.0 psia) and holding for 15 minutes. All assemblies achieved a reduced pressure of $20.68 \mathrm{kPa}$ (3.0 psia). Therefore, a pressure differential of $79.22 \mathrm{kPa}(11.49 \mathrm{psi})$ was achieved. Refer to WHC-SD-TP-OTR-001 or DOE/RL-96-57, Vol. 1, for detailed information regarding the containment boundary verification procedure that was performed in 1995 on the stainless steel shielded assemblies before and after testing. The design of the shielded assemblies used in the Hedgehog-II packaging configurations is basically the same as the original Hedgehog packaging. The only design modification is that an option has been allowed for use of Torx flat head cap screws in lieu of the socket head cap screws. Torx screws offer more resistance to stripping out than the regular socket screws offer.

Primary containment for the $1 \mathrm{~L}$ version is provided by either a wide-mouth poly bottle with poly lid (Nalgene 2105-0032) or wide-mouth glass jar (I-Chem 321-1000) and black phenolic lid with polyethylene liner (Qorpak 5082). The $1 \mathrm{~L}$ bottles have a hand-tightened lid. The $1 \mathrm{~L}$ bottles are also secured by circumferentially taping the lid/body interface with 2-in.-wide PVC film tape. The $1 \mathrm{~L}$ bottles are bagged twice in an appropriately sized bag.

\subsection{7(e) Transport by Aircraft.}

(e) Absorbent materials. Except as otherwise provided in this subchapter, liquids in Packing Group I or II of Class 3, 4, 5, 6, or 8, when in glass or earthenware inner packagings, must be packaged using material capable of absorbing and not likely to react dangerously with the liquid. Absorbent material is not required if the inner packagings are so protected that breakage of them and leakage of their contents from the outer packaging is not likely to occur under normal conditions of transportation and is not required for packagings containing liquids in Packing Group II for transport aboard cargo aircraft only. Where absorbent material is required and an outer packaging is not liquid-tight, a means of containing the liquid in the event of leakage must be used in the form of a leakproof liner, plastic bag or other equally efficient means of containment. Where absorbent material is required, the quantity and disposition of it in each outer packaging must be as follows:

(1) For packagings containing liquids in Packing Group I offered for transportation or transported aboard passenger-carrying aircraft, each packaging must contain sufficient absorbent material to absorb the contents of all inner packagings containing such liquids;

(2) For packagings containing liquids in Packing Group I offered for transportation or transported aboard cargo aircraft only and packagings containing liquids in Packing Group II offered for transportation or transported aboard passenger aircraft, each package must contain sufficient absorbent material to absorb the contents of any one of the inner packagings containing such liquids and, where they are of different sizes and quantities, sufficient absorbent material to absorb the contents of the inner packaging containing the greatest quantity of liquid.

Specify:

These requirements are not applicable to DOT-7A Type A packagings. DOT-7A Type A packagings are for transport of Class 7 (radioactive) materials. 


\subsection{7(n Transport by Aircraft.}

(f) Combination packagings. Unless otherwise specified in this part, or in $\$ 171.11$ of this subchapter, when combination packagings are offered for transportation aboard aircraft, inner packagings must conform to the quantity limitations set forth in Table 1 of this paragraph for transport aboard passenger-carrying aircraft and Table 2 of this paragraph for transport aboard cargo aircraft only, as follows: ...

Specify:

These requirements are not applicable to DOT-7A Type A packagings. DOT-7A Type A packagings are for transport of Class 7 (radioactive) materials.

\subsection{7(g) Transport by Aircraft.}

(g) Cylinders. For any cylinder containing hazardous materials and incorporating valves, sufficient protection must be provided to prevent operation of, and damage to, the valves during transportation, by one of the following methods:

(1) By equipping each cylinder with securely attached valve caps or protective head rings; or

(2) By boxing or crating the cylinder.

This requirement is not applicable to a DOT-7A Type A packaging unless it is a cylinder equipped with a valve(s) and is to be transported by aircraft. Based on the mode of transportation and packaging type, indicate below if the requirement applies or does not apply. If the requirement applies, indicate below the type of documentation that shows the requirement is met and where the documentation can be found.

This requirement: [ $\quad[\mathbf{X}]$ Does not apply. [] Applies; indicate the following.
Addressed in:
[] Drawing
[] Specification
[ ] Operating Instruction
[] Analysis Report
[ ] Manufacturer Supplied Data
[] Similarity or Documented Record

Specify:

The Hedgehog-II packaging design does not incorporate the use of cylinders; therefore, this requirement is not applicable. 


\section{HNF-13820, Rev. 0}

\subsection{7(h) Transport by Aircraft.}

(h) Tank cars and cargo tanks. Any tank car or cargo tank containing a hazardous material may not be transported aboard aircraft.

This requirement is not applicable to a DOT-7A Type A packaging unless it is a tank car or cargo tank and is to be transported by aircraft. Based on the mode of transportation and packaging type, indicate below if the requirement applies or does not apply. If the requirement applies, indicate below the type of documentation that shows the requirement is met and where the documentation can be found.

This requirement:

Addressed in:
[ ] Applies; indicate the following.

[ ] Operating Instruction

[ ] Manufacturer Supplied Data

[ ] Similarity or Documented Record

Specify:

The Hedgehog-II packaging configurations described herein are not tank cars or cargo tanks. 


\subsection{CFR 173.410 GENERAL DESIGN REQUIREMENTS.}

\subsection{0(a) Handling and Securing.}

In addition to the requirements of subparts $A$ and $B$ of this part, each package used for the shipment of Class 7 (radioactive) materials must be designed so that-

(a) The package can be easily handled and properly secured in or on a conveyance during transport.

This requirement applies to DOT-7A Type A packagings. Indicate below the type of documentation that shows this requirement is met and where the documentation can be found.

Addressed in:

[ X ] Drawing

[] Specification

[X ] Analysis Report
[ $\mathbf{X}$ ] Operating Instruction

[ ] Manufacturer Supplied Data

[] Similarity or Documented Record

Specify:

Liquid and solid Type A radioactive contents may be shipped in the approved Hedgehog-II configurations, and air transport is intended. Liquids transported in the as-tested and approved $1 \mathrm{~L}$ glass bottle shall have a specific gravity of $\leq 1.6$. Liquids transported in all other configurations shall have a specific gravity of $\leq 2.0$. The solid materials are limited in weight (to include packaging) to the gross weight of the as-tested liquids and bottles. The maximum weight of the bottle and liquid contents for the package is provided in Table A-4 (includes 10 percent ullage).

Table A-4. Maximum Gross Weights for Hedgehog-II Configurations (Nominal).

\begin{tabular}{|c|c|c|}
\hline Configuration & $\begin{array}{c}\text { Bottle and contents } \\
\text { kg(lb) }\end{array}$ & $\begin{array}{l}\text { Package gross weight } \\
\text { kg (Ib) }\end{array}$ \\
\hline $30 \mathrm{~mL}$ shielded & $\begin{array}{l}\text { Bottle and contents }=0.099(0.219) \\
\text { Contents only }=0.088(0.196)\end{array}$ & $31.30(69)$ \\
\hline $125 \mathrm{~mL}$ shielded & $\begin{array}{l}\text { Bottle and contents }=0.365(0.805) \\
\text { Contents only }=0.339(0.749)\end{array}$ & $29.94(66)$ \\
\hline $250 \mathrm{~mL}$ shielded & $\begin{array}{l}\text { Bottle and contents }=0.562(1.24) \\
\text { Contents only } \quad=0.524(1.156)\end{array}$ & $25.85(57)$ \\
\hline $1 \mathrm{~L}$ glass & $\begin{array}{l}\text { Bottle and contents }=1.72(3.8) \\
\text { Contents only }=1.27(2.8)\end{array}$ & $18.14(40)$ \\
\hline 1 L poly & $\begin{array}{l}\text { Bottle and contents }=1.99(4.4) \\
\text { Contents only } \quad=1.90(4.2)\end{array}$ & $17.92(39.5)$ \\
\hline
\end{tabular}

NOTE: Information for 125 and $250 \mathrm{~mL}$ shielded configurations was obtained from WHC-SD-OTR-001.

The Hardigg Case comprises the outermost container for this packaging. This type of case has been used extensively for other configurations involving radioactive material shipments (i.e., the "original" Hedgehog), hazardous material shipments, instruments, and sensitive equipment. The nominal external dimensions of the Hardigg Case (length/width/height) are $64 \mathrm{~cm} \times 48 \mathrm{~cm} \times 48 \mathrm{~cm}$ (25 in. $\times 19$ in. $\times 19 \mathrm{in})$. The packaging configurations are easily lifted, handled and secured during transport. The Hedgehog-II system will be marked and transported in such a manner that the inner containers remain in an upright position when transporting liquids.

Refer to IATA, Section 10.5.3.1 (IATA 2003). 
HNF-13820, Rev. 0

\subsection{0(b) Lifting Attachments.}

(b) Each lifting attachment that is a structural part of the package must be designed with a minimum safety factor of three against yielding when used to lift the package in the intended manner, and it must be designed so that failure of any lifting attachment under excessive load would not impair the ability of the package to meet other requirements of this subpart. Any other structural part of the package which could be used to lift the package must be capable of being rendered inoperable for lifting the package during transport or must be designed with strength equivalent to that required for lifting attachments.

These requirements apply to DOT-7A Type A packagings. Indicate below the type of documentation that shows these requirements are met and where the documentation can be found.
Addressed in:
[ ] Drawing
[] Specification
[ ] Operating Instruction
[ ] Analysis Report
[ X ] Manufacturer Supplied Data
[ $\mathbf{X}]$ Similarity or Documented Record

Specify:

The Hardigg Case is equipped with two handles, each with a strength of $227 \mathrm{~kg}$ (500 lb). The maximum weight of the heaviest approved Hedgehog-II packaging is approximately $31.30 \mathrm{~kg} \mathrm{(69} \mathrm{lb).} \mathrm{If} \mathrm{a} \mathrm{lifting} \mathrm{handle}$ should fail, the attachment rivets are designed to shear, preventing the case from rupturing.

Refer to IATA, Sections 10.5.3.2 and 10.5.3.3 (IATA 2003). 


\subsection{0(c) External Surface Protrusions, Decontamination.}

(c) The external surface, as far as practicable, will be free from protruding features and will be easily decontaminated.

This requirement applies to DOT-7A Type A packagings. Indicate below the type of documentation that shows this requirement is met and where the documentation can be found.
Addressed in:
[ $\mathbf{X}$ ] Drawing
[] Specification
[ $\mathbf{X}$ ] Operating Instruction
[ X ] Analysis Report
[ ] Manufacturer Supplied Data
[ X] Similarity or Documented Record

Specify:

The Hedgehog-II packaging configurations tested meet the intent of this requirement. The exterior of the Hedgehog-II is basically the same design as the original Hedgehog that was tested under Docket 94-39-7A (DOE/RL-96-57, Vol. 1). The exterior surface of the Hardigg Case is made of polyethylene. The exterior surfaces of the NFT can assembly and shielded assemblies are Type 304 stainless steel. The inner bottles for the 30, 125, and $250 \mathrm{~mL}$ versions are made of glass, polyethylene, or Teflon ${ }^{7}$ with Teflon- or polyethylenecoated lids. These bottles are considered as "packaging not required." The as-tested $1 \mathrm{~L}$ version is either a poly bottle with poly lid or a glass jar with a black phenolic lid with polyethylene liner. These materials have been shown to be easily decontaminated if no degradation of the material has occurred due to exposure to incompatible materials.

Protrusions and crevices exist on the Hardigg Case and NFT can assembly; however, the surface is smooth and these areas can easily be decontaminated.

It is the responsibility of the shipper to ensure that materials shipped in the Hedgehog-II container configurations are compatible with each other and the container.

Refer to IATA, Section 10.5.3.4 (IATA 2003).

\footnotetext{
${ }^{7}$ Teflon is a trademark of E. I. Du Pont de Nemours \& Company.
} 


\subsection{0(d) Outer Layer - Pockets, Crevices (Water Collection).}

(d) The outer layer of packaging will avoid, as far as practicable, pockets or crevices where water might collect.

This requirement applies to DOT-7A Type A packagings. Indicate below the type of documentation that shows this requirement is met and where the documentation can be found.
Addressed in:
[ $\mathbf{X}$ ] Drawing
[] Specification
[ ] Operating Instruction
[ X ] Analysis Report
[ ] Manufacturer Supplied Data
[ $\mathbf{X}$ ] Similarity or Documented Record

Specify:

The Hedgehog-II packaging configurations did not undergo the water spray test identified in 49 CFR 173.465(b), but have been evaluated as meeting this requirement due to similarity in design with the outer case of the original Hedgehog packaging.

The original Hedgehog packaging that was tested in 1995 under Docket 94-39-7A (DOE/RL-96-57, Vol. 1) underwent the water spray test. Test unit 39-TU-02 (empty case) was subjected to the water spray conditions for 1 hour with no adverse affect or loss of contents. Water collected on the top exterior of the case as the case would normally be positioned during transportation. The exterior of the case is a rotationally molded polyethylene material with rounded edges. Water flowed over the rounded edges of the case lid and stopped once it reached the interior gasket material. The Hardigg Case lid incorporates a split gasket (the split is located at the bottom of the packaging as it normally positioned during transportation). Attachment rivets connect to metal plates that are molded into the Hardigg Case. There was no in-leakage of water. Water did not cause damage to the exterior or interior of the packaging. No other packages were water spray tested in 1995 as water did not have any adverse affects on the packaging.

Refer to IATA, Section 10.5.3.5 (IATA 2003).

\subsection{0(e) Features Added at Time of Transport.}

(e) Each feature that is added to the package will not reduce the safety of the package.

This requirement applies to DOT-7A Type A packagings that have features added at the time of shipment. Based on the packaging design, indicate below if the requirement applies or does not apply. If the requirement applies, indicate the type of documentation that shows this requirement is met and where the documentation can be found.

This requirement: [ ] Does not apply. [ X ] Applies; indicate the following.

$\begin{array}{lll}\text { Addressed in: } & \text { [ ] Drawing } & \text { [ X ] Operating Instruction } \\ & \text { [] Specification } & \text { [] Manufacturer Supplied Data } \\ & \text { [] Analysis Report } & \text { [] Similarity or Documented Record }\end{array}$

Specify:

No features will be added at the time of transport except for a security seal that is attached to the sealing flange of the Hardigg Case. Instructions for attaching the security seal are included in the operating instructions (HNF-11651). The shipper is responsible to ensure this requirement is met.

Refer to IATA, Section 10.5.3.6 (IATA 2003). 


\subsection{0(f) Acceleration, Vibration.}

(f) The package will be capable of withstanding the affects of any acceleration, vibration or vibration resonance that may arise under normal conditions of transport without any deterioration in the effectiveness of the closing devices on the various receptacles or in the integrity of the package as a whole and without loosening or unintentionally releasing the nuts, bolts, or other securing devices even after repeated use (see $\$ \$ 173.24,173.24 a$, and 173.24b).

These requirements apply to DOT-7A Type A packagings. Indicate below the type of documentation that shows these requirements are met and where the documentation can be found.

Addressed in:

[ ] Drawing

[] Specification

$[\mathbf{X}$ ] Analysis Report
[ ] Operating Instruction

[ ] Manufacturer Supplied Data

[ ] Similarity or Documented Record

Specify:

The approved Hedgehog-II packaging configurations were verified to pass this requirement. Vibration testing was conducted at PNNL, located in the 300 Area of the Hanford Site. Refer to Section 8.0, 49 CFR 178.608, "Vibration Standard," of this PQCL for the vibration testing that was performed on the HedgehogII configurations. Visual examinations of the approved packaging configurations identified no rupture or leakage.

Testing and evaluation of the packaging configurations described herein indicates this requirement is satisfied. The Hardigg Case provides tamper indicationand impact limitation, but no liquid containment. The interior of the Hardigg Case is lined with 2-lb/ $\mathrm{ft}^{2}$-polyethylene foam that acts as cushioning. The NFT can assembly provides the secondary containment boundary and contains a Nitrile gasket within the threaded lid closure. When properly locked into place, the lid-locking mechanism prevents loosening due to acceleration, vibration, or vibration resonance resulting from normal conditions of transportation. The stainless steel shielded assemblies provide primary containment. The shielded assembly cover and base each incorporates an o-ring. The cover and base are secured by 8-32UNC-3A screws (4 each on cover; 4 each on base) and by applying a torque of 1.9 to $2.0 \mathrm{~N}-\mathrm{m}$ (17 to $18 \mathrm{in}-\mathrm{lb})$.

Primary containment for the $1 \mathrm{~L}$ version is provided by either a wide-mouth poly bottle with poly lid (Nalgene 2105-0032) or wide-mouth glass jar (I-Chem 321-1000) and black phenolic lid with polyethylene liner (Qorpak 5082). The $1 \mathrm{~L}$ bottles have a hand-tightened lid. The lid is further secured by taping circumferentially around the lid/body interface with 2-in.-wide PVC film tape. Refer to Appendix B of this final evaluation report or HNF-13819, Appendix A, for the specific loading instructions that were used during testing for the $1 \mathrm{~L}$ bottle configurations.

Refer to IATA, Sections 10.5.3.7 and 5.0.4.3 (IATA 2003). Vibration in commercial aircraft to which packagings may be exposed to range from $5 \mathrm{~mm}$ amplitude at $7 \mathrm{~Hz}$ (corresponding to $1 \mathrm{~g}$ acceleration) to 0.05 amplitude at $200 \mathrm{~Hz}$ (corresponding to $8 g$ acceleration). 


\subsection{0(g) Physical/Chemical Compatibility, Irradiation.}

(g) The materials of construction of the packaging and any components or structure will be physically and chemically compatible with each other and with the package contents. The behavior of the packaging and the package contents under irradiation will be taken into account.

This requirement applies to DOT-7A Type A packagings. Indicate below the type of documentation that shows this requirement is met and where the documentation can be found.
Addressed in:
[ $\mathbf{X}$ ] Drawing
[] Specification
$[\mathbf{X}]$ Analysis Report
[ ] Operating Instruction
[ ] Manufacturer Supplied Data
[ ] Similarity or Documented Record

Specify:

The Hedgehog-II configurations identified herein were tested and evaluated to ensure that the designs comply with applicable regulations within 49 CFR as identified for DOT-7A Type A packagings, as well as IAEA and IATA regulations for air transport of Type A packagings. Liquid or solid contents are intended for shipment. It is the shipper's responsibility to identify the actual contents being shipped, and to ensure that the above requirements are met.

The materials of construction for the Hedgehog-II configurations consist of the following:

- Polyethylene case with steel butterfly latches, zinc chromate hardware, and silicone sponge cording (gasket) (Bauer Cases, Part No. AL2216-1205-HHBA-724E). Includes polyethylene foam $\left(2.2 \mathrm{lb} / \mathrm{ft}^{2}\right)$, and a $0.32 \mathrm{~cm}(0.125$-in.) ABS load spreader. Polyethylene foam having a notched area for the intermediate container handle and for use with the $1 \mathrm{~L}$ configurations is assembly HHBA-724FA. Polyethylene foam that does not include the notched handle and is for use with the shielded configurations is assembly HHBA-724FB. Refer to Hanford drawing H-2830875. The polyethylene materials, silicone sponge cording (gasket), and ABS load spreader are made from materials that typically meet the packaging temperature range requirements identified in 49 CFR 173.412 (c) $\left(-40\right.$ to $70^{\circ} \mathrm{C}\left[-40\right.$ to $\left.\left.158{ }^{\circ} \mathrm{F}\right]\right)$.

- The intermediate container (i.e., the NFT can assembly) is identified as NFT Part No.21030001, and is fabricated according to Hanford drawing H-2-830876. The NFT can assembly is made of 304 stainless steel (22 gauge), incorporates a rigid handle, pull-ring plunger assembly, and threaded closure that includes a Viton (V835-75) gasket having a temperature range from -40 to $204^{\circ} \mathrm{C}\left(-40\right.$ to $\left.400^{\circ} \mathrm{F}\right)$. The $2 \mathrm{lb} / \mathrm{ft}^{2}$ foam supplied with the NFT can assembly is EVA (white), per ASTM D1056. The temperature range of the EVA foam is -73 to $82^{\circ} \mathrm{C}\left(-100\right.$ to $\left.180{ }^{\circ} \mathrm{F}\right)$.

- The shielded assemblies (inner and outer) are fabricated from 304 stainless steel. The cover and base are ASTM A240 or ASTM A276. The wall is ASTM A511 or ASTM A276. The $250 \mathrm{~mL}$ outer assembly and the $30 \mathrm{~mL}$ inner assembly each incorporate a lifting cable made of stainless steel. The shielded assemblies contain Nitrile o-rings. The N103 Parker material has a temperature range of -48 to $107^{\circ} \mathrm{C}\left(-55\right.$ to $\left.225{ }^{\circ} \mathrm{F}\right)$; and the N304 Parker material has a temperature range of -53 to $121{ }^{\circ} \mathrm{C}\left(-65\right.$ to $\left.250^{\circ} \mathrm{F}\right)$. The screws are socket or Torx flat head cap screws 8-32UNC-3A x 1-in. length or $3 / 4$-in. length depending on the shielded assembly. Refer to Hanford drawing H-2-830877.

- The as-tested and approved $1 \mathrm{~L}$ bottles are either wide-mouth poly with poly lid (Nalgene 21050032 [Fisher Scientific 02-893D]) or wide-mouth glass jar (I-Chem 321-1000 [Fisher Scientific 05-719-89]). The blue I-Chem lid that is provided with the glass jar must be replaced with a black phenolic lid with polyethylene liner (Qorpak 5082). The shipper must either use the same $1 \mathrm{~L}$ bottle/lid combinations that were approved during testing, or document that if a different bottle is used it is equivalent to what was used during testing. The poly, phenolic, and 
polyethylene materials typically meet the packaging temperature range requirements identified in 49 CFR 173.412 (c) $\left(-40\right.$ to $70^{\circ} \mathrm{C}\left[-40\right.$ to $\left.\left.158^{\circ} \mathrm{F}\right]\right)$.

- The as-tested belleville washer was made from 1075 carbon steel (Rolex AM-1608243). However, the belleville washer intended for use is made from 17/7-PH stainless steel (Rolex SAM-1608243). The operational loading for either of these materials is $5274.0 \mathrm{lb} @ 0.1779$ inch deflection with a normal load tolerance from $+10.0 \%$ to $-5.0 \%$. The stainless steel disc is made from 11 -gauge sheet. Refer to Hanford drawing H-2-830874.

- With the exception of the $30 \mathrm{~mL}$ bottle, all bottles $(125 \mathrm{~mL} ; 250 \mathrm{~mL} ; 1 \mathrm{~L}$ plastic; and $1 \mathrm{~L}$ glass) are bagged twice in an appropriately sized bag. The $30 \mathrm{~mL}$ bottle is bagged once. The lid to the $1 \mathrm{~L}$ bottles is further secured by taping circumferentially around the lid/body interface with 2-in.-wide PVC film tape. Refer to Appendix B of this final evaluation report or HNF-13819, Appendix A, for the specific loading instructions that were used during testing for the $1 \mathrm{~L}$ bottle configurations.

Refer to IATA, Section 10.5.3.8 (IATA 2003).

\subsection{0(h) Valves - Protection, Enclosure.}

(h) All valves through which the package contents could escape will be protected against unauthorized operation.

This requirement applies to DOT-7A Type A packagings that have valves. Based on the packaging design, determine if the requirement applies or does not apply. If the requirement applies, identify the type of documentation that shows this requirement is met and where the documentation can be found.

This requirement: [ $\mathbf{X}$ ] Does not apply. [ ] Applies; indicate the following.

Addressed in: [] Drawing [] Operating Instruction [ ] Specification [] Manufacturer Supplied Data

[] Analysis Report [] Similarity or Documented Record

Specify:

There are no valves incorporated into the Hedgehog-II packaging design; therefore, this requirement is not applicable.

Refer to IATA, Section 10.5.3.9 (IATA 2003). 


\subsection{0(i) For Transport by Air-}

(i) For transport by air--

(1) The temperature of the accessible surfaces of the package will not exceed $50^{\circ} \mathrm{C}\left(122^{\circ} \mathrm{F}\right)$ at an ambient temperature of $38^{\circ} \mathrm{C}\left(100^{\circ} \mathrm{F}\right)$ with no account taken for insulation;

(2) The integrity of containment will not be impaired if the package is exposed to ambient temperatures ranging from $-40^{\circ} \mathrm{C}\left(-40^{\circ} \mathrm{F}\right)$ to $+55^{\circ} \mathrm{C}\left(131^{\circ} \mathrm{F}\right)$; and

(3) Packages containing liquid contents will be capable of withstanding, without leakage, an internal pressure that produces a pressure differential of not less than $95 \mathrm{kPa}\left(13.8 \mathrm{lb} / \mathrm{in}^{2}\right)$.

These requirements apply to DOT-7A Type A packagings used for transport by aircraft. Based on the mode of transportation, indicate below if the requirements apply or do not apply. If the requirements apply, identify the type of documentation that shows these requirements are met and where the documentation can be found.

These requirements: [ ] Do not apply. [X] Apply; indicate the following.

Addressed in: $\quad[\mathbf{X}]$ Drawing [] Specification

[] Operating Instruction

[ $\mathbf{X}$ ] Analysis Report

[ X ] Manufacturer Supplied Data

[ ] Similarity or Documented Record

Specify:

The approved packaging configurations described and tested herein are authorized for transportation of liquids or solids by aircraft. The outer Hardigg Case incorporates materials made from polyethylene, silicone sponge cording (gasket), and ABS (load spreader) that all typically meet the packaging temperature range requirements identified in $49 \mathrm{CFR} 173.412$ (c) $\left(-40\right.$ to $70^{\circ} \mathrm{C}\left[-40\right.$ to $\left.\left.158{ }^{\circ} \mathrm{F}\right]\right)$.

The inner bottles have an ullage of approximately 10 percent for liquid transport. The $1 \mathrm{~L}$ bottles are required to remain intact and not break because it is a part of the identified containment system. The shipper must either use the same $1 \mathrm{~L}$ bottles that were approved during testing (either a wide-mouth poly bottle with poly lid (Nalgene 2105-0032) or wide-mouth glass jar (I-Chem 321-1000) and black phenolic lid with polyethylene liner (Qorpak 5082), or document that if a different bottle/lid are used they are equivalent to what was used during testing.

The $1 \mathrm{~L}$ bottle lids are hand-tightened. The lid is further secured by taping circumferentially around the lid/body interface with 2-in.-wide PVC film tape. Refer to Appendix B of this final evaluation report or HNF-13819, Appendix A, for the specific loading instructions that were used during testing for the $1 \mathrm{~L}$ bottle configurations. These bottles are made of glass, poly, phenolic, and polyethylene materials, which typically meet packaging temperature range requirements identified in 49 CFR 173.412 (c) $\left(-40\right.$ to $70^{\circ} \mathrm{C}[-40$ to 158 $\left.\left.{ }^{\circ} \mathbf{F}\right]\right)$.

The shielded assemblies provide primary containment as well, and were pressure-tested in 1995 under Docket 94-39-7A (DOE/RL-96-57, Vol. 1) by reducing the external pressure to $20.68 \mathrm{kPa}(3.0 \mathrm{psia})$ and holding for 15 minutes. All assemblies achieved a reduced pressure of $20.68 \mathrm{kPa}$ (3.0 psia). Therefore, a pressure differential of $79.22 \mathrm{kPa}(11.49 \mathrm{psi})$ was achieved. Refer to WHC-SD-TP-OTR-001 or

DOE/RL 96-57, Vol. 1, for detailed information regarding the containment boundary verification procedure that was performed in 1995 on the stainless steel shielded assemblies before and after testing. The design of the shielded assemblies used in the Hedgehog-II packaging configurations is basically the same as the original Hedgehog packaging. The only design modification is that an option has been allowed for use of Torx flat head cap screws in lieu of the socket head cap screws. Torx screws offer more resistance to stripping out than the regular socket screws offer. The Nitrile o-rings include N103 Parker material having a temperature range of -48 to $107^{\circ} \mathrm{C}\left(-55\right.$ to $\left.225^{\circ} \mathrm{F}\right)$; and the $\mathrm{N} 304$ Parker material having a temperature range of -53 to $121^{\circ} \mathrm{C}\left(-65\right.$ to $\left.250^{\circ} \mathrm{F}\right)$. 
The NFT can assembly provides secondary containment. The NFT can assembly was manufacturer tested and DOT-7A Type A testing also verified that it can withstand an internal pressure of $103 \mathrm{kPa}(15 \mathrm{psi})$ differential pressure. The Viton gasket has a temperature range of -40 to $204^{\circ} \mathrm{C}\left(-40\right.$ to $\left.400{ }^{\circ} \mathrm{F}\right)$. The EVA foam cushioning material has a temperature range of -73 to $82{ }^{\circ} \mathrm{C}\left(-100\right.$ to $\left.180^{\circ} \mathrm{F}\right)$.

By packaging design and testing, this requirement is met.

Refer to IATA. Sections 10.5.3.10; 10.5.3.11; and 10.5.3.12 (IATA 2003). 
HNF-13820, Rev. 0

\subsection{CFR 173.412 ADDITIONAL DESIGN REQUIREMENTS FOR TYPE A PACKAGES.}

\subsection{Tamper Indication.}

In addition to meeting the general design requirements prescribed in $\$ 173.410$, each Type $A$ packaging must be designed so that--

(a) The outside of the packaging incorporates a feature, such as a seal, that is not readily breakable, and that, while intact, is evidence that the package has not been opened. In the case of packages shipped in closed transport vehicles in exclusive use, the cargo compartment, instead of the individual packages, may be sealed.

This requirement applies to DOT-7A Type A packagings. Indicate below the type of documentation that shows this requirement is met and where the documentation can be found.
Addressed in:
[] Drawing
[] Specification
[ $\mathrm{X}$ ] Operating Instruction
[] Analysis Report
[] Manufacturer Supplied Data
[ ] Similarity or Documented Record

Specify:

The Hedgehog-II packaging configurations will use a standard lead wire seal to provide tamper indication. It is the responsibility of the shipper to ensure that appropriate precautions are taken to seal the package in a manner that will provide evidence that the package has not been opened. The operating and use instructions (HNF-11651) identify this information.

Refer to IATA, Section 10.6.2.1.1.2 (IATA 2003).

\subsection{2(b) Smallest External Dimension.}

(b) The smallest external dimension of the package is not less than 10 centimeters (4 inches);

This requirement applies to DOT-7A Type A packagings. Indicate below the type of documentation that shows this requirement is met and where the documentation can be found.
Addressed in:
[ $\mathbf{X}$ ] Drawing
[] Specification
[ ] Operating Instruction
[ ] Analysis Report
[ ] Manufacturer Supplied Data
[ ] Similarity or Documented Record

Specify:

The nominal external dimensions of the Hedgehog-II design (length/width/height) measure $64 \mathrm{~cm} \mathrm{x} 48 \mathrm{~cm} \mathrm{x}$ $48 \mathrm{~cm}$ (25 in. $x 19$ in. $x 19$ in.), which exceed the minimum dimensional requirement.

Refer to IATA, Section 10.6.2.1.1.1 (IATA 2003). 


\subsection{2(c) Containment and Shielding.}

(c) Containment and shielding is maintained during transportation and storage in a temperature range of $-40^{\circ} \mathrm{C}\left(-40^{\circ} \mathrm{F}\right)$ to $70^{\circ} \mathrm{C}\left(158^{\circ} \mathrm{F}\right)$. Special attention shall be given to liquid contents and to the potential degradation of the packaging materials within the temperature range.

This requirement applies to DOT-7A Type A packagings. Indicate below the type of documentation that shows this requirement is met and where the documentation can be found.
Addressed in:
[X] Drawing
[X] Specification
[X] Analysis Report
[ ] Operating Instruction
[ X ] Manufacturer Supplied Data
[ ] Similarity or Documented Record

Specify:

The Hardigg Case is not a containment barrier but provides confinement. The polyethylene materials, silicone sponge cording (gasket), and ABS load spreader are made from materials that typically meet the packaging temperature range requirements identified above.

The primary containment and shielding for the 30,125 , and $250 \mathrm{~mL}$ versions are provided by the Type 304 stainless steel shielded assemblies, including the Nitrile o-rings and closure screws. Stainless steel is a material preferred by the U.S. Nuclear Regulatory Commission because of its resistance to brittle fracture of a wide range of temperatures. Nitrile has a temperature range of $-54^{\circ} \mathrm{C}$ to $134^{\circ} \mathrm{C}\left(-65^{\circ} \mathrm{F}\right.$ to $\left.275^{\circ} \mathrm{F}\right)$.

No shielding is provided in the $1 \mathrm{~L}$ packaging configurations. The primary containment for the as-tested $1 \mathrm{~L}$ versions is either the wide-mouth poly bottle with poly lid (Nalgene 2105-0032) or wide-mouth glass jar (I-Chem 321-1000) and black phenolic lid with polyethylene liner (Qorpak 5082). The shipper must either use the same $1 \mathrm{~L}$ bottle/lid combinations that were approved during testing, or document that if a different bottle is used it is equivalent to what was used during testing. The $1 \mathrm{~L}$ bottles and lids are made from materials that typically meet the identified packaging temperature range requirements as stated above. PVC film tape is used to secure the lids to the $1 \mathrm{~L}$ configurations.

The secondary containment for all configurations is provided by the NFT can assembly, which includes threaded lid, canister base, and gasket. The NFT can assembly is also made from Type 304 stainless steel. The gasket material is made from Viton (V835-75), having an operating range from -40 to $204{ }^{\circ} \mathrm{C}(-40$ to $\left.400^{\circ} \mathrm{F}\right)$. The inner cushioning material (EVA foam) has a temperature range of -73 to $82^{\circ} \mathrm{C}\left(-100\right.$ to $\left.180^{\circ} \mathrm{F}\right)$.

Refer to IATA, Section 10.6.2.1.1.4 (IATA 2003). 


\subsection{2(d) Secure Containmert System.}

(d) The packaging must include a containment system securely closed by a positive fastening device that cannot be opened unintentionally or by pressure that may arise within the package during normal transport. Special form Class 7 (radioactive) material, as demonstrated in accordance with $\$ 173.469$, may be considered as a component of the containment system. If the containment system forms a separate unit of the package, it must be securely closed by a positive fastening device that is independent of any other part of the package.

This requirement applies to DOT-7A Type A packagings. Indicate below the type of documentation that shows this requirement is met and where the documentation can be found.

\author{
Addressed in:
}

[X] Operating Instruction

[ ] Manufacturer Supplied Data

[ ] Similarity or Documented Record

Specify:

The approved packaging configurations described and tested herein are authorized for transportation of liquids or solids. The primary containment for the $1 \mathrm{~L}$ versions is the bottle and lid itself. The inner bottles have an ullage of approximately 10 percent for liquid transport. The $1 \mathrm{~L}$ bottles are required to remain intact and not break because it is a part of the identified containment system. The shipper must either use the same $1 \mathrm{~L}$ bottles that were approved during testing (either a wide-mouth poly bottle with poly lid (Nalgene 2105-0032) or wide-mouth glass jar (I-Chem 321-1000) and black phenolic lid with polyethylene liner (Qorpak 5082), or document that if a different bottle/lid are used they are equivalent to what was used during testing.

The $1 \mathrm{~L}$ bottle lids are secured by taping circumferentially around the bottle/lid interface with 2 -in.-wide PVC film tape. The $1 \mathrm{~L}$ bottles are bagged twice in an appropriately sized bag. Refer to Appendix B of this final evaluation report or HNF-13819, Appendix A, for the specific loading instructions that were used during testing for the $1 \mathrm{~L}$ bottle configurations.

Primary containment for the 30,125 , and $250 \mathrm{~mL}$ versions is provided by the Type 304 stainless steel shielded assemblies that are secured with 8-32UNC-3A screws that are torqued 1.9 to $2.0 \mathrm{~N}-\mathrm{m}$ (17 to $18 \mathrm{in}-\mathrm{lb})$. The cover and base of the shielded assemblies have a Nitrile o-ring gasket. The shielded assemblies were pressure-tested in 1995 under Docket '94-39-7A (DOE/RL-96-57, Vol. 1) by reducing the external pressure to $20.68 \mathrm{kPa}(3.0 \mathrm{psia})$ and holding for 15 minutes. All assemblies achieved a reduced pressure of $20.68 \mathrm{kPa}(3.0$ psia). Therefore, a pressure differential of $79.22 \mathrm{kPa}(11.49 \mathrm{psi})$ was achieved. Refer to WHC-SD-TP-OTR001 or DOE/RL-96-57, Vol. 1, for detailed information regarding the containment boundary verification procedure that was performed in 1995 on the stainless steel shielded assemblies before and after testing. The design of the shielded assemblies used in the Hedgehog-II packaging configurations is basically the same as the original Hedgehog packaging. The only design modification is that an option has been allowed for use of Torx flat head cap screws in lieu of the socket head cap screws. Torx screws offer more resistance to stripping out than the regular socket screws offer.

The secondary containment for all configurations consists of the NFT can assembly. The secondary containment for all configurations is provided by the NFT can assembly, which includes threaded lid, canister base, and gasket. The NFT can assembly is made from Type 304 stainless steel. The gasket material is made from Viton (V835-75). The NFT can assembly was manufacturer-tested and also verified during DOT-7A Type A testing to withstand an internal pressure of $103 \mathrm{kPa}(15 \mathrm{psi})$ differential pressure.

Refer to IATA, Sections 10.6.2.1.2.1; 10.6.2.1.2.2; and 10.6.2.1.2.3 (IATA 2003). 


\subsection{2(e) Radiolytic Decomposition, Chemical Reaction, Radiolysis.}

(e) For each component of the containment system account is taken, where applicable, of radiolytic decomposition of materials and the generation of gas by chemical reaction and radiolysis.

This requirement applies to DOT-7A Type A packagings. Indicate below the type of documentation that shows this requirement is met and where the documentation can be found.
Addressed in:
[ ] Drawing
[ ] Specification
$[\mathbf{X}$ ] Operating Instruction
[ ] Analysis Report
[ X ] Manufacturer Supplied Data
[ X ] Similarity or Documented Record

Specify:

It is the responsibility of the shipper to ensure that the affects of radiation from the payload will not degrade the performance of the packaging through gas generation, chemical reaction, or radiolysis.

Refer to IATA, Section 10.6.2.1.2.4 (IATA 2003).

\subsection{2(f) Reduction of Ambient Pressure.}

(f) The containment system will retain its radioactive contents under the reduction of ambient pressure to $25 \mathrm{kPa}$ (3.6 pounds per square inch).

This requirement applies to DOT-7A Type A packagings. Indicate below the type of documentation that shows this requirement is met and where the documentation can be found.
Addressed in:
[ $\mathbf{X}$ ] Drawing
[] Specification
[ ] Operating Instruction
[ X ] Analysis Report
[ ] Manufacturer Supplied Data
[ ] Similarity or Documented Record

Specify:

The primary containment for the $1 \mathrm{~L}$ versions is the bottle and lid itself. The inner bottles have an ullage of approximately 10 percent for liquid transport. The $1 \mathrm{~L}$ bottles are required to remain intact and not break because it is a part of the identified containment system. The shipper must either use the same $1 \mathrm{~L}$ bottles that were approved during testing (either a wide-mouth poly bottle with poly lid [Nalgene 2105-0032] or wide-mouth glass jar [I-Chem 321-1000]) and black phenolic lid with polyethylene liner [Qorpak 5082]), or document that if a different bottle/lid are used they are equivalent to what was used during testing.

The $1 \mathrm{~L}$ bottles are bagged twice in an appropriately sized bag. The $1 \mathrm{~L}$ bottle lids are secured by taping circumferentially around the lid/bottle interface with 2-in.-wide PVC film tape. Refer to Appendix B of this final evaluation report or HNF-13819, Appendix A, for the specific loading instructions that were used during testing for the $1 \mathrm{~L}$ bottle configurations.

Primary containment for the 30,125 , and $250 \mathrm{~mL}$ versions is provided by the Type 304 stainless steel shielded assemblies that are secured with 8-32UNC-3A screws that are torqued 1.9 to $2.0 \mathrm{~N}-\mathrm{m}$ (17 to $18 \mathrm{in}-\mathrm{lb})$. The cover and base of the shielded assemblies have a Nitrile o-ring gasket. The shielded assemblies were pressure-tested in 1995 under Docket 94-39-7A (DOE/RL-96-57, Vol. 1) by reducing the external pressure to $20.68 \mathrm{kPa}(3.0 \mathrm{psia})$ and holding for 15 minutes. All assemblies achieved a reduced pressure of $20.68 \mathrm{kPa}(3.0$ psia). Therefore, a pressure differential of $79.22 \mathrm{kPa}(11.49 \mathrm{psi})$ was achieved. Refer to WHC-SD-TP-OTR001 of DOE/RL-96-57, Vol. 1, for detailed information regarding the containment boundary verification procedure that was performed in 1995 on the stainless steel shielded assemblies before and after testing. The design of the shielded assemblies used in the Hedgehog-II packaging configurations is basically the same as 
the original Hedgehog packaging. The only design modification is that an option has been allowed for use of Torx flat head cap screws in lieu of the socket head cap screws. Torx screws offer more resistance to stripping out than the regular socket screws offer.

The secondary containment for all configurations is provided by the NFT can assembly, which includes threaded lid, canister base, and gasket. The NFT can assembly is made from Type 304 stainless steel. The gasket material is made from Viton (V835-75). The NFT can assembly was manufacturer-tested and also verified during DOT-7A Type A testing to withstand an internal pressure of $103 \mathrm{kPa}$ (15 psi) differential pressure (see HNF-13819).

Refer to IATA, Section 10.6.1.2.5 (IATA 2003).

NOTE: This IATA requirement states, "The containment system must retain its radioactive contents under a reduction of ambient pressure to $60 \mathrm{kPa}(8.7 \mathrm{psi})$," which differs from DOT requirements.

\subsection{2(g) Valve - Protection, Enclosure.}

(g) Each valve, other than a pressure relief device, is provided with an enclosure to retain any leakage.

This requirement applies to DOT-7A Type A packagings. Indicate below the type of documentation that shows this requirement is met and where the documentation can be found.
Addressed in:
[ ] Drawing
[ ] Operating Instruction
[] Specification
[ ] Manufacturer Supplied Data
[] Analysis Report
[ ] Similarity or Documented Record

Specify:

There are no valves used in the Hedgehog-II packaging configurations; therefore, this requirement is not applicable.

Refer to IATA, Section 10.6.2.1.2.6 (IATA 2003). 


\subsection{2(h) Shielding (Enclosure).}

(h) Any radiation shield that encloses a component of the packaging specified as part of the containment system will prevent the unintentional escape of that component from the shield.

This requirement applies to DOT-7A Type A packagings. Indicate below the type of documentation that shows this requirement is met and where the documentation can be found.
Addressed in:
[ $\mathbf{X}$ ] Drawing
[ ] Operating Instruction
[] Specification
[ ] Manufacturer Supplied Data
[ X ] Analysis Report
[ ] Similarity or Documented Record

Specify:

The $1 \mathrm{~L}$ versions of the Hedgehog-II do not utilize shielding.

The stainless steel shielded assemblies are held together with 8-32UNC-3A screws that are torqued to 1.9 to $2.0 \mathrm{~N}-\mathrm{m}$ (17 to $18 \mathrm{in}-\mathrm{lb})$. There is a Nitrile o-ring in the cover and base of each assembly. The assemblies act as both shielding and containment. When serving as a shield, the assemblies retain the inner container shield. The amount of shielding provided by these assemblies is identified below:

$$
\begin{aligned}
& 30 \mathrm{~mL}=3.81 \mathrm{~cm}(1.5 \mathrm{in} .) \\
& 125 \mathrm{~mL}=2.54 \mathrm{~cm}(1.0 \mathrm{in} .) \\
& 250 \mathrm{~mL}=1.27 \mathrm{~cm}(0.5 \mathrm{in} .)
\end{aligned}
$$

The $1 \mathrm{~L}$ bottle and shielded assemblies are held within the NFT can assembly, which has a lid-locking mechanism that is engaged to the proper torque when the lid is screwed on. The NFT can assembly is not considered as shielding, but provides secondary containment and retains the primary containment.

Refer to IATA, Section 10.6.2.1.2.7 (IATA 2003).

\subsection{2(i) Tiedown (Failure).}

(i) Failure of any tie-down attachment that is a structural part of the packaging, under both normal and accident conditions, must not impair the ability of the package to meet other requirements of this subpart.

This requirement applies to DOT-7A Type A packagings. Indicate below the type of documentation that shows this requirement is met and where the documentation can be found.
Addressed in:
[ ] Drawing
[ ] Operating Instruction
[] Specification
[ ] Manufacturer Supplied Data
[] Analysis Report
[ ] Similarity or Documented Record

Specify:

There are no tie-down attachments on the Hedgehog-II packaging. The handles of the Hardigg Case may be used for tie-downs. These handles are attached with rivets to metal plates that are molded into the Hardigg Case. The strength of these handles is up to $227 \mathrm{~kg}(500 \mathrm{lb})$. If the handle fails, the rivets are designed to break away, preventing the case from rupturing.

The packaging is to be secured to a conveyance by the commercial carrier.

Refer to IATA, Section 10.6.2.1.1.3 (IATA 2003). 


\subsection{2(i) Evaluation and Testing.}

(j) When evaluated against the performance requirements of this section and the tests specified in $\$ 173.465$ or using any of the methods authorized by $\$ 173.461$ (a), the packaging will prevent--

(1) Loss or dispersal of the radioactive contents; and

(2) A significant increase in the radiation levels recorded or calculated at the external surfaces for the condition before the test.

NOTE: A significant increase may be defined as, "Loss of shielding integrity which would result in more than 20 percent increase in the radiation level at any external surface of the package" (IAEA 2000, para. 646, and IATA 2003).

This requirement applies to DOT-7A Type A packagings. Indicate below the type of documentation that shows this requirement is met and where the documentation can be found.
Addressed in:
[ ] Drawing
[] Specification
[ ] Operating Instruction
[ X ] Analysis Report
[ ] Manufacturer Supplied Data
[ ] Similarity or Documented Record

Specify:

Air transport and international regulations differ from DOT requirements (see "note" above). In these instances, the shipper must ensure that the radiation level at any surface of the packaging would not increase by more than 20 percent as a result of the decrease in distance to the center of the package load. The internal load needs to be taken into account during transportation.

Damage information from conducting testing activities is identified within the following sections of this PQCL:

- Vibration test-Section 8.0 (49 CFR 178.608)

- Containment boundary verification-Section 4.7 (49 CFR 173.465[c][1]); Section 4.8 (49 CFR 173.466[a]); and Section 8.0 (49 CFR 178.608)

- $1.2 \mathrm{~m}$ (4-ft) drop test-Section 4.7 (49 CFR 173.465[c])

- $9 \mathrm{~m}$ (30-ft) drop test-Section 4.8 (49 CFR 173.466[a])

Because of similarity in design, the Hedgehog-II packaging configurations and the original Hedgehog design (tested in 1995 under Docket 94-39-7A) were compared. Documentation is available by referencing DOE/RL96-57, Vol. 1 or WHC-SD-OTR-001. This comparison included the following tests that are documented herein:

- Water spray test-Section 4.7 (49 CFR 173.465[b])

- $1 \mathrm{~m}$ (3.3-ft) penetration bar drop test-Section 4.7 (49 CFR 173.465[e])

- $1.7 \mathrm{~m}$ (5.5-ft) penetration bar drop test-Section 4.8 (49 CFR 173.466[a])

- Stack test-Section 4.7 (49 CFR 173.465[d])

Refer to IATA, Section 10.6.2.1.1.6 (IATA 2003) and IAEA 2000 (paragraph 646). 


\subsection{2(k) Design Requirement for Liquid Packagings.}

(k) Each packaging designed for liquids will-

(1) Be designed to provide for ullage to accommodate variations in temperature of the contents, dynamic affects and filling dynamics;

This requirement applies to DOT-7A Type A packagings for use in transporting liquids. Based on the packaging design, indicate below if the requirement applies or not. If the requirement applies, identify the type of documentation that shows this requirement is met and where the documentation can be found.

This requirement: [ ] Does not apply. [X] Applies; indicate the following.
Addressed in:
[] Drawing
[] Specification
[ X ] Operating Instruction
[ X ] Analysis Report
[] Manufacturer Supplied Data
[] Similarity or Documented Record

Specify:

The operating instructions (HNF-11651) shall indicate that all bottles filled with liquid contents will be filled, leaving 10 percent ullage to allow for any expansion of the contents.

As identified in prior sections, the materials of construction for the Hedgehog-II meet the temperature range requirements identified in 49 CFR $173.412(c)$.

Refer to IATA, Section 10.6.2.1.3.3 (IATA 2003).

\subsection{2(k)(2) Evaluation and Testing of Liquid Packagings.}

(2) Meet the conditions prescribed in paragraph (j) of this section when subjected to the tests specified in $\$ 173.466$ or evaluated against these tests by any of the methods authorized by $\$ 173.461(a) ;$ and

This requirement applies to DOT-7A Type A packagings for use in transporting liquids. Based on the packaging design, indicate below if the requirement applies or not. If the requirement applies, identify the type of documentation that shows this requirement is met and where the documentation can be found.

This requirement: [ ] Does not apply. [X ] Applies; indicate the following.

$\begin{array}{lll}\text { Addressed in: } & \text { [ ] Drawing } & \text { [ ] Operating Instruction } \\ & \text { [ ] Specification } & \text { [ ] Manufacturer Supplied Data } \\ & \text { [X] Analysis Report } & \text { [] Similarity or Documented Record }\end{array}$

Specify:

The Hedgehog-II packaging configurations underwent testing activities as identified within the following sections of this PQCL:

- Vibration test-Section 8.0 (49 CFR 178.608)

- Containment boundary verification-Section 4.7 (49 CFR 173.465[c][1]); Section 4.8 (49 CFR 173.466[a]); and Section 8.0 (49 CFR 178.608).

- $\quad 1.2 \mathrm{~m}$ (4-ft) drop test-Section 4.7 (49 CFR 173.465[c])

- $9 \mathrm{~m}$ (30-ft) drop test-Section 4.8 (49 CFR 173.466[a]) 
Because of similarity in design, the Hedgehog-II packaging configurations and the original Hedgehog design (tested in 1995 under Docket 94-39-7A) were compared. Documentation is available by referencing DOE/RL96-57, Vol. 1 or WHC-SD-OTR-001. This comparison included the following tests that are documented herein:

- Water spray test-Section 4.7 (49 CFR 173.465[b])

- $1 \mathrm{~m}$ (3.3-ft) penetration bar drop test-Section 4.7 (49 CFR 173.465[e])

- $1.7 \mathrm{~m}$ (5.5-ft) penetration bar drop test-Section 4.8 (49 CFR 173.466[a])

- Compression test-Section 4.7 (49 CFR 173.465[d])

Refer to IATA, Section 10.6.2.1.3.1 (IATA 2003).

\subsection{2(k)(3) Choice of Design Requirement for Liquid Packagings.}

(3) Either--

(i) Have sufficient suitable absorbent material to absorb twice the volume of the liquid contents. The absorbent material must be compatible with the package contents and suitably positioned to contact the liquid in the event of leakage; or

(ii) Have a containment system composed of primary inner and secondary outer containment components designed to assure retention of the liquid contents within the secondary outer component in the event that the primary inner component leaks.

This requirement applies to DOT-7A Type A packagings for use in transporting liquids. Based on the packaging design, indicate below if the requirement applies or not. If the requirement applies, identify the type of documentation that shows this requirement is met and where the documentation can be found.

This requirement:

Addressed in:

Specify:
[] Does not apply.

$[\mathbf{X}]$ Drawing

$[\mathbf{X}]$ Specification

[X] Analysis Report
[X ] Applies; indicate the following.

[] Operating Instruction

[ X ] Manufacturer Supplied Data

[] Similarity or Documented Record

The Hedgehog-II relies on two levels of containment for all versions tested. The 30, 125, and $250 \mathrm{~mL}$ versions rely on the stainless steel shielded assemblies for primary containment. The $1 \mathrm{~L}$ version requires that the bottle remain intact and not break because it is a part of the identified containment system. The shipper must either use the same $1 \mathrm{~L}$ bottle/lid combinations that were approved during testing, or document that if a different bottle/lid are used they are equivalent to what was used during testing. In addition, the $1 \mathrm{~L}$ lid/bottle interface must be secured circumferentially with 2-in.-wide PVC film tape.

The secondary containment, the NFT can assembly, is made from stainless steel and incorporates a Nitrile gasket within the threaded lid closure as well as a lid-locking mechanism that is engaged to the proper torque when the lid is screwed on. The primary containment system, once placed inside the secondary containment system, is surrounded and cushioned by top, bottom, and side shock protectors made from white EVA foam having a density of $2 \mathrm{lb} / \mathrm{ft}^{2}$. Depending on the configuration to be shipped, additional packing materials consisting of either a belleville washer (made from 17/7-PH stainless steel) and/or a stainless steel disc (made from 11-gauge sheet) are inserted prior to closure of the secondary containment. These additional packing materials act as a spring and a load spreader, providing protection to both the primary and secondary containment systems.

Refer to IATA, Section 10.6.2.1.3.2 (IATA 2003). 
HNF-13820, Rev. 0

\subsection{2(l) Evaluation and Testing of Gas Packagings.}

(l) Each packaging designed for gases, other than tritium not exceeding $40 \mathrm{TBq}(1000 \mathrm{Ci})$ or noble gases not exceeding the A2 value appropriate for the noble gas, will be able to prevent loss or dispersal of contents when the package is subjected to the tests prescribed in $\$ 173.466$ or evaluated against these tests by any of the methods authorized by $\$ 173.461$ (a).

This requirement applies to DOT-7A Type A packagings for use in transporting gases. Based on the packaging design, indicate below if the requirement applies or not. If the requirement applies, identify the type of documentation that shows this requirement is met and where the documentation can be found.

This requirement: [ [ $\quad[$ ] Does not apply. [ ] Applies; indicate the following.
Addressed in:
[ ] Drawing
[] Specification
[ ] Operating Instruction
[ ] Analysis Report
[ ] Manufacturer Supplied Data
[ ] Similarity or Documented Record

Specify:

Gaseous contents are not authorized for use in the Hedgehog-II packaging configurations; therefore, this requirement is not applicable.

Refer to IATA, Section 10.6.2.1.4.1 (IATA 2003). 


\title{
4.7 49 CFR 173.465 TYPE A PACKAGING TESTS.
}

\author{
173.465(a) Packaging Tests.
}

(a) The packaging, with contents, must be capable of withstanding the water spray, free drop, stacking and penetration tests prescribed in this section. One prototype may be used for all tests if the requirements of paragraph (b) of this section are met.

This requirement applies to DOT-7A Type A packagings. Indicate below the type of documentation that shows this requirement is met and where the documentation can be found.
Addressed in:
[ ] Drawing
[] Specification
[ ] Operating Instruction
[ X ] Analysis Report
[ ] Manufacturer Supplied Data
[ ] Similarity or Documented Record

Specify:

Testing and evaluation activities for the Hedgehog-II packaging configurations are described herein. Activities were administered and witnessed by DTS in March and April 2003. Physical test facilities utilized were located at PNNL, 318 Facility, 300 Area (vibration testing); and HiLine Engineering and Fabrication, Richland, Washington (drop testing and leak testing).

Refer to IATA, Section 10.6.3.4 (IATA 2003).

\subsection{5(b) Water Spray.}

(b) Water spray test. The water spray test must precede each test or test sequence prescribed in this section. The water spray test must simulate exposure to rainfall of approximately 5 centimeters ( 2 inches) per hour for at least one hour. The time interval between the end of the water spray test and the beginning of the next test must be such that the water has soaked in to the maximum extent without appreciable drying of the exterior of the specimen. In the absence of evidence to the contrary, this interval may be assumed be two hours if the water spray is applied from four different directions simultaneously. However, no time interval may elapse if the water spray is applied from each of the four directions consecutively.

This requirement applies to DOT-7A Type A packagings. Indicate below the type of documentation that shows this requirement is met and where the documentation can be found.
Addressed in:
[ ] Drawing
[] Specification
[ ] Operating Instruction
[ X ] Analysis Report
[ ] Manufacturer Supplied Data
[ $\mathbf{X}$ ] Similarity or Documented Record

Specify:

Because of similarity in design to the original Hedgehog packaging, the water spray test was not conducted on the Hedgehog-II packaging. Therefore, this requirement is met. A summary of the information from testing conducted in 1995 under Docket 94-39-7A (DOE/RL-96-57, Vol. 1 and WHC-SD-TP-OTR-001) follows.

The water spray test was conducted after the vibration test. Test unit 39-TU-02 (empty Hardigg Case) was subjected to the water spray conditions for 1 hour with no adverse affect or loss of contents. Water collected on the top, exterior of the case as the case would normally be positioned during transportation. The exterior of the case is a rotationally molded polyethylene material and has rounded edges. Water flowed over the rounded edges of the case lid and stopped once it reached the interior gasket material. The Hardigg Case lid incorporates a split gasket (split is located at the bottom of the packaging as it is normally positioned during 
transport). Attachment rivets connect to metal plates that are molded into the Hardigg Case. The Hardigg Case was opened and the internal foam material examined for any deterioration or wetness. There was no inleakage of water, even though the Hardigg Case lid gasket is split. Water did not cause damage or deterioration to the exterior or interior of the packaging.

No other packages were water spray tested in 1995 as water did not have any adverse affects on the packaging.

Refer to IATA, Sections 10.6.3.4.1 and 10.6.3.4.2 (IATA 2003).

\subsection{5(c) Free Drop.}

(c) Free drop test. The specimen must drop onto the target so as to suffer maximum damage to the safety features being tested, and:

This requirement applies to DOT-7A Type A packagings. Indicate below the type of documentation that shows this requirement is met and where the documentation can be found.
Addressed in:
[ ] Drawing
[] Specification
[] Operating Instruction
[ X ] Analysis Report
[] Manufacturer Supplied Data
[] Similarity or Documented Record

Specify:

Several drop tests were performed on the Hedgehog-II packaging configurations as identified in the following paragraphs. The orientations chosen were intended to challenge the containment boundaries and the integrity of the packaging design.

Refer to IATA, Section 10.6.3.4.3 (IATA 2003). 


\subsection{5(c)(1) Free Drop.}

(1) The height of the drop measured from the lowest point of the specimen to the upper surface of the target may not be less than the distance specified in Table 12, for the applicable package mass. The target must be as specified in $\S 173.465(c)(5)$. Table 12 is as follows:

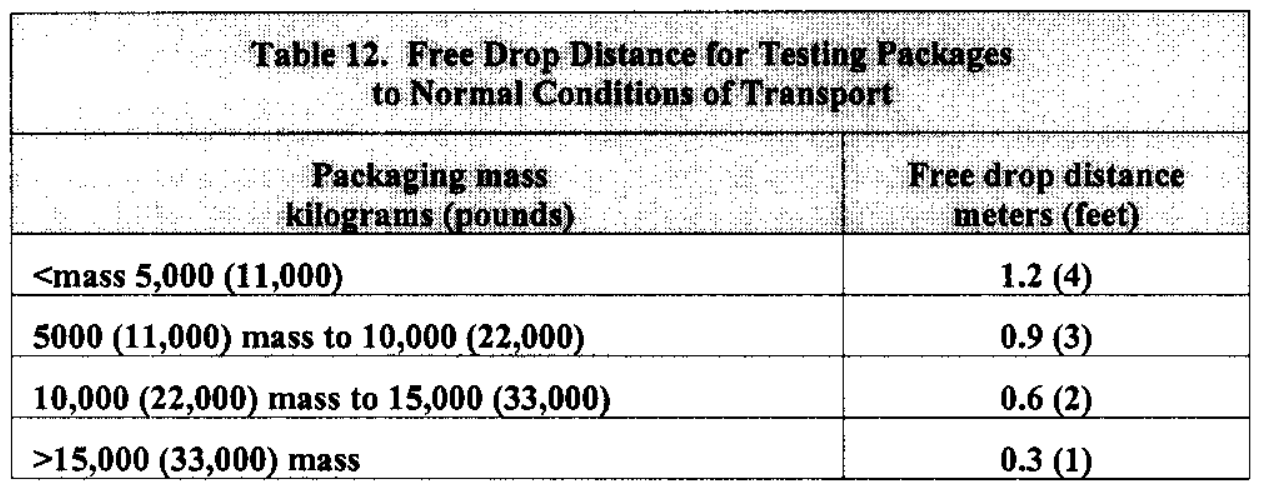

This requirement applies to DOT-7A Type A packagings. Indicate below the type of documentation that shows this requirement is met and where the documentation can be found.
Addressed in:
[ ] Drawing
[] Specification
[ X ] Analysis Report
[] Operating Instruction
[ ] Manufacturer Supplied Data
[ ] Similarity or Documented Record

Specify:

(For detailed test information, refer to the test plan, HNF-13819.) Prior to the start of testing, a containment boundary verification was performed on the NFT can assemblies. Compressed air was used to pressurize the NFT can assembly to $103 \mathrm{kPa}$ (15 psi) and this pressure was held for 5 minutes. The pressure gauges were checked for any drop in pressure, and the NFT can assemblies were checked for leakage by coating/brushing a low-viscosity soap bottle solution around the threaded lid closure. All tested NFT can assemblies passed this initial, pre-test, verification process.

The vibration testing was completed after the initial containment boundary verification. The Hedgehog-II, 1 $\mathrm{L}$ bottle configurations (glass and poly) were initially tested for liquids having a specific gravity of $\leq 2.0$. During testing activities, the $1 \mathrm{~L}$ poly bottle configuration performed adequately. However, the $1 \mathrm{~L}$ glass configuration that consisted of the I-Chem wide-mouth glass jar having a black phenolic lid with polyvinyl liner (Qorpak 5024) did not pass the vibration and $9 \mathrm{~m}(30-\mathrm{ft})$ drop tests. Therefore, two design changes were made. The bottle lid was changed to include a black phenolic lid with polyethylene liner (Qorpak 5082), and the loading of the contents was reduced to simulate a liquid having a specific gravity of $\leq 1.6$. This combination of changes was successful for the $1 \mathrm{~L}$ glass configuration. Refer to Section 8.0 of this PQCL or HNF-13819 for specific information regarding the vibration tests.

The $9 \mathrm{~m}$ (30-ft) drop tests were conducted prior to the $1.2 \mathrm{~m}$ (4-ft) drop tests. Upon conclusion of the $9 \mathrm{~m}$ $(30-\mathrm{ft})$ drop tests, a second containment boundary verification was performed on the NFT can assemblies. Refer to Section 4.8 of this PQCL or HNF-13819 for specific information regarding the $9 \mathrm{~m}$ (30-ft) drop tests.

Because of similarity in design to the original Hedgehog packaging, the water spray test was not conducted prior to conducting the $1.2 \mathrm{~m}$ (4-ft) drop tests. Refer to response provided in $\$ 173.465(\mathrm{~b})$.

The packages shown in Table A-5 were subjected to drop tests from a height of $1.2 \mathrm{~m}$ ( $4 \mathrm{ft}$ ). The as-tested and approved $1 \mathrm{~L}$ glass bottle configuration that was used in the $1.2 \mathrm{~m}$ (4-ft) drop test included the wide-mouth 
glass jar (I-Chem 321-1000) with the black phenolic lid with polyethylene liner (Qorpak 5082). The specific gravity for the simulated liquid was $\leq 1.6$. The $1 \mathrm{~L}$ poly bottle configuration and shielded configurations remained as originally identified within the test plan and were tested with a simulated liquid having a specific gravity of $\leq 2.0$. The circumference around the $1 \mathrm{~L}$ bottle/lid interface (both glass and poly bottles) must be secured with 2-in.-wide PVC film tape.

Because of the leak testing success encountered with the performance of the NFT can assemblies after the $9 \mathrm{~m}$ (30-ft) drop tests, the containment boundary verification (leak testing) was not performed on the NFT can assemblies upon the conclusion of the $1.2 \mathrm{~m}$ (4-ft) drop tests for the $1 \mathrm{~L}$ bottle (glass and poly) configurations. Upon conclusion of the $1.2 \mathrm{~m}$ (4-ft) drop test series for the shielded configuration, a leak test was successfully performed on one identified test unit (Drop 16).

By evaluation and comparison with similar materials, it was determined that the $125 \mathrm{~mL}$ and $250 \mathrm{~mL}$ versions would have no negative impact on the overall performance of the Hardigg Case, NFT can assembly, and inner and outer stainless steel shielded assemblies. The 125 and $250 \mathrm{~mL}$ versions are lighter in weight compared to the $30 \mathrm{~mL}$ version that was tested.

Refer to IATA, Section 10.6.3.4.3(a) and Table 10.6.B (IATA 2003).

Table A-5. Drop Tests- $1.2 \mathrm{~m}(4 \mathrm{ft})$.

\begin{tabular}{|c|c|c|c|}
\hline $\begin{array}{l}\text { Test Identification, Results, } \\
\text { and Drop Orientation }\end{array}$ & Packaging Components & $\begin{array}{c}\text { Component } \\
\text { Weight }\end{array}$ & $\begin{array}{l}\text { Gross: } \\
\text { Package } \\
\text { Weight }\end{array}$ \\
\hline $\begin{array}{l}\text { Drop } 11 \text { (1 L Plastic)-Pass } \\
\text { (4 ft; flat onto side at base) }\end{array}$ & $\begin{array}{l}\text { Hardigg Case: HH2-TU-02 } \\
\text { NFT Can Assembly: HH-007 } \\
1 \text { L Plastic Bottle: P-4 }\end{array}$ & $\begin{array}{r}30.0 \mathrm{lb} \\
5.1 \mathrm{lb} \\
4.5 \mathrm{lb}\end{array}$ & $39.6 \mathrm{lb}$ \\
\hline $\begin{array}{l}\text { Drop } 12 \text { (1 L Plastic)-Pass } \\
\text { (4 ft; flat onto bottom) }\end{array}$ & $\begin{array}{l}\text { Hardigg Case: HH2-TU-02 } \\
\text { NFT Can Assembly: HH-007 } \\
\text { 1 L Plastic Bottle: P-5 }\end{array}$ & $\begin{array}{r}30.0 \mathrm{lb} \\
5.1 \mathrm{lb} \\
4.4 \mathrm{lb}\end{array}$ & $39.5 \mathrm{lb}$ \\
\hline $\begin{array}{l}\text { Drop } 13 \text { (1 L Plastic)-Pass } \\
\text { (4 ft; flat onto top) }\end{array}$ & $\begin{array}{l}\text { Hardigg Case: HH2-TU-02 } \\
\text { NFT Can Assembly: HH-007 } \\
1 \text { L Plastic Bottle: P-6 }\end{array}$ & $\begin{array}{r}30.0 \mathrm{lb} \\
5.1 \mathrm{lb} \\
4.4 \mathrm{lb}\end{array}$ & $39.5 \mathrm{lb}$ \\
\hline $\begin{array}{l}\text { Drop } 14 \text { (Shielded)_Pass } \\
\text { (4 ft; flat onto bottom) }\end{array}$ & $\begin{array}{l}\text { Hardigg Case: HH2-TU-01 (refurbished) } \\
\text { NFT Can Assembly: HH-005 } \\
\text { Outer Shield: 006959-02-250-A } \\
\text { Inner Shield: 006959-02-30-A } \\
30 \mathrm{~mL} \text { bottle } \\
\text { Disk } \\
\text { Belleville Washer } \\
\text { Nylon Inserts (2) } \\
\end{array}$ & $\begin{array}{r}30.1 \mathrm{lb} \\
5.2 \mathrm{lb} \\
15.7 \mathrm{lb} \\
12.6 \mathrm{lb} \\
0.2 \mathrm{lb} \\
1.1 \mathrm{lb} \\
1.1 \mathrm{lb} \\
2.9 \mathrm{lb} \\
\end{array}$ & $68.9 \mathrm{lb}$ \\
\hline $\begin{array}{l}\text { Drop } 15 \text { (Shielded)-Pass } \\
\text { (4 ft; flat onto top) }\end{array}$ & $\begin{array}{l}\text { Hardigg Case: HH2-TU-01 (refurbished) } \\
\text { NFT Can Assembly: HH-005 } \\
\text { Outer Shield: 006959-02-250-A } \\
\text { Inner Shield: 006959-02-30-A } \\
30 \mathrm{~mL} \text { bottle } \\
\text { Disk } \\
\text { Belleville Washer } \\
\text { Nylon Inserts (2) }\end{array}$ & \begin{tabular}{r|}
$30.1 \mathrm{lb}$ \\
$5.2 \mathrm{lb}$ \\
$15.7 \mathrm{lb}$ \\
$12.6 \mathrm{lb}$ \\
$0.2 \mathrm{lb}$ \\
$1.1 \mathrm{lb}$ \\
$1.1 \mathrm{lb}$ \\
$2.9 \mathrm{lb}$ \\
\end{tabular} & $68.9 \mathrm{lb}$ \\
\hline
\end{tabular}


HNF-13820, Rev. 0

Table A-5. Drop Tests-1.2 m (4 ft).

\begin{tabular}{|c|c|c|c|}
\hline $\begin{array}{l}\text { Test Identification, Results, } \\
\text { and Drop Orientation }\end{array}$ & Packaging Components & $\begin{array}{l}\text { Component } \\
\text { Weight }\end{array}$ & $\begin{array}{l}\text { Gross } \\
\text { Package } \\
\text { Weight }\end{array}$ \\
\hline $\begin{array}{l}\text { Drop } 16 \text { (Shielded)—Pass } \\
\text { (4 ft; flat onto side at lid) }\end{array}$ & $\begin{array}{l}\text { Hardigg Case: HH2-TU-01 (refurbished) } \\
\text { NFT Can Assembly: HH-005 } \\
\text { Outer Shield: 006959-02-250-A } \\
\text { Inner Shield: 006959-02-30-A } \\
30 \mathrm{~mL} \text { bottle } \\
\text { Disk } \\
\text { Belleville Washer } \\
\text { Nylon Inserts (2) }\end{array}$ & $\begin{array}{r}30.1 \mathrm{lb} \\
5.2 \mathrm{lb} \\
15.7 \mathrm{lb} \\
12.6 \mathrm{lb} \\
0.2 \mathrm{lb} \\
1.1 \mathrm{lb} \\
1.1 \mathrm{lb} \\
2.9 \mathrm{lb}\end{array}$ & $68.9 \mathrm{lb}$ \\
\hline $\begin{array}{l}\text { Drop } 22 \text { (1 L Glass)*-Pass } \\
\text { (4 ft; flat onto bottom) }\end{array}$ & $\begin{array}{l}\text { Hardigg Case: HH2-TU-04 } \\
\text { NFT Can Assembly: HH-002 } \\
\text { 1 L Glass Bottle: Bottle \#2 (4-14-03)** } \\
\text { Disk }\end{array}$ & $\begin{array}{r}30.2 \mathrm{lb} \\
5.1 \mathrm{lb} \\
3.8 \mathrm{lb} \\
1.1 \mathrm{lb} \\
\end{array}$ & $40.2 \mathrm{lb}$ \\
\hline $\begin{array}{l}\text { Drop } 23 \text { (1 L Glass)*--Pass } \\
\text { (4 ft; flat onto top) }\end{array}$ & $\begin{array}{l}\text { Hardigg Case: HH2-TU-04 } \\
\text { NFT Can Assembly: HH-002 } \\
1 \text { L Glass Bottle: Bottle \#2 (4-14-03)** } \\
\text { Disk }\end{array}$ & $\begin{array}{r}30.2 \mathrm{lb} \\
5.1 \mathrm{lb} \\
3.8 \mathrm{lb} \\
1.1 \mathrm{lb}\end{array}$ & $40.2 \mathrm{lb}$ \\
\hline $\begin{array}{l}\text { Drop } 24 \text { (1 L Glass)*_-Pass } \\
\text { (4 ft; flat onto side at lid) }\end{array}$ & $\begin{array}{l}\text { Hardigg Case: HH2-TU-04 } \\
\text { NFT Can Assembly: HH-002 } \\
1 \text { L Glass Bottle: Bottle \#2 (4-14-03)** } \\
\text { Disk }\end{array}$ & $\begin{array}{r}30.2 \mathrm{lb} \\
5.1 \mathrm{lb} \\
3.8 \mathrm{lb} \\
1.1 \mathrm{lb}\end{array}$ & $40.2 \mathrm{lb}$ \\
\hline
\end{tabular}

* $1 \mathrm{~L}$ glass bottle tested included the phenolic lid and polyethylene liner (Qorpak 5082).

** $1 \mathrm{~L}$ glass bottle tested was previously used and identified as Bottle \#1 (4-14-03). Additional sand was added to simulate a liquid having a specific gravity of 1.6 , and the bottle was then marked as Bottle \#2. This bottle was used several times as indicated.

\section{RESULTS:}

Drop 11: Pass. This test unit was dropped flat to impact the side of the package as it would normally be positioned during transport. The side impacted was the base of the Hardigg Case. This was the third drop with HH2-TU-02. Due to the damage that occurred to the case lid from the previous drop (See Table A-5 and Drop 10 which resulted in a crack in the case lid), the particular "side" chosen for the drop was changed from the lid of the case to the base of the case. The lid and the base of the case each have the same amount of foam cushioning. The internal foam configuration was changed from the shielded version to the $1 \mathrm{~L}$ bottle version prior to this drop test. There was no additional damage to the Hardigg Case and internal foam after this drop test. A leak test was not performed on the NFT can assembly because this component performed successfully throughout the $9 \mathrm{~m}(30-\mathrm{ft})$ drop tests that were conducted prior to the $1.2 \mathrm{~m}(4-\mathrm{ft})$ drop tests. The $1 \mathrm{~L}$ plastic bottle was loaded to simulate a liquid having a specific gravity of 2.0 . The $1 \mathrm{~L}$ plastic bottle lid was secured with 2-in.-wide PVC film tape, and the bottle was double-bagged as identified in HNF-13819. There was no leakage from the bottle. Four to five drops of liquid were noted in the threaded lid area of the bottle. No other damage occurred to the other packing/cushioning materials. No shifting of contents was evident.

Drop 12: Pass. This test unit was dropped flat to impact the bottom of the package as it would normally be positioned during transport. This was the fourth drop with HH2-TU-02, and there was no additional damage to the Hardigg Case and internal foam. A leak test was not performed on the NFT can assembly because this

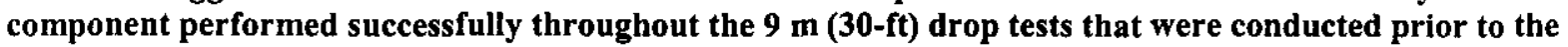
$1.2 \mathrm{~m}$ (4-ft) drop tests. The $1 \mathrm{~L}$ plastic bottle was loaded to simulate a liquid having a specific gravity of 2.0. The $1 \mathrm{~L}$ plastic bottle lid was secured with 2-in.-wide PVC film tape, and the bottle was double-bagged as identified in HNF-13819. There was no leakage from the bottle. No other damage occurred to the other packing/cushioning materials. No shifting of contents was evident. 
Drop 13: Pass. This test unit was dropped flat to impact the top of the package as it would normally be positioned during transport. This was the fifth drop with HH2-TU-02, and there was no additional damage to the Hardigg Case and internal foam. A leak test was not performed on the NFT can assembly because this

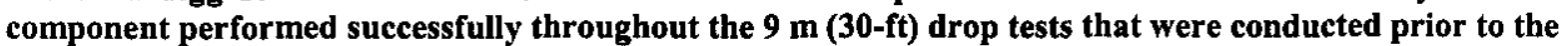
$1.2 \mathrm{~m}$ ( $4 \mathrm{ft}$ ) drop tests. The $1 \mathrm{~L}$ plastic bottle was loaded to simulate a liquid having a specific gravity of 2.0 . The $1 \mathrm{~L}$ plastic bottle lid was secured with 2-in.-wide PVC film tape, and the bottle was double-bagged as identified in HNF-13819. There was no leakage from the bottle. Liquid was noted only in the threaded area of the bottle/lid. No other damage occurred to the other packing/cushioning materials. No shifting of contents was evident.

Drop 14: Pass. This test unit was dropped flat to impact the bottom of the package as it would normally be positioned during transport. This was the first drop with the "refurbished" HH2-TU-01 case. Refurbishment consisted of the case distributor (Bauer Cases, Vancouver, Washington) replacing the external latches and hinges. In addition, the internal foam in the lid of the case was replaced with new foam. Upon conclusion of this drop test it was discovered that the ABS load spreader was slightly bent due to the impact of the NFT can assembly onto this component. A leak test was not performed on the NFT can assembly because this component performed successfully throughout the $9 \mathrm{~m}$ (30-ft) drop tests that were conducted prior to the $1.2 \mathrm{~m}$ (4-ft) drop tests. There was no damage to the NFT can or shielded assemblies. No other damage occurred to the other packing/cushioning materials. No shifting of contents was evident.

Drop 15: Pass. This test unit was dropped flat to impact the top of the package as it would normally be positioned during transport. This was the second drop with the "refurbished" HH2-TU-01 case. (See Drop 14 for refurbishment information). Upon conclusion of this drop test, slight marring of the foam situated in the lid of the case was evident. A leak test was not performed on the NFT can assembly because this

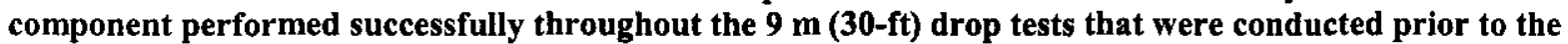
$1.2 \mathrm{~m}$ (4-ft) drop tests. There was no damage to the NFT can or shielded assemblies. No other damage occurred to the other packing/cushioning materials. No shifting of contents was evident.

Drop 16: Pass. This test unit was dropped flat to impact the side of the package as it would normally be positioned during transport. The side impacted was the lid of the case. This was the third drop with the "refurbished" HH2-TU-01 case. (See Drop 14 for refurbishment information). Upon conclusion of this drop test, the impression of the NFT can assembly was evident in the bottom foam and lid foam of the case. Continued (slight) marring of the foam situated in the lid of the case was evident due to the impact of the NFT can assembly plunger mechanism. The containment boundary verification was successfully performed on the NFT can assembly after this drop. The leak test was performed for 5 minutes at a pressure of $103 \mathrm{kPa}$ (15 psi) with no leakage indicated. No damage was evident to the NFT can or shielded assemblies. There was no damage to the other packing/cushioning materials. No shifting of contents was evident.

Drop 22: Pass. This test unit was dropped flat to impact the bottom of the package as it would normally be positioned during transport. Because of the success of the previous test (See Table A-5, Drop 21), it was decided to reuse Bottle \#2 for this drop. This was the sixth drop with HH2-TU-04, and there was no additional damage to the Hardigg Case and internal foam. A leak test was not performed on the NFT can assembly because this component performed successfully throughout the $9 \mathrm{~m}$ (30-ft) drop tests that were conducted prior to the $1.2 \mathrm{~m}$ (4-ft) drop tests. The $1 \mathrm{~L}$ glass bottle included the black phenolic lid with polyethylene liner and was loaded to simulate a liquid having a specific gravity of 1.6. The $1 \mathrm{~L}$ glass bottle lid was secured with 2-in.-wide PVC film tape, and the bottle was double-bagged as identified in HNF-13819. There was no leakage from the bottle. No other damage occurred to the other packing/cushioning materials. No shifting of contents was evident.

Drop 23: Pass. This test unit was dropped flat to impact the top of the package as it would normally be positioned during transport. Because of the success of the previous test (Drop 22), it was decided to reuse Bottle \#2 for this drop. This was the seventh drop with HH2-TU-04, and there was no additional damage to the Hardigg Case and internal foam. A leak test was not performed on the NFT can assembly because this

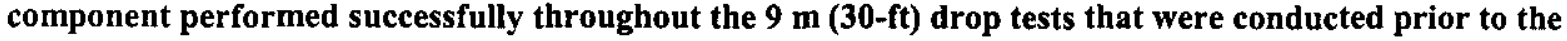
$1.2 \mathrm{~m}$ (4-ft) drop tests. The $1 \mathrm{~L}$ glass bottle included the black phenolic lid with polyethylene liner and was 
loaded to simulate a liquid having a specific gravity of 1.6. The $1 \mathrm{~L}$ glass bottle lid was secured with 2-in.wide PVC film tape, and the bottle was double-bagged as identified in HNF-13819. There was no leakage from the bottle. No other damage occurred to the other packing/cushioning materials. No shifting of contents was evident.

Drop 24: Pass. This test unit was dropped flat to impact the side of the package as it would normally be positioned during transport. The side impacted was the lid of the Hardigg Case. Because of the success of the previous test (Drop 23), it was decided to reuse Bottle \#2 for this drop. This was the eighth drop with HH2TU-04, and there was no additional damage to the Hardigg Case and internal foam. A leak test was not performed on the NFT can assembly because this component performed successfully throughout the $9 \mathrm{~m} \mathrm{(30}$ ft) drop tests that were conducted prior to the $1.2 \mathrm{~m}(4-\mathrm{ft})$ drop tests. The $1 \mathrm{~L}$ glass bottle included the black phenolic lid with polyethylene liner and was loaded to simulate a liquid having a specific gravity of 1.6. The 1 $\mathrm{L}$ glass bottle lid was secured with 2-in.-wide PVC film tape, and the bottle was double-bagged as identified in HNF-13819. There was no leakage from the bottle. No other damage occurred to the other packing/cushioning materials. No shifting of contents was evident.

NOTE: Bottle \#2 was dropped a total of 1 time from a height of $9 \mathrm{~m} \mathrm{(30-ft)} \mathrm{(See} \mathrm{Table} \mathrm{A-5)} \mathrm{and} 3$ times from

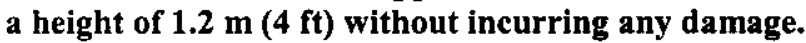

\subsection{5(c)(2) Free Drop.}

(2) For packages containing fissile material, the free drop test specified in paragraph (c)(1) of this section must be preceded by a free drop from a height of 0.3 meter ( 1 foot) on each corner, or in the case of cylindrical packages, onto each of the quarters of each rim.

This requirement applies to DOT-7A Type A packagings for use in transporting fissile material. Based on the load, indicate below if the requirement applies or not. If the requirement applies, identify the type of documentation that shows this requirement is met and where the documentation can be found.

This requirement: [ [X ] Does not apply. [ ] Applies; indicate the following.

Addressed in: [ ] Drawing

$$
\text { [] Specification }
$$

[ ] Operating Instruction

[ ] Analysis Report

[ ] Manufacturer Supplied Data

[] Similarity or Documented Record

Specify:

The Hedgehog-II packaging will not be authorized for fissile material transport; therefore, this requirement is not applicable. 


\subsection{5(c)(3) Free Drop.}

(3) For fiberboard or wood rectangular package with a mass of 50 kilograms (110 pounds) or less, a separate specimen must be subjected to a free drop onto each corner from a height of 0.3 meter (1 foot).

This requirement applies to rectangular DOT-7A Type A packagings constructed of fiberboard or wood that have a gross weight of 50 kilograms (110 pounds) or less. Based on the materials of construction and the gross weight of the package, indicate below if the requirement applies or not. If the requirement applies, identify the type of documentation that shows this requirement is met and where the documentation can be found.

This requirement: [ $\quad[\mathbf{X}]$ Does not apply. [ ] Applies; indicate the following.

Addressed in:

$$
\begin{array}{ll}
\text { [] Drawing } & \text { [ ] Operating Instruction } \\
\text { [ ] Specification } & \text { [ ] Manufacturer Supplied Data } \\
\text { [] Analysis Report } & \text { [ ] Similarity or Documented Record }
\end{array}
$$

Specify:

The Hedgehog-II packaging configurations tested and evaluated herein are not made from fiberboard or wood; therefore, this requirement is not applicable.

Refer to IATA, Section 10.6.3.4.3(b) (IATA 2003).

\subsection{5(c)(4) Free Drop.}

(4) For cylindrical fiberboard packages with a mass of 100 kilograms (220 pounds) or less, a separate specimen must be subjected to a free drop onto each of the quarters of each rim from a height of 0.3 meter ( 1 foot).

This requirement applies to cylindrical DOT-7A Type A packagings constructed of fiberboard having a gross weight of 100 kilograms (220 pounds) or less. Based on the shape and the gross weight of the package, indicate below if the requirement applies or not. If the requirement applies, identify the type of documentation that shows this

\begin{tabular}{|c|c|c|}
\hline Addressed in: & $\begin{array}{l}\text { [ ] Drawing } \\
\text { [ ] Specification } \\
\text { [] Analysis Report }\end{array}$ & $\begin{array}{l}\text { [ ] Operating Instruction } \\
\text { [ ] Manufacturer Supplied Data } \\
\text { [ ] Similarity or Documented Record }\end{array}$ \\
\hline
\end{tabular}
requirement is met and where the documentation can be found.

This requirement: [ [ $\mathbf{X}$ ] Does not apply. [ ] Applies; indicate the following.

Specify:

The Hedgehog-II packaging configurations tested and evaluated herein are not cylindrical, nor are they made from fiberboard; therefore, this requirement is not applicable.

Refer to IATA, Section 10.6.3.4.3(c) (IATA 2003). 


\subsection{5(c)(5) Free Drop.}

(5) The target for the free drop test must be a flat, horizontal surface of such mass and rigidity that any increase in its resistance to displacement or deformation upon impact by the specimen would not significantly increase the damage to the specimen.

This requirement applies to DOT-7A Type A packagings. Indicate below the type of documentation that shows this requirement is met and where the documentation can be found.
Addressed in:
[ ] Drawing
[ ] Operating Instruction
[] Specification
[ ] Manufacturer Supplied Data
[ X ] Analysis Report
[ ] Similarity or Documented Record

Specify:

The outdoor test pad used by DTS to perform drop-testing activities is located at HiLine Engineering and Fabrication, Richland, Washington. This test pad is designed to perform drop testing of packages up to $2,540.12 \mathrm{~kg}(5,600 \mathrm{lb})$. Due to the light weight of the Hedgehog-II (approximately $31.3 \mathrm{~kg}[69 \mathrm{lb}])$, this test pad is suitable for conducting the $9 \mathrm{~m}$ (30-ft) drop tests.

The combined weight of the concrete and the carbon steel plate is $25,459.23 \mathrm{~kg}(56,128 \mathrm{lb})$, which is 10 times the weight of the allowable specimen. The dimensions of the concrete pad are $295.91 \mathrm{~cm}(116.5 \mathrm{in}$.) long $x$ $279.4 \mathrm{~cm}\left(110 \mathrm{in}\right.$.) wide $\times 126.492 \mathrm{~cm}\left(49.8 \mathrm{in}\right.$.) thick. The concrete is $2.32 \mathrm{~g} / \mathrm{cm}^{3}\left(145 \mathrm{lb} / \mathrm{ft}^{3}\right), 37.474 \mathrm{MPa}$ $(5,000 \mathrm{psi})$. The total dimensions of the concrete pad are $6.1 \mathrm{~m}(20 \mathrm{ft}) \times 6.1 \mathrm{~m}(20 \mathrm{ft})$ with the hard, unyielding surface of the drop pad centered in the middle of this concrete pad. Rebar is placed on $45.72 \mathrm{~cm}(18-\mathrm{in}$.) centers throughout the pad. Rebar located in the drop pad area is bent at a 45-degree angle to a depth of $45.72 \mathrm{~cm}(18 \mathrm{in}$.) straightened horizontally across the length or width of the pad, and brought back up on the opposite side at a 45-degree angle.

Reference IATA, Section 10.6.3.3 (IATA 2003). 


\subsection{5(d) Stacking Test.}

(d) Stacking test.

(1) The specimen must be subjected for a period of at least 24 hours to a compressive load equivalent to the greater of the following:

(i) Five times the mass of the actual package; or

(ii) The equivalent of 13 kilopascals (1.9 pounds per square inch) multiplied by the vertically projected area of the package.

(2) The compressive load must be applied uniformly to two opposite sides of the specimen, one of which must be the base on which the package would normally rest.

This requirement applies to DOT-7A Type A packagings. Indicate below the type of documentation that shows this requirement is met and where the documentation can be found.
Addressed in:
[ ] Drawing
[] Specification
[ ] Operating Instruction
[ X ] Analysis Report
[] Manufacturer Supplied Data
[ $\mathbf{X}$ ] Similarity or Documented Record

Specify:

The stacking test was not conducted on the Hedgehog-II package. By evaluation in comparison with the original Hedgehog, it was determined this requirement is met. A summary of the information from testing conducted in 1995 under Docket 94-39-7A (DOE/RL-96-57, Vol. 1 and WHC-SD-TP-OTR-001) follows.

The water spray test was not conducted on the package prior to the stacking test. By evaluation in comparison to the original Hedgehog packaging, it was determined that the water spray test does not have a negative affect on the performance of the Hedgehog-II packaging, due to materials of construction and design. The compression test was successfully conducted on 39-TU-02, which was an empty packaging. The compressive load was determined by using the greater of the vertically projected area of the package as it is intended for loading and transportation and five times the estimated weight of the package. The vertically projected area was determined to be the greater load; therefore, a load of $318 \mathrm{~kg}(700 \mathrm{lb})$ was applied uniformly to two opposite sides of the package, one of which was the base on which the package would normally stand, for 24 hours. There was no deformation to the exterior of the Hardigg Case, internal foam, or ABS load spreader.

NOTE: Although the Hedgehog-II is a heavier package than the Hedgehog, the vertically projected area of the package remains greater than five times the estimated weight of the package. The external dimensions of the original Hedgehog and Hedgehog-II are identical; thus, the vertically projected area remains identical.

Refer to IATA, Section 10.6.3.4.4 (IATA 2003). 


\subsection{5(e) Penetration Test.}

(e) Penetration test. For the penetration test, the specimen must be placed on a rigid, flat, horizontal surface that will not move significantly while the test is being performed.

(1) A bar of 3.2 centimeters ( 1.25 inches) in diameter with a hemispherical end and a mass of 6 kilograms (13.2 pounds) must be dropped and directed to fall with its longitudinal axis vertical, onto the center of the weakest part of the specimen, so that, if it penetrates far enough, it will hit the containment system. The bar may not be significantly deformed by the test; and

(2) The height of the drop of the bar measured from its lower end to the intended point of impact on the upper surface of the specimen must be 1 meter (3.3 feet) or greater.

This requirement applies to DOT-7A Type A packagings. Indicate below the type of documentation that shows this requirement is met and where the documentation can be found.
Addressed in:
[ ] Drawing
[] Specification
[] Operating Instruction
[ X ] Analysis Report
[] Manufacturer Supplied Data
[ X ] Similarity or Documented Record

Specify:

The penetration test was not conducted on the Hedgehog-II package. By evaluation in comparison with the original Hedgehog, it was determined this requirement is met. A summary of the information from testing conducted in 1995 under Docket 94-39-7A (DOE/RL-96-57, Vol. 1 and WHC-SD-TP-OTR-001) follows.

The water spray test was not conducted on the package prior to the penetration test. By evaluation in comparison to the original Hedgehog packaging, it was determined that the water spray test does not have a negative affect on the performance of the Hedgehog-II packaging, due to materials of construction and design. The penetration test was successfully conducted on test unit 39-TU-02 (empty packaging). The Hardigg Case was laid flat onto the widest lengthwise side so that the impact of the penetration bar would be onto the lid of the case. Because the reinforcement bumpers are equidistant from each other (two exterior edges and the center of the case), the penetration bar was dropped in between the center bumper and one of the edge bumpers. The point of impact caused an indentation measuring $0.594 \mathrm{~cm}(0.234 \mathrm{in}$.) deep and $1.9 \mathrm{~cm}$ $(0.75$ in.) across.

Refer to IATA, Section 10.6.3.4.5 (IATA 2003). 
HNF-13820, Rev. 0

\title{
4.8 49 CFR 173.466 ADDITIONAL TESTS FOR TYPE A PACKAGING DESIGNED FOR LIQUIDS AND GASES.
}

\author{
173.466(a) Additional Tests.
}

(a) In addition to the tests prescribed in \$173.465, Type A packagings designed for liquids and gases must be capable of withstanding the following tests:

(1) Free drop test. The packaging specimen must drop onto the target so as to suffer the maximum damage to its containment. The height of the drop measured from the lowest part of the packaging specimen to the upper surface of the target must be 9 meters (30 feet) or greater. The target must be as specified in $\$ 173.465(\mathrm{c})(5)$.

(2) Penetration test. The specimen must be subjected to the test specified in $\$ 173.465(e)$ except that the height of the drop must be 1.7 meters (5.5 feet).

This requirement applies only to DOT-7A Type A packagings used to transport liquids or gases. Based on the contents of the package, indicate below if the requirement applies or not. If the requirement applies, identify the type of documentation that shows this requirement is met and where the documentation can be found.

This requirement: [ ] Does not apply. [ $\quad$ ] Applies; indicate the following.

Addressed in:

[] Drawing

[] Specification

[ X ] Analysis Report
[ ] Operating Instruction

[ ] Manufacturer Supplied Data

[ ] Similarity or Documented Record

Specify:

(For detailed test information, refer to the test plan, HNF-13819.) Prior to the start of testing, a containment boundary verification was performed on the NFT can assemblies. Compressed air was used to pressurize the NFT can assembly to $103 \mathrm{kPa}(15 \mathrm{psi})$ and this pressure was held for 5 minutes. The pressure gauges were checked for any drop in pressure, and the NFT can assemblies were checked for leakage by coating/brushing a low-viscosity soap bottle solution around the threaded lid closure. All tested NFT can assemblies passed this initial, pre-test verification process.

The vibration testing was completed after the initial containment boundary verification. The Hedgehog-II, 1 $L$ bottle configurations (glass and poly) were initially tested for liquids having a specific gravity of $\leq 2.0$. During testing activities, the $1 \mathrm{~L}$ poly bottle configuration performed adequately. However, the $1 \mathrm{~L}$ glass configuration that consisted of the I-Chem wide-mouth glass jar having a black phenolic lid with polyvinyl liner (Qorpak 5024) did not pass the vibration and $9 \mathrm{~m}$ (30-ft) drop tests. Two design changes were, therefore, made. The bottle lid was changed to include a black phenolic lid with polyethylene liner (Qorpak 5082), and the loading of the contents was reduced to simulate a liquid having a specific gravity of $\leq 1.6$. This combination of changes was successful for the $1 \mathrm{~L}$ glass configuration. The lids to the $1 \mathrm{~L}$ bottles (poly and glass) were secured with 2-in.-wide PVC film tape after contents were loaded. Refer to Section 8.0 of this PQCL or HNF-13819 for specific information regarding the vibration tests.

The water spray test was not conducted prior to conducting the $1.2 \mathrm{~m}$ (4-ft) drop tests. By evaluation in comparison to the original Hedgehog packaging, it was determined that the water spray test does not have a negative affect on the performance of the Hedgehog-II packaging, due to materials of construction and design.

(1) The packages shown in Table A-6 were subjected to drop tests from a height of $9 \mathrm{~m}$ ( $30 \mathrm{ft}$ ). The $9 \mathrm{~m}$ $(30-\mathrm{ft})$ drop tests were conducted prior to the $1.2 \mathrm{~m}$ (4-ft) drop tests. The as-tested and approved $1 \mathrm{~L}$ glass bottle configuration that was successful in the $9 \mathrm{~m} \mathrm{(30-ft)}$ drop test included the wide-mouth glass jar (I-Chem 321-1000) with the black phenolic lid with polyethylene liner (Qorpak 5082). The specific gravity for the simulated liquid was $\leq 1.6$. The $1 \mathrm{~L}$ poly bottle configuration and shielded configurations remained as 
originally identified within the test plan and were tested with a simulated liquid having a specific gravity of $\leq 2.0$. The circumference around the $1 \mathrm{~L}$ bottle/lid interface (both glass and poly bottles) must be secured with 2-in.-wide PVC film tape.

By evaluation and comparison with similar materials, it was determined that the $125 \mathrm{~mL}$ and $250 \mathrm{~mL}$ versions would have no negative impact on the overall performance of the Hardigg Case, NFT can assembly, and inner and outer stainless steel shielded assemblies. The 125 and $250 \mathrm{~mL}$ versions are lighter in weight than the $30 \mathrm{~mL}$ version that was tested.

Upon conclusion of the $9 \mathrm{~m} \mathrm{(30-ft)} \mathrm{drop} \mathrm{test,} \mathrm{a} \mathrm{containment} \mathrm{boundary} \mathrm{verification} \mathrm{was} \mathrm{performed} \mathrm{as}$ identified within HNF-13819. Compressed air was used to pressurize the NFT can assembly to $103 \mathrm{kPa}$ (15 psi) and this pressure was held for 5 minutes. The pressure gauges were checked for any drop in pressure, and the NFT can assemblies were checked for leakage by coating/brushing a low-viscosity soap bottle solution around the threaded lid closure. All NFT can assemblies passed the pressure tests upon completion of the $9 \mathrm{~m}(30-\mathrm{ft})$ drop tests.

(2) The penetration test was not conducted on the Hedgehog-II packaging. By evaluation in comparison with the original Hedgehog container, it was determined this requirement is met. A summary of the information from testing conducted in 1995 under Docket 94-39-7A (DOE/RL-96-57, Vol. 1 and WHC-SD-TP-OTR-001) follows.

The water spray test was not conducted on the packaging prior to the penetration test. By evaluation in comparison to the original Hedgehog packaging, it was determined that the water spray test does not have a negative affect on the performance of the Hedgehog-II packaging, due to materials of construction and design. The penetration test was conducted on test unit 39-TU-02 (empty packaging) and after the $1 \mathrm{~m}$ (3.3ft) penetration test. The Hardigg Case was laid flat onto its widest, lengthwise side so that the impact of the penetration bar would be onto the lid of the case. Because the reinforcement bumpers are equidistant from each other (two exterior edges and the center of the case), the penetration bar was dropped in between the center bumper and one of the edge bumpers, and adjacent to the previous bar drop location. The point of impact caused an indentation $0.879 \mathrm{~cm}(0.346 \mathrm{in}$.) deep and $1.9 \mathrm{~cm}(0.75 \mathrm{in}$.) across.

Refer to IATA, Sections 10.6.3.5; 10.6.3.5.1; and 10.6.3.5.2 (IATA 2003).

Table A-6. Drop Tests-9 m (30 ft).

\begin{tabular}{|l|l|r|r|}
\hline $\begin{array}{c}\text { Test Identification, Results, and } \\
\text { Drop Orientation }\end{array}$ & \multicolumn{1}{|c|}{$\begin{array}{c}\text { Cross } \\
\text { Packaging Components }\end{array}$} & $\begin{array}{r}\text { Component } \\
\text { Weight }\end{array}$ & $\begin{array}{c}\text { Package } \\
\text { Weight }\end{array}$ \\
\hline $\begin{array}{l}\text { Drop 1 (shielded)-Fail } \\
\text { (30 ft; flat onto bottom) }\end{array}$ & Hardigg Case: HH2-TU-01 & $30.1 \mathrm{lb}$ & $69.4 \mathrm{lb}$ \\
& NFT Can Assembly: HH-005 & $5.2 \mathrm{lb}$ & \\
& Outer Shield: 006959-02-250-C & $16.2 \mathrm{lb}$ & \\
& Inner Shield: 006959-02-30-A & $12.6 \mathrm{lb}$ & \\
& 30 mL bottle & $0.2 \mathrm{lb}$ & \\
& Disk & $1.1 \mathrm{lb}$ & \\
& Belleville Washer & $1.1 \mathrm{lb}$ & \\
\hline Drop 2 (1 L Plastic)_Pass & Hylon Inserts (2) & $2.9 \mathrm{lb}$ & \\
\hline (30 ft; flat onto bottom) & NFT Can Assembly: HH-007 & $30.0 \mathrm{lb}$ & $39.5 \mathrm{lb}$ \\
& 1 L Plastic Bottle: P-1 & $5.1 \mathrm{lb}$ & \\
\hline Drop 3 (1 L Plastic)-Pass & Hardigg Case: HH2-TU-03 & $4.4 \mathrm{lb}$ & \\
(30 ft; flat onto top) & NFT Can Assembly: HH-007 & $30.0 \mathrm{lb}$ & \\
& 1 L Plastic Bottle: P-2 & $5.1 \mathrm{lb}$ & \\
\hline Drop 4 (1 L Plastic)-Pass & Hardigg Case: HH2-TU-03 & $4.6 \mathrm{lb}$ & \\
(30 ft; flat onto side at lid) & NFT Can Assembly: HH-007 & $30.0 \mathrm{lb}$ & \\
& 1 L Plastic Bottle: P-3 & $5.1 \mathrm{lb}$ & \\
\hline
\end{tabular}


Table A-6. Drop Tests-9 m (30 ft).

\begin{tabular}{|c|c|c|c|}
\hline $\begin{array}{l}\text { Test Identification, Results, and } \\
\text { Drop Orientation }\end{array}$ & Packaging Components & $\begin{array}{l}\text { Component } \\
\text { Weight }\end{array}$ & $\begin{array}{l}\text { Gross } \\
\text { Package } \\
\text { Weight }\end{array}$ \\
\hline $\begin{array}{l}\text { Drop } 5 \text { (shielded)—Pass } \\
\text { (30 ft; flat onto bottom) }\end{array}$ & $\begin{array}{l}\text { Hardigg Case: HH2-TU-01 } \\
\text { NFT Can Assembly: HH-005 } \\
\text { Outer Shield: 006959-02-250-A } \\
\text { Inner Shield: 006959-02-30-A } \\
30 \mathrm{~mL} \text { bottle } \\
\text { Disk } \\
\text { Belleville Washer } \\
\text { Nylon Inserts (2) }\end{array}$ & $\begin{array}{r}30.1 \mathrm{lb} \\
5.2 \mathrm{lb} \\
15.7 \mathrm{lb} \\
12.6 \mathrm{lb} \\
0.2 \mathrm{lb} \\
1.1 \mathrm{lb} \\
1.1 \mathrm{lb} \\
2.9 \mathrm{lb} \\
\end{array}$ & $68.9 \mathrm{lb}$ \\
\hline $\begin{array}{l}\text { Drop } 6 \text { (Shielded)_-Pass } \\
\text { (30 ft; flat onto top) }\end{array}$ & $\begin{array}{l}\text { Hardigg Case: HH2-TU-01 } \\
\text { NFT Can Assembly: HH-005 } \\
\text { Outer Shield: 006959-02-250-A } \\
\text { Inner Shield: 006959-02-30-A } \\
30 \mathrm{~mL} \text { bottle } \\
\text { Disk } \\
\text { Belleville Washer } \\
\text { Nylon Inserts (2) } \\
\end{array}$ & $\begin{array}{r}30.1 \mathrm{lb} \\
5.2 \mathrm{lb} \\
15.7 \mathrm{lb} \\
12.6 \mathrm{lb} \\
0.2 \mathrm{lb} \\
1.1 \mathrm{lb} \\
1.1 \mathrm{lb} \\
2.9 \mathrm{lb} \\
\end{array}$ & $68.9 \mathrm{lb}$ \\
\hline $\begin{array}{l}\text { Drop } 7 \text { (Shielded)—Pass } \\
\text { ( } 30 \mathrm{ft} \text {; flat onto side at lid) }\end{array}$ & $\begin{array}{l}\text { Hardigg Case: HH2-TU-03 } \\
\text { NFT Can Assembly: HH-005 } \\
\text { Outer Shield: 006959-02-250-A } \\
\text { Inner Shield: 006959-02-30-A } \\
30 \mathrm{~mL} \text { bottle } \\
\text { Disk } \\
\text { Belleville Washer } \\
\text { Nylon Inserts (2) }\end{array}$ & $\begin{array}{r}30.0 \mathrm{lb} \\
5.2 \mathrm{lb} \\
15.7 \mathrm{lb} \\
12.6 \mathrm{lb} \\
0.2 \mathrm{lb} \\
1.1 \mathrm{lb} \\
1.1 \mathrm{lb} \\
2.9 \mathrm{lb}\end{array}$ & $68.8 \mathrm{lb}$ \\
\hline $\begin{array}{l}\text { Drop } 8 \text { (Shielded)-Fail } \\
\text { (30 ft; center-of-gravity over a } \\
\text { top [lid] corner) }\end{array}$ & $\begin{array}{l}\text { Hardigg Case: HH2-TU-03 } \\
\text { NFT Can Assembly: HH-005 } \\
\text { Outer Shield: 006959-02-250-A } \\
\text { Inner Shield: 006959-02-30-A } \\
30 \mathrm{~mL} \text { bottle } \\
\text { Disk } \\
\text { Belleville Washer } \\
\text { Nylon Inserts (2) } \\
\end{array}$ & $\begin{array}{r}30.0 \mathrm{lb} \\
5.2 \mathrm{lb} \\
15.7 \mathrm{lb} \\
12.6 \mathrm{lb} \\
0.2 \mathrm{lb} \\
1.1 \mathrm{lb} \\
1.1 \mathrm{lb} \\
2.9 \mathrm{lb} \\
\end{array}$ & $68.8 \mathrm{lb}$ \\
\hline $\begin{array}{l}\text { Drop 9 (1 L Glass)—Fail } \\
\text { (30 ft; flat onto top) }\end{array}$ & $\begin{array}{l}\text { Hardigg Case: HH2-TU-02 } \\
\text { NFT Can Assembly: HH-002 } \\
1 \text { L Glass Bottle: G-1B } \\
\text { Disk }\end{array}$ & \begin{tabular}{r|}
$30.3 \mathrm{lb}$ \\
$5.1 \mathrm{lb}$ \\
$4.9 \mathrm{lb}$ \\
$1.1 \mathrm{lb}$
\end{tabular} & $41.4 \mathrm{lb}$ \\
\hline $\begin{array}{l}\text { Drop } 10 \text { (Shielded)—Pass } \\
\text { (30 ft; center-of-gravity over a } \\
\text { top [lid] corner) }\end{array}$ & $\begin{array}{l}\text { Hardigg Case: HH2-TU-02 } \\
\text { NFT Can Assembly: HH-005 } \\
\text { Outer Shield: 006959-02-250-A } \\
\text { Inner Shield: 006959-02-30-A } \\
30 \mathrm{~mL} \text { bottle } \\
\text { Disk } \\
\text { Belleville Washer } \\
\text { Nylon Inserts (2) } \\
\end{array}$ & $\begin{array}{r}30.3 \mathrm{lb} \\
5.2 \mathrm{lb} \\
15.7 \mathrm{lb} \\
12.6 \mathrm{lb} \\
0.2 \mathrm{lb} \\
1.1 \mathrm{lb} \\
1.1 \mathrm{lb} \\
2.9 \mathrm{lb} \\
\end{array}$ & $69.1 \mathrm{lb}$ \\
\hline $\begin{array}{l}\text { Drop } 17 \text { (1 L Glass)*_-Pass } \\
\text { (30 ft; flat onto top) }\end{array}$ & $\begin{array}{l}\text { Hardigg Case: HH2-TU-04 } \\
\text { NFT Can Assembly: HH-002 } \\
1 \text { L Glass Bottle: G-3 } \\
\text { Disk }\end{array}$ & \begin{tabular}{r|}
$30.2 \mathrm{lb}$ \\
$5.1 \mathrm{lb}$ \\
$4.9 \mathrm{lb}$ \\
$1.1 \mathrm{lb}$ \\
\end{tabular} & $41.3 \mathrm{lb}$ \\
\hline
\end{tabular}


HNF-13820, Rev. 0

Table A-6. Drop Tests -9 m (30 ft).

\begin{tabular}{|c|c|c|c|}
\hline $\begin{array}{l}\text { Test Identification, Results, and } \\
\text { Drop Orientation }\end{array}$ & Packaging Components & $\begin{array}{l}\text { Component } \\
\text { Weight }\end{array}$ & $\begin{array}{l}\text { Gross } \\
\text { Package } \\
\text { Weight }\end{array}$ \\
\hline $\begin{array}{l}\text { Drop } 18 \text { (1 L Glass)*_-Pass } \\
\text { (30 ft; flat onto bottom) }\end{array}$ & $\begin{array}{l}\text { Hardigg Case: HH2-TU-04 } \\
\text { NFT Can Assembly: HH-002 } \\
1 \text { L Glass Bottle: G-2 } \\
\text { Disk }\end{array}$ & $\begin{array}{r}30.2 \mathrm{lb} \\
5.1 \mathrm{lb} \\
4.9 \mathrm{lb} \\
1.1 \mathrm{lb} \\
\end{array}$ & $41.3 \mathrm{lb}$ \\
\hline $\begin{array}{l}\text { Drop } 19 \text { (1 L Glass) }{ }^{*}-\text { Fail } \\
\text { (30 ft; flat onto side at lid) }\end{array}$ & $\begin{array}{l}\text { Hardigg Case: HH2-TU-04 } \\
\text { NFT Can Assembly: HH-002 } \\
1 \text { L Glass Bottle: G-4 } \\
\text { Disk }\end{array}$ & $\begin{array}{r}30.2 \mathrm{lb} \\
5.1 \mathrm{lb} \\
5.0 \mathrm{lb} \\
1.1 \mathrm{lb} \\
\end{array}$ & $41.4 \mathrm{lb}$ \\
\hline $\begin{array}{l}\text { Drop } 20 \text { ( } 1 \text { L Glass)*-Pass } \\
\text { (30 ft; flat onto side at base) }\end{array}$ & $\begin{array}{l}\text { Hardigg Case: HH2-TU-04 } \\
\text { NFT Can Assembly: HH-002 } \\
1 \text { L Glass Bottle: Bottle \#1 (4-14-03) } \\
\text { Disk }\end{array}$ & $\begin{array}{r}30.2 \mathrm{lb} \\
5.1 \mathrm{lb} \\
3.2 \mathrm{lb} \\
1.1 \mathrm{lb} \\
\end{array}$ & $39.6 \mathrm{lb}$ \\
\hline $\begin{array}{l}\text { Drop } 21 \text { ( } 1 \text { L Glass)*_-Pass } \\
\text { (30 ft; flat onto side at base) }\end{array}$ & $\begin{array}{l}\text { Hardigg Case: HH2-TU-04 } \\
\text { NFT Can Assembly: HH-002 } \\
1 \text { L Glass Bottle: Bottle \#2 (4-14-03)** } \\
\text { Disk }\end{array}$ & $\begin{array}{r}30.2 \mathrm{lb} \\
5.1 \mathrm{lb} \\
3.8 \mathrm{lb} \\
1.1 \mathrm{lb}\end{array}$ & $40.2 \mathrm{lb}$ \\
\hline
\end{tabular}

* $1 \mathrm{~L}$ glass bottle tested included the phenolic lid and polyethylene liner (Qorpak 5082).

** $1 \mathrm{~L}$ glass bottle tested was previously used and identified as Bottle \#1 (4-14-03). Additional sand was added to simulate a liquid having a specific gravity of 1.6 , and the bottle was then marked as Bottle \#2. This bottle was used several times as indicated.

\section{Results:}

Drop 1: Fail. A vibration test was performed on this test unit prior to the drop test. Upon conclusion of the vibration test, the NFT can assembly was not opened, and the NFT can assembly underwent a containment boundary verification. Pressure was held at $103 \mathrm{kPa}$ (15 psia) for 5 minutes. There was no leakage from the NFT can assembly. This test unit was dropped flat onto the bottom of the package as it would normally be positioned during transport. This was the first drop with HH2-TU-01. Upon conclusion of the drop test, the following damage was observed. The foam located in the lid of the case was marred by the NFT plunger assembly which dug the foam out approximately 3.8 to $5.8 \mathrm{~cm}(1.5$ to $2.0 \mathrm{in}$.) deep, due to the movement of the can assembly. The distance of the NFT can movement was measured to be approximately $13.97 \mathrm{~cm}(5.50 \mathrm{in}$.) from the imprints noted in the foam piece. The ABS load spreader located at the base of the case bent at the area of impact approximately $1.27 \mathrm{~cm}(0.50 \mathrm{in}$.) on each end, and the ABS load spreader stuck into the corresponding side foam pieces. When the foam was readjusted inside the case, the ABS load spreader had taken a "set" at the bent areas of approximately $0.635 \mathrm{~cm}(0.25 \mathrm{in})$ on each side.

The test unit was rigged so the base of the package would hit flat when it dropped; however, it hit at a very slight angle (approximately $1^{\circ}$ ). As a result, the base of the NFT can bulged outward (i.e., crowned) all around the diameter of the can. A very slight indentation was noted on one lower side of the can. The NFT can assembly successfully underwent the containment boundary verification after this drop test. Pressure was held at $103 \mathrm{kPa}$ (15 psia) for 5 minutes. There was no leakage from the NFT can assembly.

Due to the results of prior testing activities performed in 1995 with this same shielded assembly design, the shieided assemblies were not required to be opened after the vibration test (which was conducted prior to this drop test). The torque on the bottom screws for the $250 \mathrm{~mL}$ outer assembly was not checked prior to the vibration test or prior to the drop test. Upon conclusion of the containment boundary verification performed after the drop test, the NFT can assembly was opened and the $250 \mathrm{~mL}$ outer assembly removed. The base of the shielded assembly fell off due to the four bottom screws shearing at the heads. The remaining screws for the $30 \mathrm{~mL}$ inner and $250 \mathrm{~mL}$ outer assemblies were then checked. All screws loosened slightly except for one top screw on the $250 \mathrm{~mL}$ outer assembly. Both of the shielded assemblies used for this test had been used in 
prior proof-testing activities, and the screws had not been changed/replaced. This drop test orientation and loading will be redone with a new $250 \mathrm{~mL}$ outer assembly that has new screws. Refer to Drop 5 . The only additional damage to the packaging was to the foam located inside the base of the NFT can assembly. This foam was cut through from the impact of the shielded assembly.

Drop 2: Pass. A vibration test was performed on this test unit prior to the drop test. Immediately following the vibration test, the test unit was opened to confirm no leakage of contents from the bottle. A containment boundary verification was performed on the NFT can assembly prior to the drop test. Pressure was held at $103 \mathrm{kPa}(15 \mathrm{psia})$ for 1 minute. There was no leakage from the NFT can assembly prior to the drop test. This test unit was dropped flat onto the bottom of the package as it would normally be positioned during transport. This was the first drop with HH2-TU-03. Upon conclusion of the drop test, the following damage was observed. The foam located in the case lid was dug out slightly (approximately $0.635 \mathrm{~cm}[0.25 \mathrm{in}$.]) at the area where the NFT can assembly plunger intersects the lid foam, due to the movement of the NFT can assembly. The distance was measured to be approximately $7.62 \mathrm{~cm} \mathrm{(3} \mathrm{in.)} \mathrm{from} \mathrm{the} \mathrm{imprints} \mathrm{noted} \mathrm{in} \mathrm{the}$ foam piece. The NFT can assembly was removed from the case and a containment boundary verification was performed. Pressure was held at $103 \mathrm{kPa}$ (15 psia) for 5 minutes. There was no leakage from the NFT can assembly. The can assembly was opened to verify information regarding the internal $1 \mathrm{~L}$ plastic bottle. The bottle was double-bagged and held a liquid having a specific gravity equal to 2.0, as identified in HNF-13819. There was no leakage of contents from the bottle.

Drop 3: Pass. A containment boundary verification was performed on the NFT can assembly prior to the drop test. Pressure was held at $103 \mathrm{kPa}(15 \mathrm{psia})$ for 1 minute. There was no leakage from the NFT can assembly prior to the drop test. This test unit was dropped flat onto the top of the package as it would normally be positioned during transport. This was the second drop with HH2-TU-03. Upon conclusion of the drop test, the following damage was observed. The foam located in the lid of the case indicated additional marring by the plunger, due to the movement of the NFT can assembly. This distance was measured to be approximately $9.53 \mathrm{~cm}(3.75 \mathrm{in}$.) from the imprints noted in the foam piece. The NFT can assembly was removed from the case and a containment boundary verification was performed. Pressure was held at 103 $\mathrm{kPa}$ (15 psia) for 5 minutes. There was no leakage from the NFT can assembly. The can assembly was opened to verify information regarding the internal $1 \mathrm{~L}$ plastic bottle. The bottle was double-bagged and held a liquid having a specific gravity equal to 2.0, as identified in HNF-13819. There was no leakage of contents from the bottle.

Drop 4: Pass. A containment boundary verification was performed on the NFT can assembly prior to the drop test. Pressure was held at $103 \mathrm{kPa}$ (15 psia) for 1 minute. There was no leakage from the NFT can assembly prior to the drop test. This test unit was dropped flat onto the side of the package as it would normally be positioned during transport. The side of impact was the lid of the case. This was the third drop with HH2-TU-03. In the area around the NFT can assembly plunger, the foam was dug out a bit further than in the previous drop test (drop 3). Other than that, there was no additional damage to the inner foam of the case during this drop test. The NFT can assembly was removed from the case and a containment boundary verification was performed. Pressure was held at $103 \mathrm{kPa}(15 \mathrm{psia})$ for 5 minutes. There was no leakage from the NFT can assembly. The can assembly was opened to verify information regarding the internal $1 \mathrm{~L}$ plastic bottle. The bottle was double-bagged and held a liquid having a specific gravity equal to 2.0 , as identified in HNF-13819. A slight amount of liquid was indicated in the innermost bag (approximately 1/8 to $1 / 4$ teaspoon). When the tape was removed from around the circumference of the bottle lid, an additional amount of liquid (approximately 1 teaspoon) was released from where it had been held within the taped bottle threads. Liquid was visible within the threaded area of the bottle. No further liquid released from the bottle; therefore, the bottle appears to have "burped" and then resealed itself-allowing no further release of liquid contents.

Drop 5: Pass. Due to the failure of the screws located in the $250 \mathrm{~mL}$ outer shielded assembly (S/N 006959-02-250-C) that occurred during Drop 1, a new $250 \mathrm{~mL}$ outer assembly was obtained (S/N 006959-02-250-A). A containment boundary verification was performed on the NFT can assembly prior to this drop test. Pressure was held at $103 \mathrm{kPa}$ (15 psia) for 1 minute. There was no leakage from the NFT can assembly. Due to the bending of the ABS load spreader and damage to the associated foam piece within the case, the foam component with ABS load spreader was replaced with the comparable foam piece from the 
case for test unit HH-TU-03. Test unit HH2-TU-01 was dropped flat onto the bottom of the package as it would normally be positioned during transport. This was the second drop with this test unit. Damage sustained from this drop was as follows. At the impact point of the outer portion of the case, bowing was seen. This measured approximately $0.953 \mathrm{~cm}(0.375 \mathrm{in}$.) outward. The plastic inside the case at the area of the inside latch (bottom of packaging as it would normally be positioned in transport) appeared to have a slight fracture. Each end of the ABS load spreader curled up around the base of the NFT can assembly. The left-hand side of the ABS load spreader curled upward approximately $3.175 \mathrm{~cm}(1.25 \mathrm{in}$.$) , and the right-hand$ side of the ABS load spreader curled up approximately $1.27 \mathrm{~cm}(0.50 \mathrm{in})$.

The NFT can assembly base has two dents--one measuring approximately $2.54 \mathrm{~cm}(1 \mathrm{in}$.) in length, and the second measuring approximately $3.81 \mathrm{~cm}(1.50 \mathrm{in}$.) in length. The bottom of the can lifted upward on one side a distance of approximately $1.905(0.75 \mathrm{in}$.). Upon completion of this drop test, the post-test containment boundary verification was performed on the NFT can assembly. Pressure was held at $103 \mathrm{kPa}$ (15 psia) for 5 minutes. There was no leakage from the NFT can assembly. The screws on the $250 \mathrm{~mL}$ outer shielded assembly were checked for tightness and none were found to have loosened.

Drop 6: Pass. A containment boundary verification was performed on the NFT can assembly prior to this drop test. Pressure was held at $103 \mathrm{kPa}$ (15 psia) for 1 minute. There was no leakage from the NFT can assembly. This test unit was dropped flat onto the top of the package as it would normally be positioned during transport. This is the third drop with HH2-TU-01. Damage that occurred is as follows. One righthand latch and one right-hand hinge broke on the case. The top foam piece inside the case at the area of impact was cut due to the two nylon load spreaders shifting. Unless the latch and hinge are repaired, this case can no longer be used in testing. The NFT can assembly and internal foam have no additional damage from this drop. Upon completion of this drop test, the post-test containment boundary verification was performed on the NFT can assembly. Pressure was held at $103 \mathrm{kpa}(15 \mathrm{psia})$ for 5 minutes. There was no leakage from the NFT can assembly. The screws on the $250 \mathrm{~mL}$ outer shielded assembly were checked for tightness and none were found to have loosened.

Drop 7: Pass. A containment boundary verification was performed on the NFT can assembly prior to this drop test. Pressure was held at $103 \mathrm{kPa}$ (15 psia) for 1 minute. There was no leakage from the NFT can assembly. This test unit was dropped flat onto the side of the package as it would normally be positioned during transport. The side of impact was the case lid. This is the fourth drop with HH2-TU-03. The case that had been identified for use with this shielded assembly was changed out due to damage received from Drop 6. The case that had been previously used for the $1 \mathrm{~L}$ plastic bottle assembly was used. The inner foam configuration for the shielded assembly was placed into this case prior to the drop. Damage that occurred is as follows. The foam in the case lid area where the NFT can assembly impacted is slightly compressed. In addition, the foam has indented where the edge of the NFT can lid pushed into the case lid foam. This is an indent of approximately $2.54 \mathrm{~cm}(1 \mathrm{in}$.). The NFT can assembly and internal foam have no additional damage from this drop. Upon completion of this drop test, the post-test containment boundary verification was performed on the NFT can assembly. Pressure was held at $103 \mathrm{kPa}$ (15 psia) for five minutes. There was no leakage from the NFT can assembly. The NFT can assembly was not opened after the containment boundary verification was performed. Therefore, the screw torque for the $250 \mathrm{~mL}$ outer shielded assembly was not verified. See the $250 \mathrm{~mL}$ outer shielded assembly outcome from Drop 8.

Drop 8: Fail. The NFT can assembly was not opened after conducting the containment boundary verification after the conclusion of the previous drop test (Drop 7). Thus, containment was already established prior to conducting this drop test. This test unit was dropped center-of-gravity (approximately a 45-degree angle) to impact a top corner as it would normally be positioned during transport. The corner of impact was located on the lid of the case. This is the fifth drop with HH2-TU-03. The case opened upon impact, and the NFT can and nylon load spreaders were ejected from the case. The center latch on the case broke. The right-hand latch on the case was torn out. The right rear hinge on the case was torn out. The case lid foam was cut from the impact of the NFT can assembly lid. The cut has a depth of approximately 5.08 to $6.35 \mathrm{~cm}(2$ to $2.50 \mathrm{in}$.).

There was no observed damage to the NFT can assembly. Upon completion of the drop test, the post-test containment boundary verification was successfully performed on the NFT can assembly. Pressure was held 
at $103 \mathrm{kPa}$ (15 psia) for 5 minutes. There was no observed damage to the $250 \mathrm{~mL}$ outer shielded assembly. The screws ( 4 cover and 4 base) were checked and did not loosen.

Due to the ejection of the NFT can assembly, failure occurred. Because this was the fifth drop test from a height of $9 \mathrm{~m} \mathrm{(30} \mathrm{ft)} \mathrm{with} \mathrm{this} \mathrm{case,} \mathrm{it} \mathrm{was} \mathrm{decided} \mathrm{to} \mathrm{redo} \mathrm{this} \mathrm{test} \mathrm{using} \mathrm{a} \mathrm{case} \mathrm{that} \mathrm{had} \mathrm{not} \mathrm{seen} \mathrm{this} \mathrm{number}$ of drops. Refer to Drop 10.

Drop 9: Fail. A containment boundary verification was performed on the NFT can assembly prior to the drop test. Pressure was held at $103 \mathrm{kPa}(15 \mathrm{psia})$ for 5 minutes. There was no leakage from the can assembly prior to insertion into the case. This test unit was dropped flat onto the top of the package as it would normally be positioned during transport. This is the first drop with HH2-TU-02. Upon conclusion of the drop test, the following damage was observed. The left rear hinge on the case was slightly bent at the pin. The foam located in the case lid was marred by the NFT can assembly plunger due to the movement of the can assembly. This distance was measured to be approximately $7.62 \mathrm{~cm}(3 \mathrm{in}$.) from the imprints noted in the foam piece. The NFT can assembly was removed from the case and a containment boundary verification was performed. Pressure was held at $103 \mathrm{kPa}$ (15 psia) for five minutes. There was no leakage from the NFT can assembly. The can assembly was opened to verify information regarding the internal $1 \mathrm{~L}$ glass bottle. The bottle had been double-bagged. The lid of the bottle broke on one side. The entire bottle broke (blew out).

NOTE: Bottle G-1B consisted of the wide-mouth glass jar (I-Chem 321-1000 or Fisher Scientific 05-719-89) and black phenolic lid with polyvinyl liner (Qorpak 5024 or Fisher Scientific 02-883-2Q). The simulated contents were loaded to represent a liquid having a specific gravity of 2.0 . This bottle/lid combination and content weight (specific gravity) are not authorized for use in the Hedgehog-II packaging.

Drop 10: Pass. A containment boundary verification was performed on the NFT can assembly prior to this drop test. Pressure was held at $103 \mathrm{kPa}$ (15 psia) for 1 minute. There was no leakage from the can assembly. The inner foam configuration for this case was for the $1 \mathrm{~L}$ bottle configuration; therefore, the foam was changed to accommodate the shielded configuration. This test unit was dropped center-of-gravity (approximately a 45-degree angle) to impact a top corner as it would normally be positioned during transport. The corner of impact was located on the lid of the case. This was the second drop with HH2-TU02. The following damage was observed. At the corner of impact there was slight dimpling of the case. The lid of the case cracked from buckling. The crack looks like a "J" as measured from the corner of impact. The crack begins approximately $7.62 \mathrm{~cm}(3 \mathrm{in}$.) from the edge and runs a distance of approximately $35.56 \mathrm{~cm}$ $(14 \mathrm{in})$, then curves slightly to the left for a distance of approximately $15.88 \mathrm{~cm}(6.25 \mathrm{in})$, then curves upward for a distance of $5.08 \mathrm{~cm}(2 \mathrm{in})$. There was no damage to the inner foam cushioning or spacers within the case. The latches and hinges were not damaged from this drop. There was no damage observed to the NFT can. Upon completion of the drop test, the post-test containment boundary verification was performed successfully on the NFT can assembly. Pressure was held at $103 \mathrm{kPa}$ (15 psia) for 5 minutes. There was no observed damage to the $250 \mathrm{~mL}$ outer shielded assembly. The screws (4 cover and 4 base) were checked and none had loosened.

Drop 17: Pass. A containment boundary verification was not performed on the NFT can assembly prior to this drop test. This test unit was dropped flat onto the top of the package as it would normally be positioned during transport. This was the first drop with HH2-TU-04. Upon conclusion of the drop test, the following damage was observed. The left rear hinge on the case was slightly bent at the pin. The foam located in the case lid was marred by the NFT can assembly plunger due to the movement of the can assembly. This distance was measured to be approximately $7.62 \mathrm{~cm}(3 \mathrm{in}$.) from the imprints noted in the foam piece. The NFT can assembly was removed from the case and a containment boundary verification was performed. Pressure was held at $103 \mathrm{kPa}$ (15 psia) for 5 minutes. There was no leakage from the NFT can assembly. The can assembly was opened to verify information regarding the internal $1 \mathrm{~L}$ glass bottle. The bottle had been double-bagged according to the modified instructions provided in HNF-13819. Each bag was individually twisted and taped to secure the twist; however, the ends were not horse-tailed. The taped portions of the bags were laid along the side of the body bottle and not directly over the lid area-opposite each other prior to insertion into the NFT can assembly. There was no leakage from the bottle. The bottle was turned on its side and slight leakage occurred and then stopped (i.e., the bottle resealed). 
NOTE: Bottle G-3 consisted of the wide-mouth glass jar (I-Chem 321-1000 or Fisher Scientific 05-719-89) and black phenolic lid with polyethylene liner (Qorpak 5082). The simulated contents were loaded to represent a liquid having a specific gravity of 2.0. Because of the failure that occurred during Drop 19, a specific gravity of 2.0 with this $1 \mathrm{~L}$ glass bottle assembly is not authorized.

Drop 18: Pass. A containment boundary verification was not performed on the NFT can assembly prior to this drop test. This test unit was dropped flat onto the bottom of the package as it would normally be positioned during transport. This was the second drop with HH2-TU-04. The case was rigged in such a manner that the bottom of the package would be impacted (flat). However, the package actually landed on a short edge along the bottom of the package. Because of the angle of this impact, the three front latches of the case slipped slightly, but held. Slight compression was noted in the internal foam in the area of impact. The NFT can assembly was removed from the case and a containment boundary verification was performed. Pressure was held at $103 \mathrm{kPa}(15 \mathrm{psia})$ for 5 minutes. There was no leakage from the NFT can assembly. The can assembly was opened to verify information regarding the internal $1 \mathrm{~L}$ glass bottle. The bottle had been double-bagged according to the modified instructions provided in HNF-13819. Each bag was individually twisted and taped to secure the twist; however, the ends were not horse-tailed. The taped portions of the bags were laid along the side of the body bottle and not directly over the lid area-opposite each other prior to insertion into the NFT can assembly. There was slight leakage indicated from the bottle. The bottle was turned on its side and no further leakage occurred (i.e., the bottle resealed).

NOTE: Bottle G-2 consisted of the wide-mouth glass jar (I-Chem 321-1000 or Fisher Scientific 05-719-89) and black phenolic lid with polyethylene liner (Qorpak 5082). The simulated contents were loaded to represent a liquid having a specific gravity of 2.0. Because of the failure that occurred during Drop 19, a specific gravity of 2.0 with this $1 \mathrm{~L}$ glass bottle assembly is not authorized.

Drop 19: Fail. A containment boundary verification was not performed on the NFT can assembly prior to this drop test. This test unit was dropped flat onto the side of the package as it would normally be positioned during transport. The side of impact was the lid of the case. This was the third drop with HH2-TU-04. Damage sustained from the drop was as follows. The foamed lid area of the case was cut where the NFT can assembly impacted. The outer portion of the case was slightly cracked on the left-hand side of the lid at the latch area, and the lid gasket had a slight cut along the left-hand side at the latch area. The NFT can assembly was removed from the case and a containment boundary verification was performed. Pressure was held at $103 \mathrm{kPa}(15 \mathrm{psia})$ for 5 minutes. There was no leakage from the NFT can assembly. The can assembly was opened to verify information regarding the internal $1 \mathrm{~L}$ glass bottle. The bottle had been double-bagged according to the modified instructions provided in HNF-13819. Each bag was individually twisted and taped to secure the twist; however, the ends were not horse-tailed. The taped portions of the bags were laid along the side of the body bottle and not directly over the lid area-opposite each other prior to insertion into the NFT can assembly. The bottle completely broke-blew out.

NOTE: Bottle G-4 consisted of the wide-mouth glass jar (I-Chem 321-1000 or Fisher Scientific 05-719-89) and black phenolic lid with polyethylene liner (Qorpak 5082). The simulated contents were loaded to represent a liquid having a specific gravity of 2.0. Because of the failure that occurred during this drop. a specific gravity of 2.0 with this $1 \mathrm{~L}$ glass bottle assembly is not authorized.

Drop 20: Pass. A containment boundary verification was not performed on the NFT can assembly prior to this drop test. This test unit was dropped flat onto the side of the package as it would normally be positioned during transport. The side of impact was the base of the case. This was the fourth drop with HH2-TU-04. There was no additional case damage observed. There was no observed damage to the NFT can assembly and internal foam. Since this configuration was lighter than the other configurations tested where the NFT can assembly had already been shown to successfully maintain containment after various $9 \mathrm{~m} \mathrm{(30-ft)} \mathrm{drop}$ tests, the containment boundary verification on the NFT can assembly was not performed after this drop. The can assembly was opened to verify information regarding the internal $1 \mathrm{~L}$ glass bottle. The bottle had been double-bagged according to the modified instructions provided in HNF-13819. Each bag was individually twisted and taped to secure the twist; however, the ends were not horse-tailed. The taped portions of the bags were laid along the side of the body bottle and not directly over the lid area-opposite each other prior to insertion into the NFT can assembly. The bottle did not leak or break. 
NOTE: Bottle \#1 (4/14/03) consisted of the wide-mouth glass jar (I-Chem 321-1000 or Fisher

Scientific 05-719-89) and black phenolic lid with polyethylene liner (Qorpak 5082). To try and qualify a $1 \mathrm{~L}$ glass bottle configuration, it was decided to test the bottle contents at a lighter weight. The glass bottle was filled with $0.36 \mathrm{~kg}(0.8 \mathrm{lb})$ of sand and $0.64 \mathrm{~kg}(1.4 \mathrm{lb})$ of water. No steel $B B s$ were used. The gross weight for Bottle \#1 was $1.45 \mathrm{~kg}$ (3.2 lb). Upon the successful completion of Drop Test 20, it was decided that the simulated contents would be loaded slightly heavier to qualify and represent a liquid having a specific gravity of 1.6 (refer to Drop 21).

Drop 21: Pass. A containment boundary verification was not performed on the NFT can assembly prior to this drop test. This test unit was dropped flat onto the side of the package as it would normally be positioned during transport. The side of impact was the base of the case. This was the fifth drop with HH2-TU-04. There was no additional case damage observed. There was no observed damage regarding the NFT can assembly and internal foam. Since this was a lighter configuration from the other configurations tested where the NFT can assembly had already been shown to successfully maintain containment after various $9 \mathrm{~m}$ (30-ft) drop tests, the containment boundary verification on the NFT can assembly was not performed after this drop. The can assembly was opened to verify information regarding the internal $1 \mathrm{~L}$ glass bottle. The bottle had been double-bagged according to the modified instructions provided in HNF-13819. Each bag was individually twisted and taped to secure the twist; however, the ends were not horse-tailed. The taped portions of the bags were laid along the side of the body bottle and not directly over the lid area-opposite each other prior to insertion into the NFT can assembly. The bottle did not leak or break.

NOTE: Bottle \#2 (4/14/03) consisted of the wide-mouth glass jar (I-Chem 321-1000 or Fisher Scientific 05-719-89) and black phenolic lid with polyethylene liner (Qorpak 5082). Because of the success of Drop 20, it was decided to try and qualify the $1 \mathrm{~L}$ glass bottle contents at a weight that was between $1.45 \mathrm{~kg}$ $(3.2 \mathrm{lb})$ and $2.22 \mathrm{~kg}(4.9 \mathrm{lb})$. The glass bottle and lid from Drop 20 were used, and the bottle was marked as Bottle \#2. As much water as possible was removed from the bottle, and the bottle was filled with $1.04 \mathrm{~kg}$ $(2.3 \mathrm{lb})$ of sand and $0.23 \mathrm{~kg}(0.5 \mathrm{lb})$ of water. No steel BBs were used. The gross weight for Bottle \#2 was $1.72 \mathrm{~kg}(3.8 \mathrm{lb})$. Upon the successful completion of Drop 21, it was concluded that this $1 \mathrm{~L}$ bottle assembly having simulated contents loaded to represent a liquid having a specific gravity of 1.6 is approved for use. 
HNF-13820, Rev. 0

Refer to the calculation below that was used to determine the specific gravity of 1.6 for the approved, astested, $1 \mathrm{~L}$ glass bottle configuration.

This calculation determines the specific gravity of the sand and water mixture that was used to simulate waste in the glass bottles. The weight of the sand/water mixture was determined using a calibrated scale. The volume of the mixture was measured using a plastic measuring container. The density of the mixture was obtained using the measured weight and volume. The specific gravity of the mixture was determined to be 1.6.

Density of water:

$$
\rho_{\mathrm{h} 20}:=62.4 \frac{\mathrm{lbf}}{\mathrm{ft}^{3}}
$$

Volume of water/sand mixture in the glass bottle: (Measured with a plastic measuring container)

volume $:=27 \cdot \mathrm{fl} 1_{-} \mathrm{oz}$

Weight of empty bottle with lid:

(Measured with a calibrated scale)

$$
\mathrm{W}_{\text {bottle }}:=1 \cdot \mathrm{lbf}
$$

Weight of water/sand mixture in bottle with lid: (Measured with a calibrated scale)

$$
\mathrm{W}_{\text {total }}:=3.8 \cdot \mathrm{lbf}
$$

Weight of water/sand mixture:

(Measured with a calibrated scale)

$$
\begin{aligned}
& \mathrm{W}_{\text {mixture }}:=\mathrm{W}_{\text {total }}-\mathrm{W}_{\text {bottle }} \\
& \rho_{\mathrm{wt}}:=\frac{\mathrm{W}_{\text {mixture }}}{\text { volume }} \\
& \rho_{\mathrm{wt}}=99.297 \frac{\mathrm{lbf}}{\mathrm{ft}^{3}} \\
& \mathrm{SG}:=\frac{\rho_{\mathrm{wt}}}{\rho_{\mathrm{h} 2 \mathrm{o}}}
\end{aligned}
$$

Specific gravity of water/sand mixture:

$\mathrm{SG}=1.591$ 


\subsection{CFR 173.462 PREPARATION OF SPECIMENS FOR TESTING}

\subsection{2(a) Inspection.}

(a) Each specimen (i.e., sample, prototype or scale model) must be examined before testing to identify and record faults or damage, including:

(1) Divergence from the specifications or drawings;

(2) Defects in construction;

(3) Corrosion or other deterioration; and

(4) Distortion of features.

This requirement applies to DOT-7A Type A packagings. Indicate below the type of documentation that shows this requirement is met and where the documentation can be found.

$\begin{array}{lll}\text { Addressed in: } & \text { [ ] Drawing } & \text { [ ] Operating Instruction } \\ & \text { [ ] Specification } & \text { [ ] Manufacturer Supplied Data } \\ & \text { [ X ] Analysis Report } & \text { [ ] Similarity or Documented Record }\end{array}$

Specify:

Hardigg Case-All provided test units (HH2-TU-01; HH2-TU-01 [refurbished]; HH2-TU-02; HH2-TU-03; and HH2-TU-04) had the inner case foam oriented such that the split in the lid gasket was located at the top of the package as it would normally be positioned in transport-not the base of the package as it would normally be positioned during transport. It was determined that this change would not affect the results of the testing that was to be performed; however, during normal use/operations, the split MUST be located at the BASE of the package as it would normally be positioned in transport. Refer to Appendix $C$ and Hanford

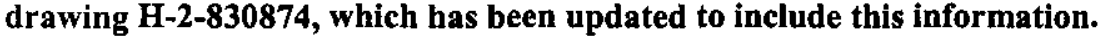

Due to the damage sustained with test unit HH2-TU-01, this case required refurbishment by the case manufacturer. The lid foam cushion was replaced with new foam. All hinges and latches were replaced with new components. After refurbishment, one hinge on the right rear of the case was loose; however, this did not affect the performance of the packaging during testing.

Due to the unanticipated damage to the test unit cases, an additional case was required/supplied. Test unit HH2-TU-04 was gray in color (not yellow); had plastic spring-loaded handles (not metal); and did not include a shipping card holder. All latches and hinges were the same as the other provided test units. It was determined that these differences were insignificant and would not affect the performance of the packaging during testing activities.

NFT Can Assembly-All provided test assemblies (S/N HH-002; HH-005; HH-006; and HH-007) had been used in proof-testing that was conducted prior to performance of the DOT-7A Type A qualification testing that is documented within this final report and PQCL. In addition, the NFT can assembly lid was modified for testing purposes to incorporate a threaded port for use in pressure testing. The incorporation of a threaded port for use in pressure testing for containment boundary verifications is a common practice at testing laboratories. The incorporation of this port had no impact on the performance of the NFT can assembly or packaging. Teflon tape was used to assist in sealing the port connections, and this was verified by use of a soap-bubble solution.

Two of the four can assemblies had slight damage from the proof testing as described below:

- HH-006 -No dents or damage to the lid of the canister is visible. However, the canister base bulges outward from approximately $0.317 \mathrm{~cm}(1 / 8 \mathrm{in}$.) to $0.476(3 / 16 \mathrm{in}$.) to $0.635 \mathrm{~cm}(1 / \mathrm{sin}$.$) . The base has a$ "dimple" or indentation approximately $0.317 \mathrm{~cm}(1 / 8 \mathrm{in}$.) deep by $1.905 \mathrm{~cm}(3 / 4 \mathrm{in}$.) long. The side of the canister has a dimple or indentation approximately $0.317 \mathrm{~cm}(1 / 8 \mathrm{in}$.) deep by $1.905 \mathrm{~cm}(3 / 4 \mathrm{in}$.) long. This component was rejected for use during qualification testing. 
- HH-007-No dents or damage to the lid or sides of the canister are visible. However, the base of the canister bulges outward approximately $0.317 \mathrm{~cm}(1 / 8 \mathrm{in}$.) when a straight-edge is laid across the base of the can. One minor dent (unmeasureable) that is located at the base of the can was marked prior to testing. Because of this minor bulge, it was determined that this component was acceptable for use.

In addition, a nonconformance report (NCR) was generated regarding the dimensional tolerances for the inner foam pieces that are provided with the NFT can assemblies. Refer to HNF-13819 for a copy of DFSNW-NCR-040. In summary, three complete sets were finally compiled from units that were used in prior proof testing and from units that were supplied for qualification testing. The foam pieces used for testing as described within this final report and PQCL were either within tolerance, or no more than $0.159 \mathrm{~cm}(1 / 16$ in.) out-of-tolerance from the dimension identified on drawing H-2-830876.

Belleville Washer-The as-tested belleville washer was made from 1075 carbon steel (Rolex AM-1608243). However, the intended belleville washer for use is made from 17/7-PH stainless steel (Rolex SAM-1608243). The operational loading for either materials is $5274.0 \mathrm{lb} @ 0.1779$ inch deflection with a normal load tolerance from $+10.0 \%$ to $-\mathbf{5 . 0} \%$. The stainless steel disc is made from 11-gauge sheet. There should be no affect upon the results of testing as the performance characteristics are identical.

Disk-The outer diameter of the as-tested disk was measured to be $16.669 \mathrm{~cm}(69 / 16 \mathrm{in})$, not $17.78 \mathrm{~cm}$ (7.0 in.) as identified on drawing H-2-830874. A $17.78 \mathrm{~cm}(7.0-\mathrm{in}$.) diameter disk could not fit into the NFT can assembly. Hanford drawing H-2-830874 in Appendix $\mathrm{C}$ has been updated to include the correct tolerances and other information.

$1 \mathrm{~L}$ Glass Bottles and Lids-The original bottle/lid combination that was planned for testing consisted of a $1 \mathrm{~L}$ wide-mouth glass bottle (I-Chem 321-100 or Fisher Scientific 05-719-89). The existing lid was replaced with a black phenolic lid with polyvinyl liner (Qorpak 5024 or Fisher Scientific 02-883-2Q). This original bottle/lid configuration was identified as being tested with a liquid having a specific gravity $\leq 2.0$. This consisted of filling the bottle with $0.494 \mathrm{~kg}(1.09 \mathrm{lb})$ of sand; $0.757 \mathrm{~kg}(1.67 \mathrm{lb})$ of shot (BB size); $0.353 \mathrm{~kg}$ $(0.78 \mathrm{lb})$ of water; and leaving a 10 percent ullage. Because of the failures that occurred during vibration and $9 \mathrm{~m}$ (30-ft) drop testing, this bottle/lid combination and specific gravity are not authorized and a change was required during testing. Therefore, the approved, as-tested bottle/lid combination for use in the Hedgehog-II packaging consists of a $1 \mathrm{~L}$ wide-mouth glass bottle (I-Chem 321-100 or Fisher Scientific 05-719-89). The existing lid is replaced with a black phenloic lid with polyethylene liner (Qorpak 5082). The bottle is taped circumferentially around the lid/body interface with 2-in.-wide PVC film tape. Shurtape V-410 was used during testing. Simulated loading that was tested and approved is a liquid having a specific gravity of $\leq 1.6$. This consists of filling the bottle with $1.043 \mathrm{~kg}(2.3 \mathrm{lb})$ of sand and $0.227 \mathrm{~kg}(0.5 \mathrm{lb})$ of water, leaving a 10 percent ullage.

In addition, the loading of the $1 \mathrm{~L}$ glass bottle into the appropriate-sized poly bags required a change from the original design. Horse-tailing of each poly bag is not acceptable. Instead, the open end of the bag is twisted closed and sealed with tape. The twisted and taped portion of the bag is placed along one side of the bottle and not directly over the lid area. This process is repeated using a second bag, and the twisted and taped portion of the second bag is placed opposite that of the first bag and not directly over the lid area. Refer to Appendix B and Appendix C of this final report.

$1 \mathrm{~L}$ Poly Bottles-The $1 \mathrm{~L}$ poly bottles require taping circumferentially around the lid/body interface with 2-in.-wide PVC film tape. Shurtape VP-410 was used during testing.

Refer to IATA, Section 10.6.3.1.3 (IATA 2003). 


\subsection{2(b) Correction.}

(b) Any deviation found under paragraph (a) of this section from the specified design must be corrected or appropriately taken into account in the subsequent evaluation.

This requirement applies to DOT-7A Type A packagings. Indicate below the type of documentation that shows this requirement is met and where the documentation can be found.
Addressed in:
[ ] Drawing
[] Specification
[ ] Operating Instruction
$[\mathbf{X}]$ Analysis Report
[] Manufacturer Supplied Data
[ ] Similarity or Documented Record

Specify:

Refer to the information/corrections that have been provided in Section 5.0, 49 CFR 173.462(a), Inspection.

\subsection{2(c) Identify Containment System.}

(c) The containment system of the packaging must be clearly specified.

This requirement applies to DOT-7A Type A packagings. Indicate below the type of documentation that shows this requirement is met and where the documentation can be found.
Addressed in:
[ $\mathbf{X}$ ] Drawing
[] Specification
[ $\mathbf{X}$ ] Analysis Report
[ ] Operating Instruction
[] Manufacturer Supplied Data
[ ] Similarity or Documented Record

Specify:

The Hedgehog-II relies on two levels of containment for all versions tested. The 30, 125, and $250 \mathrm{~mL}$ versions rely on the stainless steel shielded assemblies for primary containment. The shielded assemblies each include two Nitrile o-rings and four screws (8-32UNC-3A x $3 / 4$ in. long or $1 \mathrm{in}$. long). The $1 \mathrm{~L}$ version requires that the bottle (poly or glass) remain intact and not break because it is part of the identified containment system. The shipper must either use the same $1 \mathrm{~L}$ bottle/lid combinations that were approved during testing, or document that if a different bottle/lid are used they are equivalent to what was used during testing. The $1 \mathrm{~L}$ bottles must be taped circumferentially around the lid/body with 2-in.-wide PVC film tape.

The secondary containment, the NFT can assembly, is made from stainless steel and incorporates a Nitrile gasket within the threaded lid closure as well as a lid-locking mechanism that is engaged to the proper torque when the lid is screwed on. The primary containment system, once placed inside the secondary containment system, is surrounded and cushioned by top, bottom, and side shock protectors made from white EVA foam having a density of $2 \mathrm{lb} / \mathrm{ft}^{2}$. Depending on the configuration to be shipped, additional packing materials consisting of either a belleville washer (made from 17/7-PH stainless steel) and/or a stainless steel disc (made from 11-gauge sheet) are inserted prior to closure of the secondary containment. These additional packing materials act as a spring and a load spreader, providing protection to both the primary and secondary containment systems.

Refer to IATA, Section 10.6.3.1.4 (IATA 2003). 
HNF-13820, Rev. 0

\subsection{2(d) Identify External Features.}

(d) The external features of the specimen must be clearly identified so that reference may be made to any part of it.

This requirement applies to DOT-7A Type A packagings. Indicate below the type of documentation that shows this requirement is met and where the documentation can be found.
Addressed in:
[ $\mathbf{X}$ ] Drawing
[] Specification
[ ] Operating Instruction
[] Analysis Report
[ ] Manufacturer Supplied Data
[ ] Similarity or Documented Record

Specify:

The external features of the packaging are clearly identifiable. The Hardigg Case has two lifting handles, five butterfly latches, and three hinges. The NFT can assembly has identification numbers located on the lid and body. The operating instructions (HNF-11651) state that the packaging is not to be used if these numbers are not identical. The stainless steel shielded assemblies contain a serial number on the cover, wall, and base. The operating instructions (HNF-11651) state that the packaging is not to be used if these numbers are not identical. The cover and wall of the stainless steel shielded assemblies are also notched for alignment purposes.

Refer to IATA, Section 10.6.3.1.4 (IATA 2003). 


\subsection{MANUFACTURER'S COMMUNICATIONS}

49 CFR 178.2(c) Notification.

(c) Notification. Except as specifically provided in $\$ \$ 178.337-18$ and $178.345-10$ of this part, the manufacturer or other person certifying compliance with the requirements of this part, and each subsequent distributor of that packaging shall--

(1) Notify in writing each person to whom that packaging is transferred--

(i) Of all requirements in this part not met at the time of transfer, and

(ii) Of the type and dimensions of any closures, including gaskets, needed

to satisfy performance test requirements.

(2) Retain copies of each written notification for at least one year from date of issuance; and

(3) Make copies of all written notifications available for inspection by a representative of the Department.

These requirements apply to DOT-7A Type A packagings. Indicate below the type of documentation that shows these requirements are met and where the documentation can be found.

Addressed in:

[ $\mathbf{X}$ ] Drawing

[ $\mathbf{X}$ ] Specification

$[\mathbf{X}$ ] Operating Instruction

[ $\mathrm{X}$ ] Analysis Report

[ ] Manufacturer Supplied Data

[ ] Similarity or Documented Record

Specify:

The final report and PQCL, in conjunction with the design drawings, technical specifications, and operating instructions, identify the requirements for Type $A$ packaging that are met and those requirements that remain to be completed (i.e., identified as "shipper is to ensure"). These documents can, therefore, serve as a starting point for the notification required by this section.

NOTE: Any organization that assembles the identified components should, before using or supplying the packagings to others, prepare a notification that updates the information. The notification should be supplied with the packagings. 


\subsection{CFR 178.3 MARKING OF PACKAGINGS}

\section{3(a) What and How to Mark.}

(a) Each packaging represented as manufactured to a DOT specification or a UN Standard must be marked with specification markings conforming to the applicable specification, and with the following:

(1) In an unobstructed area, with letters, and numerals identifying the standards or specification (e.g., UN 1A1, DOT 4B240ET, etc.).

(2) Unless otherwise specified in this part, with the name and address or symbol of the packaging manufacturer or, where specifically authorized, the symbol of the approval agency certifying compliance with a UN standard. Symbols, if used, must be registered with the Associate Administrator for Hazardous Materials Safety. Duplicative symbols are not authorized.

(3) The markings must be stamped, embossed, burned, printed or otherwise marked on the packaging to provide adequate accessibility, permanency, contrast, and legibility so as to be readily apparent and understood.

(4) Unless otherwise specified, letters and numerals must be at least $12.0 \mathrm{~mm}(0.47$ inches) in height except that for packagings of less than or equal to $30 \mathrm{~L}$ ( 7.9 gallons) capacity for liquids or $30 \mathrm{~kg}$ ( 66 pounds) capacity for solids the height must be at least $6.0 \mathrm{~mm}(0.2$ inches). For packagings having a capacity of $5 \mathrm{~L}$ (1 gallon) or $5 \mathrm{~kg}$ (11 pounds) or less, letters and numerals must be of an appropriate size.

(5) For packages with a gross mass of more than $30 \mathrm{~kg}$ ( 66 pounds), the markings or a duplicate thereof must appear on the top or on a side of the packaging.

These requirements apply to DOT-7A Type A packagings. Indicate below the type of documentation that shows these requirements are met and where the documentation can be found.

Addressed in:

[ ] Drawing

[] Specification

[ $\mathbf{X}$ ] Operating Instruction

[] Analysis Report

[ ] Manufacturer Supplied Data

[ X ] Packaging

[] Similarity or Documented Record

Specify:

The Hedgehog-II consists of off-the-shelf components. Therefore, the shipper assumes the responsibilities of the manufacturer to ensure that the requirements of 49 CFR 178.3(a) are met. This responsibility includes marking the packaging with the shipper's (manufacturer's) name and address or registered symbol.

The shipper is responsible for ensuring that the requirements are met prior to the transport of the loaded packagings.

Refer to IATA, Section 10.7, "Marking and Labeling" (IATA 2003). 
HNF-13820, Rev. 0

\section{3(b) Marking.}

(b) A UN standard packaging for which the UN standard is set forth in this part may be marked with the United Nations symbol and other specification markings only if it fully conforms to the requirements of this part. A UN standard packaging for which the UN standard is not set forth in this part may be marked with the United Nations symbol and other specification markings for that standard as provided in the ICAO Technical Instructions or Annex 1 of the IMDG Code subject to the following conditions:

(1) The U.S. manufacturer must establish that the packaging conforms to the applicable provisions of the ICAO Technical Instructions or Annex 1 of the IMDG Code, respectively. (2) If an indication of the name of the manufacturer or other identification of the packaging as specified by the competent authority is required, the name and address or symbol of the manufacturer or the approval agency certifying compliance with the UN standard must be entered. Symbols, if used, must be registered with the Associate Administrator for Hazardous Materials Safety.

(3) The letters "USA" must be used to indicate the State authorizing the allocation of the specification marks if the packaging is manufactured in the United States.

These requirements apply to DOT-7A Type A packagings. Indicate below the type of documentation that shows these requirements are met and where the documentation can be found.
Addressed in:
[] Drawing
[ $\mathbf{X}$ ] Operating Instruction
[] Specification
[ ] Manufacturer Supplied Data
[ ] Analysis Report
[ ] Similarity or Documented Record
[ $\mathbf{X}$ ] Packaging

Specify:

The Hedgehog-II consists of off-the-shelf components. Therefore, the shipper assumes the responsibilities of the manufacturer to ensure that the requirements of 49 CFR 178.3(b) are met. This responsibility includes marking the packaging with the shipper's (manufacturer's) name and address or registered symbol.

The shipper is responsible for ensuring that the requirements are met prior to the transport of the loaded packagings.

Refer to IATA, Section 10.7, "Marking and Labeling" (IATA 2003). 


\section{3(c) Multiple Markings.}

(c) Where a packaging conforms to more than one UN standard or DOT specification, the packaging may bear more than one marking, provided the packaging meets all the requirements of each standard or specification. Where more than one marking appears on a packaging, each marking must appear in its entirety.

(d) No person may mark or otherwise certify a packaging or container as meeting the requirements of a manufacturing exemption unless the person is the holder of or a party to that exemption, an agent or the holder or a party for the purpose of marking or certification, or a third party tester.

This requirement applies to DOT-7A Type A packagings that also meet the requirements of a UN standard or another DOT specification. Based on the design of the package, indicate below if the requirement applies or not. If the requirement applies, identify the type of documentation that shows this requirement is met and where the documentation can be found.

This requirement: [ ] Does not apply. [X] Applies; indicate the following.

Addressed in:
[ ] Drawing
[ ] Specification
[ $\mathbf{X}$ ] Operating Instruction
[ ] Analysis Report
[] Manufacturer Supplied Data
[ X ] Packaging
[] Similarity or Documented Record

Specify:

The Hedgehog-II consists of off-the-shelf components. Therefore, the shipper assumes the responsibilities of the manufacturer to ensure that the requirements of 49 CFR 178.3(c) are met. This responsibility includes marking the packaging with the shipper's (manufacturer's) name and address or registered symbol.

The shipper is responsible for ensuring that the requirements are met prior to the transport of the loaded packagings.

Refer to IATA, Section 10.7, “Marking and Labeling” (IATA 2003). 


\subsection{CFR 178.608 VIBRATION STANDARD}

\subsection{Vibration Standard.}

(a) Each packaging must be capable of withstanding, without rupture or leakage, the vibration test procedure outlined in this section.

(b) Test method.

(1) Three sample packagings, selected at random, must be filled and closed as for shipment.

(2) The three samples must be placed on a vibrating platform that has a vertical or rotary double-amplitude (peak-to-peak displacement) of one inch. The packages should be constrained horizontally to prevent them from falling off the platform, but must be left free to move vertically, bounce and rotate.

(3) The test must be performed for one hour at a frequency that causes the package to be raised from the vibrating platform to such a degree that a piece of material of approximately 1.6 $\mathrm{mm}(0.063$ inch) thickness (such as steel strapping or paperboard) can be passed between the bottom of any package and the platform.

(4) Immediately following the period of vibration, each package must be removed from the platform, turned on its side and observed for any evidence of leakage.

(5) Other methods, at least equally effective, may be used, if approved by the Associate Administrator.

(c) Criteria for passing the test. A packaging passes the vibration test if there is no rupture or leakage from any of the packages. No test sample should show any deterioration which could adversely affect transportation safety or any distortion liable to reduce packaging strength.

The vibration standard as described above is applied for DOT-7A Type A testing to ensure that the packaging design meets the design requirements identified in 49 CFR 173.24(f); 173.24a(a)(5); and 173.410(f). Indicate below the type of documentation that shows these requirements are met and where the documentation can be found.
Addressed in:
[ X ] Drawing
[ ] Specification
[ ] Operating Instruction
[ X ] Analysis Report
[ ] Manufacturer Supplied Data
[ ] Similarity or Documented Record

Specify:

(For detailed test information, refer to the test plan, HNF-13819.) Prior to the start of testing, a containment boundary verification was performed on the NFT can assemblies. Compressed air was used to pressurize the NFT can assembly to $103 \mathrm{kPa}(15 \mathrm{psi})$ and this pressure was held for 5 minutes. The pressure gauges were checked for any drop in pressure, and the NFT can assemblies were checked for leakage by coating/brushing a low-viscosity soap bottle solution around the threaded lid closure. All tested NFT can assemblies passed this initial, pre-test, verification process.

The vibration testing was completed after the initial containment boundary verification. The Hedgehog-II, 1 $\mathbf{L}$ bottle configurations (glass and poly) were initially tested for liquids having a specific gravity of $\leq 2.0$. During testing activities, the $1 \mathrm{~L}$ poly bottle configuration performed adequately. However, the $1 \mathrm{~L}$ glass configuration that consisted of the I-Chem wide-mouth glass jar having a black phenolic lid with polyvinyl liner (Qorpak 5024) did not pass the vibration and $9 \mathrm{~m}$ (30-ft) drop tests. Two design changes were, therefore, made. The bottle lid was changed to include a black phenolic lid with polyethylene liner (Qorpak 5082), and the loading of the contents was reduced to simulate a liquid having a specific gravity of $\leq 1.6$. This combination of changes was successful for the $1 \mathrm{~L}$ glass configuration.

By evaluation and comparison with similar materials, it was determined that the $125 \mathrm{~mL}$ and $250 \mathrm{~mL}$ versions would have no negative impact on the overall performance of the Hardigg Case, NFT can assembly, and inner and outer stainless steel shielded assemblies. The 125 and $250 \mathrm{~mL}$ versions are lighter in weight compared to the $30 \mathrm{~mL}$ version that was tested. 
Refer to IATA, Sections 10.5.3.7 and 5.0.4.3 (IATA 2003). Vibration in commercial aircraft to which packagings may be exposed to range from $5 \mathrm{~mm}$ amplitude at $7 \mathrm{~Hz}$ (corresponding to $1 \mathrm{~g}$ acceleration) to 0.05 amplitude at $200 \mathrm{~Hz}$ (corresponding to $8 g$ acceleration).

Refer to Table A-7 for vibration testing information.

Table A-7. Vibration Testing.

\begin{tabular}{|c|c|c|c|}
\hline $\begin{array}{l}\text { Test Identification and } \\
\text { Package Configuration }\end{array}$ & Packaging Components & $\begin{array}{l}\text { Component } \\
\text { Weight }\end{array}$ & $\begin{array}{l}\text { Gross } \\
\text { Package } \\
\text { Weight }\end{array}$ \\
\hline Vibration (shielded)-Pass & $\begin{array}{l}\text { Hardigg Case: HH2-TU-01 } \\
\text { NFT Can Assembly: HH-005 } \\
\text { Outer Shield: 006959-02-250-C } \\
\text { Inner Shield: 006959-02-30-A } \\
30 \mathrm{~mL} \text { bottle } \\
\text { Disk } \\
\text { Belleville Washer } \\
\text { Nylon Inserts (2) }\end{array}$ & \begin{tabular}{r|}
$30.1 \mathrm{lb}$ \\
$5.2 \mathrm{lb}$ \\
$16.2 \mathrm{lb}$ \\
$12.6 \mathrm{lb}$ \\
$0.2 \mathrm{lb}$ \\
$1.2 \mathrm{lb}$ \\
$1.2 \mathrm{lb}$ \\
$2.9 \mathrm{lb}$ \\
\end{tabular} & $69.4 \mathrm{Ib}$ \\
\hline Vibration (1 L Plastic)-Pass & $\begin{array}{l}\text { Hardigg Case: HH2-TU-03 } \\
\text { NFT Can Assembly: HH-007 } \\
1 \text { L Plastic Bottle: P-1 }\end{array}$ & $\begin{array}{r}30.0 \mathrm{lb} \\
5.1 \mathrm{lb} \\
4.4 \mathrm{lb} \\
\end{array}$ & $39.5 \mathrm{lb}$ \\
\hline Vibration (1 L Glass)-Fail & $\begin{array}{l}\text { Hardigg Case: HH2-TU-02 } \\
\text { NFT Can Assembly: HH-002 } \\
1 \text { L Glass Bottle: G-1* } \\
\text { Disk } \\
\end{array}$ & $\begin{array}{r}30.3 \mathrm{lb} \\
5.1 \mathrm{lb} \\
5.0 \mathrm{lb} \\
1.1 \mathrm{lb} \\
\end{array}$ & $41.5 \mathrm{lb}$ \\
\hline Vibration (1 L Glass)-Fail & $\begin{array}{l}\text { Hardigg Case: HH2-TU-02 } \\
\text { NFT Can Assembly: HH-002 } \\
1 \text { L Glass Bottle: G-1A* } \\
\text { Disk }\end{array}$ & $\begin{array}{r}30.3 \mathrm{lb} \\
5.1 \mathrm{lb} \\
5.0 \mathrm{lb} \\
1.1 \mathrm{lb}\end{array}$ & $41.5 \mathrm{lb}$ \\
\hline Vibration (1 L Glass) ${ }^{*}$-Pass & $\begin{array}{l}\text { Hardigg Case: HH2-TU-01 (refurbished) } \\
\text { NFT Can Assembly: HH-002 } \\
\text { 1 L Glass Bottle: } \# 3(4-14-03)^{\star *} \\
\text { Disk }\end{array}$ & \begin{tabular}{r|}
$30.1 \mathrm{lb}$ \\
$5.1 \mathrm{lb}$ \\
$3.8 \mathrm{lb}$ \\
$1.1 \mathrm{lb}$ \\
\end{tabular} & $40.1 \mathrm{lb}$ \\
\hline
\end{tabular}

* $1 \mathrm{~L}$ glass bottle tested included the phenolic lid and polyvinyl liner (Qorpak 5024), and was loaded to simulate a liquid having a specific gravity equal to 2.0 .

** $1 \mathrm{~L}$ glass bottle tested included the phenolic lid and polyethylene liner (Qorpak 5082), and was loaded to simulate a liquid having a specific gravity equal to 1.6.

\section{Results:}

(1) On March 31, 2003, all three test units were placed onto the vibrating platform (at PNNL) and tested at the same time. To achieve the proper vibration height (as measured from the base of the package to the top of the vibration platform) for all three test units at once, the vibration platform required a higher hertz (HZ) due to the higher gross weight of the shielded configuration. As a result, the test units containing the $1 \mathrm{~L}$ bottles came up off the platform a much higher distance than the required $0.159 \mathrm{~cm}(0.0625$-in). The two test units containing the $1 \mathrm{~L}$ bottles appeared to leave the table at a distance of approximately 1.27 to $2.54 \mathrm{~cm}(0.50$ to $1 \mathrm{in})$. The third test unit containing the shielded configuration was confirmed to have left the platform a distance of at least $0.159 \mathrm{~cm}(0.0625 \mathrm{in})$. A $0.159 \mathrm{~cm}(0.0625 \mathrm{in}$.) piece of material was passed between the table and the test units. The table stopped after $\mathbf{4 5}$ minutes of operation for no apparent reason. The vibration equipment was 
HNF-13820, Rev. 0

immediately restarted and ran an additional 20 minutes for a total vibration time of at least 1 hour. The tested packaging configurations and results from this test were as follows:

- HH2-TU-01 contained the $30 \mathrm{~mL}$ shielded assembly. Upon conclusion of the vibration test, test unit HH2-TU-01 was turned on its side and observed for release of contents and damage. None was observed. This test unit was opened and the NFT can assembly turned on its side. No change or leakage of contents was observed. Due to past history and performance of the inner and outer shielded assemblies, the NFT can assembly was not opened after this vibration test.

- HH2-TU-02 contained the $1 \mathrm{~L}$ glass bottle assembly. Bottle $\mathrm{G}-1$ consisted of a $1 \mathrm{~L}$ widemouth glass bottle (I-Chem 321-100 or Fisher Scientific 05-719-89). The existing lid was replaced with a black phenolic lid with polyvinyl liner (Qorpak 5024 or Fisher Scientific 02-883-2Q). This bottle was tested with a liquid having a specific gravity $\leq \mathbf{2 . 0}$. This particular test unit included a disk that was "donut-shaped" instead of solid. The "donut-shaped" disk was the same material, diameter, and thickness as the solid disk for the intended design. The "donut-shaped" disk was used because the intended solid disk was included in the shielded configuration (HH2-TU-01). The use of the "donut-shaped" disk should not have an impact in the performance of the packaging during the vibration test. The $1 \mathrm{~L}$ bottles require taping circumferentially around the lid/body interface with 2-in.-wide PVC film tape. Shurtape VP-410 was used during testing. The $1 \mathrm{~L}$ bottle was double bagged.

Upon conclusion of the vibration test, test unit HH2-TU-02 was turned on its side and observed for release of contents and damage. None was observed. This test unit was opened and the NFT can assembly turned on its side. No change or leakage of contents was observed. The NFT can assembly was opened to ensure the $1 \mathrm{~L}$ glass bottle did not leak or break. Severe leakage from this bottle was indicated. Grit from sand was noted within the bottle threads. The polyvinyl gasket within the bottle lid slumped away from the lid on one side, allowing continuous loss of liquid. The bottle was reweighed and $0.136 \mathrm{~kg}(0.3 \mathrm{lb})$ of liquid was lost from the bottle as a result of this test. Approximately $1 / 2$ cup of liquid was measured as being lost from this bottle. Because of the "harshness" of the vibration test that was conducted (i.e., the test unit came up off the table much farther than the required 0.159 cm [0.0626-in.] distance), it was decided that a second vibration test would be conducted on this same $1 \mathrm{~L}$ glass bottle configuration. A new glass bottle assembly (G-1A) and only one test unit on the vibrating platform will be used to try and qualify this glass bottle configuration.

- HH2-TU-03 contained the $1 \mathrm{~L}$ poly bottle assembly. Bottle P-1 consisted of the $1 \mathrm{~L}$ widemouth poly bottle and lid (Nalgene 2105-0032 or Fisher Scientific 02-893D). This bottle was tested with a liquid having a specific gravity $\leq 2.0$. The $1 \mathrm{~L}$ bottles require taping circumferentially around the lid/body interface with 2-in.-wide PVC film tape. Shurtape VP-410 was used during testing.

Upon conclusion of the vibration test, test unit HH2-TU-03 was turned on its side and observed for release of contents and damage. None was observed. This test unit was opened and the NFT can assembly turned on its side. No change or leakage of contents was observed. The NFT can assembly was opened to ensure the inner poly bottle did not leak or break. No leakage from the bottle was indicated.

(2) Because of the $1 \mathrm{~L}$ glass bottle configuration failure during the first vibration test, a second vibration test was performed April 2, 2003. Prior to conducting this vibration test, a containment boundary verification was successfully performed on the NFT can assembly used within test unit HH2-TU-02. Bottle G-1A consisted of a $1 \mathrm{~L}$ wide-mouth glass bottle (I-Chem 321-100 or Fisher Scientific 05-719-89). The existing lid was replaced with a black phenolic lid with polyvinyl liner 
(Qorpak 5024 or Fisher Scientific 02-883-2Q). This bottle was tested with a liquid having a specific gravity $\leq 2.0$. The $1 \mathrm{~L}$ bottle was taped circumferentially around the lid/body interface with 2-in.wide PVC film tape. Shurtape VP-410 was used during testing. The $1 \mathrm{~L}$ bottle was double bagged. The solid inner disk was inserted into this test unit as identified on Hanford drawing H-2-830874 (i.e., was not the "donut shaped" disk).

This single test unit was placed onto the vibration platform. Testing was conducted and a $0.159 \mathrm{~cm}$ $(0.0625$-in.) piece of material was passed between the table and the test unit. This was a less vigorous test than the prior vibration test that was conducted with all three test units at one time because of the lighter weight being placed on the vibration platform. Upon conclusion of the vibration test, test unit HH2-TU-02 was turned on its side and observed for release of contents and damage. None was observed. This test unit was opened and the NFT can assembly was opened to ensure the inner glass bottle did not leak or break. The same test results were indicated with Bottle G-1A as had been indicated with Bottle G-1. Severe leakage from the bottle was indicated. Grit from sand was noted within the bottle threads. The polyvinyl gasket within the bottle lid slumped away from the lid on one side, allowing continuous loss of liquid. The bottle was reweighed and $0.136 \mathrm{~kg}(0.3 \mathrm{lb})$ of liquid was lost from this test. Approximately $1 / 2$ cup of liquid was measured as being lost from this bottle.

(3) A third vibration test was performed on the $1 \mathrm{~L}$ glass bottle configuration April 15, 2003. Because of the historical success of the NFT can assembly maintaining containment during testing activities, a pressure test was not performed prior to or after this vibration test. The bottle used for this vibration test was marked as "Bottle \#3 (4-14-03)" which included $1 \mathrm{~L}$ wide-mouth glass bottle (IChem 321-100 or Fisher Scientific 05-719-89). The existing lid was replaced with a black phenloic lid with polyethylene liner (Qorpak 5082). Simulated loading consisted of a liquid having a specific gravity of $\leq 1.6$. The case used to conduct this test was HH2-TU-01 "refurbished" and included new latches, hinges, and lid foam. The solid inner disk was inserted into this test unit as identified on Hanford drawing H-2-830874 (i.e., was not the donut shaped disk).

Upon conclusion of the vibration test, test unit HH2-TU-01 was turned on its side and observed for release of contents and damage. None was observed. This test unit was opened and the NFT can assembly was opened to ensure the inner glass bottle did not leak or break. The bottle did not leak or break. There was no sand (grit) evidence around the threaded lid seal or up underneath the lid liner. 


\subsection{REFERENCES}

10 CFR 71.53, "Fissile Material Exemptions," Code of Federal Regulations, as amended.

49 CFR 172, "Hazardous Materials Table, Special Provisions, Hazardous Materials Communications, Emergency Response Information, and Training Requirements," Code of Federal Regulations, as amended.

49 CFR 173, "Shippers---General Requirements for Shipments and Packagings," Code of Federal Regulations, as amended.

49 CFR 178, "Specifications for Packagings," Code of Federal Regulations, as amended.

ASTM A240, 2002, Standard Specification for Chromium and Chromium-Nickel Stainless Steel Plate, Sheet, and Strip for Pressure Vessels and for General Application, American Society for Testing and Materials, Philadelphia, Pennsylvania.

ASTM A276, 2002, Standard Specification for Stainless Steel Bars and Shapes, American Society for Testing and Materials, Philadelphia, Pennsylvania.

ASTM A511, 1996, Standard Specification for Seamless Stainless Steel Mechanical Tubing, American Society for Testing and Materials, Philadelphia, Pennsylvania.

ASTM D1056, 2000, Standard Specification for Flexible Cellular Materials-Sponge or Expanded Rubber, American Society of Testing and Materials, Philadelphia, Pennsylvania.

ASTM F835, 2000, Standard Specification for Alloy Steel Socket Button and Flat Countersunk Head Cap Screws, American Society of Testing and Materials, Philadelphia, Pennsylvania.

DFSNW-SOW-02-027, 2002, Statement of Work for Nuclear Filter Technology: Development of an Intermediate Container for the Modified Hedgehog (Type A) Packaging, Rev. 0, Duratek Federal Services, Inc., Northwest Operations, Richland, Washington.

DOE/RL-96-57, 2001, Test and Evaluation Document for DOT Specification 7A Type A Packaging, Vol. 1, Rev. 0-F, U.S. Department of Energy, Richland Operations Office, Richland, Washington.

HNF-11651, Operations and Maintenance Manual for Hedgehog-II Packaging Systems, Rev. 0, Duratek Technical Services, Richland, Washington.

HNF-13819, 2003, Test Plan for Hedgehog-II Packaging Systems, Type A Container, Rev. 1-A, Duratek Technical Services, Richland, Washington.

IAEA, 1990, Regulations for the Safe Transport of Radioactive Material, 1995 Edition, Safety Series No. 6, as amended 1990, International Atomic Energy Agency, Vienna, Austria.

IAEA, 2000, Regulations for the Safe Transport of Radioactive Material: 1996 Edition (Revised), Safety Standards Series No. TS-R-1 (ST-1 Revised), International Atomic Energy Agency, Vienna, Austria.

IATA, 2003, Dangerous Goods Regulations, $44^{\text {th }}$ Edition, Effective from 1 January through 31 December 2003, International Atomic Energy Agency, Vienna, Austria.

WHC-SD-OTR-001, 1995, Test and Evaluation Report for Westinghouse Hanford Company's Hedgehog Shielded Container, Docket 94-39-7A, Type A Container, Rev. 1, Westinghouse Hanford Company, Richland, Washington. 
HNF-13820, Rev. 0

\section{APPENDIX B}

OPENING, LOADING, AND CLOSURE INSTRUCTIONS

USED FOR TESTING 
HNF-13820, Rev. 0

This page intentionally left blank.

B-ii 
HNF-13820, Rev. 0

\section{B1.0 GENERAL INFORMATION}

The simulated payload to be used during testing is described in HNF-13819, Test Plan for Hedgehog-II Packaging Systems, Type A Container, Section 5.0. The testing sequence and the test unit configuration are described in HNF-13819, Section 6.0

\section{B2.0 HARDIGG CASE ${ }^{1}$}

\section{B2.1 HARDIGG CASE-OPENING INSTRUCTIONS}

1. The exterior top of the Hardigg Case will need to be marked "This End Up" to ensure that the packaging is loaded and unloaded properly. Ensure that the proper orientation of the case is marked. The internal, black, acrylonitrile-butadiene-styrene (ABS) load spacer is located below the Nuclear Filter Technology, Inc. $\left(\mathrm{NFT}^{2}\right)$, can assembly. The slitted gasket within the case is located at the base of the packaging as it would normally be positioned during transport. Refer to Figure B-1 for a diagram of the proper case orientation during shipping.

2. Open the case by unlatching, turning, and lifting each butterfly latch up and over the lip of the catch mechanism. Turn each latch counterclockwise.

\section{B2.2 HARDIGG CASE-CLOSURE INSTRUCTIONS}

1. Orient the case so that the lid faces upward. Close the lid.

2. Secure the case lid by hooking the butterfly latches up and over the lip of the catch mechanism, then turn clockwise until tight.

3. Orient the case in the upright position. (refer to Figure B-1).

\footnotetext{
'Hardigg Cases is a registered trademark of Hardigg Industries, Inc., Deerfield, Massachusetts.

${ }^{2} \mathrm{NFT}$ is a registered trademark of Nuclear Filter Technology, Inc., Lakewood, Colorado.
} 
HNF-13820, Rev. 0

Figure B-1. Hardigg Case (Typical).

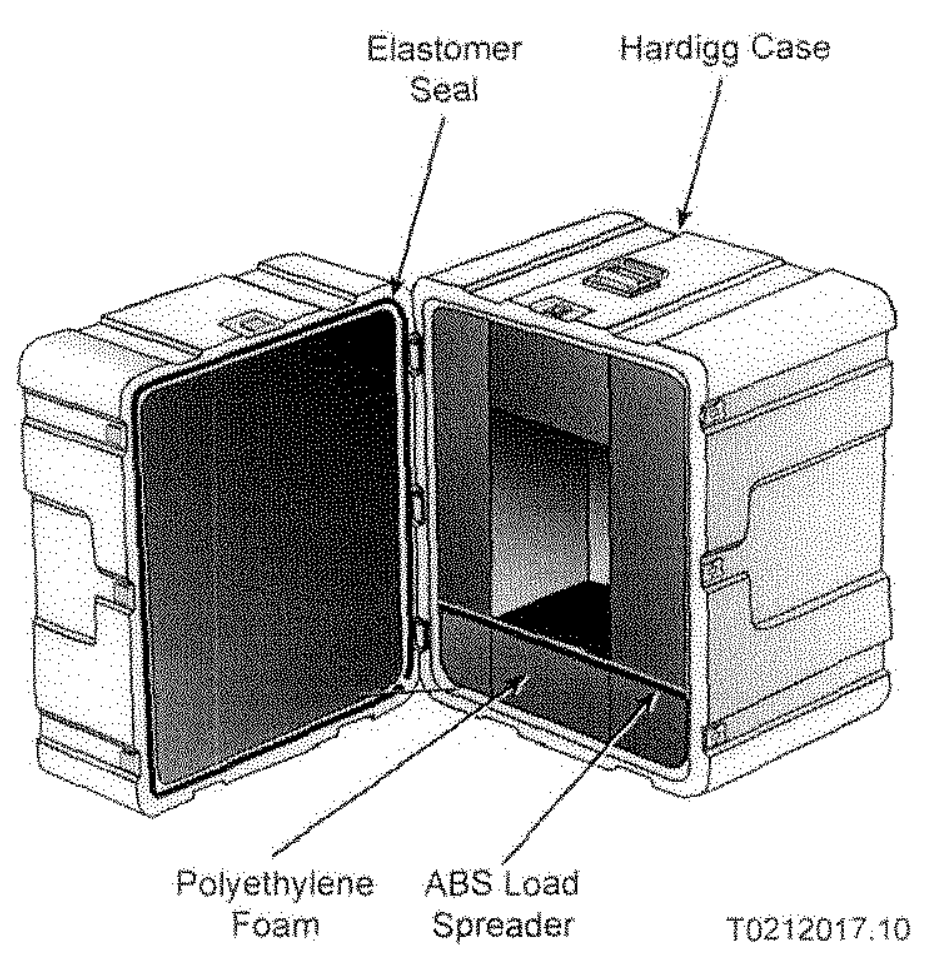

\section{B3.0 NFT CAN ASSEMBLY}

NOTE: The NFT canister body and mating lid must be marked with the same serial number.

\section{B3.1 NFT CAN ASSEMBLY-OPENING INSTRUCTIONS}

1. Secure the NFT canister body. If required, secure an appropriate-sized strap wrench around the can body.

2. Unlatch the NFT can by lifting the pull ring plunger assembly upward, and turning 90 degrees to lock it into the raised position. Refer to Figure $B-2$.

3. Unscrew the lid by turning counter clockwise. 
HNF -13820 , Rev. 0

\section{B3.2 NFT CAN ASSEMBLY-CLOSURE INSTRUCTIONS}

1. Ensure foreign material/debris is removed from the canister body, o-ring, and lid threads.

2. Ensure that o-ring is in place and undamaged.

3. Before each closure, the o-ring should be checked for cracking and lubricated using silicone based seal grease (e.g., Parker Super-O-Lube). The oring should be replaced if cracked or very dry.

4. Secure the NFT canister body. If required, secure an appropriate-sized strap wrench around the can body.

5. Lif the pull ring plunger assembly upward, and turn 90 degrees to lock it into the raised position. Refer to Figure $\mathrm{B}-2$.

6. Place the lid onto the canister body. It is important that the lid is lowered straight down onto the thread ring prior to turning and engaging threads; otherwise, cross-threading may result.

7. Gently tum the lid clockwise to engage the threads. Approximately three full tums will engage the lid to the orring.

8. Tighten the lid about 2 degrees where the center of the closure pin is over the top of the pin capture. Refer to Figure B-2.

9. Lift and turn the pin back 90 degrees to the unlocked position and finish turning the lid until the pin is engaged in the pin capture. A slight click should be heard.

Figure B-2. NFT Can Latch Mechanism.

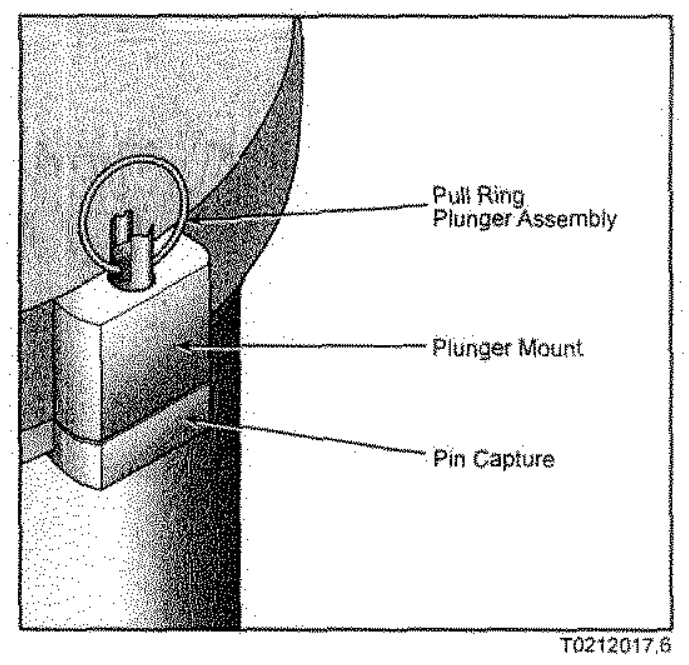


HNF-13820, Rev. 0

\section{B4.0 STAINLESS STEEL SHIELDED CONTAINERS}

NOTE: The cover of each shielded container (outer and inner container assemblies) will be notched. Each shielded container is uniquely identified. The cover, wall, and base of each shielded container must be marked with the same identification markings.

\section{B4.1 STAINLESS STEEL SHIELDED CONTAINERS-OPENING INSTRUCTIONS}

NOTE: Two different screw sizes exist with the outer container assembly. The shorter (3/4-in.) screws are to be used to attach the base to the body; the longer (1-in.) screws are to be used to attach the lid to the body. The $30 \mathrm{~mL}$ inner assembly uses 1 -in. screws for the cover and base.

NOTE: The base of the shielded containers will not require opening during testing activities.

1. To remove the cover on the stainless steel shielded container, remove the four screws and pull straight upward on the lifting cable.

\section{B4.2 STAINLESS STEEL SHIELDED CONTAINERS-CLOSURE INSTRUCTIONS}

NOTE: The shielded containers provided for use in testing will already have new o-rings installed in the cover and base. The base of the outer container will not require removal during testing; therefore, this particular o-ring will not be inspected prior to or during testing.

1. Ensure that cover o-ring groove is clean. Verify that the o-ring is not damaged. Apply a light coating of silicone-based seal grease to the o-ring.

2. Install o-ring onto cover if needed.

3. Place the cover onto the appropriate wall.

4. Align the wall and cover matching marks. The screw holes should also be aligned.

5. Insert the 1-in. cover screws. Tighten the screws in a crisscross pattern. Torque all screws to 1.9-2.0 N-m (17-18 in-lb).

6. If placing the inner shielded container into the outer shielded container, the lifting cable for the inner container will need to lie flat against its lid to acquire closure of the outer shielded container, and without causing damage to the inner container lifting cable. 
HNF-13820, Rev. 0

\section{B5.0 INTERNAL SAMPLE BOTTLE-LOADING AND CLOSURE}

Two different sizes of bottles will be used for testing: $30 \mathrm{~mL}$ and $1 \mathrm{~L}$. One $30 \mathrm{~mL}$ bottle will be used, and two different styles of $1 \mathrm{~L}$ bottles (glass and plastic) will be used in testing. Ensure that each style of $1 \mathrm{~L}$ bottle configuration is uniquely marked with the appropriate test unit number as follows:

1 L glass bottle G1 through G6

$1 \mathrm{~L}$ plastic bottle $\quad$ P1 through P6

NOTE: Field changes may occur during testing activities. Any additional components required for use in testing or marking changes made in the field during testing activities will be identified and documented on the appropriate test data sheet.

\section{B5.1 $30 \mathrm{~mL}$ SAMPLE BOTTLE}

1. The $30 \mathrm{~mL}$ bottle shall be filled with simulated contents identified to equal a specific gravity of 2.0. Refer to HNF-13819, Section 5.0 for additional information.

\section{Simulated Contents:}

60 -g (2.1 oz) of BB-size shot--Fill remainder of bottle with water, leaving a slight head space (about 10 percent ullage).

2. Wipe the bottle threads with a clean, lint-free cloth.

3. Secure the lid to the bottle until hand-tight.

4. Ensure all residue/water is removed from the outside of the bottle.

5. Install the $30 \mathrm{~mL}$ bottle in one appropriate-sized poly bag. Twist the open end of the bag closed. Wrap the excess poly bag around the bottle in such a manner that it will fit inside the $30 \mathrm{~mL}$ inner container.

\section{B5.2 1 L GLASS SAMPLE BOTTLE}

1. The $1 \mathrm{~L}$ glass bottle shall be filled with simulated contents identified to equal a specific gravity of 1.6. Refer to HNF-13819, Section 5.0 for additional information.

\section{Simulated Contents:}

Fill the bottle with $1.04 \mathrm{~kg}(2.3 \mathrm{lb})$ of sand and $0.23 \mathrm{~kg}(0.5 \mathrm{lb})$ of water, leaving a $10 \%$ ullage. Add fluorescein for leak detection purposes. 
HNF-13820, Rev. 0

2. Wipe the bottle threads with a clean, lint-free cloth.

3. Secure the lid to the bottle until hand-tight.

NOTE: The $1 \mathrm{~L}$ glass bottle will have the blue I-Chem lid replaced with a Qorpak black phenolic lid with polyethylene liner.

4. Ensure all residue/water is removed from the outside of the bottle.

5. Wrap tape circumferentially around the lid/body interface.

6. Insert the $1 \mathrm{~L}$ bottle in an appropriate-sized poly bag. Twist the open end of the bag closed (DO NOT horsetail), and seal the twisted portion with masking tape.

NOTE: The $1 \mathrm{~L}$ glass bottle shall have the twisted and taped portion of the bag placed along one side of the bottle and not directly over the lid area.

7. Repeat the process for the $1 \mathrm{~L}$ bottle using a second bag.

NOTE: The $1 \mathrm{~L}$ glass bottle shall have this second twisted and taped portion of the bag placed along the side of the bottle-opposite that of the first bag and not directly over the lid area.

\section{B5.3 1 L PLASTIC SAMPLE BOTTLE}

1. The $1 \mathrm{~L}$ plastic bottle shall be filled with simulated contents identified to equal a specific gravity of 2.0. Refer to HNF-13819, Section 5.0 for additional information.

\section{Simulated Contents:}

Fill the bottle with $0.49 \mathrm{~kg}(1.09 \mathrm{lb})$ of sand, $0.76 \mathrm{~kg}(1.67 \mathrm{lb})$ of shot, and $0.35 \mathrm{~kg}(0.78 \mathrm{lb})$ of water, leaving a $10 \%$ ullage. Add fluorescein for leak detection purposes.

2. Wipe the bottle threads with a clean, lint-free cloth.

3. Secure the lid to the bottle until hand-tight.

4. Ensure all residue/water is removed from the outside of the bottle.

5. Wrap tape circumferentially around the lid/body interface. 
HNF-13820, Rev. 0

6. Insert the $1 \mathrm{~L}$ bottle in an appropriate-sized poly bag. Twist the open end of the bag closed, and seal the twist with masking tape. Fold the taped end onto itself and re-tape; i.e., horsetail.

NOTE: For the $1 \mathrm{~L}$ poly bottle, the twisting and taping of the bag may be placed directly over the lid or along the side of the lid area.

7. Repeat the process for the $1 \mathrm{~L}$ bottle using a second bag.

\section{B6.0 PACKAGING ASSEMBLY}

\section{B6.1 SHIELDED CONTAINER-30 mL VERSION}

NOTE: The inner and outer container assemblies are used for this version. Refer to Figure B-3.

1. Place the bagged $30 \mathrm{~mL}$ bottle, filled with simulated contents, inside the $30 \mathrm{~mL}$ inner container, in the upright position.

2. Close the inner container assembly in accordance with the appropriate closure instructions per Section B4.2.

3. Place the $30 \mathrm{~mL}$ inner container assembly, in the upright position, into the outer container assembly body.

4. Close the outer container assembly in accordance with the appropriate closure instructions per Section B4.2.

5. Open the NFT can assembly per Section B3.1.

6. Ensure the bottom and side shock protectors (cushioning material) are installed in the can.

7. Insert the shielded container assembly with cover side up into the NFT can.

8. Place the foam insert, stainless steel disk, and belleville washer on top of the shielded container assembly. Ensure the concave side of the belleville washer is placed above the stainless steel disk. Refer to Figure B-3.

9. Close the NFT can in accordance with the appropriate instructions per Section B3.2. 
HNF-13820, Rev. 0

Figure B-3. $30 \mathrm{~mL}$ Shielded Configuration.

(no bags shown)

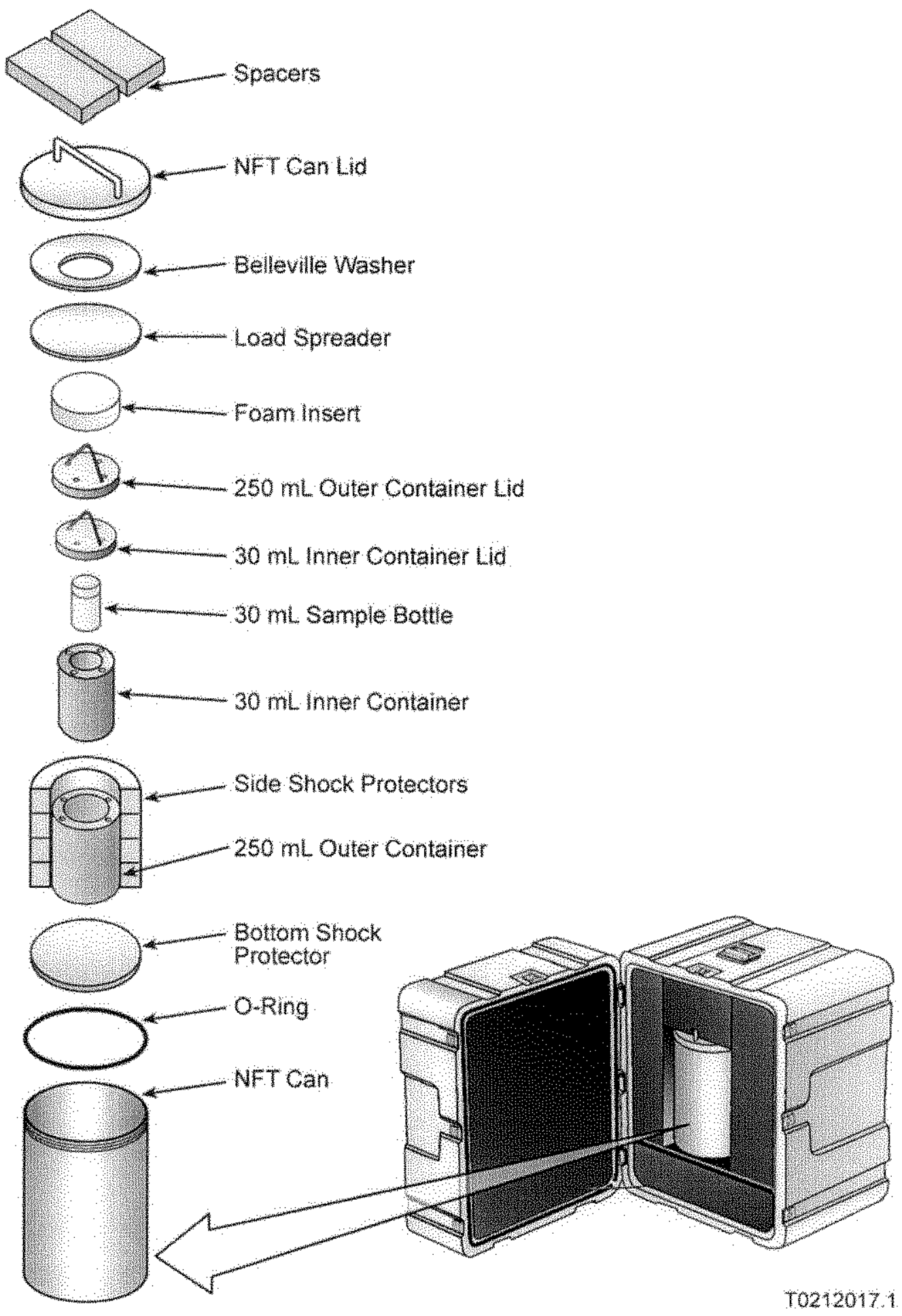


HNF 13820 , Rev. 0

\section{B6.2 11. GLASS BOTTLE CONFIGURATION}

1. Ensure the bottom and side shock protectors (cushioning material) are installed in the NFT can.

2. Place the bagged $1 \mathrm{~L}$ glass bottle, filled with simulated contents, inside the NFT can, in the upright position.

3. Place the foam insert, stainless steel load spreader, and top shock protector on top of the bottle. Refer to Figure B-4.

4. Close the NFT can in accordance with the appropriate instructions per Section B3.2.

Figure B-4. 1 L Glass Bottle Configuration.

(no bags shown)

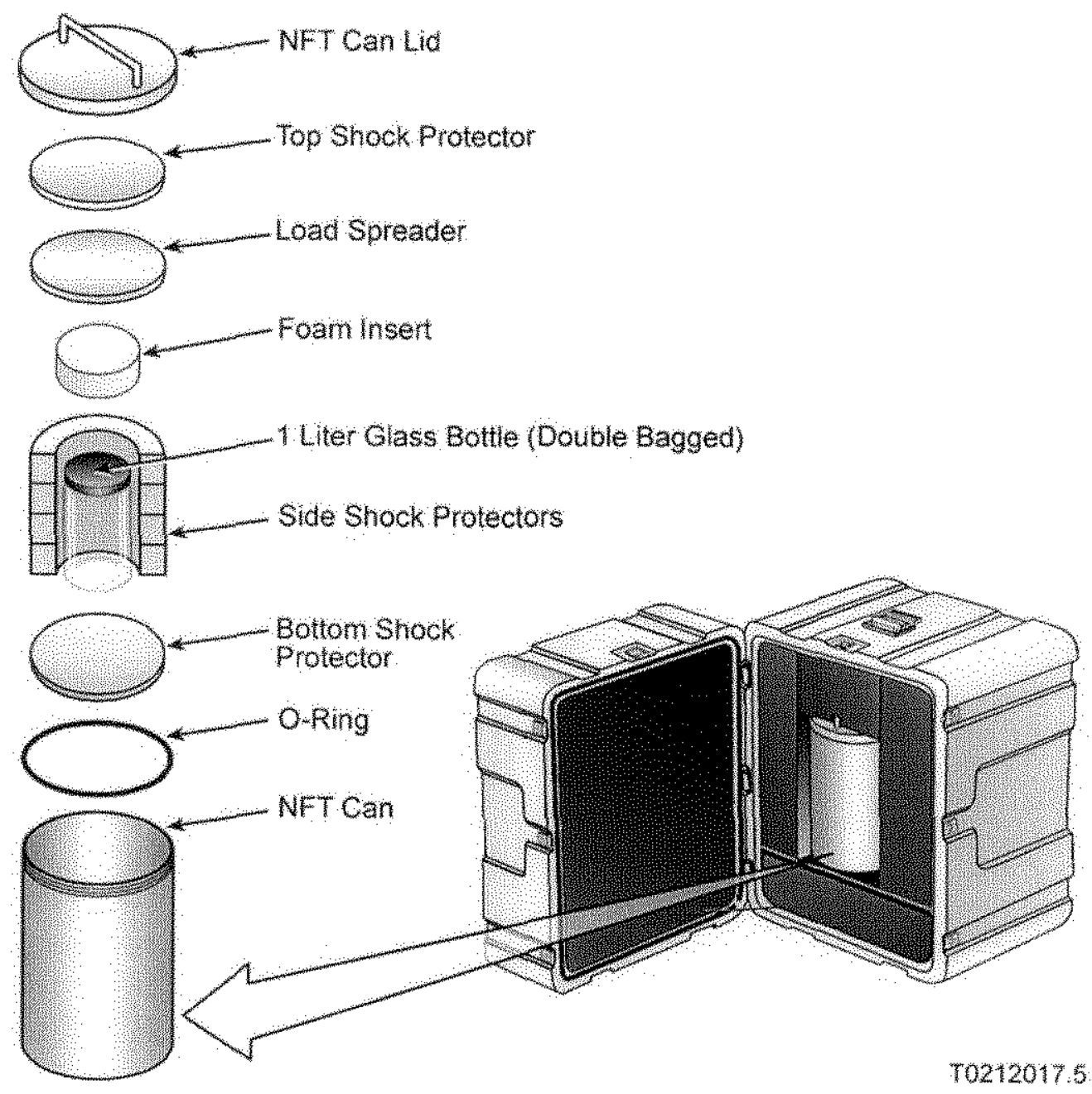


HNF-13820, Rev, 0

\section{B6.3 1 L POLY BOTTLE CONFIGURATION}

1. Ensure the bottom and side shock protectors (cushioning material) are installed in the NFT can.

2. Place the bagged $1 \mathrm{~L}$ poly bottle, filled with simulated contents, inside the NFT can, in the upright position.

3. Place the top shock protector (cushioning material) on top of the bottle. Refer to Figure $\mathrm{B}-5$.

4. Close the NET can in accordance with the appropriate instructions per Section B3.2.

Figure B-5, 1 L Poly Bottle Configuration. (no bags shown)

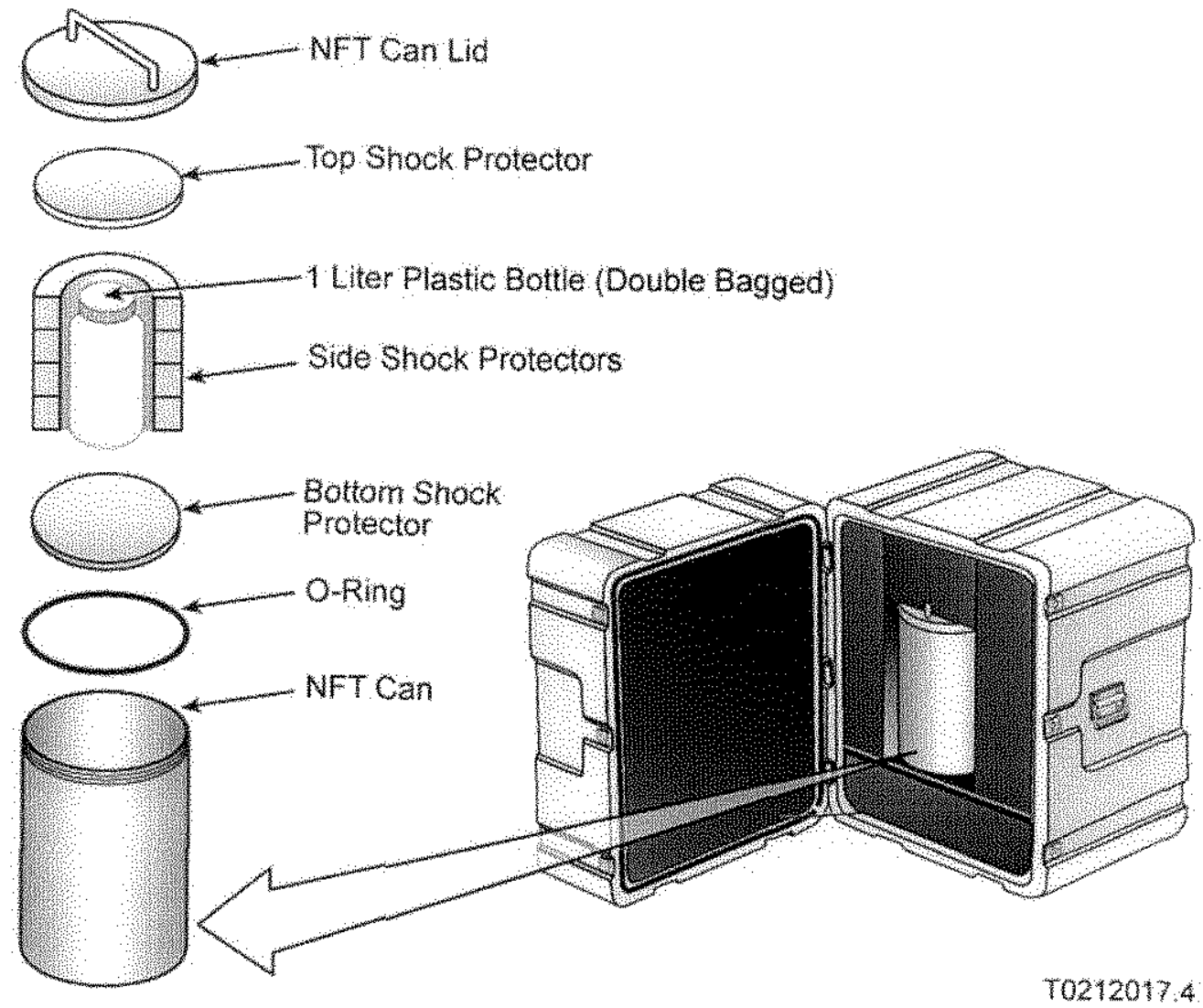


HNF-13820, Rev. 0

\section{B6.4 FINAL ASSEMBLY-ALL VERSIONS}

1. Place the NFT can assembly into an appropriate-sized poly bag. (This bag aids in the subsequent removal of the intermediate container from the case foam.)

2. Open the Hardigg Case per Section B2.1.

3. Ensure the foam arrangement for the Hardigg Case is applicable for the configuration being inserted. Refer to Figures B-6 and B-7.

4. Place the bagged NFT can assembly, loaded with simulated contents, into the foam cavity within the Hardigg Case. Ensure the top of the NFT can assembly matches the case orientation markings; i.e., the black, ABS load spacer is located underneath the NFT can; the top of the can is facing the end of the Hardigg Case marked "This End Up."

5. Ensure that the NFT can assembly is oriented such that the pull-ring plunger assembly is facing in the upward position. Refer to Figures B-6 and B-7.

6. Shielded Configuration: Ensure that the two nylon spacers are placed into position as shown in Figure B-6.

7. Close the Hardigg Case in accordance with closure instructions per Section B2.2.

8. Obtain gross packaging weight and record on appropriate test data sheet. 
HNF-13820, Rev. 0

Figure B-6. Shielded Assembly.

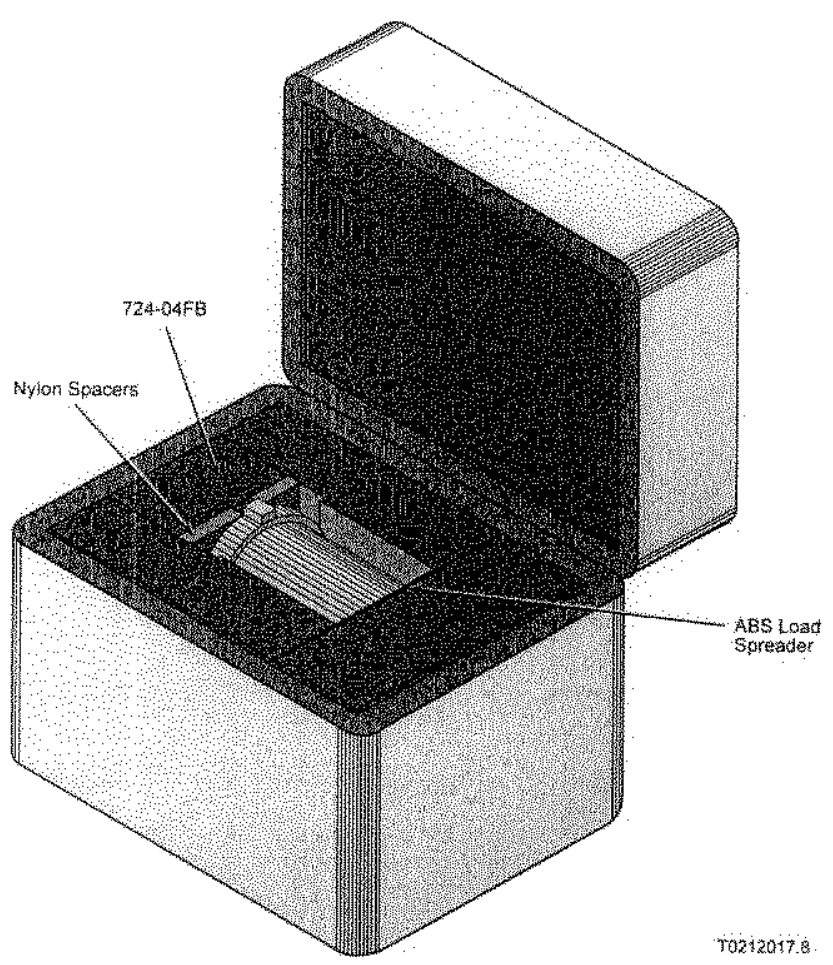

Figure B-7. 1L Bottle Assembly,

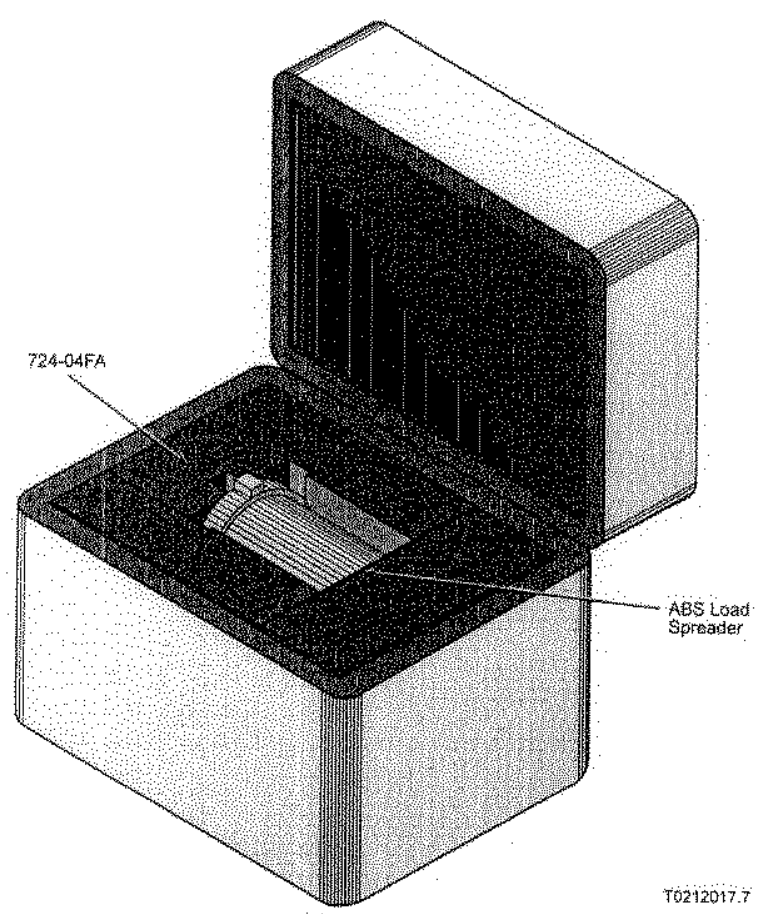

$\mathrm{B}-12$ 
HNF-13820, Rev. 0

\section{B7.0 REFERENCE}

HNF-13819, Test Plan for Hedgehog-II Packaging Systems, Type A Container, Rev. 1-A, Duratek Technical Services, Richland, Washington. 
HNF-13820, Rev. 0

This page intentionally left blank.

B-14 
HNF-13820, Rev. 0

\section{APPENDIX C DRAWINGS}

C-i 
HNF-13820, Rev. 0

This page intentionally left blank.

C-ii 


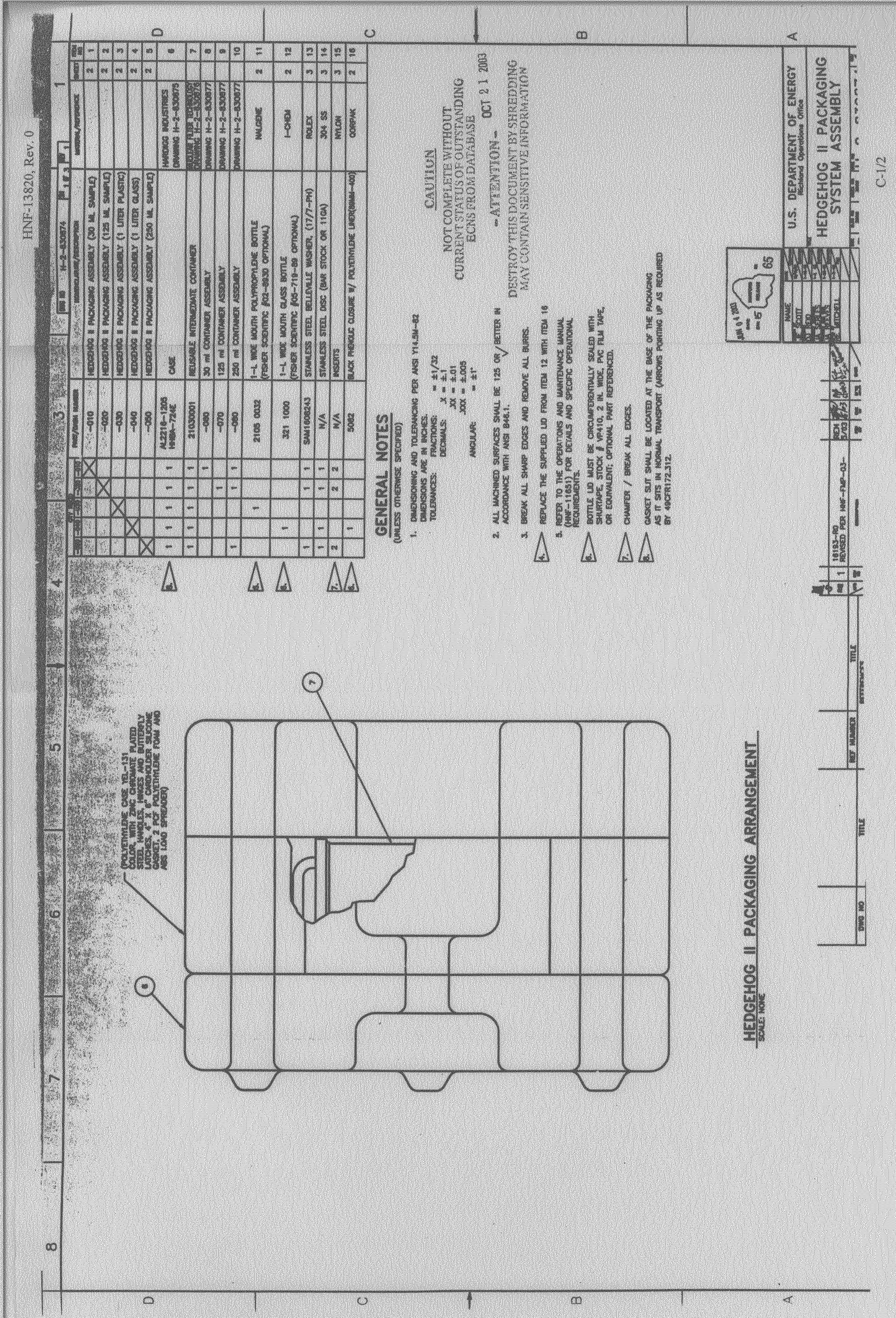




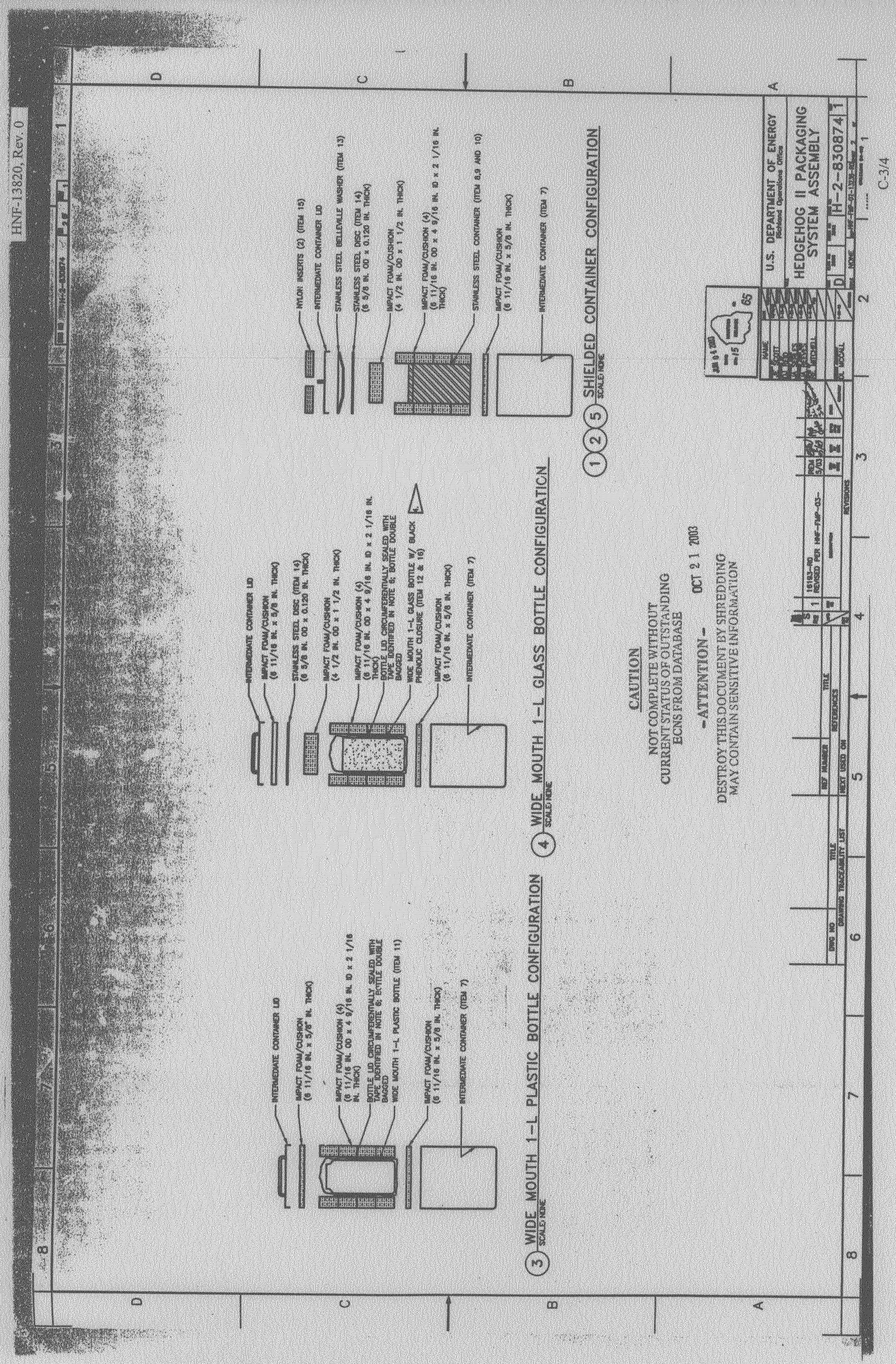




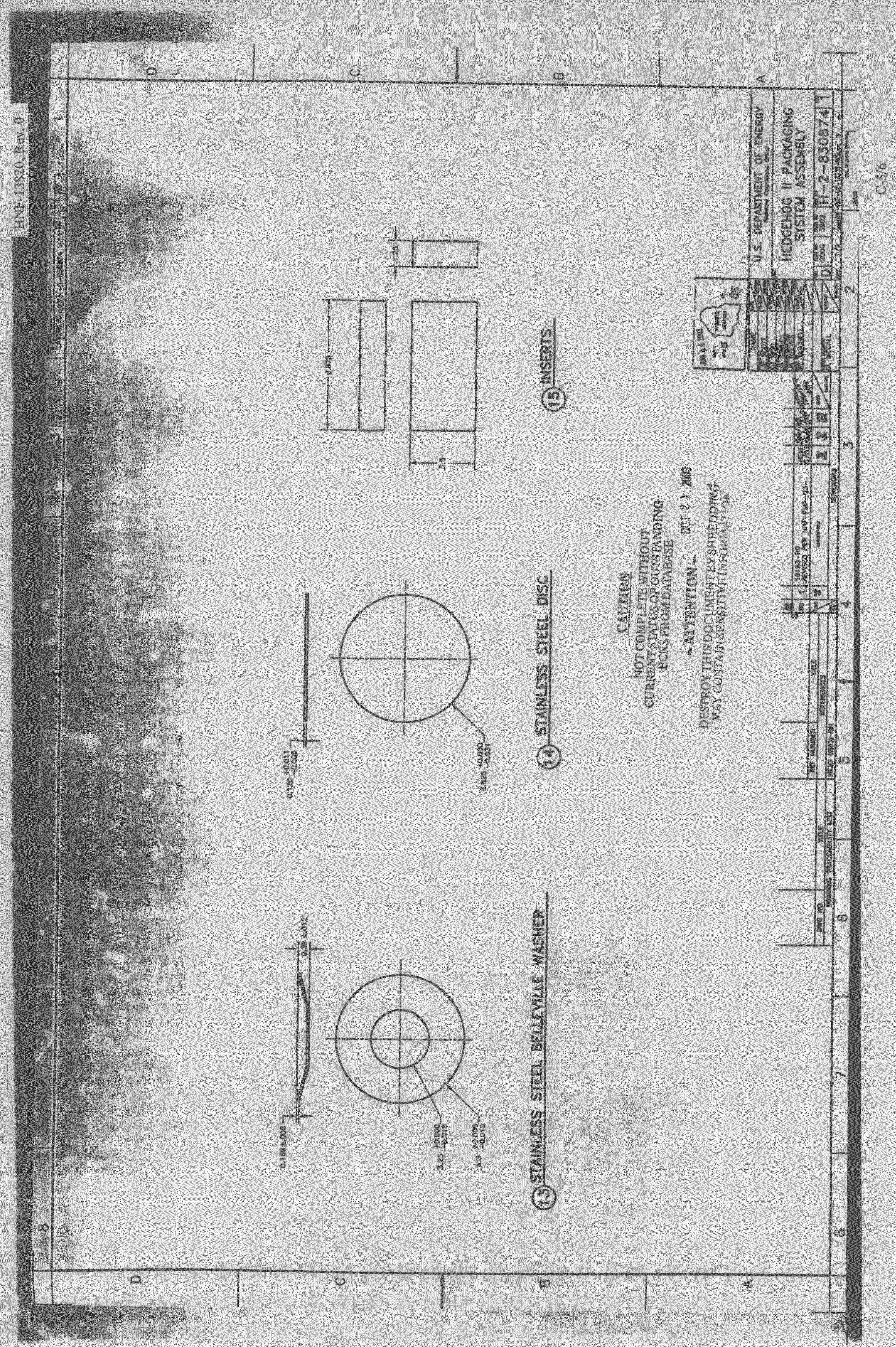




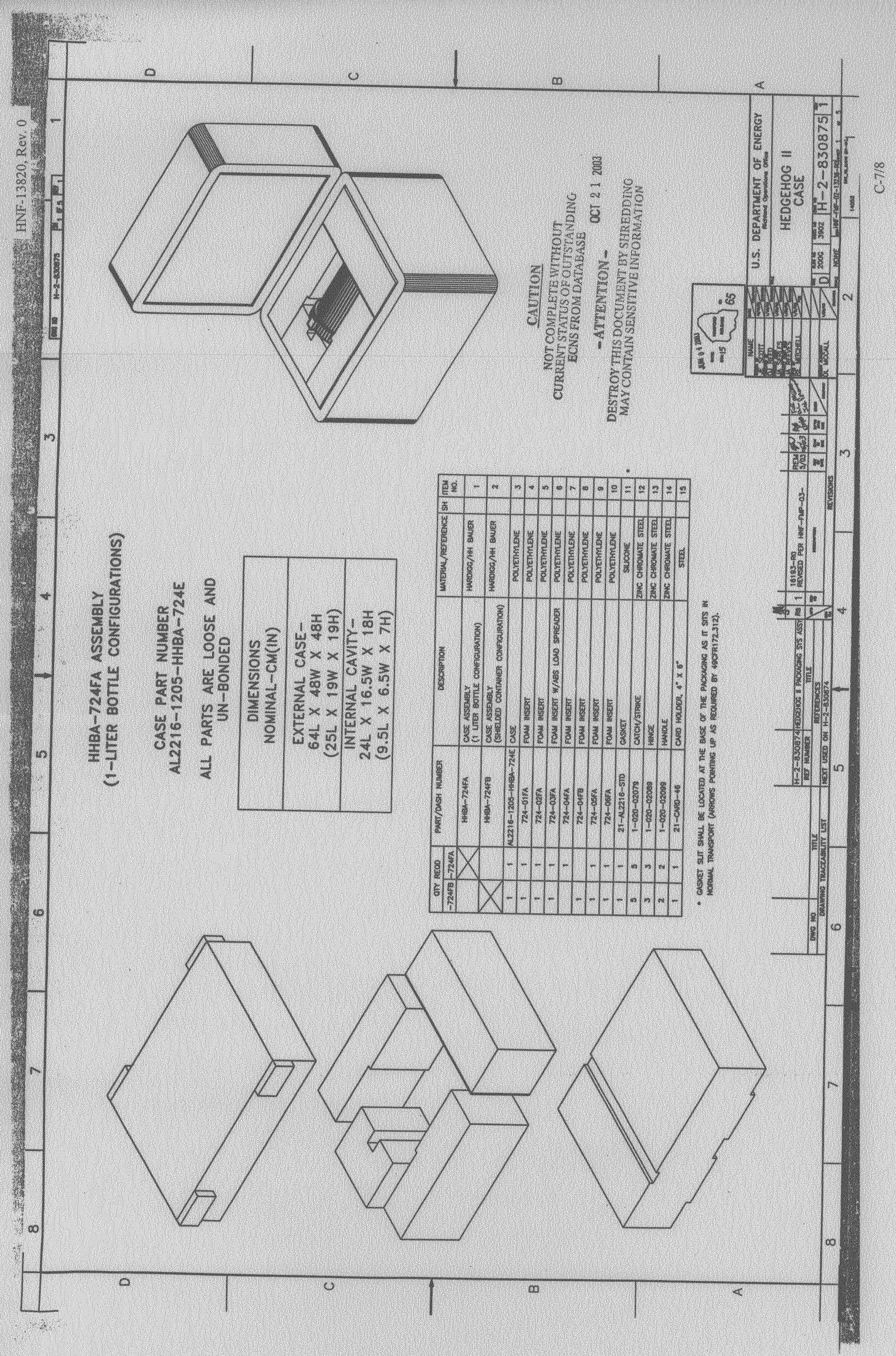




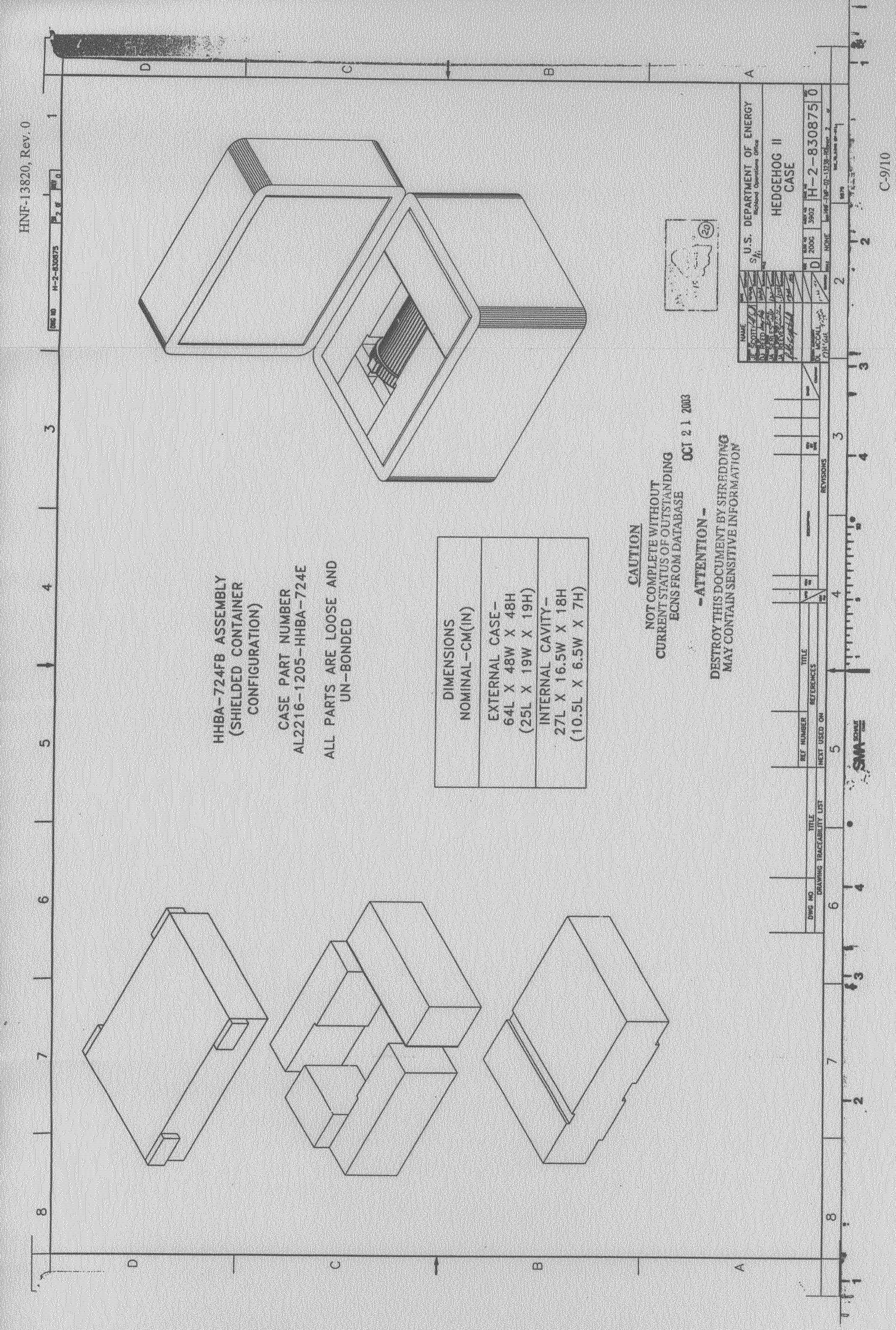




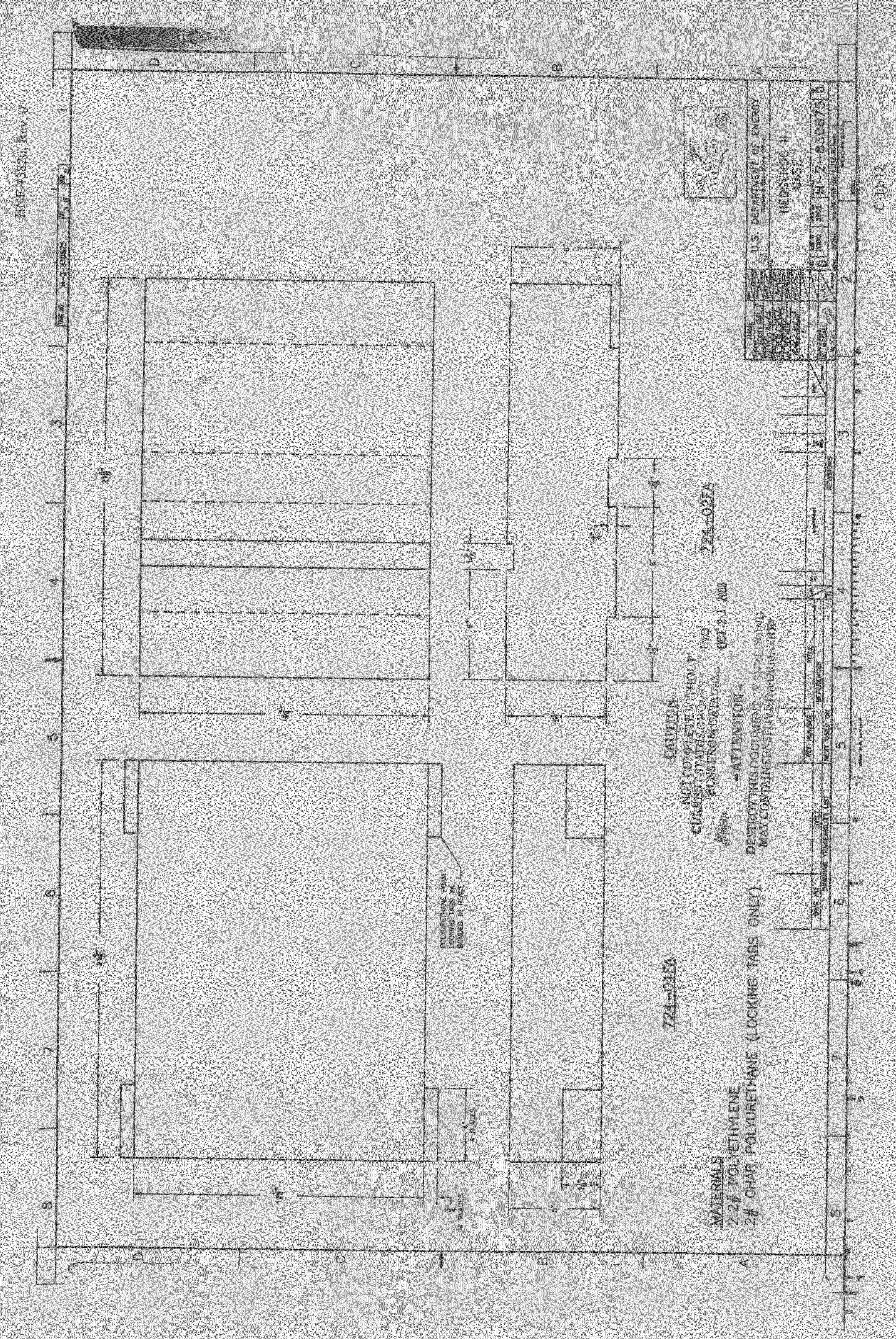




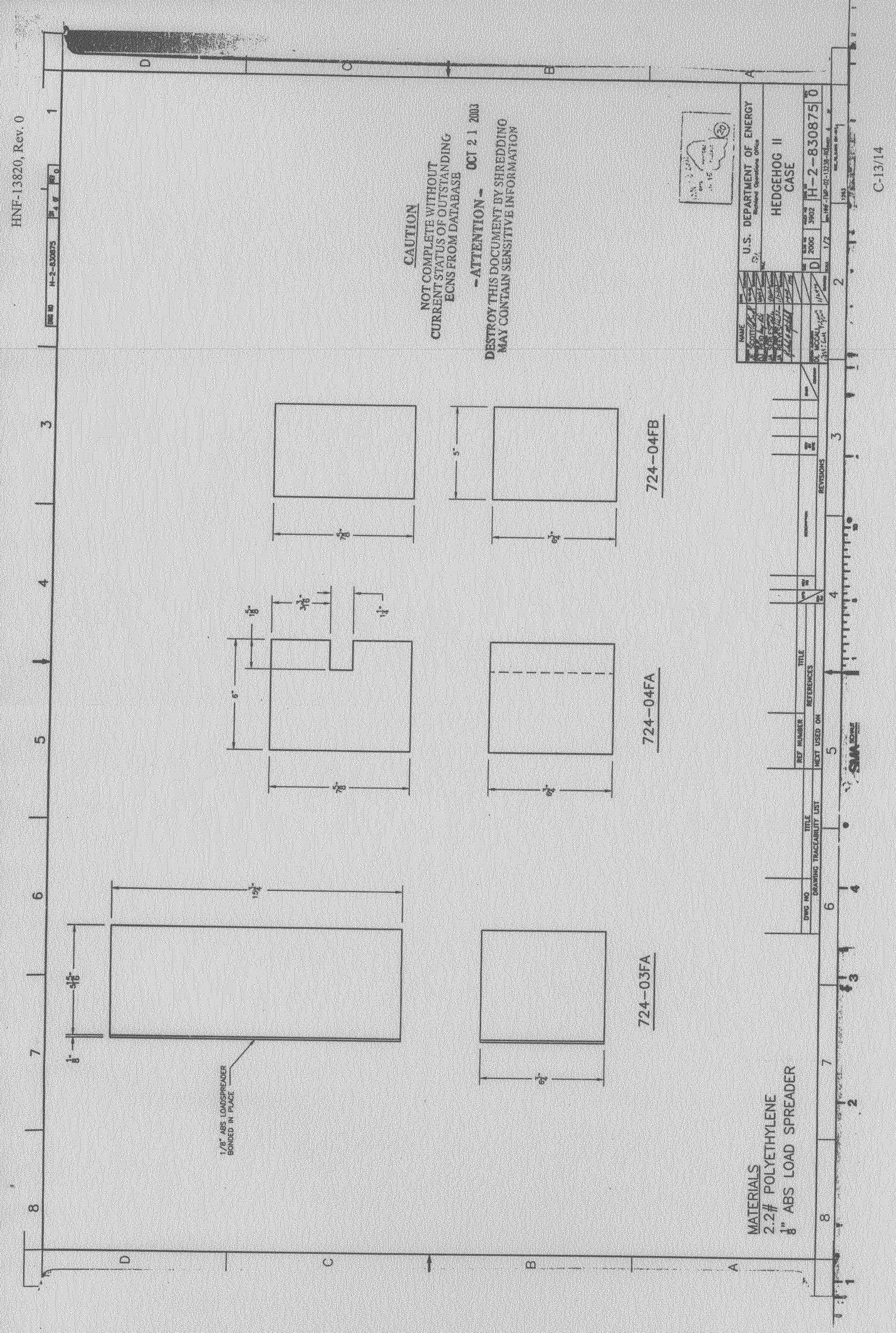




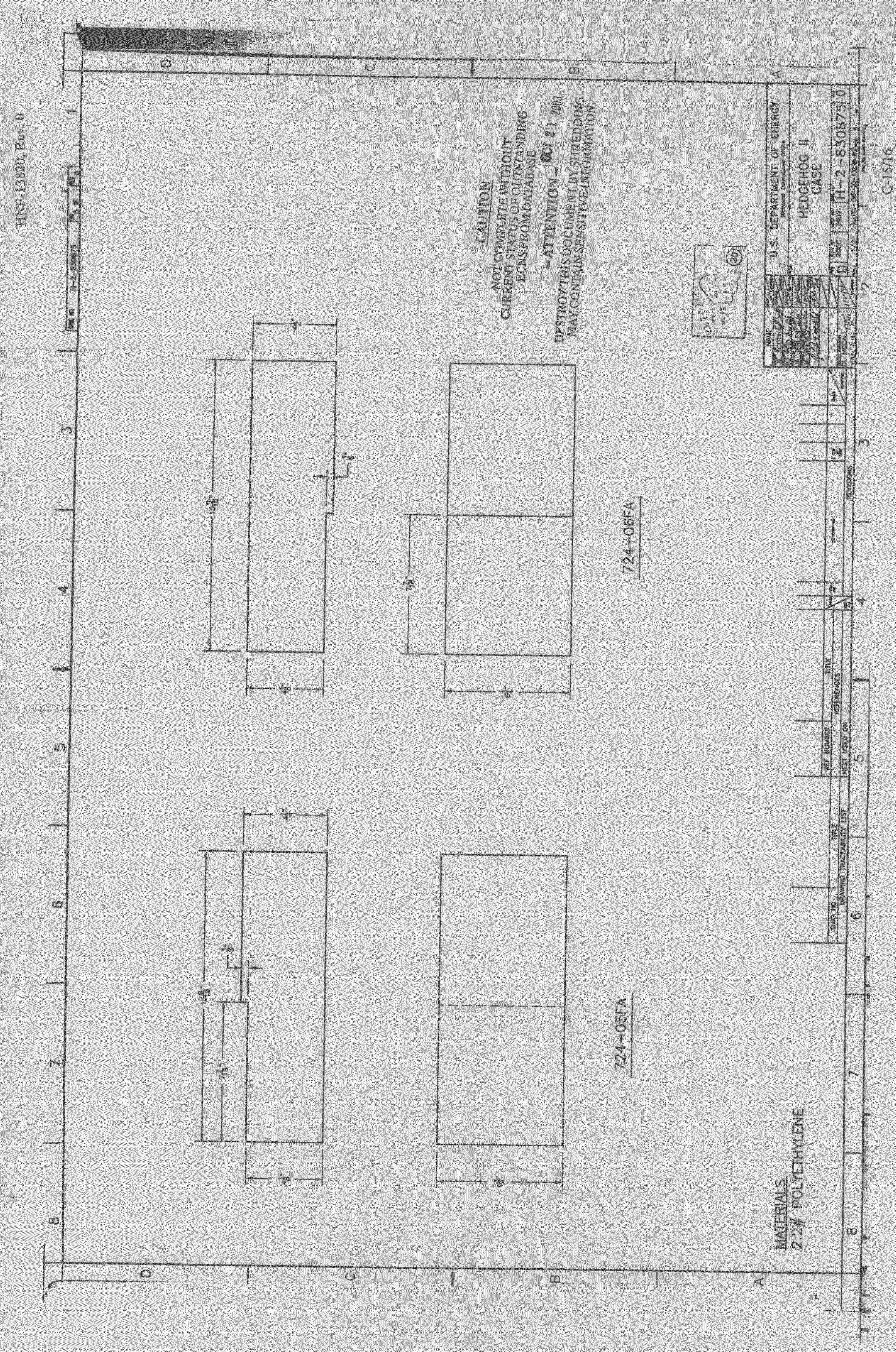




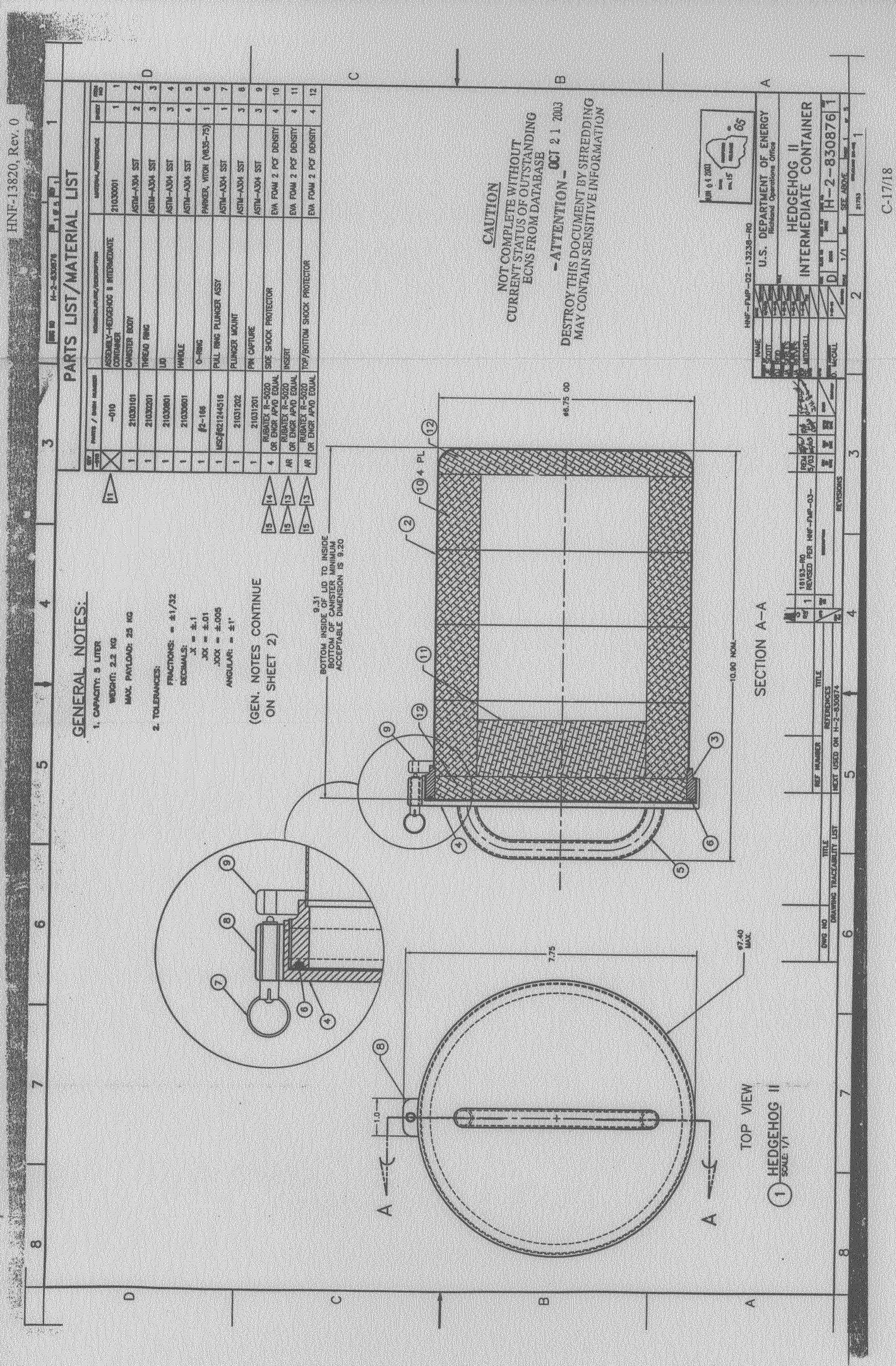




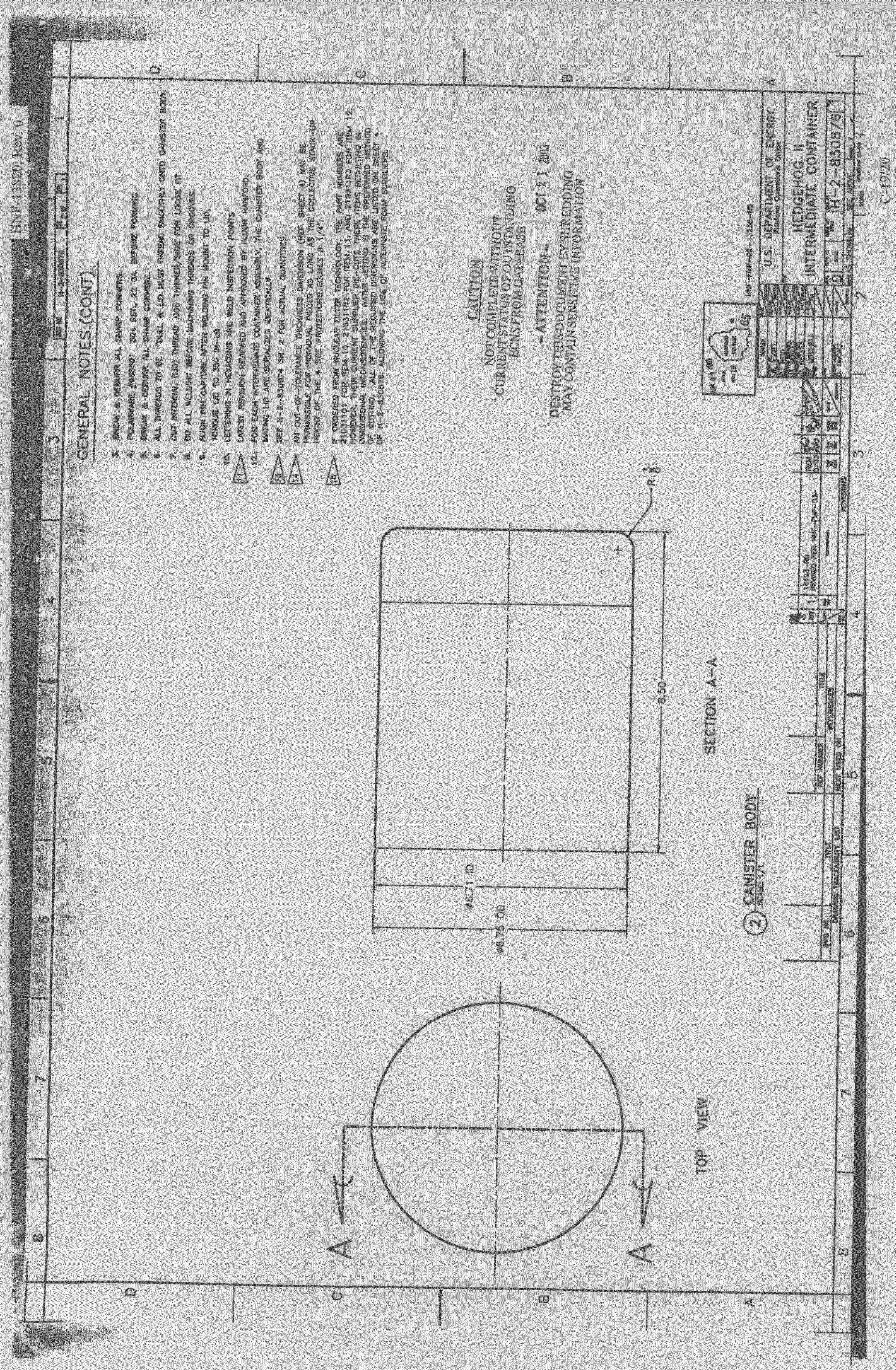




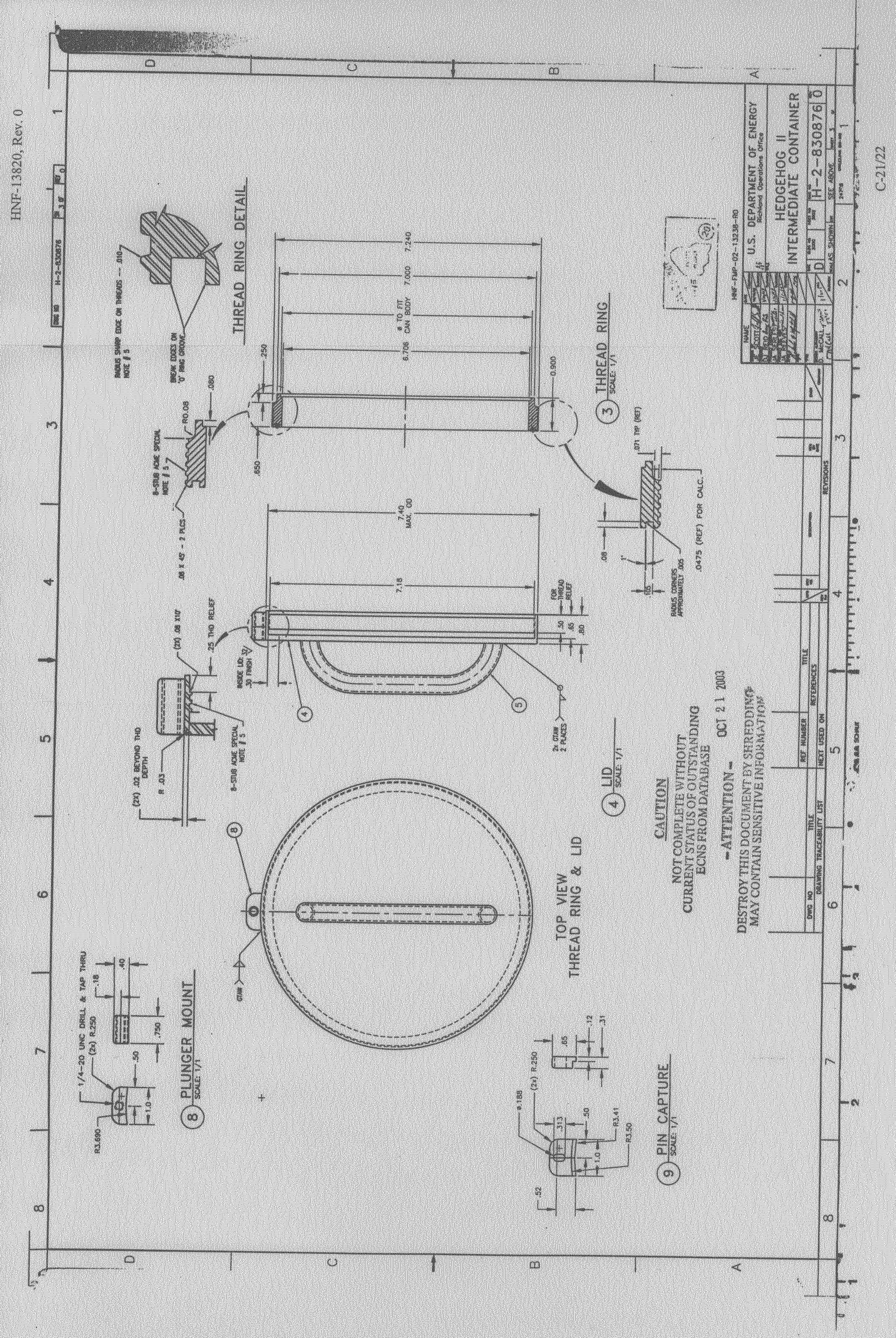




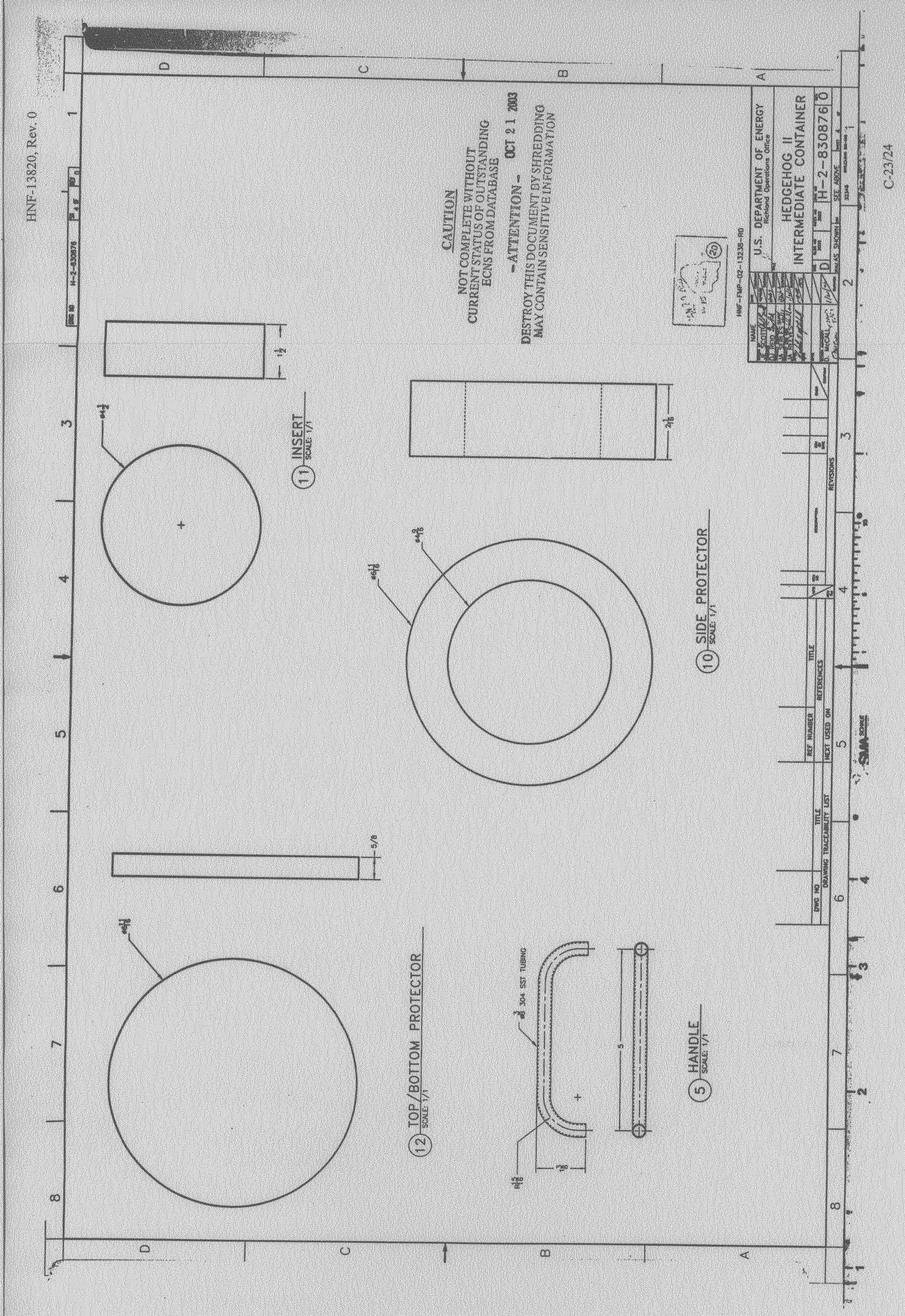




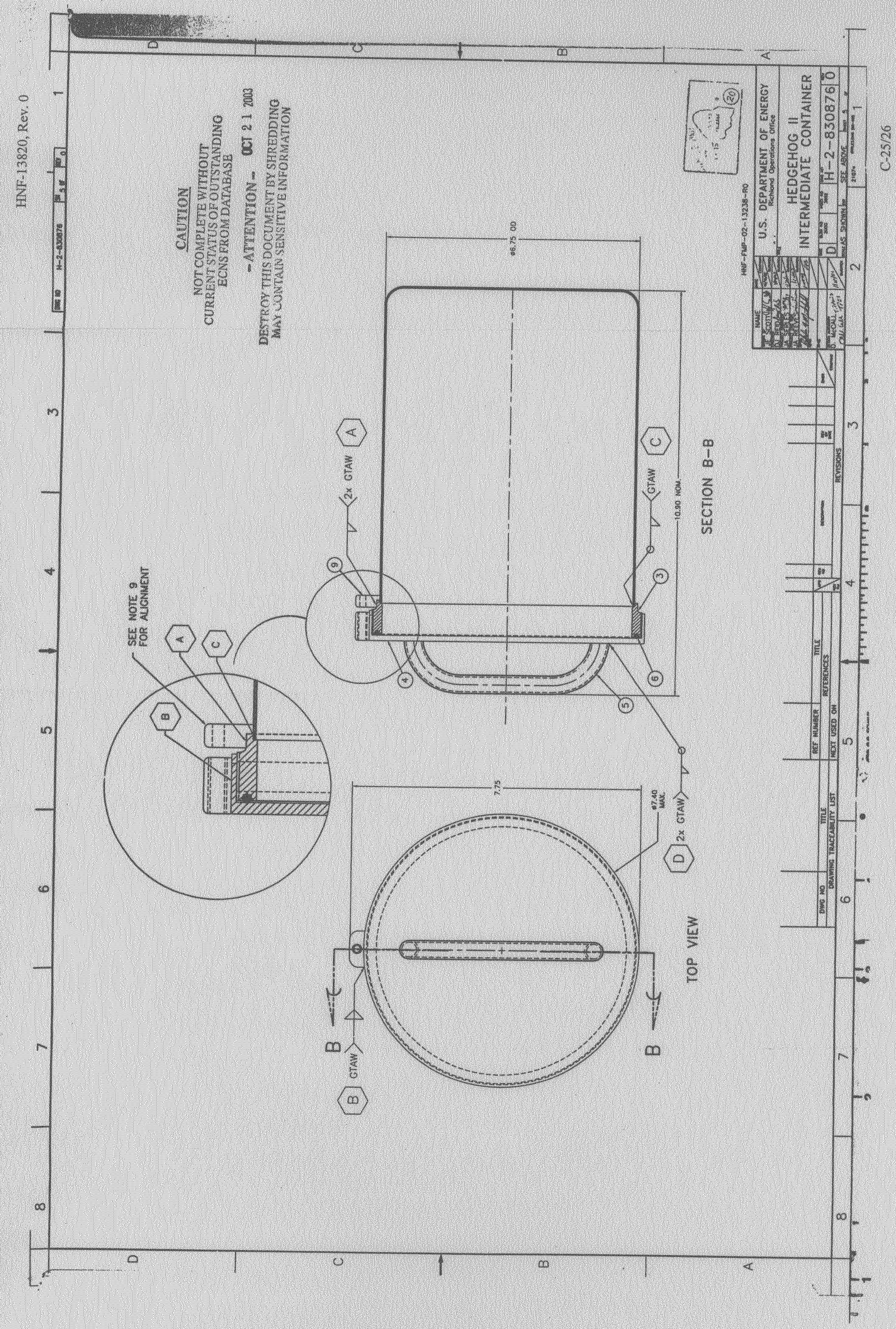




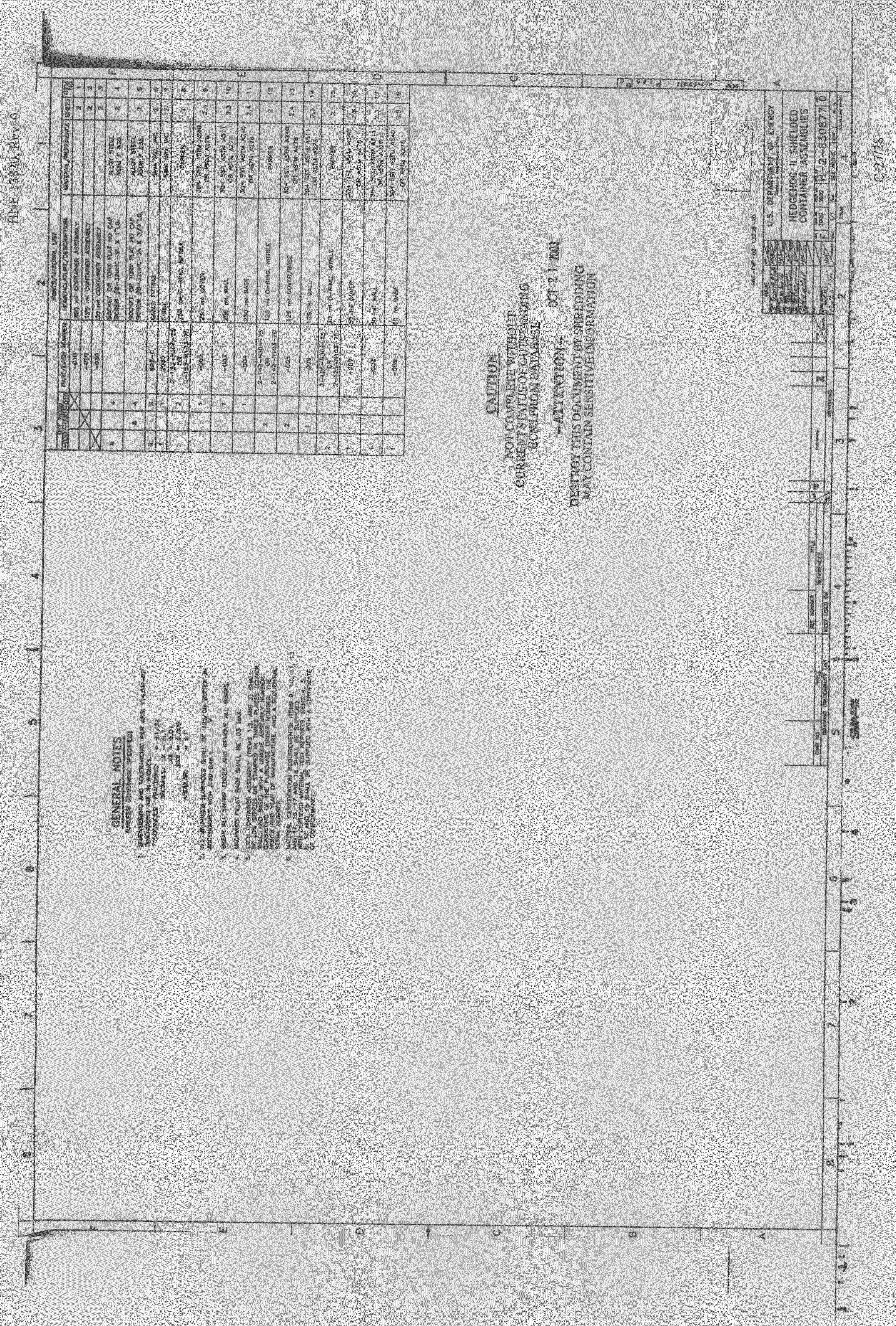




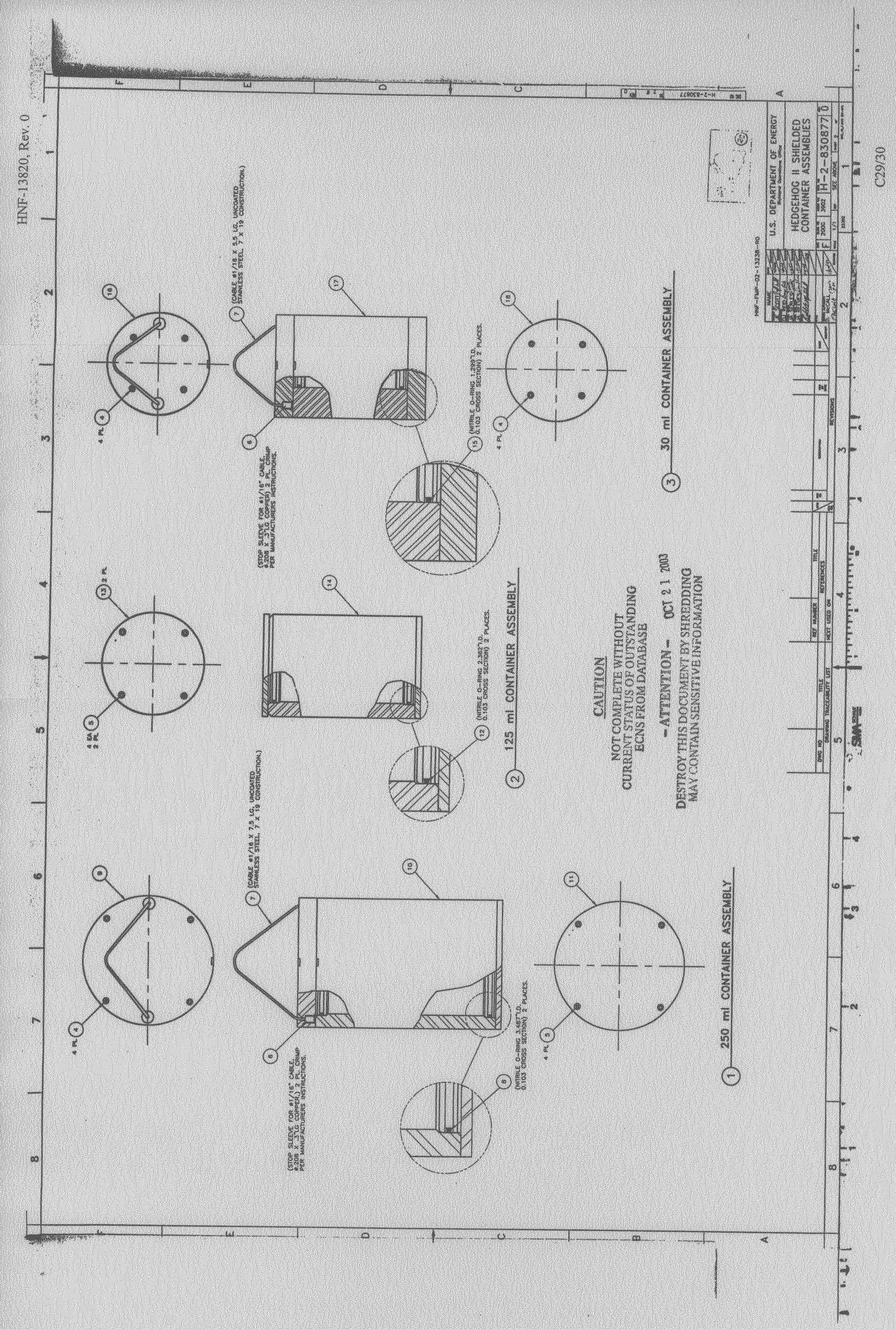




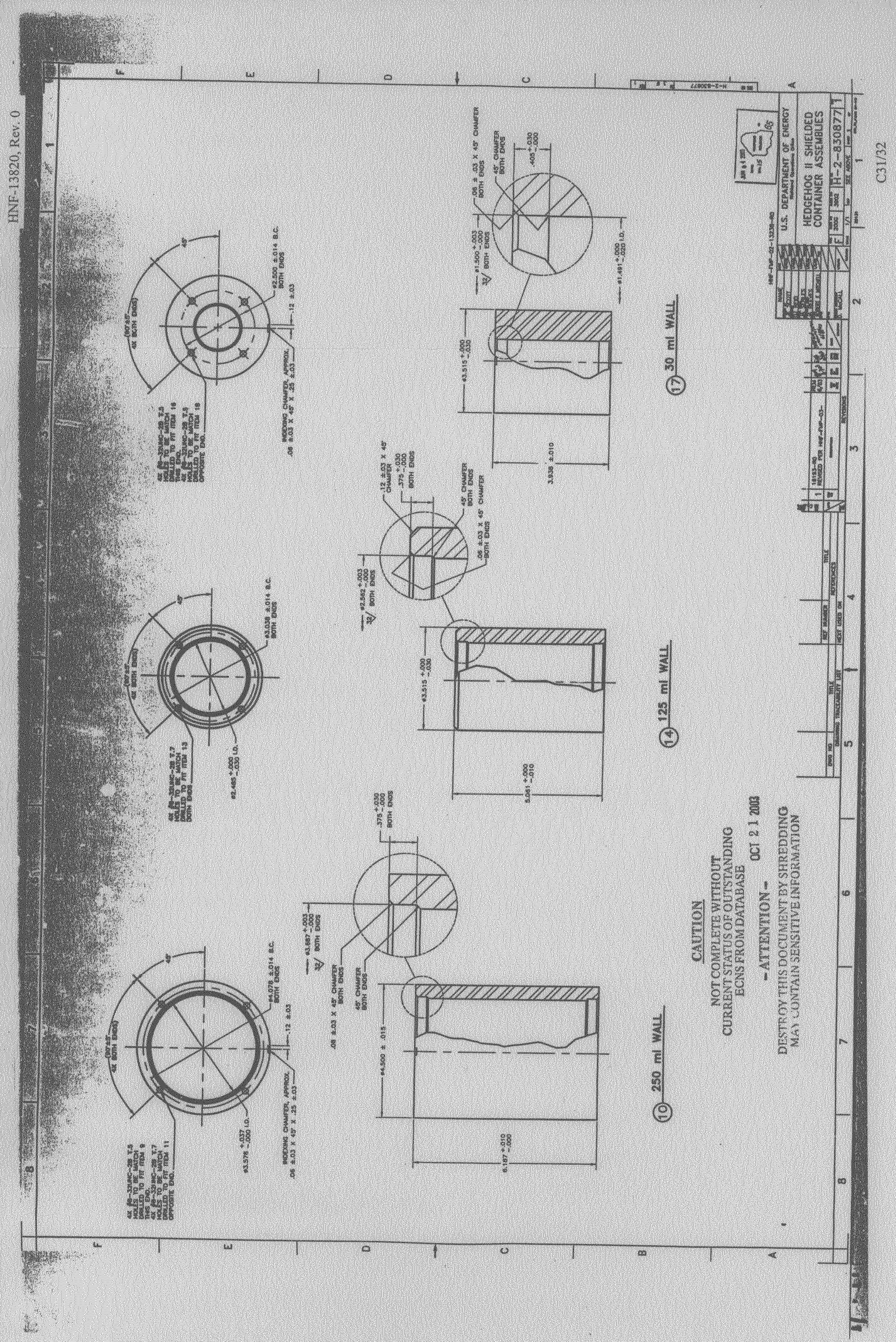




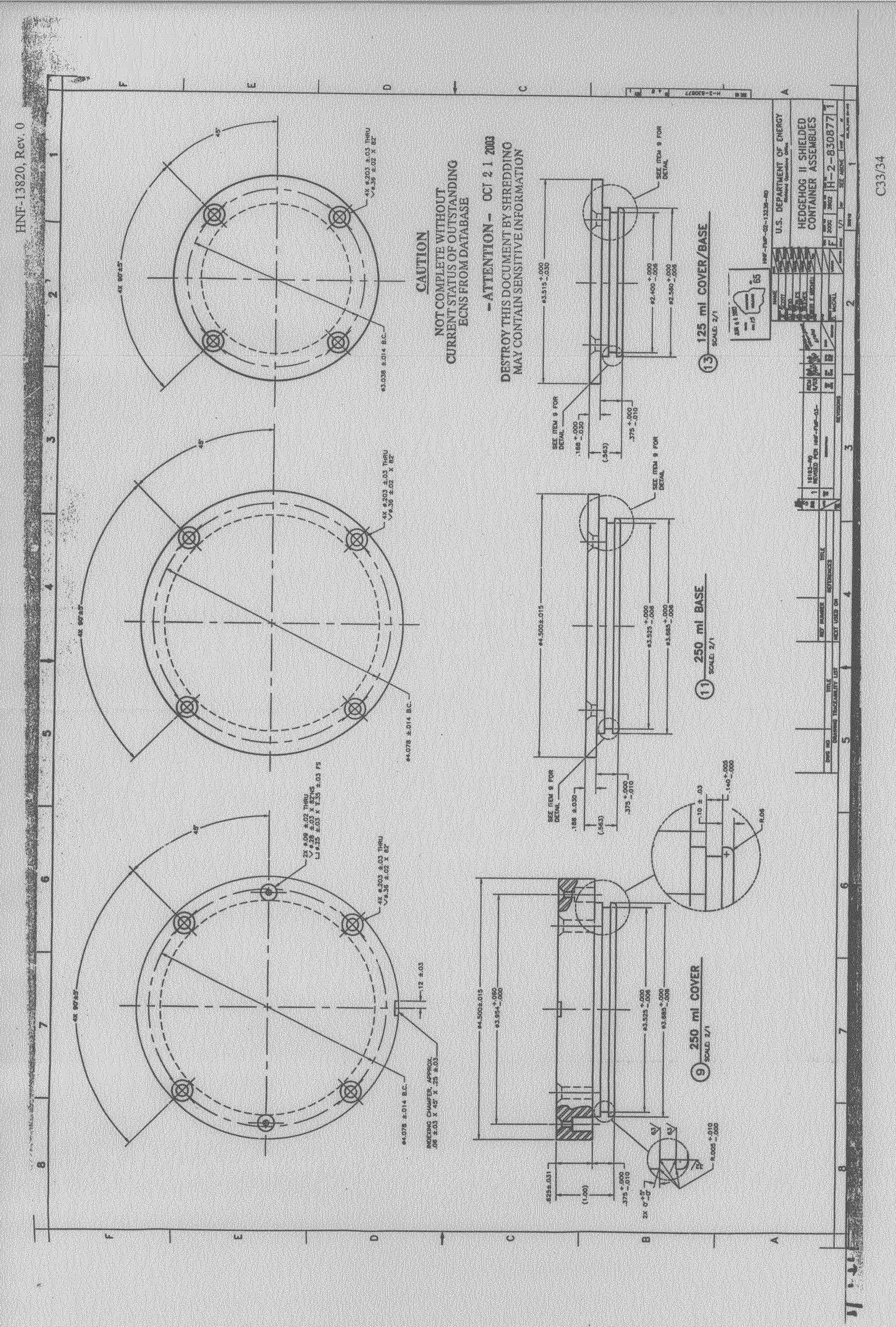


HNF-13820, Rev. 0

\section{APPENDIX D}

\section{CERTIFICATE OF CONFORMANCE}

D-i 
HNF-13820, Rev. 0

This page intentionally left blank. 


\section{APPENDIX D CERTIFICATE OF CONFORMANCE}

Duratek Technical Services (DTS) certifies that the Hedgehog-II packaging system designs, as described in the reference documentation and drawings provided below, have been tested and evaluated as meeting the DOT-7A Type A packaging requirements of Title 49, Code of Federal Regulations (CFR), Part 178, "Specifications for Packagings," $§ 178.350$, "Specification 7A; general packaging, Type A," when loaded as described in the referenced documentation.

The approved Hedgehog-II configurations are designed to ship Type A quantities of radioactive materials, normal form. Contents may be in solid or liquid form. Liquids transported in the approved $1 \mathrm{~L}$ glass bottle assembly shall have a specific gravity of $\leq 1.6$. Liquids transported in all other approved configurations shall have a specific gravity of $\leq 2.0$. Solid contents may be normal or special form. The solid contents, including packaging, are limited in weight to the gross weight of the "as tested" liquids and bottles. The approved Hedgehog-II packaging configurations may be transported by air.

NOTE: Testing was conducted using a uniform distributed load. No consideration was given to point sources being in the package. It is the responsibility of the shipper to use the damage information provided in the Final Evaluation and Test Report to determine if a significant change in radiation level would result for a specific load.

For international shipments, the shipper must ensure that the amount of radiation at any surface of the packaging would not increase by more than $20 \%$ as a result of the decrease in distance to the center of the package load or because of shifting of the load (TS-R1 [ST-1 Revised]; International Atomic Energy Agency; Vienna, Austria; 2000).

\section{Document References:}

HNF-13819, Rev. 1-A, Test Plan for Hedgehog-II Packaging Systems, Type A Container, Duratek Technical Services, Richland, Washington, 2003.

HNF-13820, Rev. 0, Test and Evaluation Report for the Hedgehog-II Packaging Systems, DOT-7A Type A Container, Duratek Technical Services, Richland, Washington, 2003.

Applicable Drawings/Revisions:

\section{H-2-830874, Hedgehog II Packaging System Assembly}

Sheets 1-3, Rev. 1

H-2-830875, Hedgehog II Case

Sheet 1, Rev. 1; Sheets 2-5, Rev. 0

H-2-830876, Hedgehog II Intermediate Container

Sheets 1-2, Rev. 1; Sheets 3-5, Rev. 0

H-2-830877, Hedgehog II Shielded Container Assemblies

Sheets 1-2, Rev. 0; Sheets 3-5, Rev. 1

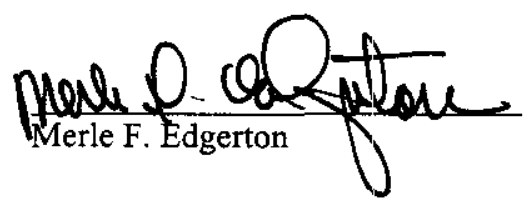

SR. QA ENGN $==$ Title

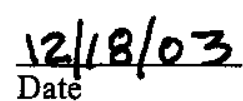


HNF-13820, Rev. 0

This page intentionally left blank.

D-2 